\title{
Conference 2013:
}

\author{
Personalized Medicine \\ $\boldsymbol{\alpha}$ \\ I ndividualized Drug Delivery \\ June 11-14, 2013 \\ University of British Columbia \\ Vancouver, BC, Canada
}

A joint conference of:

Canadian Society for Pharmaceutical Sciences

Canadian Chapter of Controlled Release Society

Scientific Chairs:

Ron Boch, BIOTECanada, Ottawa

Pieter Cullis, UBC, Vancouver

Conference Organizing Committee:

CSPS: Robert Young (chair), Frank Abbott, Terry Allen, Rob Fraser, Raimar Loebenberg, Ron Reid

CC-CRS: Mike Doschak, Larry Unsworth

Staff: $\quad$ Barbara Scollick

Bev Berekoff 


\section{Conference Program}

TUESDAY, JUNE 11, 2013

(Room 1101 Pharmaceutical Sciences Building, UBC)

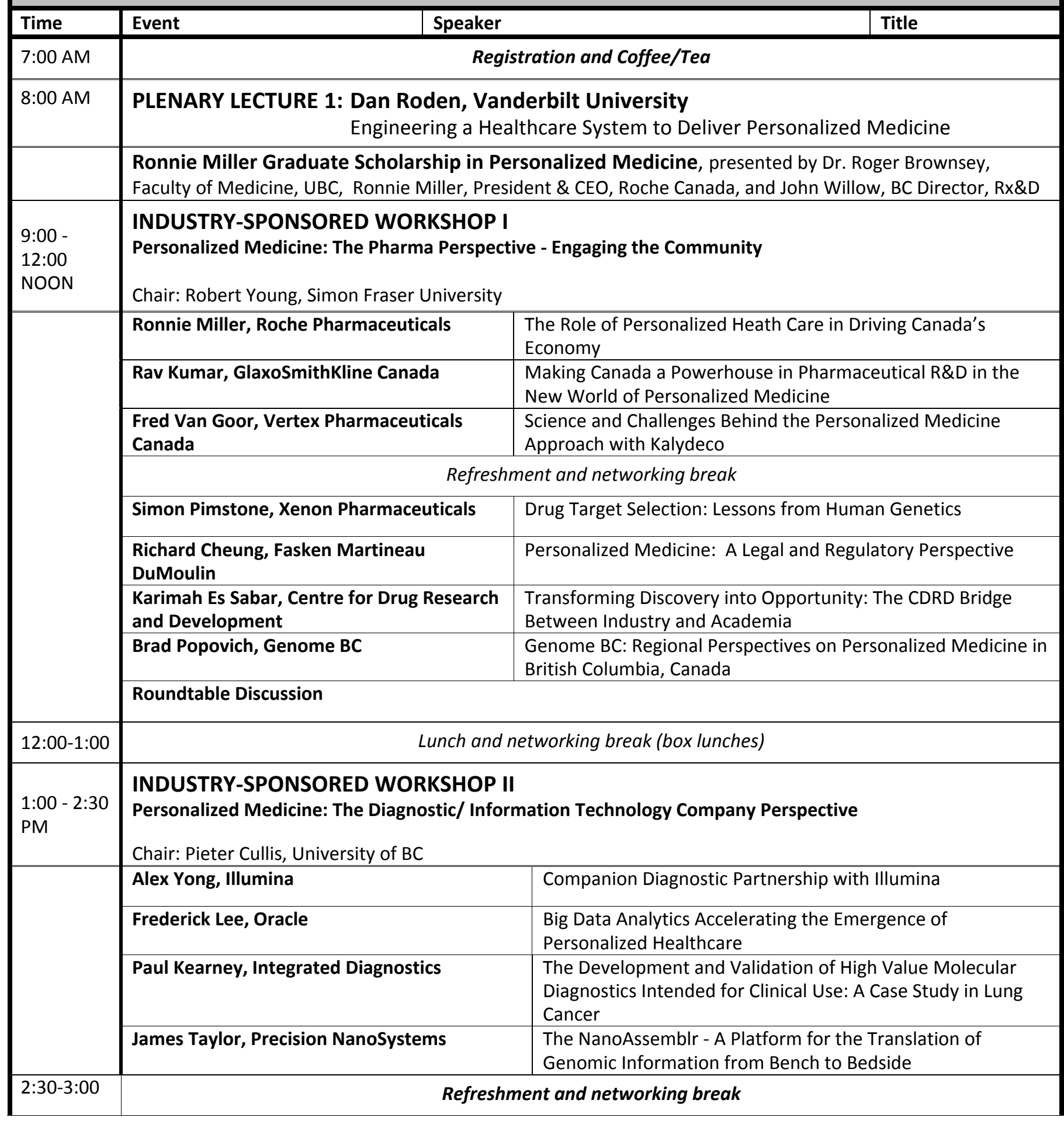




\section{TUESDAY, JUNE 11}

(Room 1101 Pharmaceutical Sciences Building, UBC)

\begin{tabular}{|c|c|c|c|c|c|}
\hline \multirow[t]{8}{*}{$\begin{array}{l}\text { 3:00 - } \\
5: 30 \mathrm{PM}\end{array}$} & \multicolumn{5}{|c|}{$\begin{array}{l}\text { INDUSTRY-SPONSORED WORKSHOP III } \\
\text { Personalized Medicine: The Biotech Perspective } \\
\text { Chair: Ron Boch, BIOTECanada, Ottawa }\end{array}$} \\
\hline & \multicolumn{2}{|c|}{$\begin{array}{l}\text { James Mansi, Novartis Pharmaceuticals } \\
\text { Canada }\end{array}$} & \multicolumn{3}{|c|}{$\begin{array}{l}\text { Fostering Effective Industry, Public Health, Academic } \\
\text { Collaborations - Optimising health Care Interventions Towards } \\
\text { Improving the Health of Canadians }\end{array}$} \\
\hline & \multicolumn{2}{|l|}{ Ali Tehrani, Zymeworks } & \multicolumn{3}{|c|}{$\begin{array}{l}\text { Zymeworks - Designing Bispecifics and other Next-Generation } \\
\text { Protein Therapeutics }\end{array}$} \\
\hline & \multicolumn{2}{|c|}{ Nathan Yoganathan, Kalgene } & \multicolumn{3}{|c|}{ Pathways to Personalized Medicine } \\
\hline & \multicolumn{2}{|l|}{ Scott Patterson, Amgen } & \multicolumn{3}{|c|}{$\begin{array}{l}\text { Translational Biomarker Research in Drug Development: } \\
\text { Challenges and Opportunities }\end{array}$} \\
\hline & \multicolumn{2}{|l|}{ Russell Weiner, Merck } & \multicolumn{3}{|c|}{$\begin{array}{l}\text { Successful Implementation of Global Biomarker Strategies: } \\
\text { Pre-Analytics Matters (But is Often Ignored) }\end{array}$} \\
\hline & \multicolumn{2}{|c|}{ Christopher J. Jowett, Abbott Molecular, Inc. } & \multicolumn{3}{|c|}{$\begin{array}{l}\text { Companion Diagnostics Success from Biomarker Discovery to } \\
\text { Global Commercialization }\end{array}$} \\
\hline & \multicolumn{5}{|l|}{ Panel Discussion } \\
\hline $\begin{array}{l}\text { 6:00 to } \\
\text { 7:30 PM }\end{array}$ & \multicolumn{5}{|c|}{ Industry-sponsored Networking, Welcome Reception, and Poster Viewing - Poster Session 1} \\
\hline \multicolumn{6}{|c|}{ WEDNESDAY, JUNE 12 - MORNING } \\
\hline Time & Event/ Speaker & Title & & Event Speaker & Title \\
\hline $\begin{array}{l}7: 00 \text { to } \\
8: 00 \text { AM }\end{array}$ & & egis & ff & Jp & \\
\hline \multirow[t]{2}{*}{$\begin{array}{l}8: 00 \text { to } \\
\text { 9:00 AM }\end{array}$} & \multicolumn{5}{|c|}{$\begin{array}{l}\text { PLENARY LECTURE 2: } \begin{array}{l}\text { Buddy Ratner, University of Washington } \\
\text { The Personalized Medicine/Tissue Engineering/Cancer/ Drug Delivery } \\
\text { Intersection }\end{array} \\
\text { (Room } 1101 \text { Pharmaceutical Sciences Building) }\end{array}$} \\
\hline & \multicolumn{3}{|c|}{$\begin{array}{l}\text { SESSION 1: Personalized Medicine and Cancer } \\
\text { Chair: David Huntsman, BC Cancer Agency }\end{array}$} & \multicolumn{2}{|c|}{$\begin{array}{l}\text { SESSION 2: Protein Drug Delivery Systems and } \\
\text { Devices } \\
\text { Co-Chairs: Michael Doschak, U of Alberta \& Brian } \\
\text { Amsden, Queen's U } \\
\text { (Room } 1201 \text { Pharmaceutical Sciences Building) }\end{array}$} \\
\hline 9:00 & $\begin{array}{l}\text { David Huntsman, } \\
\text { UBC/BC Cancer Agency }\end{array}$ & \multicolumn{2}{|c|}{$\begin{array}{l}\text { Genomic Driven Personalized } \\
\text { Cancer Control: Ready to Hit } \\
\text { the Runway? }\end{array}$} & $\begin{array}{l}\text { Robert Farra, } \\
\text { MicroCHIPS }\end{array}$ & $\begin{array}{l}\text { Enabling Remote Medicine: } \\
\text { Implantable, Wirelessly- } \\
\text { Controlled Microchip Drug } \\
\text { Delivery }\end{array}$ \\
\hline $9: 30$ & $\begin{array}{l}\text { Sohrab Shah, UBC/ BC } \\
\text { Cancer Agency }\end{array}$ & $\begin{array}{l}\text { Evolutionary Dynamics } \\
\text { High-grade Serous Ova } \\
\text { Cancers: Implications f } \\
\text { Personalized Medicine }\end{array}$ & & $\begin{array}{l}\text { Mark Tomai, 3M Drug } \\
\text { Delivery Systems }\end{array}$ & $\begin{array}{l}\text { Intradermal Delivery of } \\
\text { Small Molecules, Proteins, } \\
\text { Peptides and Vaccines using } \\
\text { Microneedle Technologies }\end{array}$ \\
\hline $10: 00$ & Refres & hment and networking & reak & nd poster viewing - Po & Session 1 \\
\hline
\end{tabular}




\begin{tabular}{|c|c|c|c|c|}
\hline \multicolumn{5}{|c|}{ WEDNESDAY, JUNE 12 - MORNING (Cont'd) } \\
\hline $10: 30$ & $\begin{array}{l}\text { Christian Steidl, } \\
\text { UBC/BC Cancer Agency }\end{array}$ & $\begin{array}{l}\text { Lymphoma Genomics: } \\
\text { Diagnostic Precision Tools for } \\
\text { Guiding Treatments }\end{array}$ & $\begin{array}{l}\text { Robert Gurny, } \\
\text { University of Geneva }\end{array}$ & $\begin{array}{l}\text { The Challenges of Protein } \\
\text { and Peptide Delivery }\end{array}$ \\
\hline $11: 00$ & $\begin{array}{l}\text { Poul Sorensen, UBC/BC } \\
\text { Cancer Agency }\end{array}$ & $\begin{array}{l}\text { Functional Validation: Linking } \\
\text { Genomic Alterations to New } \\
\text { Treatment Opportunities }\end{array}$ & $\begin{array}{l}\text { Brian Amsden, } \\
\text { Queen's University }\end{array}$ & $\begin{array}{l}\text { Formulation Strategies } \\
\text { Around Osmotically-driven } \\
\text { Therapeutic Protein Release }\end{array}$ \\
\hline $\begin{array}{l}11: 30- \\
12: 10\end{array}$ & \multicolumn{4}{|c|}{$\begin{array}{l}\text { CSPS Lifetime Achievement Award Lecture: John McNeill, Faculty of Pharmaceutical Sciences, UBC } \\
\text { Fructose Ingestion, Hypertension and the Metabolic Syndrome } \\
\text { (Room } 1101 \text { Pharmaceutical Sciences Building) }\end{array}$} \\
\hline $\begin{array}{l}12: 10 \text { to } \\
2: 00 \text { PM }\end{array}$ & \multicolumn{4}{|c|}{ Lunch break, networking and poster viewing - Poster Session 1} \\
\hline \multicolumn{5}{|c|}{ WEDNESDAY, JUNE 12 - AFTERNOON } \\
\hline \multirow[t]{2}{*}{$\begin{array}{l}\text { 2:00 to } \\
\text { 3:00 PM }\end{array}$} & \multicolumn{4}{|c|}{$\begin{array}{l}\text { PLENARY LECTURE 3: Lawrence Lesko, University of Florida } \\
\text { A Landscape Analysis of Pharmacogenomics } \\
\text { (Room } 1101 \text { Pharmaceutical Sciences Building) }\end{array}$} \\
\hline & \multicolumn{2}{|c|}{$\begin{array}{l}\text { SESSION 3: Personalized Medicine and } \\
\text { Pharmacogenomics } \\
\text { Chair: Bruce Carleton, BC Children's Hospital }\end{array}$} & \multicolumn{2}{|c|}{$\begin{array}{l}\text { SESSION 4: Nanomedicine and Gene Delivery } \\
\text { SPONSORED BY: NORTHERN LIPIDS } \\
\text { Co-Chairs: Larry Unsworth, U. of Alberta \& Emmanuel } \\
\text { Ho, U of Manitoba } \\
\text { (Room } 1201 \text { Pharmaceutical Sciences Building) }\end{array}$} \\
\hline $3: 00$ & $\begin{array}{l}\text { Bruce Carleton, BC } \\
\text { Children's Hospital }\end{array}$ & $\begin{array}{l}\text { The Two Pharmacos: } \\
\text { Vigilance and Genetics - } \\
\text { A Powerful Partnership to } \\
\text { Improve the Safe Use of } \\
\text { Drugs }\end{array}$ & $\begin{array}{l}\text { Emmanuel A. Ho, } \\
\text { University of Manitoba }\end{array}$ & $\begin{array}{l}\text { Intravaginal Delivery of } \\
\text { siRNA as Potential } \\
\text { Microbicides }\end{array}$ \\
\hline $3: 30$ & $\begin{array}{l}\text { Richard Kim, University } \\
\text { of Western Ontario }\end{array}$ & $\begin{array}{l}\text { Implementation of } \\
\text { Personalized Medicine (PM): } \\
\text { From PM Clinics to Inpatient } \\
\text { Care }\end{array}$ & $\begin{array}{l}\text { Michael Buschmann, } \\
\text { École Polytechnique }\end{array}$ & $\begin{array}{l}\text { Nucleic Acid Delivery using } \\
\text { Chitosans }\end{array}$ \\
\hline $4: 00$ & \multicolumn{4}{|c|}{ Refreshment and networking break and poster viewing - Poster Session 1} \\
\hline $4: 30$ & $\begin{array}{l}\text { Richard Weinshilboum, } \\
\text { Mayo Clinic }\end{array}$ & $\begin{array}{l}\text { Breast Cancer } \\
\text { Pharmacogenomics: Beyond } \\
\text { Biomarkers }\end{array}$ & $\begin{array}{l}\text { Larry Unsworth, } \\
\text { University of Alberta }\end{array}$ & $\begin{array}{l}\text { Programming Biomaterials } \\
\text { for Personalized, On- } \\
\text { Demand Medicine: A } \\
\text { Nanomedicine Approach }\end{array}$ \\
\hline $5: 00$ & Colin Ross, UBC & $\begin{array}{l}\text { Development of Novel Tools } \\
\text { for Personalized Genomic } \\
\text { Medicine to Improve Drug } \\
\text { Safety in Children }\end{array}$ & $\begin{array}{l}\text { Suzie Pun, University of } \\
\text { Washington }\end{array}$ & $\begin{array}{l}\text { Peptide-Targeted } \\
\text { Polycations for Nucleic Acid } \\
\text { Delivery }\end{array}$ \\
\hline $\begin{array}{l}\text { 5:30 to } \\
7: 00 \text { PM }\end{array}$ & \multicolumn{4}{|c|}{ Networking and Poster Viewing - Poster Session 2} \\
\hline 6:30 PM & \multicolumn{4}{|c|}{ CSPS Board of Directors Meeting (Room 3110 Pharmaceutical Sciences Building) } \\
\hline
\end{tabular}


THURSDAY, JUNE 13 - MORNING

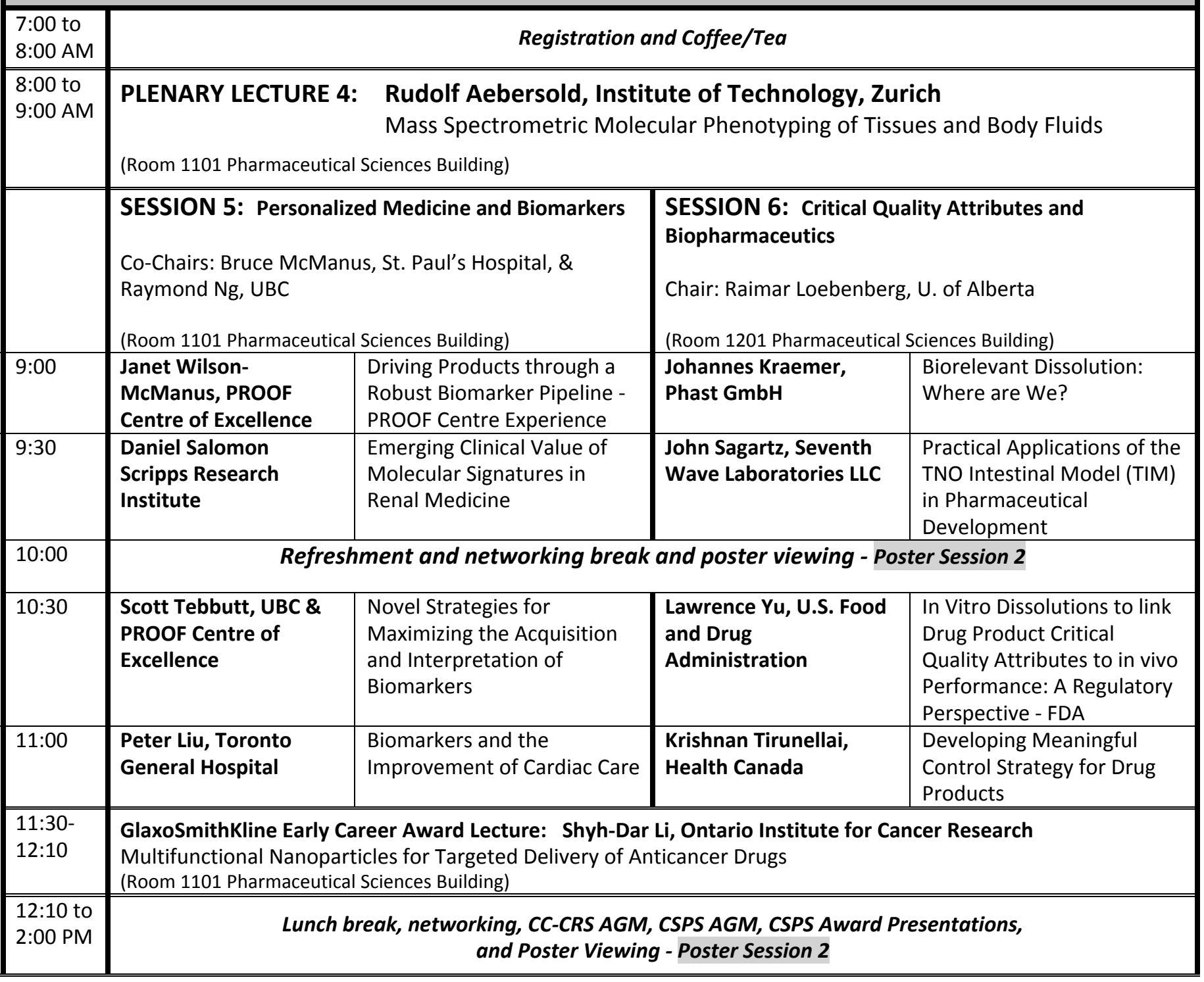


THURSDAY, JUNE 13 - AFTERNOON

\begin{tabular}{|c|c|c|c|c|c|c|}
\hline \multirow[t]{2}{*}{$\begin{array}{l}2: 00 \text { to } \\
3: 00 \text { PM }\end{array}$} & \multicolumn{6}{|c|}{$\begin{array}{ll}\text { PLENARY LECTURE 5: } & \text { Patrick Terry, Cambridge, MA } \\
& \text { Promise and Peril: Experiences of Personalized Medicine } \\
\text { (Room } 1101 \text { Pharmaceutical Sciences Building) }\end{array}$} \\
\hline & \multicolumn{2}{|c|}{$\begin{array}{l}\text { SESSION 7: Personalized } \\
\text { Medicine and Funding/ Gov't/ } \\
\text { Regulatory Issues } \\
\text { Co-Chairs: Brian Foster, U. of } \\
\text { Ottawa, and Brad Popovich, } \\
\text { Genome BC } \\
\text { (Room } 1101 \text { Pharmaceutical Sci Bldg) }\end{array}$} & \multicolumn{2}{|c|}{$\begin{array}{l}\text { SESSION 8: Interface Between } \\
\text { Analytical Method and Formulation } \\
\text { in the QbD World } \\
\text { Chair: Elisabeth Kovacs, Apotex } \\
\text { (Room } 1201 \text { Pharmaceutical Sci Bldg) }\end{array}$} & \multicolumn{2}{|c|}{$\begin{array}{l}\text { SESSION 9: Current } \\
\text { Bioequivalence Topics } \\
\text { SPONSORED BY: } \\
\text { COBALT PHARMACEUTICALS } \\
\text { Chair: Lorelei Lutter, Bio Pharma } \\
\text { Services Inc. } \\
\text { (Room } 3340 \text { Pharmaceutical Sci Bldg) }\end{array}$} \\
\hline $3: 00$ & $\begin{array}{l}\text { David Lee, } \\
\text { Health } \\
\text { Canada }\end{array}$ & $\begin{array}{l}\text { Benefits, Harms and } \\
\text { Uncertainties - } \\
\text { Regulator's } \\
\text { Perspective for } \\
\text { Personalized } \\
\text { Medicine }\end{array}$ & $\begin{array}{l}\text { Nadia Chacra, } \\
\text { Sao Paulo } \\
\text { University }\end{array}$ & $\begin{array}{l}\text { Quality by Design } \\
\text { (QbD) Case Study: } \\
\text { Establishment of a } \\
\text { Design Space for a } \\
\text { Preservative System }\end{array}$ & $\begin{array}{l}\text { Nageshwar } \\
\text { Rao Thudi, } \\
\text { Watson } \\
\text { Pharmaceutica } \\
\text { Is/ Actavis }\end{array}$ & $\begin{array}{l}\text { Highly Variable } \\
\text { Drugs and Current } \\
\text { Regulatory } \\
\text { Requirements for } \\
\text { Establishing the } \\
\text { Bioequivalence } \\
\end{array}$ \\
\hline $3: 30$ & $\begin{array}{l}\text { Hans- } \\
\text { Georg } \\
\text { Eichler, } \\
\text { EMA }\end{array}$ & $\begin{array}{l}\text { Personalized } \\
\text { Medicine, A Long } \\
\text { Learning Curve: EMA } \\
\text { Experiences }\end{array}$ & $\begin{array}{l}\text { Jon Mole, } \\
\text { Sirius } \\
\text { Analytical Inc. }\end{array}$ & $\begin{array}{l}\text { Solubility \& } \\
\text { Dissolution } \\
\text { Enhancement of } \\
\text { Weakly Basic } \\
\text { Compounds - } \\
\text { Understanding } \\
\text { Precipitation \& } \\
\text { Supersaturation }\end{array}$ & $\begin{array}{l}\text { Keith } \\
\text { Gallicano, } \\
\text { Novum } \\
\text { Pharmaceuti } \\
\text { cal Research } \\
\text { Services }\end{array}$ & $\begin{array}{l}\text { Strategies and } \\
\text { Issues in the } \\
\text { Design and Data } \\
\text { Analysis of Skin } \\
\text { Adhesion, Irritation } \\
\text { \& Sensitization } \\
\text { Studies for } \\
\text { Bioequivalence } \\
\text { Evaluation of } \\
\text { Transdermal/ } \\
\text { Topical Generic } \\
\text { Patch Systems } \\
\end{array}$ \\
\hline $4: 00$ & \multicolumn{6}{|c|}{ Refreshment and networking break and poster viewing - Poster Session 2} \\
\hline $4: 30$ & $\begin{array}{l}\text { Jane } \\
\text { Aubin, } \\
\text { CIHR }\end{array}$ & $\begin{array}{l}\text { Personalized } \\
\text { Medicine and } \\
\text { Patient-Oriented } \\
\text { Research: CIHR } \\
\text { Perspective } \\
\end{array}$ & $\begin{array}{l}\text { Michael } \\
\text { Bolger, } \\
\text { Simulations } \\
\text { Plus, Inc. }\end{array}$ & $\begin{array}{l}\text { How to Model } \\
\text { Supersaturation }\end{array}$ & $\begin{array}{l}\text { Juan He, } \\
\text { BioPharma } \\
\text { Services }\end{array}$ & $\begin{array}{l}\text { Challenges with } \\
\text { Depot Formulation } \\
\text { Products: CRO } \\
\text { Perspective }\end{array}$ \\
\hline $4: 45$ & $\begin{array}{l}\text { Bettina } \\
\text { Hamelin, } \\
\text { Pfizer }\end{array}$ & $\begin{array}{l}\text { Industry Perspective } \\
\text { of Partnerships in } \\
\text { Canada on } \\
\text { Personalized } \\
\text { Medicine }\end{array}$ & & & & \\
\hline $5: 00$ & $\begin{array}{l}\text { Pierre } \\
\text { Meulien, } \\
\text { Genome } \\
\text { Canada }\end{array}$ & $\begin{array}{l}\text { Challenges in } \\
\text { Translating Genomics } \\
\text { Technologies to the } \\
\text { Clinic: A Funders } \\
\text { Perspective }\end{array}$ & $\begin{array}{l}\text { Kai Zhuang, } \\
\text { BASF }\end{array}$ & $\begin{array}{l}\text { Pharma Polymers } \\
\text { for Solubility } \\
\text { Enhancement }\end{array}$ & $\begin{array}{l}\text { Barbara } \\
\text { Davit, } \\
\text { Merck \& Co. }\end{array}$ & $\begin{array}{l}\text { Recommendations } \\
\text { for Improving } \\
\text { Quality of } \\
\text { Bioequivalence } \\
\text { Data Submitted to } \\
\text { ANDAs in the US }\end{array}$ \\
\hline 5:15 & \multicolumn{2}{|c|}{ Panel Discussion } & & & & \\
\hline $6: 30 \mathrm{PM}$ & \multicolumn{6}{|c|}{$\begin{array}{c}\text { Conference Gala Dinner at the Museum of Anthropology: } \\
\text { tour, entertainment, cash bar, Salmon Barbeque }\end{array}$} \\
\hline
\end{tabular}


FRIDAY, JUNE 14 - MORNING

\begin{tabular}{|c|c|c|c|c|}
\hline $\begin{array}{l}\text { 7:00 to } \\
8: 00 \text { AM }\end{array}$ & \multicolumn{4}{|c|}{ Registration and Coffee/Tea } \\
\hline $\begin{array}{l}\text { 8:00 to } \\
\text { 9:00 AM }\end{array}$ & \multicolumn{4}{|c|}{$\begin{array}{l}\text { PLENARY LECTURE 6: } \begin{array}{l}\text { Corey Nislow, University of British Columbia } \\
\text { Simultaneous Translation: Opportunities and Challenges for Next Generation } \\
\text { Pharmacogenomics }\end{array} \\
\text { (Room } 1101 \text { Pharmaceutical Sciences Building) }\end{array}$} \\
\hline 9:00 & $\begin{array}{l}\text { Karen Gelmon, BC } \\
\text { Cancer Agency }\end{array}$ & $\begin{array}{l}\text { Setting the Stage - Bringing } \\
\text { Personalized Medicine into } \\
\text { the Oncology Clinic }\end{array}$ & Pieter Cullis, UBC & $\begin{array}{l}\text { The BC Personalized } \\
\text { Medicine Initiative }\end{array}$ \\
\hline 10:00 & \multicolumn{4}{|c|}{ Refreshment and networking break } \\
\hline $10: 30$ & $\begin{array}{l}\text { Richard Schilsky, } \\
\text { University of Chicago } \\
\text { Medicine }\end{array}$ & $\begin{array}{l}\text { Implementing Personalized } \\
\text { Cancer Medicine in the Clinic }\end{array}$ & $\begin{array}{l}\text { Jim Russell, Department } \\
\text { of Medicine, UBC }\end{array}$ & $\begin{array}{l}\text { Clinical Research in } \mathrm{BC} \text { : } \\
\text { Integration and } \\
\text { Synergizing across the } \\
\text { Clinical Research Spectrum }\end{array}$ \\
\hline 11:00 & $\begin{array}{l}\text { Francois Benard, BC } \\
\text { Cancer Agency }\end{array}$ & $\begin{array}{l}\text { Using Functional Imaging and } \\
\text { Novel Tracers to Accelerate } \\
\text { Personalized Treatments }\end{array}$ & $\begin{array}{l}\text { Carlo Marra, Faculty of } \\
\text { Pharmaceutical Sciences, } \\
\text { UBC }\end{array}$ & $\begin{array}{l}\text { The Potential For Value For } \\
\text { Money With } \\
\text { Pharmacogenomics }\end{array}$ \\
\hline $12: 00$ & \multicolumn{4}{|c|}{ Main Conference Concludes } \\
\hline
\end{tabular}


FRIDAY, JUNE 14 - AFTERNOON

CSPS SPECIAL WORKSHOP -

HEALTH ECONOMICS AND THE BEST OF CARE

Through generous educational grant support from Roche Canada

\begin{tabular}{|c|c|c|c|}
\hline Time & \multicolumn{3}{|c|}{ Speaker } \\
\hline \multirow[t]{2}{*}{$\begin{array}{l}12: 00- \\
1: 00\end{array}$} & \multicolumn{3}{|c|}{ LUNCH AND NETWORKING } \\
\hline & \multicolumn{3}{|c|}{$\begin{array}{l}\text { FACILITATOR: } \\
\text { CHAN ENNS, PRESIDENT, LIFESCIENCES BC } \\
\text { PANELISTS: } \\
\text { Christopher McCabe (University of Alberta) } \\
\text { Fiona Miller (University of Toronto) } \\
\text { David Shum (Roche Canada) } \\
\text { Louis Theriault (Conference Board of Canada) }\end{array}$} \\
\hline \multirow{3}{*}{$\begin{array}{l}1: 00- \\
1: 30\end{array}$} & \multirow{3}{*}{$\begin{array}{l}\text { Introduction to Personalized } \\
\text { Health Care/Personalized } \\
\text { Medicine: Definition/Where do we } \\
\text { stand today? }\end{array}$} & Carlo Marra, & Opening remarks \\
\hline & & Panelists & Individual response \\
\hline & & \multicolumn{2}{|l|}{ Audience Participation } \\
\hline \multirow[t]{2}{*}{$\begin{array}{l}1: 30- \\
2: 00\end{array}$} & \multirow{4}{*}{$\begin{array}{l}\mathrm{PHC} / \mathrm{PM} \text { in the context of } \\
\text { Healthcare Operations }\end{array}$} & \multirow[t]{2}{*}{ Fiona Miller } & $\begin{array}{l}\text { Buying personalized medicine: the role of } \\
\text { health technology assessment }\end{array}$ \\
\hline & & & Audience Participation \\
\hline \multirow[t]{2}{*}{$\begin{array}{l}2: 00- \\
2: 30\end{array}$} & & \multirow[t]{2}{*}{ Christopher McCabe } & $\begin{array}{l}\text { Personalised medicine and population health: } \\
\text { a testing evaluation? }\end{array}$ \\
\hline & & & Audience Participation \\
\hline $\begin{array}{l}2: 30- \\
2: 45\end{array}$ & \multicolumn{3}{|c|}{ Refreshment Break } \\
\hline \multirow{2}{*}{$\begin{array}{l}2: 45- \\
3: 15\end{array}$} & \multirow{4}{*}{$\begin{array}{l}\mathrm{PHC} / \mathrm{PM} \text { in the context of } \\
\text { Healthcare Operations }\end{array}$} & \multirow{2}{*}{ David Shum } & An industry perspective on PM and HTA \\
\hline & & & Audience Participation \\
\hline \multirow[t]{2}{*}{$\begin{array}{l}3: 15- \\
3: 45\end{array}$} & & \multirow[t]{2}{*}{ Louis Theriault } & $\begin{array}{l}\text { Personalized Medicine: What Employers have } \\
\text { to do with it? }\end{array}$ \\
\hline & & & Audience Participation \\
\hline $\begin{array}{l}3: 45- \\
4: 15\end{array}$ & PHC/PM: Outlook (5 - 10 year). & Panelists & $\begin{array}{l}\text { Comment on the mid to long term outlook that } \\
\text { PHC/PM will affect overall operations of our } \\
\text { Healthcare System }\end{array}$ \\
\hline 4:15 PM & & Conj & des \\
\hline
\end{tabular}




\section{Table of Contents}

SPEAKER ABSTRACTS

PLENARY LECTURE 1

Engineering a Healthcare System to Deliver Personalized Medicine 19s

Dan Roden, Vanderbilt University, School of Medicine, Nashville, TN

\section{INDUSTRY WORKSHOP 1 PERSONALIZED MEDICINE: THE PHARMA PERSPECTIVE - ENGAGING THE COMMUNITY}

The Role of Personalized Heath Care in Driving Canada's Economy $20 \mathrm{~s}$ Ronnie Miller, President and CEO of Hoffmann-La Roche Limited (Roche Canada)

Making Canada a Powerhouse in Pharmaceutical R\&D in the New World of Personalized Medicine.......21s Rav Kumar, PhD., Vice-President, R\&D Operations/ Business Development, GlaxoSmithKline Canada

Science and Challenges Behind the Personalized Medicine Approach with Kalydeco. 21s Fred Van Goor, Vertex Pharmaceuticals Canada

Drug Target Selection: Lessons from Human Genetics. $21 \mathrm{~s}$ Simon Pimstone, President and Chief Executive Officer, Xenon Pharmaceuticals

Personalized Medicine: A Legal and Regulatory Perspective $22 \mathrm{~s}$ Richard Cheung, Fasken Martineau DuMoulin LLP

Transforming Discovery into Opportunity: The CDRD Bridge Between Industry and Academia $23 \mathrm{~s}$ Karimah Es Sabar, President \& CEO, The Centre for Drug Research and Development, Vancouver, BC

Genome BC: Regional Perspectives on Personalized Medicine in British Columbia, Canada $24 s$ Brad Popovich, Chief Scientific Officer, Genome British Columbia

\section{INDUSTRY WORKSHOP 2 PERSONALIZED MEDICINE: THE DIAGNOSTIC/INFORMATION TECHNOLOGY COMPANY PERSPECTIVE}

Companion Diagnostic Partnership with Illumina........................................................................................................25s Alex Yong, Global Sales Manager Pharma Market, Illumina

Big Data Analytics Accelerating the Emergence of Personalised Healthcare. $25 \mathrm{~s}$ Frederick S. Lee MD, MPH, Director of Clinical \& Translational Informatics, Oracle Health Sciences

The Development and Validation of High Value Molecular Diagnostics Intended for Clinical Use: A Case Study in Lung Cancer 26s Paul Kearney, President and Chief Science Officer, Integrated Diagnostics, Seattle, WA

The NanoAssemblrTM - A Platform for the Translation of Genomic Information from Bench to Bedside.26s R. James Taylor, CEO \& Co-Founder, Precision NanoSystems, Inc.

\section{INDUSTRY WORKSHOP 3: PERSONALIZED MEDICINE: THE BIOTECH PERSPECTIVE}

Fostering Effective Industry, Public Health, Academic Collaborations - Optimising Health Care Interventions towards Improving the Health of Canadians $.28 \mathrm{~s}$ James A. Mansi, Ph.D., Novartis Pharma Canada Inc., Vaccines and Diagnostics

Zymeworks - Designing Bispecifics and other Next-Generation Protein Therapeutics $28 \mathrm{~s}$ Ali Tehrani, Zymeworks 
Pathways to Personalized Medicine

T. Nathan Yoganathan, PhD, President and CSO

Translational Biomarker Research in Drug Development: Challenges and Opportunities 29s Scott D. Patterson, Ph.D., Executive Director, Medical Sciences, Head, Medical Sciences IVD Group, Amgen Inc, Thousand Oaks, CA USA

Successful Implementation of Global Biomarker Strategies: Pre Analytics Matters (But Often Ignored).30s Russell Weiner, PhD, Executive Director, Head, Clinical Biomarker and Diagnostics Lab, Merck Research Laboratories

Companion Diagnostics Success from Biomarker Discovery to Global Commercialization. $31 \mathrm{~s}$ Christopher J. Jowett, Global Head of Companion Diagnostics, Abbott Molecular, Inc., Des Plaines, IL

\section{PLENARY LECTURE 2}

The Personalized Medicine/ Tissue Engineering/ Cancer / Drug Delivery Intersection ... $32 \mathrm{~s}$ Buddy D. Ratner, Ph.D., Floyd Karp and J. Alaina Floyd, Departments of Bioengineering and Chemical Engineering, University of Washington, Seattle, Washington

\section{SESSION 1: PERSONALIZED MEDICINE AND CANCER}

Genomic Driven Personalized Cancer Control: Ready to Hit the Runway? $34 s$ David G. Huntsman, MD, FRCPC, FCCMG, UBC/BC Cancer Agency

Evolutionary Dynamics of High-grade Serous Ovarian Cancers: Implications for Personalized Medicine35s Sohrab Shah, UBC/ BC Cancer Agency, Vancouver, BC

Lymphoma Genomics: Diagnostic Precision Tools for Guiding Treatments $35 \mathrm{~s}$ Christian Steidl, Department of Pathology, University of British Columbia; Department of Experimental Therapeutics, BC Cancer Research Centre, Vancouver, BC

Functional Validation: Linking Genomic Alterations to New Treatment Opportunities $36 s$ Poul H.B. Sorensen, Department of Molecular Oncology, BC Cancer Research Center, Vancouver, BC

\section{SESSION 2: PROTEIN DRUG DELIVERY SYSTEMS AND DEVICES}

Enabling Remote Medicine: Implantable, Wirelessly-Controlled Microchip Drug Delivery .........................38s Robert Farra, President, MicroCHIPS, Inc.

Intradermal Delivery of Small Molecules, Proteins, Peptides and Vaccines using Microneedle Technologies. 38

Mark Tomai and Kris Hansen. 3M Drug Delivery Systems, St. Paul, Minesota

The Challenges of Protein and Peptide Delivery 39s R. Gurny, M. Veurink, L. Asmus, B. Kaufmann and M. Möller, School of Pharmaceutical Sciences, University of Geneva, Geneva, Switzerland

Formulation Strategies Around Osmotically-driven Therapeutic Protein Release $40 \mathrm{~s}$ Brian Amsden, Department of Chemical Engineering, Queen's University, Kingston, ON

\section{CSPS LIFETIME ACHIEVEMENT AWARD LECTURE}

Fructose Ingestion, Hypertension and the Metabolic Syndrome $41 \mathrm{~s}$ John H. McNeill, PhD, Professor and Dean Emeritus, Faculty of Pharmaceutical Sciences, University of British Columbia, Vancouver, B.C. 


\section{PLENARY LECTURE 3}

A Landscape Analysis of Pharmacogenomics $42 \mathrm{~s}$ Lawrence Lesko, Center for Pharmacometrics and Systems Pharmacology, University of Florida, Orlando, Florida

\section{SESSION 3: PERSONALIZED MEDICINE AND PHARMACOGENOMICS}

The Two Pharmacos: Vigilance and Genetics - A Powerful Partnership to Improve the Safe Use of Drugs $43 \mathrm{~s}$

Bruce C. Carleton, PharmD, Professor of Paediatrics, Faculty of Medicine, University of British Columbia; Director, Pharmaceutical Outcomes Programme, BC Children's Hospital, Vancouver

Implementation of Personalized Medicine (PM): From PM Clinics to Inpatient Care $44 s$ Richard B. Kim, Professor of Medicine, Physiology \& Pharmacology, and Oncology, Department of Medicine, Schulich School of Medicine \& Dentistry, University of Western Ontario, London, Canada

Breast Cancer Pharmacogenomics: Beyond Biomarkers $44 s$ Richard Weinshilboum, MD, Mary Lou and John H. Dasburg Professor for Cancer Genomics Research; Chair, Division of Clinical Pharmacology; Professor of Molecular Pharmacology \& Experimental Therapeutics and Medicine, Mayo Clinic, Rochester, Minnesota

Development of Novel Tools for Personalized Genomic Medicine to Improve Drug Safety in Children.....45s Colin Ross, MSc, PhD, Assistant Professor, Departments of Pediatrics and Medical Genetics, University of British Columbia, Vancouver, BC, Canada

\section{SESSION 4: NANOMEDICINE AND GENE DELIVERY}

Intravaginal Delivery of siRNA as Potential Microbicides. $47 \mathrm{~s}$ Emmanuel Ho, Ph.D., Faculty of Pharmacy, University of Manitoba, Laboratory for Drug Delivery and Biomaterials

Nucleic Acid Delivery using Chitosans $48 \mathrm{~s}$ Michael D. Buschmann, Canada Research Chair in Cartilage Tissue Engineering, Director Biomedical Science and Technology Research Group (FRSQ), Department of Chemical Engineering, Institute of Biomedical Engineering, École Polytechnique de Montréal

Programming Biomaterials for Personalized, On-Demand Medicine: A Nanomedicine Approach $48 \mathrm{~s}$ Larry Unsworth, University of Alberta

Peptide-targeted Polycations for Nucleic Acid Delivery $48 \mathrm{~s}$ Suzie Pun, University of Washington, Seattle, WA

\section{PLENARY LECTURE 4}

Mass Spectrometric Molecular Phenotyping of Tissues and Body Fluids $50 \mathrm{~s}$ Ruedi Aebersold, Department of Biology, Institute of Molecular Systems Biology, ETH Zurich and Faculty of Science, University of Zurich, Switzerland

\section{SESSION 5: PERSONALIZED MEDICINE AND BIOMARKERS}

Driving Products through a Robust Biomarker Pipeline - PROOF Centre Experience $51 \mathrm{~s}$ Janet Wilson-McManus, Chief Operating Officer, PROOF Centre of Excellence

Emerging Clinical Value of Molecular Signatures in Renal Medicine Daniel R. Salomon, M.D., Professor, Molecular and Experimental Medicine, Director, Laboratory for Functional Genomics, The Scripps Research Institute, Program Medical Director, Scripps Center for Organ Transplantation

Novel Strategies for Maximizing the Acquisition and Interpretation of Biomarkers. $52 \mathrm{~s}$ 
Scott J. Tebbutt, Ph.D., Department of Medicine, University of British Columbia, Vancouver, Canada

Biomarkers and the Improvement of Cardiac Care $53 \mathrm{~s}$

Peter Liu, Toronto General Hospital

\section{SESSION 6: CRITICAL QUALITY ATTRIBUTES AND BIOPHARMACEUTICS}

Biorelevant Dissolution: Where are We? $54 s$ Johannes Kraemer, Phast GmbH, Homburg, Germany

Practical Applications of the TNO Intestinal Model (TIM) in Pharmaceutical Development $55 \mathrm{~s}$ John Sagartz, Seventh Wave Laboratories LLC

In Vitro Dissolutions to Link Drug Product Critical Quality Attributes to in vivo Performance: A Regulatory Perspective - FDA $55 \mathrm{~s}$ Lawrence X. Yu, Ph.D. Deputy Director (acting), Office of Pharmaceutical Science, Food and Drug Administration

Developing Meaningful Control Strategy for Drug Products 56s Krishnan Tirunellai, Ph.D., Senior Scientific Advisor, Bureau of Pharmaceutical Sciences, Therapeutic Products Directorate, Health Canada and Visiting Professor, University of Ottawa

\section{GLAXOSMITHKLINE EARLY CAREER AWARD LECTURE}

Multifunctional Nanoparticles for Targeted Delivery of Anticancer Drugs $57 \mathrm{~s}$ Shyh-Dar Li, Ph.D., Ontario Institute for Cancer Research, Toronto, Ontario, Leslie Dan Faculty of Pharmacy, University of Toronto

\section{PLENARY LECTURE 5}

Enabling Industrialized Disruption of Medicine $58 \mathrm{~s}$ Patrick F. Terry, Cambridge, MA

\section{SESSION 7: PERSONALIZED MEDICINE AND FUNDING/GOVERNMENT/REGULATORY ISSUES}

Benefits, Harms and Uncertainties - Regulator's Perspective for Personalized Medicine $.59 \mathrm{~s}$ David K. Lee, Director of the Office of Legislative and Regulatory Modernization, Health Canada, Ottawa, ON

Personalized Medicine, A Long Learning Curve: EMA Experiences 59s Hans-Georg Eichler, European Medicines Agency

Personalized Medicine and Patient-Oriented Research: CIHR Perspective 60s Jane Aubin, Chief Scientific Officer and Vice-President, Research, CIHR

Industry Perspective of Partnerships in Canada on Personalized Medicine $61 \mathrm{~s}$ Bettina Hamelin, Director, Research \& Development and Medical Lead, Western Canada, Pfizer Canada, and Head, Strategic Research Partnerships, External R\&D Innovation, WRD, Pfizer Inc

Challenges in Translating Genomics Technologies to the Clinic: A Funder's Perspective $62 \mathrm{~s}$ Pierre Meulien, Ph.D., President and CEO, Genome Canada

\section{SESSION 8: INTERFACE BETWEEN ANALYTICAL METHOD AND FORMULATION IN THE QBD WORLD}

Quality by Design (QbD) Case Study: Establishment of a Design Space for a Preservative System $63 s$ Nadia Chacra, University of Sao Paulo, Brazil 
Solubility \& Dissolution Enhancement of Weakly Basic Compounds - Understanding Precipitation \&

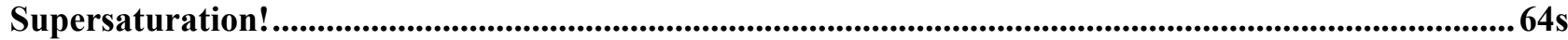

Jon Mole, Executive Vice President, Sirius Analytical Inc.

How to Model Supersaturation 64s Michael B. Bolger, Chief Scientist, Simulations Plus, Inc., Lancaster, CA

Pharma Polymers for Solubility Enhancement $65 \mathrm{~s}$ Kai Zhuang, Senior Technical Service Representative, BASF, Tarrytwon, NY

\section{SESSION 9: CURRENT BIOEQUIVALENCE TOPICS}

Highly Variable Drugs and Current Regulatory Requirements for Establishing the Bioequivalence.... 66s Nageshwar Rao Thudi, Ph.D., Associate Director - Biopharmaceutics, Watson Pharmaceuticals Inc.

Strategies and Issues in the Design and Data Analysis of Skin Adhesion, Irritation \& Sensitization Studies for Bioequivalence Evaluation of Transdermal/ Topical Generic Patch Systems. $67 \mathrm{~s}$ Keith Gallicano, Ph.D., Vice President, Scientific Affairs, Novum Pharmaceutical Research Services

Challenges with Depot Formulation Products: CRO Perspective $68 \mathrm{~s}$ Juan He, Senior Director of Pharmacometrics, BioPharma Services Inc.

Recommendations for Improving Quality of Bioequivalence Data Submitted to ANDAs in the US $68 \mathrm{~s}$ Barbara Davit, Merck \& Co., Rahway, NJ

\section{PLENARY LECTURE 6}

Simultaneous Translation: Opportunities and Challenges for Next Generation Pharmacogenomics .......... 70s Corey Nislow, Ph.D., Associate Professor, Department of Pharmaceutical Sciences, University of British Columbia, Vancouver, BC

\section{SESSION 10: PERSONALIZED MEDICINE AND THE CLINIC}

Setting the Stage - Bringing Personalized Medicine into the Oncology Clinic $71 \mathrm{~s}$ Karen A Gelmon, MD FRCPC, Professor Medicine, University of British Columbia, Medical Oncologist, BC Cancer Agency, Vancouver Cancer Centre

Molecular Characterization of Cancer in the Clinical Setting - Translation and Applications $72 \mathrm{~s}$ Lillian L. Siu, MD, FRCPC, Professor of Medicine, University of Toronto, Cancer Care Ontario Research Chair, Experimental Therapeutics, Medical Oncologist, Co-Director of Drug Development Program, Princess Margaret Cancer Centre

Implementing Personalized Cancer Medicine in the Clinic $73 \mathrm{~s}$ Richard L. Schilsky, MD, FASCO, Chief Medical Officer, American Society of Clinical Oncology

Using Functional Imaging and Novel Tracers to Accelerate Personalized Treatments..................................74s Francois Benard, MD, FRCPC. BC Leadership Chair in Functional Cancer Imaging, UBC and BC Cancer Agency

\section{SESSION 11: THE BC PERSONALIZED MEDICINE INITIATIVE}

The BC Personalized Medicine Initiative $75 \mathrm{~s}$ Pieter R. Cullis, Department of Biochemistry and Molecular Biology, University of British Columbia, Vancouver

Implementation of Pharmacogenomics into Clinical Care Decision Making in BC $76 \mathrm{~s}$ Martin Dawes, MB.BS, PhD, DRCOG, FRCG. Royal Canadian Legion Professor \& Head for the Department of Family Practice at University of British Columbia

Clinical Research in BC: Inegration and Synergizing Across the Clinical Research Spectrum $76 \mathrm{~s}$ Jim Russell, Professor, Department of Medicine, University of British Columbia, Vancouver 
The Potential for Value for Money with Pharmacogenomics $.77 \mathrm{~s}$ Carlo Marra, Faculty of Pharmaceutical Sciences, UBC, Vancouver, BC

Physician Education - An Important Factor for the uptake of Pharmacogenomics $.78 \mathrm{~s}$ Jan Friedman, Department of Medical Genetics, UBC, Vancouver, BC

POSTER SESSION 1

TUESDAY 6:00 PM THROUGH WEDNESDAY AFTERNOON COFFEE BREAK

\section{CSPS - POSTER SESSION 1}

Biomedical Sciences

1. Effect of Protein Kinase Inhibitors on the Activity and Expression of P-glycoprotein Drug Efflux Transporter. $.80 \mathrm{~s}$

2. A Novel, Biocompatible and Multivalent Macromolecular Reversal agent for Clinically available Parenteral Anticoagulants 80s

3. Suppression of Cardiac Myocyte Hypertrophy by Cannabinoid Receptors Involves AMP-activated Protein Kinase (AMPK)-Endothelial Nitric Oxide Synthase (eNOS) Crosstalk ......................................81s

4. Synthesis of Fluorescent Methyl Ketones as Inhibitors of Atg4B ..........................................................82s

5. Cardioprotective Effects of Gnetol (a Stilbene Derivative) via AMP-activated Protein Kinase ...........8 82s

6. Combination Effects of Anti-Cancer Drugs and Flaxseed Lignans in Prostate Cancer Cells .............. 83s

7. Effect of Glucosamine on Arachidonic Acid Metabolite Formation under Inflammatory Condition .83s

8. Effect of Glucosamine on Renin-Angiotensin System under Inflammatory Condition ........................84s

9. Cytochrome P450 Metabolites of Arachidonic Acid in Rat Heart as Mediators of NSAIDs Induced Cardiovascular Risk in Adjuvant Arthritis Model of Inflammation........................................................ 85s

10. NSAIDs Induced Changes in Angiotensin II Receptor (AT1, AT2) and Angiotensin 1-7 Receptor (MASS) Protein Expression in the Heart in Adjuvant Arthritis Rat Model ........................................85s

11. Inhibition of PCSK9 Increases Survival in Human Septic Shock and Murine Models of Bacteremia 86s

12. Evaluating Methods to Modulate Levels of Valproyl-1-O-Glucuronide in Sandwich-Cultured Rat Hepatocytes Treated with Valproic Acid 87s

Clinical Sciences and Pharmacy Practice

13. Canadian Values, Attitudes and Willingness to Pay for Expensive Medications for Rare Diseases .... 87s

14. Polymorphism of V1b Receptor is Associated with Increased Risk of Serious Adverse Events during Norepinephrine Infusion in Septic Shock 88s

Pharmaceutical \& Analytical Chemistry

15. 1,4-Diaryl-substituted Triazoles as Cyclooxygenase-2 Inhibitors: Synthesis, Biological Evaluation and Molecular Modeling Studies.... 89s

16. Synthesis and Bio-evaluation of Fluorescent Cyclooxyegenase-2 Inhibitors as Cancer Imaging Agents 89s

17. Simultaneous Determination of Bioactive Eicosanoids by Simple, Sensitive, Reliable and Cost-effective Reversed-Phase HPLC Method Using Fluorescence Detection $.90 \mathrm{~s}$

Pharmacokinetics \& Pharmacodynamics

18. Efficacy and Toxicity of Novel Oral Lipid-based Formulation of Amphotericin B (iCo-010) in a Rat Model of Invasive Candidiasis.

19. Pharmacokinetics of a Novel Lipid Based and Tropically Stable Formulation of Amphotericin B (iCo 010) following Oral Administration to Rats.

20. Agonism of Human Pregnane $X$ Receptor by Rilpivirine and Etravirine: Comparison with First Generation Non-nucleoside Reverse Transcriptase Inhibitors $.92 \mathrm{~s}$ 
21. Pharmacometrics of Gnetol: A Resveratrol Analogue from Asian Medicinal Plants

22. Pharmacokinetics of Tulathromycin, a Macrolide Antibiotic, in North-American Bison Following Mass Spectrometric Analysis

93s

23. First-In-Human Clinical Program Design for New Entities: a Comparison Between the Traditional Linear Approach and the Integrated Multiple Parts Approach ......................................................94s

24. Stereoselective Pharmacokinetics of Nebivolol in the Rat ............................................................94s

Drug Delivery \& Pharmaceutical Technology

25. ${ }^{111}$ In Labeled Gold Nanoparticles Conjugated to Trastuzumab $\left({ }^{111}\right.$ In-Au-T) Selectively Target HER-2 Overexpressed Breast Cancer Cells and Cause DNA Double Strand Breaks ...........................................95s

26. Role of Stereoregularity in the Stability of Polymeric Micelles and their Release Profiles...................95s

27. In Silco Modelling (Gastroplus ${ }^{\mathrm{TM}}$ ) to Overcome Pharmacogenomic Variation in Humans using Different Dextromethophan Dosage Forms

$.96 \mathrm{~s}$

28. Effect of Disodium Ascorbyl Phytostanol Phosphates on ABC-transporter within Caco-2 cells and the Potential Application as Enhancer of Chemotherapeutic Agents....................................................97s

29. Development and Characterization of Tacrolimus-Loaded PLGA Nanoparticles ..............................97s

30. Stromal Depletion and Suppression of Metastases in Breast Cancer Models with a Docetaxel-

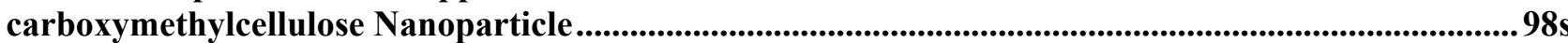

31. Effect of Gemini Surfactant on Amyloid Beta Aggregation ................................................................99s

32. Evaluation of the Cholesterol Lowering Plant Sterols using an in vitro Lipolysis Model..................... 100s

33. In Vivo Degradation Biodistribution and Biocompatibility of Biodegradable Hyperbranched Polyglycerols in Mice $100 \mathrm{~s}$

34. Development and Characterization of a Novel Intravaginal Nanomedicine for the Targeted Delivery of Saquinavir to CD4+ T-Cells $101 \mathrm{~s}$

35. Nanoparticle-based Gel for the Intravaginal Targeted Delivery of siRNA to Immune Cells of the Mucosa $101 \mathrm{~s}$

36. An Innovative Two-Component Intravaginal Ring for Sustained Protein Delivery............................ 102s

37. Enhanced Teatment of Lung Metastasis of Triple Negative Breast Cancer by Doxorubicin-mitomycin C Co-loaded Polymer Lipid Nanoparticles 103s

38. Design of Progesterone Binding Nano-Carriers for the Treatment of Alzheimer's Disease ............... 103s

39. Chitosan Coated Nanostructured Lipid Carriers Containing Dexamethasone Acetate: Development and PhysicalCchemical Characterization 104s

40. Lipid Nanoparticles Containing siRNA Synthesized by Microfluidic Mixing Exhibit an Electron-Dense Nanostructured Core 105s

\section{CC-CRS - POSTER SESSION 1}

41. A Bilayer Hydrogel System with Bioinspired Mucoadhesion for Buccal Drug Delivery...................... 106s

42. Development of Bone-Seeking Magnetic Nanoparticles as MRI Contrast Agents for Imaging Bone Metabolic Activity . 106s

43. Highly Elastic and Degradable Poly(N-isopropylacrylamide)-Magnetite Nanoparticle Composite Hydrogels for Controlled Drug Delivery. $107 \mathrm{~s}$

44. Development of an Analytical Method for the Simultaneous Quantification by LC-MS/MS of 8 Standard Drugs used in Permeability Assays $108 \mathrm{~s}$

45. The Long Term Stabilization of Chitosan/DNA Polyelectrolyte Complexes for Gene Delivery ......... 108s

46. Self-Assembling MMP-2 Cleavable Hydrogel Drug Delivery Systems 109s

47. Intrinsic and Extrinsic Parameters Affecting Efficiency and Toxicity of Chitosan-siRNA Nanoparticles for Gene Silencing $110 \mathrm{~s}$ 


\section{CSPS POSTERS - SESSION 2}

Biomedical Sciences

48. Targeting Intracellular Cholesterol Synthesis in Castration-resistant Prostate Cancer Cells ........... 112s

49. Endothelial Heparanase Secretion Induced by High Glucose Amplifies Fatty Acid Delivery to Cardiomyocytes

50. Multi-disease Animal Model for Examining the Relationship Between Stroke and Rheumatoid Arthritis. $113 \mathrm{~s}$

51. Non-Canonical Function of Telomerase Reverse Transcriptase in the Protection Against Genotoxic Events $114 s$

52. Characterization of Ribosomal RNA Pseudouridine Modification and Ribosomal Protein Translation in Telomerase-rescued X-linked Dyskeratosis Congenita Cells $114 s$

53. Effect of Acute Exercise on Pharmacokinetics of Diltiazem in a Freely Moving Rat Model .............. 115s

54. Protein Expression Changes of Nerve Growth Factor (NGF) During the Inflammatory Predemyelinating Stages of Experimental Autoimmune Encephalomyelitis (EAE): Implications in Multiple Sclerosis (MS). $115 \mathrm{~s}$

55. Characterization of Xenobiotic-Metabolizing Enzyme Expression, at the Protein Level, in Adult Rat Testis 116s

56. Screening for Inhibitors of the Cancer Related Enzyme Atg4B …................................................116s

57. Cross-cancer Profiling of Molecular Alterations within the Human Autophagy Interaction Network 117

Clinical Sciences \& Pharmacy Practice

58. Implementation of Pharmacogenomics (PGx) Testing in Community Pharmacy: A Pilot Project in Montréal, Québec $118 \mathrm{~s}$

59. An Evaluation of Hypertension Self-Management Applications for the iPhone $118 \mathrm{~s}$

60. Synthesis of Inhibitors of a Streptococcus Pneumoniae Virulence Factor 119s

Pharmacokinetics \& Pharmacodynamics

61. The Influence of Inflammation on the Ontogeny of L-Carnitine Homeostasis Mechanisms in the Rat Neonate. $120 \mathrm{~s}$

62. Quantifying Dabigatran Etexilate Pharmacokinetics and Pharmacodynamics in Hemodialysis Patients 120s

63. Hyperbranched Polyglycerol Conjugation Significantly Improves Vascular Residence and Reduces the Toxicity of Small Molecular Weight Iron Chelator $121 \mathrm{~s}$

Pharmaceutical \& Analytical Chemistry

64. Gastric Anti-ulcer, Anti-secretory and Cytoprotective Properties of Celery "Apium graveolens L." in Rats

65. A Simple and Sensitive Method for Simultaneous Determination of Vitamins $D_{3}$ and $K_{1}$ in Rat Plasma: Application for an in-vivo Pharmacokinetic Study $122 \mathrm{~s}$

66. Structure-activity Relationships of Inhibitors of Human $O$-GlcNAc Hydrolase. $123 \mathrm{~s}$

Drug Delivery \& Pharmaceutical Technology

67. Synthesis and in vitro Characterization of Hyaluronic Acid $\alpha$-tocopherol Succinate Based Selfassembling Micelles for Targeted Delivery of Rifampicin to Macrophages $124 s$

68. The Behaviour of Rifampicin Loaded Hyaluronic Acid $\alpha$-tocopherol Succinate Micelles in Alveolar Macrophages. $124 s$

69. Design and Evaluation of M1 Acetylcholine Receptor Selective Allosteric Potentiator BQCA Loaded 
PLGA Nanoparticles to treat Alzheimer's Disease........................................................................................ 125s

70. Cytotoxic Effect of Novel Dehydro-epiandrosterone Derivatives on Different Cancer Cell Lines..... 126s

71. Preparation and in vitro Characterization of Mixed Micelles System to Improve Solubility of Poorly

Soluble Drug Nicergoline 126s

72. Targeted Gemini Surfactant-Based Nucleic Acid Delivery for Melanoma Gene Therapy ................. 127s

73. Cell Toxicity Correlation with Physicochemical Characteristics of Curcumin Analog Inclusion in Novel Cyclodextrin-gemini Delivery Agent $127 \mathrm{~s}$

74. Novel Biosimilar Gemini Surfactant Lipid-Based Nanoparticles as Effective and Safe Non-Viral Gene Delivery Agents. $128 \mathrm{~s}$

75. Cross-linked Hyaluronic Acid-lipoic Acid Micelles for Enhanced Solubility, Stability and Targeted Delivery of Curcumin to Breast Cancer Cells $129 \mathrm{~s}$

76. Prospects of Drug Delivery using Dendritic Polymer Functionalized Red Blood Cells......................... 129s

77. In vitro Susceptibility Testing Candida spp and Aspergillus spp to New Formulation of Itraconazole for Pulmonary Administration. 130s

78. Enhanced Avian Influenza Specific Immune Responses Using Dendritic Cell Targeted DNA Loaded Chitosan Nanoparticles via Intranasal Immunizaton. $131 \mathrm{~s}$

79. Development of Thermo-Reversible Gels Based on Tri Block Copolymers of Poly(ethylene glycol) and Functionalized Poly( $\varepsilon$-caprolactone) for Drug Delivery $131 \mathrm{~s}$

80. In Vivo Assessment of Optimized Small Long Circulating Lipid Nanoparticles for Delivery of Bioactive Agents to bone 132s

81. Targeted LNP-siRNA Systems for Silencing the Androgen Receptor............................................133s

82. Production of Limit Size Lipid Nanoparticle Systems with a Potential Utility as Drug Delivery Systems 133s

83. Lipid Nanoparticle Delivery of siRNA to Silence Neuronal Gene Expression in the Brain 134s

84. Microfluidic Synthesis of Highly Potent Limit-Size Lipid Nanoparticles for In Vivo Delivery of siRNA 135s

85. Development of Lipid Nanoparticles for Targeted Drug Delivery to Bone $135 s$

86. Engineered Breast Tumor Targeting Peptide Ligand Modified Liposomal Doxorubicin and the Effect of Peptide Density on Anticancer Activity 136s

87. A Novel Tropically Stable Oral Amphotericin B Formulation (Ico-010) Exhibits Efficacy against

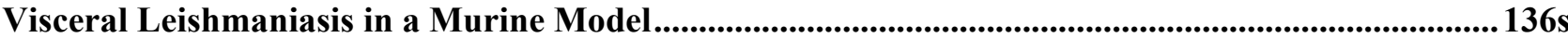

88. Biodistribution of Solid Lipid Nanoparticles (SLN) Incorporated into Insitu Forming System ........ 137s

\section{CC-CRS - POSTER SESSION 2}

89. Oxygen Delivery for Tissue Engineering. $138 \mathrm{~s}$

90. The Effect of Polymer Architecture on Drug Release Kinetics of Injectable, Degradable Hydrogels 138s

91. Acetylcholine Esterase Inhibitors Favor Bone Mass 139s

92. The Effect of Core Structure on the Physicochemical and Biological Stability of Polymeric Micelles based on Poly(ethylene Oxide) and Functionalized Poly(epsilon-caprolactone): an in-vitro Study.... 140s

93. Carboxymethyl Starch and Lecithin Complex used as Matrix for Targeted Drug Delivery ............... 140s

94. Synthesis, Characterization and Biodistribution Studies of ${ }^{125}$ I-Radioiodinated di-PEGylated Bone Targeting Salmon Calcitonin Analogue in Normal Rats

95. External, Targeted Control of Drug Release using Thermosensitive Magnetic Nanocomposite Hydrogels 141s

INDEX $143 S$ 


\section{Speaker Abstracts}

18s | CSPS / CC-CRS Conference 2013 


\section{Tuesday, June 11}

\section{Plenary Lecture 1}

\section{Engineering a Healthcare System to Deliver Personalized Medicine}

Dan Roden, Vanderbilt University, School of Medicine, Nashville, TN

Variability in disease susceptibility and drug response is the hallmark of human pathophysiology. While the increasing pace of discovery of genomic and other markers for these phenotypes holds the promise of personalizing care, implementing highdimensional information in clinical practice presents major challenges. It is our working hypothesis that advanced electronic medical record (EMR) systems can serve not only as tools for delivery of decision support-guided care but also as tools for discovery and validation of novel biomarkers of drug response and of disease susceptibility and progression. Studies in BioVU, the Vanderbilt DNA repository (containing samples from $>160,000$ subjects) linked to a de-identified image of the EMR, have replicated known genotype associations, discovered new associations, and have provided a platform for the development of the new phenome-wide association study (PheWAS) paradigm that searches across the range of diagnostic codes and other phenotypes to identify associations with specific genetic variation.

Initial steps are also being taken to execute a popular but as yet untested vision of genomic medicine in which EMRs to deliver point of care prescribing advice based on genomic data "preemptively" embedded in individual patient records, thereby avoiding logistic hurdles in a reactive pharmacogenomic prescribing strategy. In the Vanderbilt PREDICT (Pharmacogenomic Resource for Enhanced Decisions In Care and Treatment) project, we have created a framework for evaluating "actionability"; identifying patients likely to receive target drugs (such as clopidogrel, warfarin, simvastatin, azathioprine, or tamoxifen); obtaining and analyzing raw genotypic data and depositing genotypes into the EMR; delivering point of care prescribing advice when a drug target drug is prescribed for a patient with a variant genotype; and tracking outcomes and costs. Early lessons from PREDICT, which now embeds pharmacogenomic variant data in EMRs of $>12,000$ patients, include the need for a highly collaborative scientific environment and extensive institutional commtment.
Aggregation of resources such as BioVU and PREDICT across multiple sites - now being undertaken in the NHGRI's Electronic Medical Records and Genomics (eMERGE) network - holds the hope of expanding discovery efforts which will in turn provide the evidence base for further implementation of an EMR-driven vision of personalized healthcare.

\section{Dan Roden}

Dan Roden was born and raised in Montreal, and received his medical degree and training in Internal Medicine from McGill University. He then went to Vanderbilt where he trained in Clinical Pharmacology and Cardiology, and has been a faculty member there since. His initial career focus that he has maintained - was studies of the clinical, genetic, cellular, and molecular basis of arrhythmia susceptibility and variability responses to arrhythmia therapies, and he is widely-recognized for his expertise in drug-induced arrhythmias. Over the last 10 years, he has led Vanderbilt's broader efforts in pharmacogenomics discovery and implementation.

Dr. Roden is Principal Investigator for the Vanderbilt sites of the NIH's Pharmacogenomics Research Network and the Electronic Medical Records and Genomics Network. He directs the Vanderbilt DNA databank BioVU, and is one of the key leaders overseeing the Vanderbilt PREDICT project that is preemptively embedding pharmacogenomic variant data in the Vanderbilt electronic medical record.

Dr. Roden served as Director of the Vanderbilt Arrhythmia Service, director of the Division of Clinical Pharmacology (1992-2004), and in 2006 was named Assistant Vice-Chancellor for Personalized Medicine. Dr. Roden has received the Leon Goldberg Young Investigator Award and the Rawls Palmer Progress in Science Award from the American Society for Clinical Pharmacology and Therapeutics and the Distinguished Scientist Award and the Douglas Zipes lectureship from the Heart Rhythm Society. He currently serves on the Science Board of the FDA. He has been elected to membership in the American Society for Clinical Investigation and the Association of American Physicians, and fellowship in the American Association for the Advancement of Science. 


\section{Tuesday, June 11}

\section{Industry Workshop 1}

\section{Personalized Medicine: The Pharma Perspective - Engaging the Community}

\section{The Role of Personalized Heath Care in Driving Canada's Economy}

Ronnie Miller, President and CEO of Hoffmann-La Roche Limited (Roche Canada)

The pharmaceutical industry has undergone a significant transformation in the past decade, and the future will be equally dynamic and demanding. As our industry evolves, there are considerable changes facing the entire healthcare sector that will present several opportunities and challenges in both Canada and worldwide. An aging population, a strained health care system and increased competition from emerging markets are among the many realities of the environment in which we operate. These realities require new approaches and strategies to maintain the level of health care Canadians have come to expect.

Personalized health care represents more than just one element of the solution to these challenges It is a major driver of the Canadian economy. As a key component of the innovative health care industry, PHC serves as a conduit for collaboration between the private and public sectors, supports a thriving life-sciences workforce and attracts significant domestic and global investment in ground-breaking research initiatives.

A leader in both pharmaceuticals and diagnostics, Roche is uniquely positioned to meet the challenges of the changing health care landscape, and provide patients with truly individualized treatment and better outcomes.

\section{Ronnie Miller}

Ronnie Miller is the President and CEO of Hoffmann-La Roche Limited (Roche Canada). In this role, Ronnie is responsible for the strategic direction, profitability and operations of the pharmaceuticals division in Canada.

Ronnie has over 30 years of extensive and varied experience in the pharmaceutical industry. $\mathrm{He}$ began his career in the United Kingdom as a medical sales representative, and accepted a series of progressive positions including Sales Management, Product Management, Business Unit Director and National Sales Manager.

Since joining Roche in 1988, Ronnie has held a held a number of positions of increasing importance, including Business Unit Director in the United Kingdom, International Product Manager in Switzerland, Marketing Director and Deputy Divisional Director of the Pharmaceutical Division in Japan, Xenical global task force leader, and Divisional Director of Pharmaceuticals in the United Kingdom. He was appointed President and CEO of Roche Pharmaceuticals in Canada in April 2000.

Ronnie Miller is a member of the Board of Directors of $\mathrm{Rx} \& \mathrm{D}$, the national association representing Canada's research-based pharmaceutical companies. He was Chair of the Board of Directors of Rx\&D from November 2007 to November 2008 and served two subsequent terms as Past Chair. Prior to becoming Rx\&D Board Chair, he served on several industry committees including Public Affairs, and Stakeholder Relations and was Chair of the Rx\&D Federal Affairs/FPT Relations Standing Committee.

Outside Rx\&D, Ronnie is a member of the Swiss Canadian Chamber of Commerce and the University Health Network Research Committee.

Ronnie holds a Bachelor of Science in Economics and Geography from Glasgow University. 


\section{Making Canada a Powerhouse in Pharmaceutical R\&D in the New World of Personalized Medicine}

Rav Kumar, PhD., Vice-President, R\&D Operations/ Business Development, GlaxoSmithKline Canada

After years of decline, and following an agreement with the Canadian government to re-establish globally competitive pharmaceutical patent protection, the industry began to invest significantly in Canadian life sciences R\&D. Combined with government investment, this has helped to create a very strong life sciences sector in Canada. During the last decade, the business model for the global pharmaceutical industry has been changing significantly including loss of clinical trials to emerging markets and consolidation of $R \& D$ centres.

Whilst this has not been ideal in terms of loss of pharma jobs and investment, there are actually many possibilities which can arise out of the evolving pharma industry R\&D model which includes greater externalization of $R \& D$. This presents a tremendous opportunity for the excellent science which has been built up in Canada over the past two decades.

Innovation clusters have emerged all over Canada to capitalize on this opportunity and bring industry and academia together to create new products, companies and jobs.

The Canadian government is encouraged to develop a "Life Sciences Strategy" for the country which would align and bring together the many initiatives which are all focussed on the same vision including a focus on personalized medicine as an area for Canada to become a global leader.

\section{Rav Kumar}

Dr. Rav Kumar leads GlaxoSmithKline's Canadian R\&D/Business Development organization involved in Clinical Research, Regulatory Affairs, External R\&D Alliances and New Business Development.

Rav is a pharmacy graduate with a $\mathrm{PhD}$ in pharmaceutical sciences (from Bath University, UK) involving research into controlled delivery of drugs such as insulin. He has more than 25 years of global drug development experience having worked for start-up and multinational pharmaceutical companies in the United Kingdom, France and North America.

Rav has been very involved in the Canadian Pharmaceutical R\&D "Ecosystem" over the past decade including time as President of the Canadian Society for Pharmaceutical Sciences (CSPS), ViceChair of Regulatory and Medical/Clinical
Committees at Rx\&D and Chair of several DIA Canada conferences. He also serves as President of SAPNA - a non-profit organization dedicated to improving the health and health awareness of South Asian Canadians.

\section{Science and Challenges Behind the Personalized Medicine Approach with Kalydeco}

\author{
Fred Van Goor, Vertex Pharmaceuticals Canada
}

[Abstract and bio not available]

\section{Drug Target Selection: Lessons from Human Genetics}

Simon Pimstone, President and Chief Executive Officer, Xenon Pharmaceuticals

Drug development remains fraught with risks and still today, despite the advances in technologies and predictive algorithms, more drugs fail in development than succeed. A major and age-old challenge remains the pharmaceutical properties of the molecule - no matter what the therapeutic modality. The other key development risk is contributed to by the choice of target against which the therapeutic is designed to interact. The advent of cost effective genetic technologies such as high throughput whole genome and exome sequencing, is allowing the identification of genetic factors underlying human diseases in an efficient and costeffective manner. What were once complex catchall disorders such as pain are increasingly being considered as multiple distinct disorders where a better appreciation of the basic molecular mechanisms of the disease, might allow more diverse and targeted therapeutic approaches to treatment. To reduce the risk of drug target selection, Xenon Pharmaceuticals has been pioneering the study of extreme human phenotypes to provide important insights into drug targets which exhibit a potential major biological effect. In the area of pain therapeutics, Xenon's genetic insights have yielded a novel small molecule drug developed against a human target which has a profound effect on pain modulation in humans. Variations in this SCN9A sodium channel gene are being increasingly identified underlying various pain states such as erythromelalgia, persistent episodic pain disorder 
and idiopathic small fiber neuropathy. Furthermore, common polymorphisms in SCN9A might play an important role in pain perception in the general population. The field of pain therapeutics might benefit significantly from such novel genetic insights.

\section{Simon Pimstone, MD, PhD, FRCPC}

Simon is a founder, Director, and President and Chief Executive Officer at Xenon Pharmaceuticals Inc., one of Canada's leading privately owned biotechnology companies. Xenon is engaged in discovering and developing novel pharmaceuticals for rare human diseases using its unique genetic platform for novel target discovery.

He received his MD from the University of Cape Town. $\mathrm{He}$ is an internal medicine specialist (FRCPC) with an interest in cardiovascular disease. Prior to his specialization, he trained as a clinical research fellow with the Department of Medical Genetics at the University of British Columbia and obtained his $\mathrm{PhD}$ through the University of Amsterdam in cardiovascular genetics. $\mathrm{He}$ is a consultant physician at the UBC Hospital, Cardiology Clinic.

Simon is a director and the past Chair of LifeSciences British Columbia. He also serves as a director of Providence Health Care. He is a member of the Translation Advisory Committee of the PROOF (Prevention of Organ Failure) Centre, a member of the Advisory Board of the Centre for Molecular Medicine and Therapeutics (CMMT) and a member of the BC Health Research Strategy Advisory Board for the Michael Smith Foundation for Health Research. He is Vice Chair of the Executive Management Team for the BC Clinical Research Infrastructure Network (BCCRIN). Simon is also a Member of the Science, Technology and Innovation Council, which reports to the Federal Ministry of Industry and is co-chair of the 2013 State of the Nation Report on Canadian Science and Technology.

Simon serves as Director of the biotechnology companies Enject in California and Indel Therapeutics and Eupraxia in Vancouver.

\section{Personalized Medicine: A Legal and Regulatory Perspective}

Richard Cheung, Fasken Martineau DuMoulin LLP

Personalized medicine, a rapidly emerging area in healthcare, promises many therapeutic advantages including the ability to identify patients who will benefit from a particular drug, reduce the number and severity of adverse drug reactions, and increase patient adherence to a drug treatment. However, since personalized medicine involves the coordinated application of a diagnostic device and a drug, various legal and regulatory issues may arise that are important for stakeholders to be aware of -for example, liability for drug companies and other stakeholders, regulation of laboratory developed tests, and reimbursement of drugs and diagnostic tests -- as they may limit our ability to fully realize these benefits going forward. This presentation will explore some of the foregoing issues and consider possible strategies to overcome these challenges.

\section{Richard Cheung}

Richard Cheung is an associate lawyer in the Toronto office of the Fasken Martineau DuMoulin LLP Intellectual Property Group and a member of its Life Sciences industry group. Richard practises in all areas of intellectual property law with a focus on patents. In addition, he counsels clients on regulatory issues related to health products in Canada including compliance and enforcement matters, drug pricing and reimbursement, data protection, patent listing, and medical device licensing. Richard also has experience in a wide range of matters involving the innovative pharmaceutical and biotechnology industry, including proceedings under thePatented Medicines (Notice of Compliance) Regulations.

Richard is a licensed pharmacist in the Province of Ontario with experience in community and hospital pharmacy. His doctorate thesis involved the development of a novel particulate delivery system for anti-cancer drugs. He has broad technical experience in the areas of pharmacy and pharmaceutical sciences. 


\section{Transforming Discovery into Opportunity: The CDRD Bridge Between Industry and Academia}

Karimah Es Sabar, President and CEO, The Centre for Drug Research and Development (CDRD), Vancouver, BC

Around the world, billions of dollars are invested in medical research each year - most of it into universities and research institutions (and a significant portion of it targeted towards personalized medicine). Impressive results in terms of scientific discoveries have been achieved, yet it is extremely difficult to translate these discoveries into new therapies and other $\mathrm{PM}=$ related technologies that are ultimately adopted in the healthcare system. The main reason is risk and cost.

Many players (from academic institutions and granting agencies, to translational research organizations, foundations and industry) must therefore find new avenues to come together to fill the gaps in the development continuum, and effectively de-risk early-stage technologies in risk/reward share models.

In this context, The Centre for Drug Research and Development (CDRD) was established in 2007 as Canada's fully-integrated, national drug development and commercialization centre, providing expertise and infrastructure to enable researchers from leading health research institutions to advance promising early-stage drug candidates. A Canadian Centre of Excellence for Commercialization and Research (CECR), its mandate is to de-risk discoveries stemming from publicly-funded health research and transform them into viable investment opportunities for the private sector - thus successfully bridging the commercialization gap between academia and industry, and translating research discoveries into new and more effective therapies for patients.

CDRD fulfills this mandate by working with scientists from academic research centres across the country and around the world to identify the most commercially-promising discoveries, and then performing the additional proof-of-concept research and business analysis required in order to develop and de-risk those discoveries into commerciallyviable opportunities for industry. Industry partners are then well-positioned to take on the responsibility of developing them further into new treatments for patients - and in doing so, generating strong economic returns on the original public investment in health research.
This presentation will describe CDRD's mandate and model, introduce the expertise and resources it provides, and highlight the national and international partnerships across industry and academia it has built to successfully advance new innovations.

\section{Karimah Es Sabar}

A highly-recognized Canadian life sciences leader, Karimah Es Sabar brings 30 years of dynamic global business experience to her role as President and CEO of The Centre for Drug Research and Development (CDRD) headquartered in Vancouver, British Columbia, Canada. She previously held the position of Senior Vice-President, Business and Strategic Affairs at CDRD, responsible for ensuring the organization's long-term sustainability, while leading its business functions and successfully building the many national and international alliances and strategic partnerships which are now contributing significantly to advancing the goals of CDRD. In 2013, Ms. Es Sabar was appointed Founding Chair of the Global Alliance of Leading Drug Discovery and Development Centres, an association of international peer organizations dedicated to translating health research into new medicines.

Prior to joining CDRD, Ms. Es Sabar took on the role of leading BC Biotech in 2005, reengineering and rebranding the organization to LifeSciences BC. As President, she led the organization to its greatest levels of success as a strong business development organization for the life science industry and the scientific research community. Ms. Es Sabar has also held senior management positions with international multinational companies, most notably as Director International Division, and later Director Marketing and Business Development at Connaught Laboratories Limited [Sanofi Pasteur] based in Toronto. Ms. Es Sabar also served as Vice President and Chief Operating Officer for a Vancouver medical devices company, Medsurge Medical Inc., and was the founder and Managing Director of SAL Healthcare Limited, a leading healthcare organization in Kenya specializing in pharmaceutical marketing, distribution and healthcare consulting services. The company set new standards in the marketing and distribution of biopharmaceutical products in the region.

Ms. Es Sabar currently serves as Chair of the Board of Trustees of the Providence Healthcare Research Institute, and also sits on the Boards of a 
number of organizations including the Michael Smith Foundation for Health Research (MSFHR); the Prostate Centre Advisory Board, Vancouver General Hospital; the Prostate Centre's Translational Research Initiative for Accelerated Discovery and Development (PC-TRIADD); NRC - IRAP Advisory Board; and also Chairs MOSAIC, a multilingual non-profit organization dedicated to addressing issues that affect immigrants and refugees in the course of their settlement and integration into Canadian society. She has also lent her leadership expertise by participating in a number of advisory committees for organizations such as the Natural Sciences and Engineering Research Council of Canada (NSERC); MITACS; the British Columbia Institute of Technology / University of British Columbia Biotechnology Degree Program; The Indus Entrepreneurs (TIE); India Market Advisory Committee, and the British Columbia Asia-Pacific Trade Council. She is also a former board member of LifeSciences British Columbia, the Aga Khan National Economic Planning Board of Canada and Aga Khan National Health Boards in Canada and Kenya.

In 2007, Ms. Es Sabar received Canada's Gold Award for Business Excellence (CABE) while at Sanofi Pasteur, was the recipient of the YWCA Women of Distinction Award in 2010 for Industry, Science and Technology, was included amongst "The Vancouver Power 50" listing of the most influential people in BC by Vancouver Magazine, and in "BC's Top 100 Women of Influence" by the Vancouver Sun.

Ms. Es Sabar holds a BSc. Joint Honours degree in Biochemistry/Chemistry from the University of Salford, England, and a MSc. degree in Neurochemistry from the Institute of Psychiatry, University of London, England.

\section{Genome BC: Regional Perspectives on Personalized Medicine in British Columbia, Canada}

Brad Popovich, Chief Scientific Officer, Genome British Columbia

Genome British Columbia is a catalyst for the life science cluster on Canada's West Coast managing a cumulative portfolio of over $\$ 625 \mathrm{M}$ in 180 genomics research project and science and technology platforms. Now in its twelfth year of operation, Genome $\mathrm{BC}$ is working with governments, academia and industry to translate advances in genomics to generate social and economic benefit for British Columbia and Canada. Within the field of human health, Genome BC is working with world-leading academic researchers and stakeholders across the healthcare system to realize the potential of "personalized medicine". This presentation will review Genome BC's approaches to support personalized medicine and will reflect on some of the challenges to implementation.

\section{Brad Popovich}

Brad Popovich is the Chief Scientific Officer at Genome British Columbia in Vancouver BC (2011present). His involvement in the organization spans many years; Brad sat on the board of directors from 2006-2011. He also acted as chair for the Scientific Committee at Genome British Columbia from 20082010. Outside his present role at Genome BC, Brad serves as Chairman, Genetic Information Management Systems, and Director, Centre for Drug Research and Development Ventures.

Brad was the President and Chief Executive Officer of Sirius Genomics from 2006-2009 and was the VP, Operations at Xenon Pharmaceuticals (20012005). Previously, he was the founding Director to the Molecular Diagnostics Laboratory at Oregon Health Sciences University where he was also the Director of Graduate Education and the Executive Director, Genetic Service Laboratories at the University Hospital.

Brad's genetic training is in genetic counseling (MS, Sarah Lawrence College) biochemical genetics (MS, McGill University), molecular genetics ( $\mathrm{PhD}$, McGill University), and postdoctoral training / clinical fellowship (University of Wisconsin, and University of North Carolina (laboratory of Nobel Laureate Oliver Smithies.) 


\section{Tuesday, June 11}

\section{Industry Workshop 2}

\section{Personalized Medicine: The Diagnostic/Information Technology Company Perspective}

\section{Companion Diagnostic Partnership with Illumina}

Alex Yong, Global Sales Manager Pharma Market, Illumina

Illumina provides a comprehensive line of products that address the scale and breadth of functional analysis required to achieve the goals of molecular medicine. From biomarker discovery to the development of molecular diagnostic assays, our offering includes leading-edge solutions for sequencing, SNP genotyping, copy number variation, gene expression profiling, and DNA methylation. In this session we will provide an update on our Diagnostics business unit, highlight a new next-generation targeted sequencing panel focusing on genes implicated in solid tumors, and discuss the work we are doing to position ourself as a leading partner for the development of companion diagnostics.

\section{Alex Yong}

Alex Yong is the Global Sales Manager of the Pharmaceutical Market at Illumina. He is part of the Market Development team responsible for broader strategic partnerships between Illumina and Pharma. This includes profiling new applications of interest to Pharma throughout the entire drug development process, as well as companion diagnostics partnerships. Alex has a Ph.D. in Neurobiology from the University of California, Irvine.

\section{Big Data Analytics Accelerating the Emergence of Personalised Healthcare}

Frederick S. Lee MD, MPH, Director of Clinical \& Translational Informatics, Oracle Health Sciences

Big data analytic platforms have emerged that accelerate every aspect of the value chain in personalized healthcare. Learn how pioneers are using such platforms to impact a diversity of domains from drug discovery, individualized regimens, drug repositioning, molecular decision support, patient engagement solutions, to post approval monitoring.

\section{Frederick Lee}

Fred leads business development strategies in clinical \& translational informatics and personalized healthcare for Oracle's Health Sciences Global Business Unit. He has helped establish and grow the burgeoning field of personalized healthcare through his ability to merge perspectives from the life sciences, healthcare delivery, clinical informatics, and public health.

Prior to Oracle, Fred was the Founding Executive Director \& Chief Medical Officer of the P4 Medicine Institute, a translational innovation consortium dedicated to creating a predictive, preventive, personalized, \& participatory future of healthcare. In this role, he helped establish Lee Hood's vision of P4 Medicine by developing partnerships between systems biology \& major academic health centers. He continues to play a key role in P4 Medicine, as the first official fellow of the P4 Medicine Institute.

Fred brings a unique and broad range of professional experiences to the task of creating healthcare of the future, having spent time as a practicing clinician, as a healthcare executive, and as an industry technologist. From the industry perspective, Fred led product strategy efforts for 
McKesson Corporation in its Provider Technologies division, focusing on enhancing electronic health records to support genomic \& molecular medicine. He has also held leadership roles in General Electric Healthcare, leading product strategy for GE Healthcare Information Technologies in the United Kingdom while working on the UK's National Health Service Connecting for Health program.

Fred has held executive leadership roles in health systems in the New York / Long Island area, as a Chief Operating Officer and as a Chief Medical Information Officer of a large ambulatory care network in New York.

Fred's clinical background is in general surgery and preventive medicine. He received a BS from the Massachusetts Institute of Technology in Life Sciences, an MD and residency training from the Stony Brook University School of Medicine, and a Masters in Public Health degree from the Mailman School of Public Health at Columbia University.

\section{The Development and Validation of High Value Molecular Diagnostics Intended for Clinical Use: A Case Study in Lung Cancer}

Paul Kearney, President and Chief Science Officer, Integrated Diagnostics, Seattle, WA

[Abstract and Bio not available]

\section{The NanoAssemblrTM - A Platform for the Translation of Genomic Information from Bench to Bedside}

\author{
R. James Taylor, CEO \& Co-Founder, Precision \\ NanoSystems, Inc.
}

The current revolution of genomic data acquisition and analysis is promising to have an unprecedented impact on the understanding, diagnosis, and treatment of disease. However, to fully realize the potential of translating genomic information from bench to bedside, experimental and clinical challenges remain. Nanoparticle technologies will play a significant role in solving these challenges by allowing scientists to more easily study the roles of genes in disease and by allowing clinicians to treat disease at the genetic level. Precision NanoSystems is democratizing the use and development of nanoparticle technologies through its nanoparticlebased SUB9KITS ${ }^{\text {TM }}$ for the functional study of genes and disease and its NanoAssemblr ${ }^{\mathrm{TM}}$ platform for the development and manufacture of nanoparticle drugs.

SUB9KITS ${ }^{\mathrm{TM}}$ allow for the nanoparticle-based delivery of RNA to difficult to transfect primary cell lines in vitro and in vivo. SUB9KITS ${ }^{\mathrm{TM}}$ represent a fundamentally different technology to existing transfection reagents or methods. Whereas existing methods disturb the cells membrane to deliver RNA into cells either chemically (i.e. cationic lipids or polymers) or physically (i.e. through high voltages using electroporation), SUB9KITS ${ }^{\mathrm{TM}}$ use receptor mediated delivery to achieve delivery with minimal disturbance. As such SUB9KITS ${ }^{\mathrm{TM}}$ are highly potent without having the toxicities of incumbent approaches. SUB9KITS ${ }^{\mathrm{TM}}$ have been used for the delivery of siRNA for loss of function studies in neurons, [Neuro $]_{9}$ Kit, and in hepatocytes, $[\text { Hepato }]_{9}$ Kit and are manufactured using NanoAssemblr ${ }^{\mathrm{TM}}$ instrument.

The NanoAssemblr ${ }^{\mathrm{TM}}$ Instrument is a novel, scalable microfluidics-based system for the development and manufacture of nanoparticles. Traditional methods for producing nanoparticles are inconsistent, difficult to scale, and labor-intensive. The NanoAssemblr ${ }^{\mathrm{TM}}$ uses custom engineered microfluidic chips to enable millisecond mixing of nanoliter reaction volumes containing nanoparticle components. This well-controlled process mediates bottom-up self-assembly of nanoparticles with process and formulation dependent characteristics, including limit-sized lipid nanoparticles (lsLNP), the smallest stable structure possible for a lipid nanoparticle (LNP). Rapid mixing of nanoparticle components with nucleic acids provides precise control over nanoparticle formation and size, resulting in nucleic acid solid-core nanoparticles ranging in diameter from 15-200 nm with low polydispersity (PDI < 0.1). Size is an important determinant of nanoparticle biodistribution and behavior in vivo.

Seamless scale-up of nanoparticle drugs is achieved through the parallelization of microfluidic mixers. Individual NanoAssemblr ${ }^{\mathrm{TM}}$ microfluidic mixers are capable of producing LNP at 0.5-20 $\mathrm{mL} / \mathrm{min}$. Parallelization ensures that large-scale reaction conditions remain identical to single mixer devices. Pilot studies have demonstrated an n-fold increase in LNP output by arraying $\mathrm{n}$ mixers in parallel, with no differences in LNP characteristics (eg. Size) with scale. 


\section{James Taylor}

James has a Ph.D. in genetics from the Institute for Systems Biology in Seattle, WA and a B.A.Sc. in engineering physics from the University of British Columbia. James worked at the Seattle based Venture Capital firm, the Accelerator Corporation concurrent with his Ph.D. and has over 8 years of experience in the science and commercialization of microfluidics, nanotechnology, and systems biology. James has been the leader of Precision's technology and commercialization since invention. 


\section{Tuesday, June 11}

\section{Industry Workshop 3: Personalized Medicine: The Biotech Perspective}

\begin{abstract}
Fostering Effective Industry, Public Health, Academic Collaborations - Optimising Health Care Interventions towards Improving the Health of Canadians
\end{abstract}

James A. Mansi, Ph.D., Novartis Pharma Canada Inc., Vaccines and Diagnostics

We find ourselves at the nexus of an evolution in vaccinology. Advances in genomics and innovative strategies such as bio-informatics and structurebased antigen design have changed the concepts and approaches to vaccine candidate selection and development. These new vaccine technologies have the potential to make continued and important contributions to improving our quality of life by targeting diseases that could not be effectively covered through more conventional approaches. In this modern era of vaccinology, the lifecycle of vaccine development offers many opportunities and challenges for collaboration between private industry, clinical and academic life sciences, and public health. Given the complexities of these new technologies and immunisation paradigms, such partnerships would allow a means of addressing research and public health priorities whilst bridging important clinical and educational gaps underpinning successful implementation. Optimally, such engagements would need to address common objectives and focus on complementary areas of interest between the identified partners. Establishing clear and transparent platforms would be required that both define and govern the partnerships, towards producing results that would be acceptable by all stakeholders; academic researchers, clinical practitioners, and public health practitioners. During the course of this presentation, we shall explore the dynamics of the collaborative platforms and discuss a series of critical governing principles. Expanding upon specific case studies, we shall describe the continuum of different potential engagements along the life-cycle of a vaccine candidate, from early development to pre- licensure clinical evaluation, education, and postlicensure surveillance.

\section{James A. Mansi}

James A. Mansi is the Director of Medical Affairs for Vaccines \& Diagnostics at Novartis Canada.

James completed his doctoral studies in physiology/endocrinology at Universite Laval in Quebec City. Prior to joining Novartis, James was the regional director, medical and scientific affairs for vaccines at Merck Frosst Canada. Among the many hats he wore, he was responsible for protocol development and implementation of local research studies towards supporting immunisation recommendations with national and international scope and impact.

He is involved in providing clinical, medical and scientific expertise in the area of vaccines and as such works closely with global development, regional medical affairs and local stakeholders through phases I/II/III and medical affairs phase IV studies while ensuring their safety and standards adherence.

James has several publications in the area of immunization across various therapeutic areas such human papilomavirus, rotavirus, zoster and invasive meningococcal disease.

\section{Zymeworks - Designing Bispecifics and other Next-Generation Protein Therapeutics}

Ali Tehrani, Zymeworks

Antibody therapeutics are one of the largest and fastest growing segments of the pharmaceutical market. In the very competitive landscape of antibodies, bi-specific antibody therapeutics are highly sought after because they enable novel biologies and mechanisms of action as compared to cocktails and combination therapies. Zymeworks has developed a proprietary platform for the development of bi-specific antibodies, which the company is using to form collaborative drug 
development partnerships with big Pharma, and to develop its own pipeline of antibody based therapeutics. In 2011 Zymeworks announced its first partnership with pharma; a \$187M deal with Merck to develop bi-specific antibody therapeutics using Zymeworks' Azymetric platform.

\section{Ali Tehrani}

Dr. Tehrani is one of Zymeworks' co-founders and currently serves as President and CEO of the company. He has been an integral part of many of the Company's corporate achievements including raising seed and angel financing and overseeing the Company's technical operations and patent filings. Dr. Tehrani holds both Bachelors and Masters of Science degrees in Biochemistry from the University of Massachusetts, and has a Doctoral degree in Microbiology and Immunology from the University of British Columbia.

\section{Pathways to Personalized Medicine}

\section{T. Nathan Yoganathan, PhD, President and CSO}

Personalized medicine promises to revolutionize the practice of medicine, transform the global healthcare industry, and ultimately lead to longer and healthier lives. We will be discussing what role Kalgene Pharmaceuticals is playing in the development of personalised medicine in the area of Oncology.

\section{T. Nathan Yoganathan}

Dr. Yoganathan brings the know-how to efficiently build companies and raise capital as well as the scientific expertise to guide KalGene's research and development programs. Dr. Yoganathan previously founded Med BioGene Inc. (MBI) and acted as its President and CSO. He participated in listing MBI on the TSX-Venture and in raising several million. $\mathrm{He}$ has authored numerous scientific papers and is the co-inventor of several patent and pending patent applications. Dr. Yoganathan has over 25 years of experience in scientific research in cell signaling and gene expression technology. He is the recipient of numerous awards including ones from the Natural Sciences and Engineering Research Council of Canada and the Thyroid Foundation of Canada. He also serves as a mentor for the student biotechnology network (SBN) of British Columbia. Dr. Yoganathan was a faculty member of the Department of Medicine at the University of Toronto and was affiliated with the Mt. Sinai
Samuel Lunenfeld Research Institute. He holds a B.Sc. (Honours) from the University of North London, a M.Sc. from the University of Sussex and a Ph.D. from the University of Oslo.

\section{Translational Biomarker Research in Drug Development: Challenges and Opportunities}

Scott D. Patterson, Ph.D., Executive Director, Medical Sciences, Head, Medical Sciences IVD Group, Amgen Inc, Thousand Oaks, CA USA

The development of targeted therapeutics for global populations requires identification of that segment of the patient population that displays the greatest benefit:risk profile, enabling demonstration of the value of the therapeutic to patients and associated stakeholders. Patient selection is accomplished through the use of biomarkers, the measurement of which informs patient eligibility for a given therapeutic. When the target of the therapeutic displays restricted expression in the patient population, the measurement of the target as a biomarker for patient selection is a relatively straightforward scenario, i.e., ignoring potential analytical challenges of determining the cut-off value or clinical decision point from early in a clinical development program. However, signaling pathway elements downstream of the therapeutic target may also represent valid biomarkers of patients' response. Developing sufficient levels of evidence to gain confidence to test a novel biomarker-based patient selection hypothesis is challenging within the timelines of clinical development, especially as the key endpoint to predict is overall survival benefit. Layered on top of both these scenarios is the additional challenge of potential differences in the underlying biology which could differentially impact benefit:risk between patient populations. Exploring these differences in a pre-competitive manner, through the generation of high-quality data from well annotated biobanked specimens (complete clinical annotation, including response to lines of treatments), supplement where appropriate with defined prospective studies, can inform differences in expression of targets as well as key pathway elements between populations that could influence the biological response. Ultimately such an undertaking has the potential to increase knowledge of disease biology.

\section{Scott D. Patterson}

Dr. Patterson is an Executive Director in Medical 
Sciences at Amgen and has for the past 9 years been involved in translational research, applying biomarkers for pharmacodynamic assessments and ultimately patient selection. He formed and led the successful biomarker program as Molecular Sciences head from 2004-2012 and now heads the In Vitro Diagnostic Group, responsible for the transition of biomarkers to IVDs encompassing the identification, implementation and management of diagnostic partnering strategies for all Amgen therapeutics (e.g., the development of KRAS as a predictive biomarker and companion diagnostic for Vectibix ${ }^{\circledR}$ therapy). He has published extensively in the field of proteomics and biomarkers, holds editorial board positions and is a frequent guest lecturer. He was previously Vice President of Proteomics at the Celera Genomics Group and the Chief Scientific Officer of Farmal Biomedicines, LLC. While at Celera, he established the company's initial foray into identification of cell surface targets for oncology, a number of which have been licensed. Dr. Patterson was at Amgen from 1993-2000 ultimately leading the Department of Biochemistry and Genetics. His academic career, encompassing work on analytical protein chemistry applications and apoptosis, began at The University of Queensland where he received his Ph.D. and B.Sc. In 1991 he joined the faculty of Cold Spring Harbor Laboratory, New York.

[5 selected publications]

1. Amado, R.G., Wolf, M., Peeters, M., Van Cutsem, E., Siena, S., Freeman, D., Juan, T., Sikorski, R., Suggs, S. Radinsky, R., Patterson, S.D. and Chang, D.O. (2008) Wild-type KRAS is required for Panitumumab efficacy in patients with metastatic colorectal cancer: Results from a randomized, controlled trial. J. Clin Oncol. 26, 16261634.

2. Wang, H.L., Lopategui, J., Amin, M.B. and Patterson, S.D. (2010) KRAS Mutation Testing in Human Cancers: The Pathologist's Role in the Era of Personalized Medicine. Adv. Anat. Pathol., 17, 23-32.

3. Burns, O.K., Hughes, A.R., Power, A., Wang, S-J. and Patterson, S.D. (2010) Designing Pharmacogenomic Studies to be Fit for Purpose. Pharmacogenomics 11, 1657-1667.

4. Shaw, P.M. and Patterson, S.D. (2011) The value of banked samples for oncology drug discovery and development, J. Natl Cancer lnst. Monogr. 42, 46-49.

5. Patterson, S.D., Cohen, N., Karnoub, M., Louis Truter, S., Emison, E., Khambata-Ford, S., Spear, B., lbia, E., Sproule, R., Barnes, D., Bhathena, A., Bristow, M.R., Russell, C., Wang, D., Warner, A., Westelinck, A., Brian, W., Snapir, A., Franc, M.A., Wong, P., and Shaw, P.M. (2011) Prospective-retrospective biomarker analysis for regulatory consideration: white paper from the industry pharmacogenomics working group. Pharmacogenomics $12,939-951$.

\section{Successful Implementation of Global Biomarker Strategies: Pre Analytics Matters (But is Often Ignored)}

Russell Weiner, PhD, Executive Director, Head, Clinical Biomarker and Diagnostics Lab, Merck Research Laboratories

Generation of high quality biomarker data begins with the development and validation of a robust, accurate and precise method. While developing a robust method plays a critical role in generating data of high quality, it is not sufficient. In fact, some would argue, and many studies have shown, that the activities preceding sample analysis, the so-called preanalytical activities, are as important, if not more important than the method itself. With some reports citing up to $70 \%$ of assay variability being attributed to what happens before the sample arrives in the bioanalytical lab, one must pay close attention to how the sample is collected, processed and lastly, how it is shipped. To illustrate what can happen in the field, case studies and corrective guidance will be presented that touch upon several common preanalytic areas of special concern.

\section{Russell Weiner}

Russ is currently Executive Director and Head of the Clinical Biomarker and Diagnostics Lab at Merck. In this role he is responsible for delivering on global biomarker and companion diagnostic strategies for all of Merck's therapeutic areas. After receiving his Ph.D. in Biochemistry from Albany Medical College, Russ then spent the next 18 years at BristolMyers Squibb where he was responsible for regulated (GLP and clinical) bioanalysis in support of PK and immunogenicity of biologic therapeutics and biomarkers. Russ has extensive experience in clinical project leadership, clinical trial conduct and development of pharmaceutical and biologics therapeutics. He is strategic thinker versed in using biomarkers for early decision making and is a wellrecognized thought leader on regulated bioanalysis and biomarker assay development and validation. Lastly, Russ is an active member of the American Association of Pharmaceutical Scientists (AAPS) where he currently serves on the Executive Committee. 


\section{Companion Diagnostics Success from Biomarker Discovery to Global Commercialization}

Christopher J. Jowett, Global Head of Companion Diagnostics, Abbott Molecular, Inc., Des Plaines, IL

Developing a successful global commercialization strategy for a companion diagnostic can be a significant challenge. Critical capability factors need to be discussed prior to entering into the partnership to minimize risk. Understanding the IVD manufacturers' capabilities to develop, manage the required clinical trials, navigate the regulatory environment for approval, and drive sales and marketing efforts in all targeted countries for the therapeutic launch is essential. This talk will focus on a variety of strategies to support a successful launch of a companion diagnostic program.

\section{Christopher J. Jowett}

Christopher J. Jowett is the Global Commercial Head, Companion Diagnostics for Abbott Molecular, he was appointed to his current role in April 2012. Previously, he served as GM Commercial Operations, U.S. \& Canada for Abbott Molecular responsible for Sales, Marketing for greater than 450 molecular products in the areas of Infectious Disease, Genetics, and Oncology.

Jowett joined Abbott in 1991 and has served in various Sales \& Marketing positions across multiple Abbott Divisions with increasing level of responsibility. These include Director of Sales U.S., Abbott Molecular, Director of Marketing, U.S. \& Canada, Abbott Molecular, and Global Marketing Manager, Abbott Molecular.

Jowett leads the Companion Diagnostic organization responsible for managing the development of CDx Products for multiple Pharma Partnerships including but not limited to the following Pfizer, GSK, Merck, and Janssen, as well as the development of new Companion Diagnostic business for Abbott Molecular. 


\section{Wednesday, June 12}

\section{Plenary Lecture 2}

\section{The Personalized Medicine/ Tissue Engineering/ Cancer / Drug Delivery Intersection}

Buddy D. Ratner, Ph.D., Floyd Karp and J. Alaina Floyd, Departments of Bioengineering and Chemical Engineering, University of Washington, Seattle, Washington

Personalized medicine empowers the physician to delivery therapeutic agents tuned to the specific needs of each individual. Tissue engineering using autologous tissue is an obvious personalized medicine approach since the patient's own cells are used to create new tissue to heal and regenerate. As a first example, sphere-templated porous polymers will be described that recruit the patient's macrophages and direct them toward a healing, regenerative pathway in skin, bone, sclera and other tissues. An example of a personalized strategy to deliver drugs within the globe of the eye will then be described. Beads of a hydrogel polymer coated with a rate limiting membrane can deliver antibiotics, anti-proliferatives or steroids over a one month period of time. By prescribing multiple beads, the physician can tune the therapeutic regimen to the patient needs. Finally, an approach to deliver drugs to aggressive gliomas will be described. The approach uses an aqueous solution of a biodegradable form of poly(n-isopropyl acrylamide) (PNIPAM) that is sprayed on the brain surface during surgery after excision of the tumor. At room temperature the solution is clear and slightly viscous. When it contacts a surface at $37^{\circ} \mathrm{C}$ (i.e., the brain), it almost instantly hardens and adheres. The solution is used to carry in suspension three types of microspheres, each type of microsphere containing a different anti-tumor drug. The microspheres are designed to degrade rapidly, slowly or at an intermediate time. Thus, three different anti-cancer agents dose the tumor over months period of time addressing the resistance tumors build up to a single drug and also addressing the need to bring the therapeutic in close proximity to residual tumor missed during excision surgery. Since the physician can engineer the drug regimen with different drugs and different delivery profiles, the therapy is personalized for the patient.

\section{Buddy D. Ratner}

Buddy D. Ratner is Director of the University of Washington Engineered Biomaterials (UWEB21) Engineering Research Center. He holds the Michael L. and Myrna Darland Endowed Chair in Technology Commercialization and is Professor of Bioengineering and Chemical Engineering, University of Washington.

Buddy Ratner received his Ph.D. (1972) in Polymer Chemistry from the Polytechnic Institute of Brooklyn. He has been at the University of Washington since 1972. From 1985-1996, he directed the National Institutes of Health-funded National ESCA and Surface Analysis Center for Biomedical Problems. In 1996, he assumed the directorship of UWEB (now UWEB21).

Ratner is a fellow of the American Institute of Medical and Biological Engineering (AIMBE), the AVS (formerly the American Vacuum Society), the American Association for the Advancement of Science, the Biomedical Engineering Society (BMES), the American Chemical Society (ACS), the International College of Fellows Biomaterials Science and Engineering and the Tissue Engineering and Regenerative Medicine Society (TERMIS). He is a past president of the Society for Biomaterials. He served as president of AIMBE (2002-2003). In 2003 he was elected President of the Tissue Engineering Society of North America. In 2002, Ratner was elected a member of the National Academy of Engineering, USA. He serves on the National Advisory Council of the National Institute of Bioimaging and Bioengineering (NIBIB), NIH (2009-2013).

Ratner has won numerous awards. A partial list includes the Medard W. Welch Award of the American Vacuum Society (2002), Founders Award of the Society for Biomaterials (2004), C. William Hall Award from the Society for Biomaterials (2006), the BMES Pritzker Distinguished Lecturer Award (2008), the Acta Biomaterialia gold medal (2009), the University of Washington Faculty Lecture (2011), the Pierre Galletti Award from the 
American Institute of Medical and Biological Engineering (2011) and the George Winter Award of the European Society for Biomaterials (2012-2013).

He has authored over 400 scholarly works and has over 20 issued patents. He is Editor of the Journal of Undergraduate Research in BioEngineering, on the advisory board of Biointerphases and serves on the editorial boards of ten other journals. $\mathrm{He}$ is the lead editor for Biomaterials Science: An Introduction to Materials in Medicine, a textbook that has sold over 25,000 copies.

Buddy Ratner's interests include biomaterials, tissue engineering, polymers, biocompatibility, drug delivery, surface analysis, self-assembly, nanobiotechnology, RF-plasma thin film deposition, technology commercialization and biomaterials education. He has participated in the launch of eight companies based on technologies from his laboratory, and serves as a consultant for numerous other companies. 


\section{Wednesday, June 12}

\section{SESSION 1:}

\section{Personalized Medicine and Cancer}

\section{Genomic Driven Personalized Cancer Control: Ready to Hit the Runway?}

David G. Huntsman, MD, FRCPC, FCCMG, UBC/BC Cancer Agency

Although arguably overhyped there is a consistent trend towards the further stratification and ultimately the personalization of cancer control. The imperative for this shift from generic approaches through to stratified and now more personalized approaches comes from a desperate need to improve our capacity to prevent, diagnose and treat cancers and also from the opportunities emerging through the application of new technologies such as next generation sequencing to the cancer problem. A truly personalized approach to cancer would be to harness the power of genomics to predict cancer susceptibility and potential adverse drug reactions and use the analysis of tumors to determine what treatment could be best applied to target the specific vulnerabilities of cancers. Current cancer treatment decisions are made through combining information garnered from the site of origin of the tumor, its microscopic appearance, and in some cases, molecular analysis. It has been suggested that the molecular nature of the tumor, i.e. its mutational profile, could replace the site of origin as the prime determinant of cancer treatments. Identifying an effective treatment to target the specific genetic abnormality is only one step in this process - in order for the target to be effective in treating the cancer there are 3 further criteria to be met: First is to determine whether the mutation is clonally dominant in the tumor i.e. is it present in the majority of cancer cells. Second is to determine whether the mutation is active in the tumor at the time treatment is considered. Third is to determine whether the particular mutation is targetable in the cellular context from which the tumor arose. Using this information, it will enable us to contextualize genomic features and potentially change them into actionable items. Perhaps the greatest challenge facing the personalization of cancer care is the concern that the heterogeneity of tumors makes assessment of targetable features in any single sampling impossible. There is hope however that the use of mutational analysis of circulating tumor DNA maybe a way to better diagnose and monitor the molecular nature of cancers and ultimately become a decision aid for the monitoring of cancer treatments.

\section{David G. Huntsman}

Dr. David Huntsman is a Professor in the Departments of Pathology and Laboratory Medicine and Obstetrics and Gynaecology at The University of British Columbia (UBC) and is the Dr. Chew Wei Memorial Professor of Gynaelcologic Oncology. He is a a Staff Pathologist at the BC Cancer Agency (BCCA), and a Consulting Pathologist at the Vancouver General Hospital (VGH).

Dr. Huntsman is currently the Director of the BC multidisciplinary ovarian cancer research team (OvCaRe), Medical Director of the Centre for Translational and Applied Genomics (CTAG) at the BCCA, and co-Director of the Genetic Pathology Evaluation Centre (GPEC) at the Jack Bell Research Centre, VGH.

Dr. Huntsman research has led to development of predictive and prognostic tissue based cancer biomarkers for ovarian cancer and a wide variety of other tumour types. His team created a blueprint for subtype specific ovarian cancer control and have been leaders in the application of novel genomics technologies to ovarian cancer. As collaboration is critical in his field, Dr. Huntsman happily leads and engages in a wide number of multidisciplinary research groups. Most recently he has been working on the creation of broad based personalized medicine initiative for British Columbia. 


\section{Evolutionary Dynamics of High-grade Serous Ovarian Cancers: Implications for Personalized Medicine}

Sohrab Shah, UBC/ BC Cancer Agency, Vancouver, $\mathrm{BC}$

High-grade serous ovarian cancer (HGSC) is characterized by poor outcomes, often attributed to emergence of treatment-resistant subclones. We sought to measure the degree of genomic diversity within primary, untreated HGSC to examine the natural state of tumor evolution prior to therapy. We performed exome sequencing, copy number analysis, targeted amplicon deep sequencing and gene expression profiling on thirty-one spatially and temporally separated HGSC tumor specimens (six patients) including ovarian masses, distant metastases and fallopian tube lesions. We found widespread intra-tumoral variation in mutation, copy number and gene expression profiles, with key driver alterations in genes present in only a subset of samples (e.g. PIK3CA,CTNNB1,NF1). On average, only $51.5 \%$ of mutations were present in every sample of a given case (range: $10.2 \%-91.4 \%$ ), with TP53 as the only somatic mutation consistently present in all samples. Complex segmental aneuploidies such as whole genome doubling was present in a subset of samples from the same individual, with divergent copy number changes segregating independently of point mutation acquisition. Reconstruction of evolutionary histories showed one patient with mixed HGSC and endometrioid histology with common etiologic origin in the fallopian tube and subsequent selection of different driver mutations in the histologically distinct samples. We observed mixed cell populations in the early FT lesion, indicating diversity arises at early stages of tumorigenesis. Our results highlight that HGSC exhibit highly individual evolutionary trajectories and diverse genomic tapestries prior to therapy, requiring consideration in future design of personalized therapeutic solutions and investigation of mechanisms of drug resistance.

\section{Sohrab Shah}

Dr. Sohrab Shah is an Assistant Professor in the Depts of Pathology and Computer Science, University of British Columbia and is a Scientist at the BC Cancer Agency. He is the recipient of a Terry Fox New Investigator Award, and is a Michael Smith Foundation for Health Research Career
Investigator. Dr. Shah's work focuses on computational characterization of cancer genomes for determination of pathogenic driver mutations in cancer subtypes and measuring and quantifying tumour evolution. His recent work describing new cancer genes in ovarian cancer has been published in the New England Journal of Medicine and his work describing mutational evolution in breast cancer has been featured in Nature.

\section{Lymphoma Genomics: Diagnostic Precision Tools for Guiding Treatments}

Christian Steidl, Department of Pathology, University of British Columbia; Department of Experimental Therapeutics, BC Cancer Research Centre, Vancouver, BC

Collectively lymphoid cancers are the $4^{\text {th }}$ most common cancers in men and women and affect patients of all ages. Lymphoid cancers are highly heterogeneous in their clinical, pathological and molecular features, and are therefore heavily subclassified to report lymphoma diagnoses according to internationally accepted standards that are used to guide treatment decisions. Advances in diagnostic accuracy and improvements in treatment have already resulted in better overall survival for lymphoma patients, and notably lymphomas represent cancers that can be cured by systemic therapy even when widely disseminated. However, even the best current diagnostic testing is not able to identify with high accuracy the subset of patients who are likely to succumb to their disease. It is a widely accepted, but yet largely unproven, concept that further therapeutic improvements are at least in part contingent on deciphering the underlying molecular heterogeneity that will be needed to tailor therapies to the individual characteristics of tumour cells of an individual patient ("individualized molecular therapy"). Genome-wide research projects including next generation sequencing initiatives have significantly advanced our knowledge about the mutational landscapes of specific lymphoma subtypes. However, identification of targetable phenotypes associated with these genomic findings is needed to overcome the current translational roadblock. The most novel and promising avenues translating next generation sequencing findings into clinically meaningful knowledge gain will be reviewed and illustrated by specific examples of somatic gene mutations in B cell lymphoma. 


\section{Christian Steidl}

Dr Steidl is an Assistant Professor in the Department of Pathology (University of British Columbia) and Experimental Therapeutics (BC Cancer Agency). He is holding an MD degree from the University of Muenster, Germany, and a $\mathrm{PhD}$ equivalent degree from University of Witten-Herdecke, Germany. Dr Steidl has expertise in clinical malignant hematology, cytogenetics, molecular genetics, next generation sequencing and functional genomics. Dr Steidl joined the Centre for Lymphoid Cancer at the British Columbia Cancer Agency in 2006. He is currently supervising a translational research laboratory focusing on the pathogenesis of B cell lymphomas. Dr Steidl is most known for his work on biomarkers in Hodgkin lymphoma and discovery of novel gene fusions in B cell lymphomas. He has authored 41 refereed articles in the field of hematological malignanices and has been an invited speaker at many conferences. He also serves as a member of the Lymphoma Research Foundation's Panel of Scientific Advisors and the Medical Expert Committee of the Cancer Research Society. Dr Steidl holds research funding as the principle investigator by the Canadian Institutes of Health Research (CIHR), the Leukemia and Lymphoma Society of Canada (LLSC), the Canadian Hematology Society (CHS), and is co-investigator on a Genome Canada grant to advance personalized treatments of lymphoid cancer patients. Dr Steidl also holds a career investigator award by the Michael-Smith Foundation for Health Research.

\section{Functional Validation: Linking Genomic Alterations to New Treatment Opportunities}

Poul H.B. Sorensen, Department of Molecular Oncology, BC Cancer Research Center, Vancouver, $\mathrm{BC}$

Next generation sequencing (NGS) of human tumors generates tremendous amounts of complex data, and the challenge is to extract clinically applicable information from such NGS studies, particularly in the context of personalized medicine. One approach, of course, is use new and emerging bioinformatic algorithms to narrow down the list of possible candidates for further validation. However, this alone does not address the question of whether an observed genetic lesion is biologically or clinically relevant. In addition, many biomarkers which are not genetically altered may instead be over- or underexpressed due to non-genetic mechanisms. Only through concerted biological and other functional studies, including animal modeling, can mutated or overexpressed candidate proteins or pathways be functionally validated. Then molecular pathological analyses such as immunohistochemical probing of tumor specific tissue microarrays can be invoked to assess the incidence of a given alteration in different tumor types. It can be argued that only then should these findings be extended to the development of novel therapeutics to target the involved pathways. In this session, our approaches to functional validation of leads emerging from NGS or other genomic or molecular pathology studies will be described, along with specific examples currently under investigation in our laboratory.

\section{Poul H.B. Sorensen}

Dr. Poul Sorensen is a molecular pathologist specializing in the molecular pathology of pediatric cancers. He undertook his undergraduate, medical, and $\mathrm{PhD}$ degrees at the University of British Columbia (UBC) and McGill University, Montreal. He completed postdoctoral training at the University of Minnesota, Minneapolis and Children's Hospital Los Angeles, University of Southern California, after his Pathology training. He then returned to Vancouver to start his own laboratory at Children's and Women's Hospital in Vancouver. Dr. Sorensen holds the Asa and Kashmir Johal Endowed Chair in Childhood Cancer Research, and he is Professor of Pathology and Laboratory Medicine at UBC, as well an Honorary Professor at University College London, UK. Dr. Sorensen's research laboratory is located in the Department of Molecular Oncology at the BC Cancer Research Centre, where he is a senior scientist. His research focuses on targeting aberrant signaling pathways that are activated in childhood cancers and breast carcinoma. Dr. Sorensen's laboratory uses a combination of genetic and biochemical/proteomic approaches to identify proteins that are specifically altered in human tumours. His laboratory has discovered many novel genetic alterations in childhood cancer and breast tumours, and these discoveries have been translated into new diagnostic tests for specific tumours, and have advanced our understanding of how the involved proteins transmit signals that cause cells to become cancerous. Such information then allows for the rapid implementation of strategies to target these proteins therapeutically. Dr. Sorensen is the Chair of the Translational Research Committee of the Children's Oncology Group (COG), the largest 
pediatric oncology clinical trials network in the world.

Research Statement: The overall premise of Dr. Sorensen's research is that a greater understanding of how childhood cancer cells respond to extra- or intracellular signals is necessary to identify tumourspecific pathways. Only then can these pathways be targeted therapeutically in a manner that minimizes effects on normal cells. This is critically important in childhood cancer to avoid toxic effects of treatments on the intellectual, physical, and emotional development of a growing child. An ongoing difficulty with this approach is how to find the relevant pathways to target. Over the years the Sorensen laboratory has been characterizing recurrent genetic alterations in childhood tumours to more efficiently identify novel cancer genes. This is part of their belief that analysis of primary tumours is preferable for initial identification of pathophysiologically relevant alterations in human malignancies. With the advent of next-generation sequencing (NGS), they have been extending this approach to NGS of childhood cancers to better understand the mutational landscape of these tumours. Then, once the involved proteins have been identified, model systems can be invoked to further study relevant biology and how the pathways they are involved in become activated. The group then uses various biochemical approaches as well as proteomics to rigorously characterize the involved proteins, their functional interactors, and the signal transduction pathways they participate in. This forms the basis for subsequent strategies to therapeutically target candidate proteins in childhood cancers. 


\title{
Wednesday, June 12
}

\author{
SESSION 2:
}

\section{Protein Drug Delivery Systems and Devices}

\section{Enabling Remote Medicine: Implantable, Wirelessly-Controlled Microchip Drug Delivery}

Robert Farra, President, MicroCHIPS, Inc.

Microchip-based sensors and drug delivery systems have been designed, successfully implanted and tested in humans. The presentation will provide an overview of the technology and the design of microchips-based implants. The first clinical trial and results of an implantable microchip-based drug delivery device will be presented. Human parathyroid hormone fragment [hPTH(1-34)] was delivered from the implanted device. Next steps in advancing the technology for broader use will be discussed.

\section{Robert Farra}

Robert Farra has more than two decades of leadership experience successfully developing complex electro-mechanical and fluidic-based medical devices and combination products. His development experience spans concept generation through all stages of development and commercialization, as well as managing intellectual property. Mr. Farra's product experience spans drugdelivery combination products, implantable drug delivery systems, implantable sensors, life support systems, ventricular assist devices, artificial hearts, intra-aortic balloons and pumps, and minimally invasive laparoscopic and endoscopic surgical devices. Mr. Farra has an SMME from the Massachusetts Institute of Technology.

\section{Intradermal Delivery of Small Molecules, Proteins, Peptides and Vaccines using Microneedle Technologies}

Mark Tomai and Kris Hansen. 3M Drug Delivery Systems, St. Paul, Minesota

Biologic drugs including proteins, peptides and vaccines comprise the fastest growing market segment in the pharmaceutical industry. Currently, biologic drug products are largely administered via standard syringe and needle or through various autoinjector systems. In the vaccine space, it is welldocumented that injection of antigen into the epidemis/dermis may lead to an enhanced immune response compared to standard intramuscular injection. Recently, the approval of an intradermal syringe for delivery of an influenza vaccine has shown the potential utility for intradermal delivery of vaccines. In addition to this commercial product, there are many more iterations of micro/mini needlebased drug delivery devices that have been developed to deliver vaccines to the skin. 3M's solid Microstructured Transdermal System (sMTS) is a coated microneedle technology that is very effective at delivering vaccines. Data collected in animal models demonstrate similar or enhanced immune responses compared to standard IM injection. Other potential benefits of the microneedle approach include potential for better compliance due to needle free delivery, room temperature and freeze/thaw stability and reduced risk of needle stick injuries. 3M's sMTS is currently undergoing Phase 2 evaluations for delivery of a small peptide for the treatment of osteoporosis.

Although coated microneedle systems are excellent for the delivery of vaccines and highly potent proteins and peptides to the skin, many of the biological drug products, including monoclonal antibodies, exceed the dose capacity of a coated microneedle system. To address the need for high dose/high volume protein delivery, $3 \mathrm{M}$ has 
developed a hollow microneedle system (hMTS) that contains up to $2.0 \mathrm{~mL}$ for self-administration of liquid-based formulations of proteins/peptides. Because the drug is being delivered to the dermis, there is potential for increased bioavailability compared to subcutaneous administration, especially for large molecules where systemic uptake occurs exclusively through the lymphatic capillaries. Other potential benefits of the hMTS include capabilities around delivery of highly viscous drug formulations and the potential for increased compliance due to its less threatening device design.

\section{Mark Tomai}

Mark Tomai, Ph.D. has been Head of Microneedle (MTS) and Toll-like Receptor Business Development at 3M Drug Delivery Systems for the past 6 years. Dr. Tomai is responsible for partnering and licensing agreements involving 3M's novel microstructured transdermal systems (MTS), for delivery of vaccines, proteins and peptides, as well as licensing its proprietary toll-like receptor (TLR) 7 and 8 agonists for use as vaccine adjuvants. He also oversees research efforts regarding these compounds.

Dr. Tomai spent 16 years working in $3 \mathrm{M}$ Pharmaceuticals. $\mathrm{He}$ was responsible for introducing 4 TLR agonists into clinical development and was also responsible for pharmacology studies for Aldara the TLR7 agonist approved for topical treatment of genital warts and skin cancer. $\mathrm{He}$ is considered an expert on the biological activity of the TLR7 and TLR8 agonists, an author on over 80 publications and an inventor on 12 issued patents. Dr. Tomai did his post-doctoral training at the University of Tennessee and at the University of Minnesota-Duluth. He received his Ph.D. in Microbiology/Immunology from the University of Minnesota 1988 and received his BS in Microbiology from the same institution in 1983.

\section{The Challenges of Protein and Peptide Delivery}

R. Gurny, M. Veurink, L. Asmus, B. Kaufmann and M. Möller, School of Pharmaceutical Sciences, University of Geneva, Geneva, Switzerland

We describe a novel concept in which the sustained release of peptides or proteins from an injectable drug delivery system is investigated. The carrier is based on a biodegradable polymer of low molecular weight, i.e. poly(2-hydroxyoctanoic acid), which is a viscous liquid at room temperature that can be injected using conventional injection systems. The rationale behind the system is the fact that it forms a drug depot in situ that slowly releases the incorporated API upon hydrolysis of the polymer. Moreover, incorporation of the drug is accomplished by simply mixing the polymer and the API under mild conditions, avoiding additional heat or organic solvents that may affect the stability of the protein drug. Routes of administration that are under investigation are subcutaneous and intravitreal injection, aiming at a sustained release of peptides or antibody fragments for the treatment of retinal occlusions, macular degeneration or prostate cancer.

The in vitro, ex vivo and in vivo sustained release profiles of various API are presented, showing a release over several weeks and months of peptides and antibody fragments. Furthermore, in an aqueous environment, the polymer system shows to protect the incorporated peptide or protein against degradation. In order to investigate the biocompatibility, the effects of 2-hydroxyoctanoic acid, the only degradation products of the polymer, are tested on ARPE-19 cells and on ex vivo retinal tissues.

A polymer system with a molecular weight of $2500 \mathrm{~g} / \mathrm{mol}$ and with low polydispersity displays the most promising properties with a zero order release profile, good biocompatibility and injectability. To conclude, the results demonstrate the great potential of this injectable and biodegradable polymer as an intravitreal or subcutaneous drug depot for the sustained release of therapeutic peptides and proteins.

\section{Further reading:}

1. Asmus L.R., Tille J.C., Kaufmann B., Melander L., Weiss T., Vessman K., Koechling W., Schwach G., Gurny R., Möller M., In vivo biocompatibility, sustainedrelease and stability of triptorelin formulations based on a liquid, degradable polymer, J Control Release 165; 199206 (2013).

2. Asmus L.R., Kaufmann B., Melander L., Weiss T., Schwach G., Gurny R., Möller M., Single processing step toward injectable sustained-release formulations of Triptorelin based on a novel degradable semi-solid polymer, Eur J Pharm Biopharm 81; 591-599 (2012).

3. Asmus L.R., Gurny R., Möller M., Solutions as solutions - Synthesis and use of a liquid polyester excipient to dissolve lipophilic drugs and formulate sustained-release parenterals, Eur J Pharm Biopharm 79; 584-591 (2011).

4. Trimaille T., Gurny R., Möller M., Poly(hexylsubstituted lactides): novel injectable hydrophobic drug delivery systems, J Biomed Mater Res A 80; 55-65 (2007) 
5. Veurink M., Mangioris G., Kaufmann B., Asmus L., Hennig M., Heiligenhaus A., Pournaras C.J., Gurny R., Möller M., Development of an intravitreal peptide (BQ123) sustained release system based on poly(2hydroxyoctanoic acid) aiming at a retinal vasodilator response, (submitted to Invest Ophthalmol Vis Sci)

\section{Robert Gurny}

Robert Gurny is professor and former President of the School of Pharmaceutical Sciences at the University of Geneva.

$\mathrm{He}$ is one of the pioneers in the field of colloidal drug carriers and drug targeting. He also developed new degradable biopolymers, long acting implants and more recently he established a working group on protein and peptide delivery. The improvement of ocular therapy, especially intravitreal and subretinal medication, represents an additional field of interest and includes the design of new carrier systems for drug delivery. $\mathrm{He}$ is consultants to numerous pharmaceutical companies around the world.

$\mathrm{He}$ is also the author or coauthor of more than 350 peer reviewed articles, several books and book chapters, more than 230 abstracts of presentations as well as the author or coauthor of 40 patents. Until now, over $50 \mathrm{Ph} . \mathrm{D}$. theses were presented at the Faculty of Sciences under his direction.

For several years, Professor Gurny was the Scientific Secretary of the "Controlled Release Society". In 1998, he was Vice President of the International Association for Pharmaceutical Technology (APV) and currently he is the Editor-inChief of the European Journal of Pharmaceutics and Biopharmaceutics. He received a large number of awards and is Fellow of over 16 professional and scientific societies.

\section{Formulation Strategies Around Osmotically- driven Therapeutic Protein Release}

Brian Amsden, Department of Chemical Engineering, Queen's University, Kingston, ON

Protein therapeutics are a rapidly growing drug class, with current sales in the area of \$US 50-60 billion with sales forecasted to reach \$US 143 billion by 2015 . They are presently administered primarily by injection, although there is increasing recognition that many proteins would benefit from long-term, localized delivery. Such delivery represents a significant challenge due principally to protein stability concerns. Many of these stability problems are based on the degradation products of the polymers used as delivery depots. Polymeric delivery systems that rely on osmotic pressure driven drug release may prove to be an effective formulation approach as protein(s) can be released using this mechanism before significant degradation of the polymer occurs. This talk will overview various polymer strategies for achieving prolonged and highly bioactive therapeutic protein delivery utilizing osmotic pressure as the delivery mechanism, both in vitro and in vivo, with a focus on the delivery of pro-angiogenic proteins.

\section{Brian Amsden}

Brian Amsden obtained his $\mathrm{PhD}$ in Chemical Engineering from Queen's University in 1996, in the area of therapeutic protein delivery from hydrogels and polymer microspheres. He worked for Angiotech Pharmaceuticals in Vancouver from 1996-97 as a Research Associate, leading projects involving the formulation of paclitaxel for localized delivery to treat post-operative adhesions and psoriasis, and participating in projects developing degradable microsphere and micellar formulations of paclitaxel for intra-articular delivery and systemic delivery, respectively. He left Angiotech to join the Faculty of Pharmacy at the University of Alberta and is currently a Professor in the Department of Chemical Engineering at Queen's University where he has been since July 2000. His current research interests include the development of biodegradable elastomers, hydrogels, and low viscosity hydrophobic polymers for the local delivery of small molecules, peptides and proteins, and stem cells, and as scaffolds for soft and connective tissue regeneration. $\mathrm{He}$ is a principal investigator and the Biomaterials Theme Leader in the 20/20 Ophthalmic Biomaterials Network, as well as a principal investigator in the CREATE Biointerfaces Network and the CREATE Bone and Joint Health Technologies Network. He has received the Alberta Health Foundation for Medical Research Independent Establishment Award, the Ontario Premier's Research Excellence Award, the Queen's University Chancellor's Research Award, and the Ontario Centres of Excellence Award of Excellence for Research Collaboration and Commercialization. 


\section{Wednesday, June 12}

\section{CSPS Lifetime Achievement Award Lecture}

\section{Fructose Ingestion, Hypertension and the Metabolic Syndrome}

John H. McNeill, PhD, Professor and Dean Emeritus, Faculty of Pharmaceutical Sciences, University of British Columbia, Vancouver, B.C.

For the last three decades data show that human fructose ingestion has steadily increased not only in North America but around the world. Ironically, the increase began when public pressure on food companies over the fat content in food initiated the addition of sugar to replace fat content. Rather than decreasing obesity and the problems associated with weight gain the increase in sugar consumption is now believed to be a significant factor in the increase in cardiovascular diseases, type 2 diabetes and its associated pathopysiological effects, kidney disease and non-alcohol associated liver disease as well as others. The problem has been further enhanced by the introduction of relatively inexpensive high fructose corn syrup to replace sucrose as a food additive. Data from the literature will be shown to illustrate these effects. Fructose is metabolized differently than glucose and when ingested metabolism occurs in very few tissues, the liver is the major organ involved. In our own laboratory we have worked with a model of prediabetes and metabolic syndrome known as the fructose fed hypertensive rat which, following feeding with high fructose levels, develops hypertension and many of the symptoms of metabolic syndrome found in humans. Our work has shown that these animals are insulin resistant, have high triglyceride levels and rapidly develop elevated systolic blood pressure. The changes are accompanied by alterations in vasoconstrictor substances, endothelial dysfunction and other events that enhance the metabolic syndrome. Fructose metabolism results in elevated lipids and an increased synthesis of uric acid and these changes are believed to be major factors in the development of the changes noted in the metabolic syndrome. The influence of increased fructose use on public health will be discussed.

\section{John H. McNeill}

Dr. McNeill completed his BSc (Pharm) and MSc at the University of Alberta and his $\mathrm{PhD}$ in Pharmacology at the University of Michigan (1967). He taught at Michigan State University (Assistant Professor of Pharmacology) until moving to UBC as an Associate Professor in 1971. He served as Chair, Division of Pharmacology and Toxicology and Associate Dean and became Dean of the Faculty in 1985. Since 1996 he has returned to research and teaching. Dr. McNeill has had interests in cardiac receptors, cyclic nucleotides and cardiac metabolism. For the last 30 years he has concentrated his research on diabetic cardiomyopathy and the metabolic syndrome using rat models. He has published more than 500 papers and reviews and his work has been cited more than 12,000 times. His h-index is 56 . He has trained 75 graduate and post-doctoral trainees. He is a Fellow of the Royal Society, Fellow of the Canadian Academy of Health Sciences and a Fellow of the International Academy of Cardiovascular Sciences. $\mathrm{He}$ has received the Upjohn Award from the Pharmacology Society of Canada, the McNeil Award and the Janssen Ortho Award from AFPC, the Biely Prize (UBC) and others for his research work. In addition, he has received the Killam Teaching Prize from UBC. Dr. McNeill has served as President of the Pharmacological Society of Canada, Canadian Foundation of Pharmacy and the Canadian Council of Animal Care. He has received awards from the Heart and Stroke Foundation of B.C., the BC College of Pharmacy and the BC Pharmacists' Society for his service. He has served on and chaired committees for MRC, Canadian Heart and Stroke Foundation, the Canadian Diabetes Association, Rx and D Foundation and is on the jury for Prix Galien. 


\section{Wednesday, June 12}

\section{Plenary Lecture 3}

\section{A Landscape Analysis of Pharmacogenomics}

Lawrence Lesko, Center for Pharmacometrics and Systems Pharmacology, University of Florida, Orlando, Florida

The case for pharmacogenomics (PGx) is selfevident, isn't it? Not so fast! Despite the exponential growth in the technical development of genetic tests and the generation of genomic information for the purpose of predicting drug response, most patients today face a high burden of lack of drug efficacy, medication-induced adverse events and insufficient infrastructure to deliver PGx services to those that need them. PGx is a subset of personalized medicine and can be defined as the technology that analyzes how the genetic makeup of an individual affects his or her response to drugs. The main objective of a landscape analysis is to assess the current situation of PGx and to identify both positive and negative factors that will influence the likelihood of future genetic test development and clinical adoption of genomic information to support healthcare decisions. This presentation will focus on emerging technologies, factors influencing industry investment in PGx tests, the ability of the healthcare setting to provide PGx tests where and when needed the experience and expertise of healthcare professionals, reimbursement barriers, and oversight and regulations. Examples of encouraging initiatives that will facilitate and increase the likelihood of adopting PGx tests for healthcare purposes will be presented such as use of electronic health records, highly multiplexed, customized gene polymorphism assay platforms, regulator guidances for industry, decision support trees for using PGxdrug pairs and electronic algorithms to enable actionable results from genetic tests. Changes in the landscape, especially in evidence generation (clinical utility) will make the case for PGx - at least in some cases - self-evident in the future.

\section{Lawrence J. Lesko}

Lawrence J. Lesko, Ph.D., F.C.P. has been leading UF's new Center for Pharmacometrics and Systems Pharmacology in the interdisciplinary Institute of Therapeutic Innovation at the UF Research and Academic Center in Lake Nona (Orlando) since July 2011.

Before joining UF, Dr. Lesko worked nearly 20 years in the Food and Drug Administration's Center for Drug Evaluation and Research as the Director of the Office of Clinical Pharmacology. He was also Chair of the Clinical Pharmacology Coordinating Subcommittee of the FDA's Medical Policy Coordinating Committee and authored or coauthored numerous Guidance for Industry, and started the FDA's Voluntary Genomics Data Submission Program and Mechanistic Drug Safety Program.

Lesko has published more than 200 peerreviewed scientific publications and is a frequent invited national and international speaker in clinical pharmacology, personalized medicine, pharmacometrics and systems pharmacology. His research interests include drug development and regulatory science, quantitative clinical pharmacology and pharmacogenomics.

In 2011, Lesko received the Gary Neil Prize for Innovation in Drug Development from the American Society of Clinical Pharmacology and Therapeutics (ASCPT). He also received the Coriell Scientific Leadership Award for Personalized Medicine (2010), the Rawls-Palmer Progress in Medicine award from ASCPT (2007), the University of North Carolina Institute for Pharmacogenomics and Individualized Therapy Award for Clinical Service (2007), and the Nathanial B. Kwit Distinguished Service Award for Clinical Pharmacology from the American College of Clinical Pharmacology (2007). Lesko served as President of the American College of Clinical Pharmacology in 2004-2006. He is a Fellow in the Japanese Society for the Study of Xenobiotics, American College of Clinical Pharmacology and the American Association of Pharmaceutical Scientists. He is Board Certified in Clinical Pharmacology and a registered pharmacist. 


\title{
Wednesday, June 12
}

\author{
SESSION 3:
}

\section{Personalized Medicine and Pharmacogenomics}

\section{The Two Pharmacos: Vigilance and Genetics - A Powerful Partnership to Improve the Safe Use of Drugs}

Bruce C. Carleton, PharmD, Professor of Paediatrics and Co-Chair, Division of Translational Therapeutics, Faculty of Medicine, University of British Columbia; Director, Pharmaceutical Outcomes Programme, BC Children's Hospital; Senior Clinician Scientist, Child \& Family Research Institute, Vancouver

Adverse Drug Reactions (ADRs) cause significant morbidity and mortality. 95\% of all ADRs are never reported. We built a national network in Canada to characterize ADRs in children and find genomic solutions to the lack of predictability of many severe reactions. Clinicians who conduct surveillance are employed by the Network and identify children who have suffered ADRs and matched controls from inpatient, outpatient and emergency departments at 13 major paediatric tertiary care hospitals in Canada. Drug biotransformation genes are analyzed to determine their role in the development of specific ADRs and to identify novel predictive genomic markers. Identified biomarkers are validated with functional and pharmacokinetic studies. As of March 2013, 5,914 ADR cases and 54,269 matched controls have been enrolled. Relevant biomarkers for three serious ADRs have been identified: anthracycline associated heart failure, cisplatin hearing loss and maternal codeine use and infant death. Ongoing studies include vincristine-induced peripheral neuropathy, drug-induced Stevens Johnson syndrome and others. Active ADR surveillance networks can be effective strategies for both complete ADR reporting and drug safety biomarker research. The network was designed to capture a broad range of ADR cases and target the surveillance of specific drugs or ADRs of principal concern. The identification of genetic markers is essential for developing diagnostic tests to predict children who are at higher risk of developing ADRs.
Ultimately, this will lead to the modification of treatment for susceptible individuals, and therefore, a reduction in the incidence of severe ADRs.

\section{Learning Objectives:}

1. Cite the areas in which pharmacogenomics have applications at the bedside.

2. Identify ways pharmacogenomics are transforming practical clinical drug dosing strategies.

3. List the barriers that remain to the advancement of bench to bedside care.

\section{Bruce C. Carleton, PharmD}

Dr. Carleton's lifelong goal is to make medication use more effective and safer for all patients, particularly children. His research focus is on the impact of drug therapy on human health and quality of life. He is particularly interested in developing better ways to evaluate the effectiveness of drugs, medication-use models designed to improve patient health, as well as practical surveillance systems to improve the safe use of medication.

A key element of Dr. Carleton's research is the communication of results to clinicians, patients, healthcare administrators, and government officials - those who also hold responsibilities to improve patient care and our systems of healthcare delivery.

Dr. Carleton earned his Bachelor degree in pharmaceutical sciences in 1986 from Washington State University. He continued at the University of Utah, earning his Doctorate in Pharmacy degree in 1989. After completing a residency in Clinical Therapeutics at the University of Utah and Primary Children's Medical Centers, he accepted a postdoctoral fellowship at the University of Minnesota focusing on Experimental Therapeutics. Dr. Carleton completed a second Fellowship in Immunopharmacology at the University of Minnesota Transplant Center, and then joined the faculty at the University of British Columbia in 1991.

In addition to his appointment as Professor of Paediatrics and Co-Chair of the Division of Translational Therapeutics, Department of Pediatric Medicine at UBC, Dr. Carleton is a Senior Clinician 
Scientist at the Child \& Family Research Institute. He directs the Pharmaceutical Outcomes Programme at BC Children's Hospital and he has served in this capacity since 1994 . He holds appointments at UBC in the Centre for Health Services and Policy Research, the School of Population \& Public Health and the Faculty of Pharmaceutical Sciences and the School of Health Information Science, University of Victoria. Dr. Carleton's public service is expansive. It includes serving as a charter member on the national Canadian Expert Drug Advisory Committee. Dr. Carleton was recently asked to serve the US Government as a Special Government Employee to advise the Advisory Committee for Pharmaceuticals and Clinical Pharmacology of the FDA.

\section{Implementation of Personalized Medicine (PM): From PM Clinics to Inpatient Care}

Richard B. Kim, Professor of Medicine, Physiology \& Pharmacology, and Oncology, Department of Medicine, Schulich School of Medicine \& Dentistry, University of Western Ontario, London, Canada

Current drug therapy is largely an iterative process of trial and error. This practice often results in unexpected toxicity, lack of efficacy, or both. We now recognize that inter-individual variability in a patient's ability to metabolize drugs is a major contributor to development of toxicities, hospitalizations, and deaths from even a standard dose of a medication. We outline our approach to deliver personalized medicine, made feasible through the commitment of our medical centre London Health Sciences Centre (LHSC) - in enabling a hospital-wide deployment and implementation of personalized medicine (PM). Specifically, approaches and technologies focused on rapid pharmacogenomics diagnostics, creation of a personalized medicine consult team, as well as LCMS/MS-based drug and metabolite level analysis for drugs such as statins, warfarin, clopidogrel, and tamoxifen are outlined.

\section{Richard B. Kim}

Dr. Kim received his medical degree from the University of Saskatchewan in 1987. After completing an internship and residency training in Internal Medicine, he went on to carry out fellowship training in Clinical Pharmacology at Vanderbilt University he remained at Vanderbilt as a faculty member in Clinical Pharmacology where he rose to the rank to tenured full Professor by 2004. Since 2006, he has been Professor and Chair of the Division of Clinical Pharmacology at Western, and holds the Wolfe Medical Research Chair. $\mathrm{He}$ is leading a program of excellence in Personalized Medicine. He is an elected Member of the American Society for Clinical Investigation (ASCI) and Fellow of the American Association of Pharmaceutical Scientists (AAPS) and Canadian Academy of Health Sciences (CAHS).

\section{Breast Cancer Pharmacogenomics: Beyond Biomarkers}

Richard Weinshilboum, MD, Mary Lou and John H. Dasburg Professor for Cancer Genomics Research; Chair, Division of Clinical Pharmacology; Professor of Molecular Pharmacology \& Experimental Therapeutics and Medicine, Mayo Clinic, Rochester, Minnesota

Breast cancer is the major invasive cancer of women worldwide. Major advances have been made in the therapy of breast cancer, advances that include both endocrine therapy and chemotherapy. The Mayo Clinic-NIH Pharmacogenomics Research Network (PGRN) has focused its recent research efforts on genome-wide studies of both of these approaches to the treatment of breast cancer, but those efforts have extended beyond the identification of "biomarkers" to also include functional validation of the biomarkers identified and pursuit of underlying mechanisms. This presentation will describe the use of germline DNA to perform genome-wide association studies (GWAS) of both the endocrine therapy (selective estrogen receptor modulators (SERMs) and aromatase inhibitors) to both treat and prevent breast cancer and the use of taxaneanthracycline-based chemotherapy to treat breast cancer. Both drug efficacy and drug-related toxicity have been studied. In all cases, functional validation of GWAS SNP "signals" and the pursuit of underlying mechanisms responsible for their association with drug efficacy and toxicity have taken place. In summary, this presentation will describe the use of genome-wide techniques to study the pharmacogenomics of endocrine therapy and chemotherapy of breast cancer. 


\section{Richard Weinshilboum}

Dr. Weinshilboum received B.A. and M.D. degrees from the University of Kansas, followed by residency training in Internal Medicine at the Massachusetts General Hospital, a Harvard teaching hospital, in Boston. He was also a Pharmacology Research Associate at the National Institutes of Health in Bethesda, Maryland, in the laboratory of Nobel laureate Dr. Julius Axelrod. Dr. Weinshilboum began his affiliation with the Mayo Medical School and Mayo Clinic in Rochester, Minnesota, in 1972 where he is presently Professor of Molecular Pharmacology \& Experimental Therapeutics and Internal Medicine as well as Mary Lou and John H. Dasburg Professor in Cancer Genomics Research. He also directs the Pharmacogenomics Program of the Mayo Center for Individualized Medicine. Dr. Weinshilboum's research has focussed on pharmacogenetics and pharmacogenomics, and he has authored over 350 scientific manuscripts which address these topics. A major area of investigation initially was the pharmacogenetics of drug metabolism, with a focus on methylation and sulfation but, in recent years, his research has increasingly applied genome-wide pharmacogenomic techniques rather than candidate gene or candidate pathway-based approaches. Dr. Weinshilboum has been the recipient of many awards and honors including an Established Investigatorship of the American Heart Association, a Burroughs Wellcome Scholar Award in Clinical Pharmacology Award, the Oscar B. Hunter Award of the American Society for Clinical Pharmacology and Therapeutics, the Harry Gold Award of the American Society for Pharmacology and Experimental Therapeutics, the Catecholamine Club Julius Axelrod medal, the U.S. Food and Drug Administration William B. Abrams Lectureship Award, and the Edvard Poulsson Award from the Norwegian Pharmacology Society.

\section{Development of Novel Tools for Personalized Genomic Medicine to Improve Drug Safety in Children}

Colin Ross, MSc, PhD, Assistant Professor, Departments of Pediatrics and Medical Genetics, University of British Columbia, and Scientist, Child and Family Research Institute (CFRI) at the BC Children's Hospital, Vancouver, BC, Canada

Severe adverse drug reactions (ADRs) are a striking problem for many different medications. The consequences for patients who experience severe ADRs are often catastrophic. In Canada, severe ADRs claim 10,000-21,800 lives each year and cause many more life-long disabilities. Removing medications from the market is not the optimal solution, because this leaves patients without otherwise effective therapies. Children are at greater risk than adults for severe ADRs. The high rate of morbidity and mortality due to ADRs is readily evident in the treatment of pediatric cancer, where $40 \%$ of patients suffer severe permanently disabling, life-threatening, or lethal ADRs; and ADRs alone account for $22 \%$ of all pediatric oncology patient admissions into hospital. An individual's susceptibility to an ADR is often determined by their genetic make-up. To tackle this complex problem requires a multi-faceted collaborative linking of scientists and clinicians with complementary expertise in an environment that promotes teamwork. The Canadian Pharmacogenomics Network for Drug Safety (CPNDS), a unique national linking of Canadian healthcare resources established to recruit patients that suffer severe ADRs and matched control patients to identify novel predictive markers of severe ADRs in children. Building upon our identification of novel pharmacogenetic susceptibility variants for codeineinduced mortality, cisplatin-induced deafness, anthracycline-induced heart failure, and vincristineinduced neurotoxicity we are working towards clinical implementation to demonstrate the benefits of predicting in whom the genetic risk of a severe ADR is greatest.

\section{Colin Ross}

Colin Ross, MSc, PhD, Assistant Professor, Departments of Pediatrics and Medical Genetics, University of British Columbia, and Scientist, Child and Family Research Institute (CFRI) at the BC Children's Hospital, Vancouver, BC, Canada

Dr. Ross's research seeks to improve the lives of 
children by developing new tools for safer and more effective health care based upon an individual's genetic blueprint using the tools of molecular genetics for personalized medicine. The debilitating and sometimes lethal consequences of severe adverse drug reactions (ADRs) are a striking problem in modern medicine. The costs of ADRs to the health care system currently outweighs the costs of all medications. The consequences for patients who experience severe ADRs can be catastrophic.
Dr. Ross helped establish the 'Canadian Pharmacogenomics Network for Drug Safety' (CPNDS), a network of clinicians and researchers in pediatric hospitals across Canada to identify patients that have suffered severe ADRs. The overarching goal of this research is to identify the genetic and/or clinical factors of severe ADRs so that in the future these ADRs could be prevented by identifying those patients at greatest risk before the drug is administered. 


\section{Wednesday, June 12}

\section{SESSION 4: \\ Nanomedicine and Gene Delivery \\ SPONSORED BY: NORTHERN LIPIDS}

\section{Intravaginal Delivery of siRNA as Potential Microbicides}

Emmanuel Ho, Ph.D., Faculty of Pharmacy, University of Manitoba, Laboratory for Drug Delivery and Biomaterials

In 2011, UNAIDS (Joint United Nations Programme on HIV/AIDS) reported that approximately 34 million people globally are living with HIV and 2 million have died that year alone. Heterosexual intercourse is identified as the main mode of HIV transmission among women. Due to biological vulnerabilities e.g. larger surface area of the vagina and cervix in comparison to the male penis, women are at a two-times higher risk of infection than men when exposed to unprotected sexual intercourse. Ever since the identification of HIV as the etiological agent for AIDS in 1984, researchers around the world have desperately attempted to develop an effective vaccine but have been unsuccessful. Some of the reasons include the fact that conventional vaccines are meant to protect against disease and not infections and HIV infection can remain latent for long periods of time before causing AIDS. These concerns along with the lack of understanding of the virus make vaccine development difficult.

In the absence of an effective vaccine, development of preventative technologies such as microbicides (products designed for vaginal or rectal application for the purpose of reducing sexually transmitted infections) remains a priority for combating the spread of HIV/AIDS. RNA interference (RNAi) has been utilized as a strategy for treating/preventing HIV infection, but the use of siRNA directly within the vaginal tract for the treatment/prevention of disease is a newly emerging field. For siRNA to be developed into an effective vaginal microbicide, it must overcome the adhesive properties of cervicovaginal mucus, the acidic nature of cervicovaginal fluid (CVF; $\mathrm{pH} 3.5-4.9$ ) and the presence of nucleases in CVF, all of which may contribute to the degradation of siRNA. Moreover, it is important to design a microbicide that can deliver siRNA to the target host cells and provide protection against HIV infection. For example, HIV has been shown to penetrate into the gaps between the squamous epithelial layers of the mucosa and infect CD4+ immune cells such as Langerhans cells and T lymphocytes. As a result, the goal of my research program is to develop nanomedicines that can improve delivery of siRNA to immune cells of the vaginal mucosa as a strategy for the treatment or prevention of HIV infection.

\section{Emmanuel Ho}

Dr. Emmanuel Ho joined the University of Manitoba, Faculty of Pharmacy as an Assistant Professor in July 2010. He is also cross-appointed to the Faculty of Engineering, Department of Biomedical Engineering and the Faculty of Medicine, Department of Immunology. He earned his Ph.D. in Pharmaceutical Sciences from the University of Toronto and was awarded numerous scholarships, most notably, a doctoral graduate scholarship from the Natural Sciences and Engineering Research Council of Canada (NSERC). As a post-doctoral fellow at the British Columbia Cancer Research Center, Dr. Ho was awarded the Canadian Institutes of Health Research (CIHR) PostDoctoral Fellowship along with the Michael Smith Foundation for Health Research Post-Doctoral Fellowship (MSFHR). His current research interests include the development and characterization of novel medical devices, vaccines, and drug delivery strategies for the treatment and prevention of HIV/AIDS. Dr. Ho's research program is supported by grants from the Bill and Melinda Gates Foundation, CIHR, Canada Foundation for Innovation (CFI), Manitoba Health Research Council (MHRC), Manitoba Medical Service Foundation (MMSF), and the Dr. Paul Thorlakson Foundation Fund. 


\section{Nucleic Acid Delivery using Chitosans}

Michael D. Buschmann, Canada Research Chair in Cartilage Tissue Engineering, Director Biomedical Science and Technology Research Group (FRSQ), Department of Chemical Engineering, Institute of Biomedical Engineering, École Polytechnique de Montréal

We have developed nanoparticles that are electrostatic complexes of the natural cationic polymer chitosan with plasmid DNA (pDNA) or with small interfering RNA (siRNA) and have achieved high levels of transgene expression from pDNA and specific gene silencing using siRNA. A series of in vitro cell transfection studies revealed the importance of preparing specific chitosans, that are polymers of glucosamine and $\mathrm{N}$-acetylated glucosamine, to obtain an optimal level of transgene expression. Live intracellular confocal imaging has provided mechanistic insight into the transfection process while physicochemical and nano-imaging have further allowed the establishment of structure function relationships. The most efficient chitosans were then tested in vivo and shown to express the growth factors FGF-2 and PDGF-BB via subcutaneous and intramuscular administration. By tailoring the type of chitosan used in these latter studies we were able to either stimulate or abrogate the generation of neutralizing antibodies to the transgene product. An important recent study has further shown significant therapeutic potential of these systems in the delivery of glucagon-like peptide 1 in a small animal diabetes model. Recently we have begun to address manufacturing challenges of these nanoparticle suspensions in order to make these systems more generally available for multiple applications in cell transfection, in vivo expression of transgenic proteins and gene silencing.

\section{Michael Buschmann}

Michael Buschmann received a B. Engineering Physics from the University of Saskatchewan in 1984, and a Ph.D. in Medical Engineering and Medical Physics from the Division of Health Sciences and Technology at the Massachusetts Institute of Technology and Harvard University in 1992. His postdoctoral training in cartilage microscopy and histology was then completed at the University of Bern in Switzerland in 1994. Since 1994, Dr. Buschmann is Professor of Biomedical Engineering and Chemical Engineering at Ecole Polytechnique. His research program focuses on the use of biomaterials to repair joint tissues including articular cartilage and on the discovery and development of polymer-based gene and drug delivery systems for Diabetes, Cancer and Inflammatory diseases (http://www.groupes.polymtl.ca/tissue/). He is one of the primary inventors of the BST-CarGelTM technology that successfully completed an international clinical trial and is commercially available in Europe (http://bstcargel.piramal.com/media/index.html). Diagnostic instruments for cartilage and arthritis were patented and transferred to another Canadian company (http://www.biomomentum.com/). Dr. Buschmann has published 115 articles, 241 conference proceedings and 15 patented or patent pending inventions. He is Director of the FRSQ Group in Biomedical Science and Technology and has received the Innovator Prize from the Quebec Association for Industrial Research (ADRIQ), the Melville Medal from the American Society of Mechanical Engineers (ASME), and an Award of Merit of the Canadian Arthritis Network of Centres of Excellence. He is a board member and scientific program committee member of the International Cartilage Repair Society and NanoQuebec.

\section{Programming Biomaterials for Personalized, On- Demand Medicine: A Nanomedicine Approach}

Larry Unsworth, University of Alberta

[Abstract and bio not available]

\section{Peptide-targeted Polycations for Nucleic Acid Delivery}

Suzie Pun, University of Washington, Seattle, WA

Living polymerization is a relatively new method for synthesizing polymers with well-defined structures and low polydispersity. We have been synthesizing peptide-containing polycations using living polymerization techniques. One class of materials are the peptide-based copolymers synthesized by copolymerization of peptide macromonomers. We have incorporated peptides for nucleic acid binding, endosomal release and cell targeting into welldefined peptide-based polymers using RAFT 
polymerization. The second class of materials are block copolymer materials that have sheddable hydrophilic shields synthesized using a "doublehead agent" that allows for two types of controlled polymerization strategies. The cationic polymers have been tested in vitro to neuron-like, differentiated PC-12 cells and by direct brain injection. We demonstrate that these materials are versatile and can be tuned for efficient gene transfer with low accompanying toxicity.

\section{Suzie Pun}

Suzie H. Pun received her Chemical Engineering $\mathrm{Ph} . \mathrm{D}$. degree in 2000 from the California Institute of Technology. She then worked as a senior scientist at Insert Therapeutics for 3 years before joining the Department of Bioengineering at University of Washington (UW). She is currently the Robert J Rushmer Associate Professor of Bioengineering, an Adjunct Associate Professor of Chemical Engineering, and a member of the Molecular Engineering and Sciences Institute at UW. She was recognized with a Presidential Early Career Award for Scientists and Engineers in 2006. Her research focus area is in drug and gene delivery systems and she has published over 60 research articles in this area. 


\section{Thursday, June 13}

\section{Plenary Lecture 4}

\section{Mass Spectrometric Molecular Phenotyping of Tissues and Body Fluids}

Ruedi Aebersold, Department of Biology, Institute of Molecular Systems Biology, ETH Zurich and Faculty of Science, University of Zurich, Switzerland

Systems biology is focused on the study of dynamic networks of interacting molecules and places such networks between genotype and phenotype. It is assumed that a specific genome encodes the molecules that constitute such a network and that the network is modulated by perturbing effects such as environmental factors. The properties emerging from the network as a whole determine observable phenotypes. Many of the molecular networks of the cell consist of or involve proteins. Therefore, the precise determination of the acute state of protein networks is highly informative as an acute phenotypic readout.

Mass spectrometry based proteomics is a central life science technology that has realized great progress towards the identification, quantification and characterization of the proteins that constitute a proteome. In this presentation we will discuss how mass spectrometry based proteomics has been applied to network biology to identify the nodes and edges of biological networks, to detect and quantify perturbation induced network changes and to correlate dynamic network rewiring with the cellular phenotype. We will also discuss future directions for mass spectrometry based proteomics within the network biology paradigm and their significance for the study of networks perturbed in human disease.

\section{Ruedi Aebersold}

Dr. Ruedi Aebersold is a Professor in the field of proteomics and systems biology with joint appointments at the ETH (Swiss Federal Institute of Technology) Zurich, Switzerland and the University of Zurich. He has served on the faculties of the
Universities of Washington and British Columbia. $\mathrm{He}$ co-founded the Seattle Institute for Systems Biology, and participates as a member of Scientific Advisory Boards for a number of academic and private sector research organizations. Dr. Aebersold, one of the pioneers in the field of proteomics and systems biology, is known for developing a series of methods and technologies for quantitative proteomics that can be applied to enhance our understanding of the structure, function, and control of complex biological systems. His group was instrumental in the landmark development of methods and reagents for stable isotopic labeling of protein samples enabling a quantitative dimension to biological mass spectrometry and the development of software tools for the statistically supported analysis of proteomics data. Recently, the group has pioneered the use of targeted mass spectrometry for the generation of consistent quantitative proteomic datasets on differentially perturbed systems. Dr. Aebersold has published more than 500 peer reviewed papers that have generated $>55.000$ citations. He has reached an $\mathrm{h}$-factor of 115 and is the recipient of numerous awards for his contribution to the field of protein sciences and proteomics including the Thompson Medal (2012), the EuPA Pioneer award (2012), MCP-HUPO lectureship (2011), the ASBMB Herbert Sober award (2009) the Otto Naegeli Prize (2009), the ABRF Award (2008), the FEBS Buchner Medal (2006), the HUPO Award (2005), the ASMS Biemann medal (2002) the Widmer award (2002), and the 2003 World Technology award. His group is currently focused on establishing novel label-free methods, leveraging new instrumentation and knowledge of representative "proteotypic" peptides, to rapidly and quantitatively profile global proteomes for discovery of new diagnostic markers for disease, and to facilitate a more complete understanding of the biochemical processes that control and constitute cell physiology. 


\title{
Thursday, June 13
}

\author{
SESSION 5:
}

\section{Personalized Medicine and Biomarkers}

\section{Driving Products through a Robust Biomarker Pipeline - PROOF Centre Experience}

Janet Wilson-McManus, Chief Operating Officer, PROOF Centre of Excellence

Caregivers, scientists and policy makers are committed to providing more patient-specific care. The Centre of Excellence for the Prevention of Organ Failure (PROOF Centre) was established to implement biomarker solutions that define risk, predict disease occurrence, diagnose, prognose, or refine our understanding of responses to therapies and other care interventions along the life cycle of heart, lung and kidney failure. The Centre's experience and directions with regards to biomarker identification and clinical evaluation as "fit for purpose" has been based on work related to immune rejection of transplanted hearts and kidneys, and more recently arising from questions related to "acute COPD attacks" and various forms of heart failure.

This presentation will highlight lessons learned from the PROOF Centre journey in applying its development process to bring new biomarker-based tools to the clinic:

- Seamless science, building on clinically-driven needs, well-phenotyped clinical cohorts, establishment of quality-assured, state-of-the-art platforms for biological interrogation, and rigorous data mining

- Translation of technology platforms that can be cost-effective and workable in real-world clinical laboratory settings

- Shared commitment of a diversity of clinicians, life and computational scientists, policy makers, health economists, technologists, and patients.

- Pursuing health system implementation by evaluating biosignatures for intellectual property value, interfacing with regulatory agencies, and entraining experts in health system implementation processes for new diagnostic tests
- Pushing to better understand the biology of injury and repair of hearts, lungs and kidneys, and enabling pharma in drug discovery

\section{Janet Wilson-McManus}

Ms. Janet Wilson-McManus has served as Chief Operating Officer for the Centre of Excellence for the Prevention of Organ Failure (PROOF Centre) since March, 2009. Janet brings more than 30 years of hands-on research and program management experience from the clinical laboratory and basic and translational health research environments. Over the last decade, she has been instrumental in bringing in and managing large-scale funding to the UBC community. These initiatives range from laboratory renovations and equipment installation to operational infrastructure for research centres and institutions, all involving partner engagement and funding from academia, health care, industry, and private foundations. She is a co-author on more than 80 full length publications and chapters and is contributor to two patents to date. Janet obtained her Bachelor of Science degree in Biology and Chemistry from the University of Southern Colorado and a Bachelor of Science in Medical Technology as well as post-graduate courses in Statistics at the University of Nebraska Medical Center.

\section{Emerging Clinical Value of Molecular Signatures in Renal Medicine}

Daniel R. Salomon, M.D., Professor, Molecular and Experimental Medicine, Director, Laboratory for Functional Genomics, The Scripps Research Institute, Program Medical Director, Scripps Center for Organ Transplantation

The time is now to move the last decade of biomarker discovery in renal medicine and kidney transplantation into real applications for patients, advance the field and enhance both safety and patient outcomes. There is a huge, unmet medical 
need for successful molecular diagnostics that can detect kidney injury early and with higher sensitivity and can also predict the ultimate development of CKD in high risk populations. There is an equally huge need to personalize immunosuppression management in kidney transplantation to optimize safety and efficacy. The critical challenge now is the best way to define the value propositions of a molecular diagnostic for renal medicine and kidney transplantation and then validate these in real clinical practice. In fact, there are multiple different value propositions for molecular diagnostics this area and it is critical to review these many possibilities for clarity and insure that the next stage of clinical studies truly validate these propositions. Moreover, while it is useful to follow the experience with genetic diagnostics and the evolution of cancer diagnostics recently, the truth is that kidney disease, transplantation and immunology have their own unique challenges and these differences are critical to consider and incorporate into our strategies and study designs. If we make this next transition successfully, we can change the clinical practice of renal medicine and transplantation dramatically. If we fail to be responsible and transparent, then all we will do is muddy the water with hype and marketing, ultimately setting back the field instead of advancing it.

\section{Daniel Salomon, M.D.}

Dr. Salomon is a Professor at The Scripps Research Institute, Department of Molecular and Experimental Medicine and Program Medical Director, Scripps Center for Organ Transplantation. He is currently the President of the American Society of Transplantation. Dr. Salomon has published 124 peer-reviewed manuscripts, 43 chapters and reviews and edited 3 books. He has served on numerous national and international committees, including: Executive Board member, Program Committee Chair, Cell Transplantation Committee Chair, and Xenotransplantation Committee Chair for American Society of Transplantation; Chair, National Institutes of Health Islet Cell Resources Steering Committee; Chair, NIH Genomics of Transplantation Cooperative Research Program Steering Committee, Founding Member, US Secretary of Health's Xenotransplantation Advisory Committee and Chair, FDA Biological Response Modifiers Advisory Committee. He continues to serve on multiple NIH Study Sections and Special Emphasis Panels, presently a standing member of AITC. Dr. Salomon's laboratory work is focused on various aspects of organ and cell transplantation and immunology with a primary focus on functional genomics, proteomics and genetics. One set of objectives is to discover biomarkers for the diagnosis of acute and chronic rejection that will enable the personalized management of immunosuppression. Another objective is prognostic markers for transplant outcomes using genetics, transcriptional profiling and proteomics. Another set of objectives is to understand the multidimensionality of transcriptional regulation. These studies include microRNA regulation, alternative splicing and RNA binding proteins and the dynamic impact of epigenetic changes, both methylation and histone marking, on lymphocyte activation and differentiation into memory.

\section{Novel Strategies for Maximizing the Acquisition and Interpretation of Biomarkers}

Scott J. Tebbutt, Ph.D., Department of Medicine, University of British Columbia, Vancouver, Canada

Peripheral whole blood is often the sample of choice for molecular profiling ("omics") biomarker studies. Its collection is cost-effective and non-invasive, allowing for serial sampling study designs. As a vehicle of the immune system, blood is uniquely suited to the study of immune processes in health and disease. Measuring genome-wide changes in transcript abundance in blood can deliver a comprehensive view of the status of the immune system and gene expression changes in peripheral whole blood have been useful in studying the pathobiology of many diseases and in identifying biomarkers. However, $>40 \%$ of the variability found in peripheral blood gene expression data may be attributed to differences in the cellular composition of the samples under study. When not accounted for, this necessarily reduces the sensitivity of analyses carried out in peripheral whole blood and makes drawing meaningful inferences from such data problematic. Experimental separation to the component cell types of blood prior to RNA extraction is an obvious solution, but greatly increases costs, introduces additional technical variability and is dependent on the availability of cell-surface markers and antibodies. Statistical deconvolution approaches, which can infer the cellular composition or cell type-specific expression profiles from complex tissue expression data, offer a 
cost effective alternative. In this talk, I will highlight recent deconvolution strategies that we have used in molecular profiling projects that have utilized peripheral blood samples to investigate disease-related conditions in two different organs lung and kidney.

\section{Scott J. Tebbutt}

Scott Tebbutt is Associate Professor in the Department of Medicine, Division of Respiratory Medicine, University of British Columbia, and Principal Investigator at the James Hogg Research Centre, St. Paul's Hospital, Vancouver. His academic research program is focused on the molecular mechanisms of complex respiratory disease, including the early and late reactions in atopic asthma and allergic rhinitis. Dr. Tebbutt is also Chief Scientific Officer of the Prevention of Organ Failure (PROOF) Centre of Excellence - a not-for-profit organization dedicated to moving research findings into health care, and focused on non-invasive biomarkers that can diagnose and/or predict organ failure (heart, lung and kidney). Dr. Tebbutt earned his Bachelor's degree in Biochemistry from the University of Oxford, England, and his Ph.D. in Molecular Biology from the University of East Anglia (Cambridge Laboratory, John Innes Centre). He pursued postdoctoral fellowships in the laboratories of Professor Ann Harris (University of Oxford, Institute of Molecular Medicine) and Professor Diana Hill (University of Otago, Dunedin, New Zealand), where he studied the molecular genetics of cystic fibrosis. Dr. Tebbutt has published original research contributions in journals such as the Proceedings of the National Academy of Sciences (U.S.A.), PLOS ONE, Journal of Asthma, Journal of Heart and Lung Transplantation, Proteomics Clinical Applications, Journal of Medical Genetics, BMC Medical Genomics, BioTechniques, and Bioinformatics. He has published numerous technical reviews as well as book chapters on the role of genetic variation in respiratory disease. He has served as reviewer on several grant panels, including the Canadian Institutes of Health Research and the Michael Smith Foundation for Health Research, and he is Associate Editor for the journal BMC Genetics. He has been awarded competitive research funding from organizations such as the National Sanitarium Association (Canada), the British Columbia Lung Association, AllerGen NCE Inc. (Allergy, Genes and Environment Network), and the Canadian Institutes of Health Research. He is a member of the Canadian Thoracic Society, The Transplantation Society, and the Canadian Society for Molecular Biosciences.

\section{Biomarkers and the Improvement of Cardiac Care}

Peter Liu, Toronto General Hospital

[Bio and abstract not available] 


\title{
Thursday, June 13
}

\author{
SESSION 6:
}

\section{Critical Quality Attributes and Biopharmaceutics}

\section{Biorelevant Dissolution: Where are We?}

Johannes Kraemer, Phast GmbH, Homburg, Germany

Successful authorization of drugs requires mostly the proof of bioavailability requiring numerous studies in humans. Substitution of clinical testing by meaningful laboratory in vitro methods would speed up authorization procedures. An increasing number of poorly water soluble drug substances used for oral application and the limitations of the traditional procedures require ongoing research and development to link in vitro and in vivo performance testing.

The term biorelevant used by most scientists in the area of dissolution still seems to need ongoing discussion for a precise definition. . The use of biorelevant media is increasing. To understand their benefit knowledge of human physiology is needed. The use is often based upon the hypothesis: the closer the test conditions to the GI physiology, the better the chances of predicting product performance. The term "biorelevant" may be described as an attribute for an in vitro test that utilizes conditions and environment mimicking in vivo environment and conditions, and / or laboratory test capable of predicting in vivo response not necessarily mimicking in vivo environment but providing quantitative predictions.

One way to prove the predictive power of an in vitro performance test is to compare the findings obtained with data generated by in vivo performance tests. i.e. bioavailability studies. The classical approach to correlate in vitro with in vivo performance data is the IVIVC (in vitro / in vivo correlation) preferred by authorities and described in recently revised USP chapter $<1088>$. The three level correlation scale reaches from point to point correlation called Levy plot to levels after data reduction, where entire profiles are represented by single parameters such as $\mathrm{C}_{\max }$ or MRT (mean residence time). As one common prerequisite classical IVIVC is based on the assumption, that in vivo dissolution is the rate limiting step. This explains, why IVIVC are most successful with ER dosage forms and may fail with IR dosage forms.

Often IVIVC is used to set meaningful specifications. Those specifications may also help to apply the biowaiver concept on different strengths of one product being compositionally proportional.

\section{Johannes Krämer}

Dr. Krämer is the founder and managing director of the "PHAST group" with sites in Germany, France, and Switzerland. Since 1987, he is working in the field of dosage form performance testing.

$\mathrm{He}$ obtained his degree in pharmacy from Frankfurt University. After specializing in pharmaceutical analysis, he obtained his Ph.D. in pharmaceutical technology and biopharmacy from Heidelberg University.

Dr. Krämer is an elected member of the USP Dosage Forms Expert Committee and chairman of USP's Subcommittee K (medicated gums). With the International Pharmaceutical Federation (FIP) he is member of the Focus Group on Dissolution/In Vitro Release Performance Testing. He is a member of the American Association of Pharmaceutical Scientists, the Biopharmaceutics Group within APV (International Association for Pharmaceutical Technology), and the Deutsche Pharmazeutische Gesellschaft (DPhG).

His scientific interest is focused on IVIVCbased (in vitro in vivo correlations) in vitro performance testing method-development for pharmaceutical dosage forms, with special regard to stability problems. He is the author of several publications and several book chapters as well as coeditor of a book on dissolution testing. 


\section{Practical Applications of the TNO Intestinal Model (TIM) in Pharmaceutical Development}

\author{
John Sagartz, Seventh Wave Laboratories LLC
}

Pharmaceutical formulation development relies heavily on in vitro testing in attempting to predict in vivo solubility and dissolution of the active pharmaceutical ingredient (API). Standard dissolution tests typically employ models that incorporate a limited number of static physiological conditions such as $\mathrm{pH}$, body temperature, mixing, fed vs. fasted conditions, and in some cases the use of bio-relevant media. However, few of the existing in vitro methods are designed to replicate the dynamic and complex luminal aspects of the gastrointestinal environment which may impact the solubility and dissolution of API's. Thus, static dissolution testing schemes often poorly predict bioavailability. Because the release from formulation, solubility, accessibility, and interactions with other drugs, food, or nutrients are important aspects affecting formulation performance, pharmaceutical product development would benefit from accurate simulation of physiologically relevant gastrointestinal parameters. Dynamic dissolution testing allows for the investigation of a drug and its formulation when exposed to physiologically relevant parameters and enables development of mechanistic understanding of variables impacting drug dissolution and solubility. Using the TIM-1 (TNO Intestinal Model) simulated gastrointestinal system, we have evaluated the bioaccessibility (the amount of soluble API available for absorption) of API's from a number of drug formulations and correlated findings with in vivo observations. These studies suggest that dynamic dissolution methodologies may not only enhance the quality of in vitro predictions, but may also provide mechanistic insight into variables affecting formulation performance.

John E. Sagartz, DVM, Ph.D., Diplomate, ACVP John E. Sagartz is President of Seventh Wave Laboratories, LLC. He received his Doctor of Philosophy from The Ohio State University, Department of Veterinary Biosciences, Columbus, $\mathrm{OH}$, completed his Residency in Veterinary Pathology at Ohio State University, Department of Veterinary Pathobiology, Columbus, OH, Doctor of Veterinary Medicine from Kansas State University, College of Veterinary Medicine and his BS from Kansas State University, College of Agriculture in
Manhattan, Kansas. From 1997 to 2003 he held positions as a Investigative Pathologist, Section Head, Assistant Director, Director and Preclinical Development Site Head, Pharmacia Fellow Manager at Global Investigative Toxicology, St. Louis, MO. John has been the recipient of numerous honors and awards including recognition as a Pharmacia Fellow in 2003. The Pharmacia Fellow Program recognizes individuals who demonstrated outstanding proficiency and accomplishment in their field and a strong record of technical leadership. In addition, Dr. Sagartz received the W.E. Upjohn award in 2001 which is granted to individuals with sustained high impact contribution to the performance of Pharmacia Corporation. Further, Seventh Wave Laboratories was awarded the 2009 Outstanding Entrepreneur Award by the St. Louis County Economic Council. Past Professional Activities include Chair, American College of Veterinary Pathologists Endowment Committee, Endocrine Pathology Program Planning Committee, American College of Veterinary Pathologists annual meeting, 1999. Dr. Sagartz is a member of the Society of Toxicologic Pathologists, Society of Toxicology, American Society of Investigative Pathology, American College of Veterinary Pathologists, and American Veterinary Medical Association, and serves on the Board of Directors for the Missouri Biotechnology Association. He has authored and coauthored over 40 publications related to experimental and spontaneous disease.

\section{In Vitro Dissolutions to Link Drug Product Critical Quality Attributes to in vivo Performance: A Regulatory Perspective - FDA}

Lawrence X. Yu, Ph.D. Deputy Director (acting), Office of Pharmaceutical Science, Food and Drug Administration

In vitro dissolution testing has been evolving over the years from use as a product quality characterization tool to serving as a link between in vitro and in vivo product performance. With advances in technology and increased understanding of in vivo absorption, often dissolution methods that have clinical or in vivo relevance can be developed such that the method may provide more mechanistic information lending to greater product understanding. Implementation of Quality by Design $(\mathrm{QbD})$ principles into drug development efforts, and 
availability of the in vivo prediction models support advancing in vitro methods into reliable benefit/risk assessment tools linking in vitro and in vivo product performance and patient benefit. The desired future state of in vitro dissolution testing may be characterized as tests that are:

- sensitive enough to detect relevant product changes so as to ensure the quality and consistent performance of products

- predictive of in vivo performance of drug products and thus reduce unnecessary human studies, accelerate drug development, and hasten validation of post-approval changes

This presentation will focus on the current landscape of in vitro dissolution testing, including apparatus, media, and in vivo and in vitro correlations. The discussion will focus on the development needs and future direction of in vitro dissolution testing.

\section{Lawrence X. Yu}

Dr. Lawrence $\mathrm{X} . \mathrm{Yu}$ is the Deputy Director (acting), Office of Pharmaceutical Science, Food and Drug Administration, overseeing Office of New Drug Quality Assessment, Office of Generic Drug Quality Assessment, Office of Biotechnology Products, and Office of Testing and Research. He is also adjunct Professor of Pharmaceutical Engineering at the University of Michigan. Dr. Yu's research interests have centered on the prediction of oral drug delivery and the development of pharmaceutical Quality by Design. His compartmental absorption and transit (CAT) model has laid the foundation for the commercial software, GastroPLUS ${ }^{\mathrm{TM}}$ and Simcyp ${ }^{\circledR}$, which are being widely used in the pharmaceutical industry. Dr. $\mathrm{Yu}$ is a fellow and the past section Chair of the American Association of Pharmaceutical Scientists and an Associate Editor of the AAPS Journal. Dr. Yu has authored/co-authored over 200 papers, book chapters, and abstracts, and given over 150 invited presentations. He is a coeditor of the book entitled "Biopharmaceutics Applications in Drug Development”.

\section{Developing Meaningful Control Strategy for Drug Products}

Krishnan Tirunellai, Ph.D., Senior Scientific Advisor, Bureau of Pharmaceutical Sciences, Therapeutic Products Directorate, Health Canada and Visiting Professor, University of Ottawa
To develop a meaningful Control Strategy (CS) in product development it is essential to choose the right manufacturing process that is commensurate with the risks involved in achieving the set Quality Target Product Profile (QTPP). To achieve this goal, science and risk based approaches should connect Critical Quality Attributes (CQAs) and Critical Product Profiles (CPPs). The CS developed in this manner would reduce variability and consistently meet expected quality. In this presentation an attempt will be made to highlight the importance of selecting the right manufacturing process so as to achieve the above objectives. This approach will not only ensure acceptable quality in all batches it will also prevent market recalls that are burdensome to the public, the industry and the regulatory agency.

\section{Krishnan Tirunellai}

Krishnan has Bachelor and Master degree in Pharmacy (India), and Ph.D. in Biopharmaceutics, (Dalhousie University, Canada). He served as a scientist at AstraZeneca and Patheon, in R\&D and Manufacturing divisions for six years, and as a tenured Associate Professor, School of Pharmacy, Memorial University of Newfoundland, Canada, for seven years. For the past thirteen years Krishnan has been serving Health Canada in various capacities including Senior Reviewer, and Manager of the New Drugs and Generic Quality divisions. $\mathrm{He}$ is presently serving the Bureau of Pharmaceutical Sciences as a Senior Scientific Advisor and as an A/Manager of the Generic Quality division. He also teaches drug delivery systems as a Visiting Professor at the Department of Biopharmaceutical Sciences, University of Ottawa.

Krishnan's areas of expertise are drug delivery systems and manufacturing and he has over 35 research papers and abstracts. He has served the ICH Q8(R) expert working group, and the ICH Q8, 9, 10 - Quality Implementation Working Group.

Krishnan received the Killam Scholarship for his graduate studies at Dalhousie. At Memorial University he received Bristol-Myers Squibb Professor of the Year in 1995, and at Health Canada the first Claire Franklin Award for Excellence in Continuous Learning, in 2005 for his contributions in continuing education, and in 2012 Deputy Minister's award for excellence in innovation and creativity. 


\section{Thursday, June 13 \\ GlaxoSmithKline Early Career Award Lecture}

\section{Multifunctional Nanoparticles for Targeted Delivery of Anticancer Drugs}

Shyh-Dar Li, Ph.D., Ontario Institute for Cancer Research, Toronto, Ontario, Leslie Dan Faculty of Pharmacy, University of Toronto

Nanoparticle-based drug delivery is an emerging technology for targeting anticancer drugs to tumors, and a number of nanoparticle-based drugs are now in clinical applications as chemotherapeutics. While these nanomedicines exhibit reduced toxicity, most candidates and products do not enhance efficacy in human patients. The failure of current nanomedicines to achieve enhanced safety and efficacy can be largely attributed to limited tumor bioavailability, and is an issue of suboptimal drug release profile. For example, drug release from Doxil $^{\circledR}$ (PEGylated liposomal doxorubicin) is slow $(<1 \% /$ day $)$, leading to reduced bioavailability in tumors; paclitaxel partitions rapidly out of Abraxane $^{\circledR}$ (nanoparticle albumin bound paclitaxel) during systemic circulation, and the pharmacokinetic and biodistribution profiles are not enhanced compared to the native drug. My research focuses on addressing the critical issue of site-specific drug release, and my team has created two nanoparticle drug delivery technologies that enhance tumor bioavailability. The first technology is a thermosensitive liposome that is triggered to burst- release the drug cargo in seconds within a locally heated tumor $\left(39-43^{\circ} \mathrm{C}\right)$. By co-encapsulating an MR contrast agent, the intratumoral uptake of the drug can be quantitatively mapped out by MRI and correlated to its antitumor efficacy. The second technology is a polysaccharide drug conjugate that targets docetaxel to tumor stroma and exhibits significant microenvironment modulating activity and anti-metastatic efficacy.

\section{Shyh-Dar Li}

Dr. Shyh-Dar Li obtained his Ph.D. in Pharmaceutical Sciences from The University of North Carolina at Chapel Hill, and finished his postdoctoral training at the Moores Cancer Centre at the University of California, San Diego. He is currently a Principal Investigator at the Ontario Institute for Cancer Research, and is cross-appointed at the Leslie Dan Faculty of Pharmacy, University of Toronto. His research focuses on developing nanoparticle-based drug delivery systems for enhancing cancer chemotherapy. His work has been published in scholarly journals, and his lab has been supported by major funding agencies in Canada and the U.S. Dr. Li has won several research awards from American Association of Pharmaceutical Scientists, Prostate Cancer Foundation, Liposome Research Days Conference and Taiwanese Government. 


\section{Thursday, June 13}

\section{Plenary Lecture 5}

\section{Enabling Industrialized Disruption of Medicine}

Patrick F. Terry, Cambridge, MA

The presentation will discuss how the patient advocacy community and consumer-movement in health care is currently engaged in deploying new network models, shared resources, and novel solutions to alter the landscape and timetable of progress of the biomedical research enterprise.

Examples of various technologies being developed around patient-owned data, disease registries, individualized genomics, health information records, clinical outcomes data, treatment protocols, clinical care pathways, and aggregated big-data analytics that will alter how products will be developed, delivered, and paid for in an era of iterative translational medicine. The presentation will discuss both industry and lay community efforts to intentionally disrupt the traditional agent-model of the pharmaceutical industry, product development, and biomedical research.

The presentation will illustrate how the predominately risk-based regulatory paradigm of command-and-control therapeutic and medical device development will change and how industry and regulators will be powerless to stop it.

\section{Patrick F. Terry}

Patrick has co-founded numerous life science organizations in the last 20 years and has been called a godfather of applied genomics and personalized medicine.

Patrick Terry is a social entrepreneur who has founded a series of innovative philanthropic, research, and commercial organizations based on the life sciences, applied technology, and social-network theory. In 2000, he and a group of prominent leaders in the fields of genomics, bioinformatics, and biotechnology founded Genomic Health, Inc. (NASDAQ: GHDX), a pioneering personalized medicine company based in California. His perspective is forged from personal and family experiences with genetic disease, cancer, and extensive work in the patient advocacy community. He has published dozens of peer-reviewed scientific papers and book chapters in the fields of genetics, precision medicine, and biomedical research. His activities have included leadership positions on numerous trade associations, professional societies, corporate boards, editorial boards, and a number of national and international advisory bodies. He has experience doing hands-on bench science, coordinating human genetics research, conducting basic research on rare diseases, and manages multiple life science patents. He has been involved in shepherding multiple biotechnology products through commercial development to clinical delivery in the North, Central and South America, Europe, South Africa, Israel, Japan, and China. He has received many honors and awards in the business and scientific communities internationally. He has dedicated his career to helping people and advancing a patient-centered perspective in research, product development, and translational medicine. $\mathrm{He}$ is active internationally with corporate management and financing of stratified medicine companies for numerous clinical indications and technologies.

$\mathrm{He}$ is also an accomplished adventure sports athlete. 


\section{Thursday, June 13}

\section{SESSION 7: \\ Personalized Medicine and Funding/Government/Regulatory Issues}

\section{Benefits, Harms and Uncertainties - Regulator's Perspective for Personalized Medicine}

David K. Lee, Director of the Office of Legislative and Regulatory Modernization, Health Canada, Ottawa, ON

The regulation of health products and food is an important activity that supports the health and wellbeing of Canadians. Governments routinely make changes to their regulatory frameworks (legislation and regulation) to address minor issues or to reflect new policy. One of the key drivers that influence Health Canada's regulatory activities (to reflect new policies) is new and emerging science and technologies. Health Canada's regulatory frameworks were developed at different points in time, and although some are fairly modern, others are not, and it has become increasingly difficult for Health Canada to respond efficiently and effectively to these drivers. This presentation will examine modernization objectives being undertaken to support regulatory reform and the influence of new science and technologies such as personalized medicine.

\section{David K. Lee}

David K. Lee is the Director of the Office of Legislative and Regulatory Modernization, Health Canada.

The mandate of the Office of Legislative and Regulatory Modernization is to modernize the Canadian Food and Drugs Act and corresponding regulatory frameworks. The modernization of these regulatory tools will focus on food safety frameworks and the implementation of a life-cycle approach to the regulation of health products, including pharmaceuticals, biologics, and medical devices.

Formerly, Mr. Lee was the Director of the Office of Patented Medicines and Liaison which administers the Patented Medicines (Notice of Compliance) Regulations and provides liaison for Therapeutic Products Directorate litigation under the Food and Drugs Act and Regulations along with the Department of Justice. The scope of proceedings managed under the Food and Drug Regulations has included judicial reviews in the Federal Court of Canada, actions and class actions relating to drug injury and alleged regulatory negligence and coroner's inquiries.

Mr. Lee received his law degree at Queen's University at Kingston Ontario, and articled at the Federal Court of Canada. He worked in private practice until joining Health Canada in 1999. He has lectured extensively on intellectual property law and pharmaceuticals law both nationally and internationally.

\section{Personalized Medicine, A Long Learning Curve: EMA Experiences}

Hans-Georg Eichler, European Medicines Agency

[Abstract not available]

\section{Hans-Georg Eichler}

Hans-Georg Eichler, M.D., M.Sc., is the Senior Medical Officer at the European Medicines Agency in London, United Kingdom, where he is responsible for coordinating activities between the Agency's scientific committees and giving advice on scientific and public health issues. From January until December 2011, Dr. Eichler was the Robert E. Wilhelm fellow at the Massachusetts Iinstitute of Technology's Center for International Studies, participating in a joint research project under the MIT's NEWDIGS initiative. He divided his time between the MIT and the EMA in London. Prior to joining the European Medicines Agency, Dr. Eichler was at the Medical University of 
Vienna in Austria for 15 years. He was vice-rector for Research and International Relations since 2003, and professor and chair of the Department of Clinical Pharmacology since 1992. His other previous positions include president of the Vienna School of Clinical Research and co-chair of the Committee on Reimbursement of Drugs of the Austrian Social Security Association. His industry experience includes time spent at Ciba-Geigy Research Labs, U.K., and Outcomes Research at Merck \& Co., in New Jersey.

Dr. Eichler graduated with an M.D. from Vienna University Medical School and a Master of Science degree in Toxicology from the University of Surrey in Guildford, U.K. He trained in internal medicine and clinical pharmacology at the Vienna University Hospital as well as at Stanford University.

\section{Personalized Medicine and Patient-Oriented Research: CIHR Perspective}

Jane Aubin, Chief Scientific Officer and VicePresident, Research, CIHR

In 2009, CIHR laid out its five year vision in Health Research Roadmap: Creating innovative research for better health and health care. In it, CIHR recognized that investment in health research requires careful consideration of where Canada can capitalize on areas of strength and excellence, energize identified priority areas, and build research capacity in new fields of health research to have the biggest impact.

The Personalized Medicine Signature initiative aims to build upon Canadian health researchers' strengths in identifying disease-related genes and biomarkers and in translational research in order to integrate evidenced-based medicine and precision diagnostics into clinical practice. This initiative converges with the Strategy for Patient Oriented Research (SPOR), which seeks to demonstrably improve health outcomes and enhance patients' health care experience through integration of evidence at all levels in the health care system. Dr. Aubin will speak to these initiatives and on-going transformative research that is being supported by CIHR.

\section{Jane Aubin}

Dr. Jane E. Aubin was appointed Chief Scientific Officer (CSO) and Vice-President (VP), Research at CIHR in July 2011, later renamed Research and Knowledge Translation Portfolio. As CSO, Dr. Aubin is responsible for the oversight of all scientific affairs at CIHR and provides CIHR with expert advice on matters relevant to science and technology, potential opportunities and emerging orientations and trends in the national and international health research community. As VP, Research and Knowledge Translation, she is responsible for all aspects of adjudication of grants and awards at CIHR and finally, as a member of the Scientific Council, she participates in the development, implementation, and reporting on CIHR's research and knowledge translation strategy.

Dr. Aubin's career path has included several senior academic administrative positions, including Chair of the Graduate Department of Dentistry and Director of Postgraduate Dental Education and Chair of the Department of Anatomy and Cell Biology at the University of Toronto. She is currently a member of the Faculty of Medicine at the University of Toronto where she is a Professor of Molecular Genetics and the Director of the Bone Program in the Centre for Modeling Human Disease. Dr. Aubin has been Scientific Director and CEO of the Canadian Arthritis Network of Centres of Excellence and until recently, Scientific Director of CIHR's Institute of Musculoskeletal Health and Arthritis (IMHA), specializing in arthritis, musculoskeletal, oral and skin conditions.

Dr. Aubin received a B.Sc. (Hons; Chemistry and Mathematics) and the Gold Medal in Chemistry at Queen's University in Kingston. She then completed her Ph.D. in Medical Biophysics at the University of Toronto. She later did her postdoctoral training in Molecular Biology and Biochemistry at the Max Planck Institute for Biophysical Chemistry in Goettingen, Germany. 


\section{Industry Perspective of Partnerships in Canada on Personalized Medicine}

Bettina Hamelin, Director, Research \& Development and Medical Lead, Western Canada, Pfizer Canada, and Head, Strategic Research Partnerships, External R\&D Innovation, WRD, Pfizer Inc

Strategic partnerships are a cornerstone in Pfizer's effort to deliver the medicines and vaccines that matter most to people in need across the globe. We recognize that to continue to develop groundbreaking new medicines, Pfizer needs to access the best science globally and, in turn, we are proud to offer access to our world-class research scientists, our global network of external research collaborations, and our industry-leading manufacturing and commercial capabilities. In Canada, we have fostered over the years a series of productive partnerships that leverage the great Canadian science capabilities and creative funding mechanisms to jointly develop novel IP and mutually beneficial commercialization opportunities.

Pfizer's precision medicine approach integrates clinical and molecular information to understand the biological basis of disease thus leading to better selection of disease targets and identification of patient populations that demonstrate improved clinical outcomes. Biomarkers and companion diagnostics are becoming an integral part of every drug discovery and development program at Pfizer.

Hear from Bettina Hamelin, Director Research and Development, Western Canada at Pfizer and responsible for external research partnerships in Western Canada, how Pfizer is partnering externally and how Canadian researchers might position genomics capabilities in the global pharmaceutical market place.

\section{Bettina Hamelin}

Dr. Bettina Hamelin is currently the Medical Lead and Director, Research and Development for Western Canada at Pfizer Canada Inc. In this role, Bettina manages the Western Canada Medical Affairs team and leads the development and implementation of a medical and research partnership strategy across 4 therapeutic areas and 4 provinces including public private partnerships and a range of investigator-initiated or Pfizerpartnered preclinical and clinical research efforts. As Head of Strategic Research Partnerships, Bettina is also one of the global scouts for Pfizer's
Worldwide Research and Development Outreach group, the External R\&D Innovation team. In this role, Bettina leverages Canadian science and research capabilities with the global organization by facilitating collaborations between Canadian scientists in academia or biotech and Pfizer WRD. Most recently, Bettina was asked to take on a temporary assignment as Medical Director of the Primary Care Business Unit at Pfizer Pharma AG, Germany. There, Bettina lead a large Medical Affairs team across all Primary Care Business Unit therapeutic areas for 7 months and reinforced Medical support during the prelaunch and launch phase of the novel Factor Xa inhibitor apixaban.

Prior to joining Pfizer, Bettina was tenured professor at the Faculty of Pharmacy at Laval University in Quebec City, where she ran a wellfunded research program on the pharmacokinetics and pharmacogenetics of cardiovascular drugs, and cardiovascular disease risk factors and treatment in women. From 1999 until 2004, she held Senior Scientist, then Team Leader, and lastly Director positions at Biochem Pharma/Shire Biochem to manage Shire Biochem's Drug Metabolism and Pharmacokinetics Division.

Bettina pursued a Bachelor of Science in Chemistry and a Bachelor of Science in Pharmacy in Germany as well as in the US and also holds a Doctor of Pharmacy degree from the University of Kentucky. In 2011, Bettina graduated from the Sauder School of Business at the University of British Columbia with an Executive Master of Business Administration degree with focus on Healthcare, a demanding 20 months program for leaders in the health care industry.

During her academic career, Bettina has published over 35 publications, over 85 abstracts and 5 patents. She has been actively involved in many professional associations and served as the President of the Canadian College of Clinical Pharmacy. She joined Pfizer in 2004 as a cardiovascular Regional Medical and Research Specialist with the responsibility of developing relationships and key strategic partnerships with the biomedical and research community in Quebec and the Atlantic provinces.

Bettina relocated to Vancouver in 2007 with her husband Richard and her boys, Christian and David. Bettina enjoys playing the violin and the piano, and she is an avid outdoors enthusiast alongside her husband and sons. 


\section{Challenges \\ Technologies \\ Perspective \\ in Translating Genomics \\ to the Clinic: A Funder's}

Pierre Meulien, Ph.D., President and CEO, Genome Canada

Over the past decade Canada has built a world class capacity in genomics research, which can now be applied across a number of life science sectors. The integration of genomics based technologies into the healthcare system is confronting a number of challenges reflective of the inherent lack of receptor pull in a complex system that is financially strained. It is often the case that new technologies that are proposed to those assessing them are seen as add-on costs to the system.

Genome Canada, in partnership with the regional Genome Centres and CIHR (among other funders), has launched a large $\$ 150$ million Personalised Health research program, which strives to build an important bridge between the academic research laboratories and the clinical space. This ambitious program attempts to both understand more clearly some of the challenges to be overcome and demonstrate successes that will be seen from scientific, clinical and economic standpoints to be valid contributions to the sustainability of a modern healthcare system in Canada.

The challenges to be discussed will include the following:

$\checkmark$ Development of a mature translational space where receptor capacity can be built

$\checkmark$ How to involve the private sector

$\checkmark$ Education and training of health care professionals

$\checkmark$ Maximizing the utility of e-health records

$\checkmark$ Encouraging an increased role for patients and advocacy groups

$\checkmark$ Technology assessment

\section{Pierre Meulien, Ph.D.}

Dr. Pierre Meulien was appointed President and CEO of Genome Canada in October 2010. Prior to this appointment, he served as Chief Scientific Officer for Genome British Columbia from 2007 to 2010. From 2002 to 2007, Dr. Meulien served as the founding CEO of the Dublin Molecular Medicine Centre (now Molecular Medicine Ireland) which linked the three medical schools and six teaching hospitals in Dublin to build a critical mass in molecular medicine and translational research. The Centre managed the Euro 45 Million "Program for Human Genomics" financed by the Irish government and was responsible for coordinating the successful application for the first Wellcome Trust funded Clinical Research Centre to be set up in Ireland. For over 20 years, Dr. Meulien has managed expert research teams with a number of organizations, including Aventis Pasteur in Toronto (Senior Vice President of R\&D), and in Lyon, France (Director of Research). He also spent seven years with the French biotechnology company Transgene in Strasbourg, France as a research scientist and part of the management team. Dr. Meulien's academic credentials include a $\mathrm{PhD}$ from the University of Edinburgh and a post-doctoral appointment at the Institut Pasteur in Paris. 


\title{
Thursday, June 13
}

\author{
SESSION 8:
}

\section{Interface Between Analytical Method and Formulation in the QbD World}

\section{Quality by Design (QbD) Case Study: Establishment of a Design Space for a Preservative System}

Nadia Chacra, University of Sao Paulo, Brazil

The expression "as much as necessary as little as possible" precisely defines the formulators' wish concerning the incorporation of antimicrobial agents in products. The official test to evaluate the preservative system in medicines consists in challenging the formula against specific strains of microorganisms and the determination of survivors in defined time intervals. The test requires, at least, 28 days and the extensive labor making impractical to screening new preservatives and testing its different concentrations and combinations. Thus, the conventional approach to incorporate antimicrobial agents in products does not allow establishing a design space, required in the quality by design $(\mathrm{QbD})$ environment. $\mathrm{QbD}$ is a relatively new concept introduced in 2004 as a result of the FDA's $21^{\text {st }}$ century cGMP initiative. It was defined, according ICH Q8, as a systematic approach to development that begins with predefined objectives and emphasizes product and process understanding and process control, based on sound science and quality risk management. The design space is determined by combination of experimental data and DoE (design of experiment) and is defined as the multidimensional combination and interaction of input variables, such as material attributes, and process parameters that have been demonstrated to provide assurance of quality. This case-study shows the use of DoE to determine the optimum concentration of the preservative system (space design) in the development of a fluid emulsion for eye region.

\begin{abstract}
Nadia Bou-Chacra
Professor of Pharmaceutical Technology, Faculty of Pharmaceutical Sciences, University of Sao Paulo, Brazil. Dra. Nadia Bou-Chacra holds a BS in pharmacy from the Faculty of Pharmaceutical Sciences, University of Sao Paulo, Brazil. She started her career in the pharmaceutical industry in 1986, in a global leader of eye care, Alcon Laboratories. She received her $\mathrm{PhD}$ in pharmaceutics from the same University in 1994 and she joined the faculty at the University of São Paulo in 2002. Her research interest is nanotechnologybased drug delivery and quality by design in pharmaceutical manufacturing. In 2008, she conducted a postdoctoral research under the supervision of Professor Raimar Löbenberg, Faculty of Pharmacy and Pharmaceutical Sciences, University of Alberta, entitled 'Toward Global Standards for comparator pharmaceutical products: case studies of amoxicillin, metronidazole and zidovudine in Americas. She was also a visiting scientist in 2012 at United States Pharmacopeia responsible for the project "Orthogonal analytical strategy to detect counterfeit and substandard antiTB medicines: simultaneous quantitative isoniazid and rifampicin determinations in capsules containing different excipients". She is also conducting several research projects including research projects funded by FAPESP.
\end{abstract}




\section{Solubility \& Dissolution Enhancement of Weakly Basic Compounds - Understanding Precipitation \& Supersaturation!}

Jon Mole, Executive Vice President, Sirius Analytical Inc.

This presentation will explore:

- Experimental methods for establishing different classes of precipitation behaviour

- Using precipitation behaviour to understand solubility enhancement opportunities

- How to preserve some compounds in their more soluble form

- Real-time observation of changes in crystal form of suspensions

- Applying this knowledge in small-scale dissolution studies with solubility enhancement and simulated absorption

\section{Jon Mole}

Jon Mole is Executive Vice President for Sirius Analytical Inc., Sirius' US subsidiary based in Beverly, MA and is responsible for managing and developing Sirius' business in North America.

Jon joined Sirius Analytical in 2002, after graduating from the University of Bath (UK) with a Masters degree in Chemistry.

Initially Jon provided scientific customer support on products for Solubility a! nd Permeability analysis, whilst also running samples on Sirius' inhouse instruments for our Analytical Service. He then moved into product management roles for Sirius products for $\mathrm{pKa}, \log \mathrm{P}$, solubility, dissolution and particle size/shape measurement.

Jon has installed many different instruments worldwide, provided training and support to hundreds of Sirius instrument users, and analysed over 1500 drug compounds for physchem properties with our analytical service. He has given many scientific and sales presentations around the world and regularly lectures on Sirius training courses. In 2011 he moved from the UK to the US as Executive VP where he is charged with developing Sirius business in North America and supporting customers in the US \& Canada.

\section{How to Model Supersaturation}

Michael B. Bolger, Chief Scientist, Simulations Plus, Inc., Lancaster, CA

Predictive mechanistic simulation of in vivo supersaturation and precipitation during oral absorption using experimental parameters derived from in vitro measurement is an important goal in preclinical development of NCEs as well as in generic formulation and bioequivalence. Such studies support quality by design (QbD) by facilitating an understanding of how drug properties influence absorption and bioavailability. This study evaluated several literature models for the in vitro estimation of supersaturation and precipitation to determine whether parameters derived from those studies could be used to enhance the in silico advanced compartmental absorption and transit (ACAT ${ }^{\mathrm{TM}}$ ) model and its simulation of in vivo precipitation. We evaluated supersaturation and precipitation data from the following two in vitro studies: 1) transfer of dipyridamole from low-pH simulated gastric fluid (SGF) into fasted-state and fed-state simulated intestinal fluid (FaSSIF and FeSSIF), and 2) dissolution and precipitation of AZD0865 using the stirring model and the transfer assay. Using those data, we compared the following three theoretical models of in vivo precipitation; 1) simple first-order precipitation, 2) multipleexponential first-order precipitation, and 3) mechanistic homogenous nucleation and growth. The sensitivity of input parameters for precipitation rate, nucleation rate, particle growth rate, interfacial tension, molar volume, and diffusion layer thickness, were tested to find the practical limits that explain the in vitro data. A mechanistic oral absorption PBPK model that describes the pharmacokinetics of dipyridamole and AZD0865 was developed with GastroPlus $^{\text {TM }}$ (Simulations Plus, Inc.). Direct application of a single in vitro precipitation time resulted in an exaggerated degree of precipitation for the in vivo simulation. Application of either a double-exponential precipitation ACAT model using the in vitro transfer assay results or a model of homogenous nucleation and growth using only two fitted parameters, produced good simulations of the observed clinical data both in the presence and absence of omeprazole pretreatment. 


\section{Michael B. Bolger, Ph.D.}

Dr. Bolger is Chief Scientist at Simulations Plus, Inc. He obtained a B.A. in Biology and Chemistry from UC San Diego in 1973 and a Ph.D. in Pharmaceutical Chemistry from UC San Francisco in 1978. From 1978-1980 he was an NIH Postdoctoral Fellow in pharmacology at the UC San Diego School of Medicine. For the next 23 years, he was a professor of Pharmaceutical Sciences at USC School of Pharmacy, Los Angeles, California and retired from USC in 2004. During this period he developed an interest in the computational aspects of drug design and drug development. As a faculty member at USC School of Pharmacy, his research was supported by several NIH basic science research grants and he published over 50 peer-reviewed publications. From 1989-1991 he served as a US Food and Drug Administration National Science Advisor. He has served as a reviewer for numerous scientific publications. $\mathrm{He}$ is currently Adjunct Professor of Pharmaceutical Sciences at USC. From 1987-1993 he was a founder and Director of Medicinal Chemistry at CoCensys Inc. There, he studied the chemistry and use of novel neuroactive steroids for treatment of anxiety, epilepsy, and sleep disorders. Drug candidates emanating from seven of Dr. Bolger's patents have been tested in Phase I and II clinical trials for petite mal epilepsy, sleep disorders, and migraine. Dr. Bolger programmed the first version of GastroPlus ${ }^{\mathrm{TM}}$ and currently works with a team of scientist / programmers at Simulations Plus, Inc. (Lancaster, CA) in the development of software (ADMET Predictor ${ }^{\mathrm{TM}}$ / Modeler ${ }^{\mathrm{TM}}$, MedChem Studio ${ }^{\mathrm{TM}} /$ Designer $^{\mathrm{TM}}$, GastroPlus, DDDPlus ${ }^{\mathrm{TM}}$, and MembranePlus ${ }^{\mathrm{TM}}$ ) for estimation of biopharmaceutical properties, simulations of absorption and bioavailability, automated generation QSP/AR model building, in vitro dissolution, and cell culture permeability simulation. He was elected to the rank of Fellow of the American Association for the Advancement of Science in 1996.

\section{Pharma Polymers for Solubility Enhancement}

Kai Zhuang, Senior Technical Service Representative, BASF, Tarrytwon, NY

Solubility enhancement has become an increasing important topic in the pharmaceutical industry. It is estimated that about $40 \%$ of new drug candidates are poorly water soluble and cannot be absorbed effectively. As a result, about $41 \%$ of new drug candidates fail during the development stage due to poor bioavailability. There is an increasing need for solubility enhancing tools in the pharmaceutical industry. Of the various methods investigated, the use of polymer to enhance the solubility of active ingredient and its bioavailability has shown promising results. Polymers can be used in many ways to increase the solubility of the active ingredients. Proven techniques include solid dispersions, nano-suspensions, and lipid formulations. Polymers are commonly used in these formulations as solubility enhancers, matrixes, emulsifiers, stabilizing agents, and crystalline inhibitors. New polymers have been introduced to meet the challenging demand of formulating poorly soluble active ingredients. This presentation will highlight the various techniques that polymers are used to enhance the solubility of active ingredients. Emphasis will be placed on hot melt extrusion (HME) as a promising technology to enhance the solubility for many active ingredients. Examples of polymers used in HME will be given in the presentation. The presentation will also introduce a new polymer, Soluplus ${ }^{\circledR}$, and its use in solving the solubility challenge.

\section{Kai Zhuang}

Senior Technical Service Representative, BASF, 500 White Plains Rd, Tarrytwon, NY 10591.

Kai Zhuang joined BASF Corp in 2006 as senior technical service representative where he is responsible for promoting BASF pharmaceutical excipients to the industry, helping customers in the application of BASF excipients and developing innovative applications and technologies in the areas of drug solubilization, controlled release, tablet compression and coating.

Before joined BASF, Kai was with Wyeth, where he was responsible for formulation development for new chemical entities. Kai started his career with Baxter PPI, where he worked on formulation development for injectable. Kai has a Master of Science degree in Industrial Pharmacy from St. Johns University of New York. 


\title{
Thursday, June 13
}

\author{
SESSION 9:
}

\section{Current Bioequivalence Topics}

\section{SPONSORED BY: COBALT PHARMACEUTICALS}

Highly Variable Drugs and Current Regulatory
Requirements for Establishing the
Bioequivalence

Nageshwar Rao Thudi, Ph.D., Associate Director Biopharmaceutics, Watson Pharmaceuticals Inc.

The definition of high intra-subject variability of pharmacokinetic data, proposed at the BioInternational Conference 1989 and confirmed at the 1992 Conference is as follows: 'Drugs that exhibit intra-subject variability of $>30 \%\left(\mathrm{CV}_{\mathrm{ANOVA}}\right)$ are to be classified as highly variable.'

The AAPS/FDA Workshop's (Crystal City, Arlington, VA, March 6-8, 1995) report stated that, 'For some highly variable drugs and drug products, the bioequivalence (BE) standard should be modified by changing the BE limits while maintaining the current confidence interval at $90 \%$.' The intention was to scale the BE limits based on the intra-subject variance associated with the reference formulation, yet keep the consumer risk at 5\%. This requires the estimation of intra-subject variation.

Although global harmonization is a general goal, to date, bioequivalence has not been accepted as a topic by the International Conference on Harmonization (ICH). Nonetheless, the resource and ethical concerns for highly variable drugs/products in bioequivalence are generally recognized by international regulatory agencies. It is thus useful to review the differing regulatory approaches before an informed recommendation is made on the topic. The following outlines the bioequivalence standards used in different regions:

Both US FDA and the European Agency for the Evaluation of Medicinal Products (EMEA) allow use of a reference-scaled average bioequivalence (RSABE) approach for highly variable drug products (HVDP). A reference-replicated crossover design is required to evaluate the reference intra-subject variability for use in the RSABE approach. For those HVDP that have a reference intra-subject variability of $30 \%$ or more, the RSABE approach allows the $\mathrm{BE}$ limits to expand with increase in the variability of the reference product, but the geometric mean ratio of test-to reference (point estimate) must be within the standard BE interval of $80-125 \%$. For US submission both AUC and Cmax parameters can be subjected to RSABE but for EMEA submission the RSABE approach applies only to Cmax parameter and the BE acceptance interval can be widened only to a maximum of $69.84-143.19 \%$.

In Canada, for drugs with uncomplicated characteristics, a 90\% confidence interval approach applies to AUC parameter, but not to Cmax parameter, for which only the point estimate must be within the BE acceptance range of $80-125 \%$. There are no provisions for use of a RSABE approach for Canadian submissions.

This presentation will discuss the advantages and disadvantages of the current RSABE requirements for US FDA and EMEA drug applications, and whether these requirements should be considered by Health Canada for HVDP.

\section{Nageshwar Rao Thudi}

Dr. Nageshwar Rao Thudi is currently working as Associate Director-Biopharmaceutics at Watson Pharmaceuticals, Parsippany, NJ, USA. Prior to Watson he worked at Ranbaxy Canada, Pharma Medica, Chembiotek and VIMTA Labs.

Dr. Thudi has nearly 15 years of generic as well as CRO experience in the field of Bioavailability and Bioequivalence. Dr. Thudi got his Ph.D. degree in pharmacy from the University of Jadavpur, India. Dr. Thudi has 25 publications in international peer reviewed journals. His interest is to harmonize various regulatory requirements for biowaivers and bioanalytical validations. 
At Watson he is responsible for Biopharmaceutics function for many international markets and he is responsible for designing a wide variety of $\mathrm{PK} / \mathrm{PD} / \mathrm{In}$ vitro studies.

\section{Strategies and Issues in the Design and Data Analysis of Skin Adhesion, Irritation \& Sensitization Studies for Bioequivalence Evaluation of Transdermal/ Topical Generic Patch Systems}

Keith Gallicano, Ph.D., Vice President, Scientific Affairs, Novum Pharmaceutical Research Services

Transdermal/topical drug delivery systems (TDDS, commonly called patches) are designed to deliver drug by passive diffusion through intact skin for systemic (transdermal) or local (topical) effect. These systems are formulated as either matrix or reservoir systems. A matrix system contains drug substance in a pressure-sensitive adhesive layer. Whereas a reservoir system contains drug substance in a polymer matrix that is separated from the skin by a rate-controlling membrane.

The common clinical testing requirements for a generic TDDS application in the US (FDA) are single-dose pharmacokinetic (PK) studies, skin adhesion, and skin irritation and sensitization studies. EMA submissions also require multipledose PK studies and additional clinical testing dependent on the product. Canadian (TPD) submissions will require single-dose PK and skin adhesion studies. For patches such as Lidoderm ${ }^{\mathbb{R}}$ (lidocaine) and Flector $^{\circledR}$ (diclofenac epolamine) intended for more localized sites of action, clinical endpoint studies may also be required by some regulatory agencies.

Adhesion studies can be conducted within the PK or irritation studies, or as a standalone study. The scientific preference for separate adhesion studies with simultaneous applications of test and reference products will be discussed. The different subjective rating scales recommended by the different regulatory authorities will be presented, and a more objective "dot-matrix" methodology with appropriate statistical analysis will be proposed.

Irritation and sensitization studies are typically combined into a single study and require a sample size of 200 evaluable subjects to be able to detect the probability of sensitization in at least $1 \%$ of the general population, with greater than $80 \%$ power.
The standard design for these studies will be presented.

To demonstrate non-inferiority of the test compared to the reference product with regard to the cumulative irritation and adhesion scores, the FDA recommends that the upper bound of the one-sided $95 \%$ confidence interval of the mean test product score minus 1.25 times the mean RLD score must be less than or equal to 0 . This requirement is stringent for well-adhering and low-irritating products, as the likelihood of passing becomes more difficult with the inherent high intra-subject variability that results from low mean scores. There is no statistical approach recommended by EMA or TPD for evaluation of non-inferiority in adhesion and irritation studies. Various statistical procedures for this type of data analysis, along with some real life examples, will be presented.

\section{Keith Gallicano}

Dr. Gallicano is Vice President, Scientific Affairs, Novum Pharmaceutical Research Services. He received his Ph.D. in chemistry from the University of British Columbia in 1981. In 1986 he joined the Royal Canadian Mounted Police and trained as a Forensic Chemist, specializing in the analysis and comparison of materials, such as petroleum, paint, glass, building products, headlamps and explosives, from scenes of crime. From 1988 to 1997 Dr. Gallicano was a Research Scientist in the former Bureau of Drug Research, Health Protection Branch (HPB), Ottawa, where he pursued his interests in development and validation of bioanalytical assays and in clinical pharmacokinetic studies, particularly those involving drug interactions of drugs used in HIV therapies. In 1997 he left HPB as a senior Research Scientist and Head of the Biopharmaceutics and Pharmacokinetics Section to join the Clinical Investigation Unit, Division of Infectious Diseases, Ottawa General Hospital as a clinical research scientist and the University of Ottawa as an Assistant Professor of Medicine. He returned to Vancouver in 2000 as Director, Pharmacokinetics, Axelson Biopharma Research, then moved to California in 2003 to work with Watson Laboratories, Inc. In 2012 he left Watson as Director, Biopharmaceutics, to take on his current position at Novum.

Dr. Gallicano has co-authored 73 publications, including research papers, reviews, and book chapters. He was a member of the Editorial Board of the Journal of Chromatography and the British Journal of Clinical Pharmacology. Dr. Gallicano 
has given numerous invited lectures on bioanalytical and bioequivalence issues and on pharmacokinetic and pharmacostatistical aspects of drug interactions, as well as chaired or co-chaired international meetings on these topics.

\section{Challenges with Depot Formulation Products: CRO Perspective}

Juan He, Senior Director of Pharmacometrics, BioPharma Services Inc.

Bioequivalence study of depot formulation products can be challenging and needs thorough study designs. Parallel instead crossover design is usually used due to the long absorption and elimination halflife. One of the big challenges would be the sampling schedule and caution should be used for properly capturing the Cmax (and Tmax) which is usually the most sensitive pharmacokinetic parameter to demonstrate bioequivalence, since the absorption phase is very slow. Also, the high intraand inter-subject variability of the absorption is common for depot formulation so lead to a large sample size for the biostudy and potential multiple dosing groups. The study can last few months and can even exceed 4 or 5 months, therefore the dropout can be a significant factor to impact on the study outcome. This presentation will highlight some of the major challenges and provide some case example of bioequivalence study of depot formulation such as the length of sampling schedule, the sample size and recruitment.

\section{Juan He}

Juan is currently a Senior Director of Pharmacometrics at BioPharma Services Inc. Juan received her MSc.Phm. from the University of Toronto. She then worked at Eli Lilly Canada for 5 years in Bioanalytical and Pharmacoeconomics areas which including the drug Evista. Subsequently, she has been working in the clinical research mainly focus on phase I and $\mathrm{BA} / \mathrm{BE}$ trials for over 12 years in two CROs. Juan has contributed greatly to the life cycle of completed clinical trial product from a CRO perspective including study design, protocol development, data analysis, as well as the study report. She was also involved in several GPhA working groups previously and AAPS focus groups currently.

\section{Recommendations for Improving Quality of Bioequivalence Data Submitted to ANDAs in the US}

Barbara Davit, Merck \& Co., Rahway, NJ

The Divisions of Bioequivalence in FDA's Office of Generic Drugs (OGD) currently receive over 900 Abbreviated New Drug Applications (ANDAs) and over 1000 associated amendments for review per year. Most ANDAs contain one or two in vivo bioequivalence (BE) studies as part of the submission. BE submissions usually consist of a clinical section, a bioanalytical section, and a statistical section. The clinical and analytical portions of in vivo BE studies are often conducted at Contract Research Organizations (CROs). In 2011, about $1 / 2$ of these CROs were located in North America, and about $1 / 2$ were located in Asia. FDA's Office of Scientific Investigations (OSI) is responsible for on-site inspections of the clinical and bioanalytical studies. The objective of this presentation will be to briefly discuss the process whereby OGD asks OSI to conduct inspections, with an emphasis on inspection outcome. There will also be a discussion of ways in which applicants can improve the clinical, bioanalytical, statistical, and other portions of the ANDA submission. Submission of high-quality applications will shorten the time needed for regulatory review, and hopefully expedite the marketing approval decision.

\section{Barbara M. Davit}

Barbara M. Davit recently joined Merck \& Co. as an Executive Director in the Product Value Extension group, where she is responsible for conducting clinical bioavailability and bioequivalence studies primarily in early drug development. Prior to joining Merck, Dr. Davit worked at the Center for Drug Evaluation and Research at the US-FDA, where she was Director of the Division of Bioequivalence II in the Office of Generic Drugs. Dr. Davit holds a B.S. in Chemistry from Georgian Court University, a Ph.D. in Nutrition Science from University of California, Davis, and a J.D. from George Mason University School of Law. Her graduate work focused on ADME of water-soluble vitamins, and she trained in pharmacokinetics as a Fellow at the California Primate Research Center. After several years in the CRO industry, Dr. Davit joined the USFDA in 1991 as a pharmacology reviewer, and, throughout her US-FDA tenure, ascended to positions of increasing responsibility in the Office of 
Clinical Pharmacology and Office of Generic Drugs. Dr. Davit has written numerous articles and book chapters on various bioequivalence-related topics, and is regarded as a national and international expert in bioequivalence issues. 


\section{Friday, June 14}

\section{Plenary Lecture 6}

\section{Simultaneous Translation: Opportunities and Challenges for Next Generation Pharmacogenomics}

Corey Nislow, Ph.D., Associate Professor, Department of Pharmaceutical Sciences, University of British Columbia, Vancouver, BC

Recent advances in DNA sequencing, high throughput screening and bioinformatics have combined to create a unique opportunity in the life sciences in which genotypic information can be used by health care practitioners to directly impact patient health. For example, the availability of fully sequenced genomes, in large numbers, has facilitated development of systematic methods to probe gene function and to explore the role of rare variants. Combined with bioinformatics and chemi-informatic tools, this information is being used to better understand drug mechanism of action and to improve on the application of existing therapeutics by tailoring treatments. In parallel, in the laboratory, systematic screens in model organisms have allowed for comprehensive interrogation of drug action in context and in vivo and their dependence on the genetic make-up of the organism tested. The result is a positive, iterative cycle in which advances in basic bench science are being translated to the bedside and, equally importantly, our improved appreciation of patient responses informs the design of experiments to test these observations. I will discuss the systematically screening efforts of our team against several thousand drugs and drug-like compounds in vivo, highlighting the influence of genetic background on drug response and offer perspective on how we are combining these data with whole genome and whole exome analysis for precision medicine.

\section{Corey Nislow}

Corey Nislow completed a Doctor of Philosophy in Cell and Molecular Biology at the University of Colorado and was an American Cancer Society Postdoctoral Fellow. He served as group leader at MJ Research and Cytokinetics, Inc. and as a Senior Genome Scientist at Stanford University. Prior to joining UBC, Dr. Nislow was Associate Professor at the University of Toronto. $\mathrm{He}$ is an Associate Professor and Director of the Pharmaceutical Sciences Sequencing Centre (PSSC).

His lab employs genomics and develops biotechnology tools to address you know what you fundamental and applied biological questions including parallel genome-wide chemical genomic screens in yeast and mammalian cells using gene knockout and gene knockdown technology. The research team uses Next Generation Sequencing to performing whole genome and whole exome sequencing as well as developing pathway and organelle-specific sequencing assays.

The questions his research addresses all share the goal of understanding how the cell takes him instructions in its DNA, i.e. its genotype, and manifests that information into phenotype in both normal and deranged circumstances. For example, how can environmental and drug stress elucidate the condition-specific function of genes? How does the structure and architecture of the genome, manifested as chromatin, influence gene expression and cell physiology? And finally, how can one apply the tools developed for model organisms to human biology? 


\section{Friday, June 14}

\section{SESSION 10:}

\section{Personalized Medicine and the Clinic}

\section{Setting the Stage - Bringing Personalized Medicine into the Oncology Clinic}

Karen A Gelmon, MD FRCPC, Professor Medicine, University of British Columbia, Medical Oncologist, BC Cancer Agency, Vancouver Cancer Centre

The term 'personalized medicine' has been used for over a decade to emphasize the need for tailoring treatments to the individual if cancer outcomes are going to improve. With the advent of genomics and molecular pathology, the opportunity to provide targeted therapy to tumours which express specific molecular markers has developed. With this excitement major gains have been made in a number of malignancies, including breast, lung, colorectal, prostate, ovarian and other cancers as well as melanomas, sarcomas and lymphomas. Many of our targeted therapies are providing both more effective and in some cases, less toxic treatments. But with increased interrogation of tumours the heterogeneity of malignancy has become more apparent, explaining some of the resistance that develops causing treatment failure. With sequencing technologies, these variations are even more apparent making apparent the need for individualized or personalized medicine but also highlighting the issues. Challenges exist for the treatment of the individual in the clinic, for developing new drugs, for the design of clinical trials and for regulatory approval of new agents. As well as tumour variability, we also are now recognizing the variability of the host. Pharmacogenomics leads to a new understanding of the patients' response to treatment which also adds to the complexity of bringing personalized medicine to the clinic. At the BC Cancer Agency we have a number of initiatives that are trying to bring personalized medicine to the clinic and these initiatives with their challenges and successes will be discussed. Population based care and guidelines have brought us success. The next step to bring personalized medicine across the population is challenging.

\section{Karen A Gelmon}

Dr. Gelmon is a Professor of Medicine at the UBC and a Medical Oncologist at the BCCA, combining clinical and translational research. She is Co Chair of the Breast Site Committee for the NCIC Clinical Trials Group and a member of the NCI Breast Steering Committee and of the BIG (Breast International Group) Advisory Group. She sits on the NCIC-CTG IND executive and is a past Chair of this committee. She is Clinical Leader of Experimental Therapeutics department at the BCCA. She currently sits on the International Advisory Board of The Lancet, The Oncologist and Clinical Breast Cancer. She is Co Chair of the Scientific Advisory Board (SAB) of the Ontario Institute of Cancer Research (OICR) and a member of the SAB for the Susan Komen Foundation. She has been track chair for the ASCO Breast program and Education Committee. She is an active teacher interested in education of health care professionals and the public and has published extensively. She has been a member of the Board of the $\mathrm{BC}$ Cancer Foundation, on the Medical Advisory Board of the $\mathrm{BC} /$ Yukon Chapter of the Canadian Breast Cancer Foundation and sits on the board of Rethink Breast Cancer. She was the recipient of a YWCA Woman of Distinction award. She is the mother of two daughters and is active on volunteer boards for the arts and community in Vancouver. 


\section{Molecular Characterization of Cancer in the Clinical Setting - Translation and Applications}

Lillian L. Siu, MD, FRCPC, Professor of Medicine, University of Toronto, Cancer Care Ontario Research Chair, Experimental Therapeutics, Medical Oncologist, Co-Director of Drug Development Program, Princess Margaret Cancer Centre

The current diagnostic and therapeutic paradigms in oncology are primarily based on histopathological information, supplemented by a limited panel of molecular profiling tests in some tumor types, such as HER2 testing in breast cancer and KRAS genotyping in colorectal cancer. In the cancer genomics era, it seems likely that evaluating drug efficacy against tumors defined by a combination of histopathology and molecular genetic profiles will result in a greater therapeutic gain. Given that the definition of molecular subsets will stratify tumor types into smaller subgroups, and that the same or related genomic aberrations can exist in multiple tumor types, innovation and transformation in clinical trial designs are necessary to help address this impending paradigm shift in cancer treatment decisions. Many cancer groups have already initiated large-scale institution-based or country-based molecular profiling programs. The results of genomic characterization are being utilized in realtime to assign therapy to approved drugs or to direct patients to specific clinical trials of investigational agents targeting the genotypes of interest. A tumorbased approach (e.g. BATTLE, I-SPY2 and FOCUS-4 trials) requires access to different molecularly targeted agents, which can be difficult unless there is cooperation and collaboration of multiple industrial sponsors. A histologyindependent, genomics-based approach is of interest but requires screening of large numbers of patients especially if mutations are uncommon in the selected tumor types for inclusion. Furthermore, it is likely that the functionality varies for the same aberration in different tumor types, rendering it insufficient to interpret clinical trial results under one context. This presentation will describe some of the potential clinical trial designs and discuss their advantages as well as pitfalls. Lastly, the existence of intratumor heterogeneity and clonal evolution further complicates diagnostic and therapeutic assessments in the genomics era. The reliability of archived, remote primary tumor specimens to guide current treatment selection has been questioned. Yet, repeated procurements of tumor samples via biopsies or other procedures from multiple regions are not clinically practical. Advances of serial, non-invasive molecular characterization using circulating free nucleic acids or tumor cells are attractive, as are modern radionuclide-based molecular imaging, to help tackle temporal and spatial heterogeneity. This presentation will address some possible solutions to evaluate tumor heterogeneity and clonal evolution in the clinic.

\section{Lillian L. Siu, MD, FRCPC}

Dr. Lillian Siu is a senior medical oncologist at Princess Margaret Cancer Centre, and a Professor of Medicine at the University of Toronto. Dr. Siu is the Director of the Phase I Program and Co-Director of the Robert and Maggie Bras and Family Drug Development Program. Dr. Siu currently holds a Tier I Cancer Care Ontario Chair in Experimental Therapeutics. She serves on the Board of Directors for the American Society of Clinical Oncology for 2012-2016. She is the Principal Investigator of a phase I cooperative agreement U01 award sponsored by the United States National Cancer Institute. In addition to her active research in early phase clinical trials, Dr. Siu has been leading genomics initiatives in the area of personalized cancer medicine at the Princess Margaret Hospital.

Internationally, Dr. Siu was the recipient of the US NCI Michaele C. Christian Award in Oncology Drug Development in 2010. Dr. Siu was the ASCO Conquer Cancer Foundation Grants Selection Committee Chair in 2009-2010. Dr. Siu was the Chairperson of the AACR Education Committee for the 2012 Annual Meeting. She has published over 160 peer-reviewed manuscripts, and is currently an editor for the Journal of Clinical Oncology and Cancer Discovery. 


\section{Implementing Personalized Cancer Medicine in the Clinic}

Richard L. Schilsky, MD, FASCO, Chief Medical Officer, American Society of Clinical Oncology

The potential rewards and significant challenges of implementing personalized cancer care are becoming clear as we strive to incorporate information on the molecular profile of tumors into clinical decision-making. At the present time, developing a personalized medicine plan for a patient with cancer requires interrogation of a tumor biopsy for "actionable" molecular aberrations that can direct a specific therapeutic approach. Few guidelines exist regarding the minimum standards for tissue acquisition, handling, preservation, transport, and storage to insure that each patient has a specimen of suitable quality available to guide their medical care. Professional organizations of pathologists are well positioned to issue such guidelines as they possess the necessary expertise and influence to insure adoption by the pathology community. Beyond standards regarding tissue acquisition, clinical practice guidelines are necessary that specify the molecular workup of tumors, including the relevant molecular aberrations, the appropriate testing platforms, the definition of positive and negative test results, reporting standards, and a description of the limitations of the test. In the United States, such testing is typically done by hospital or commercial laboratories and is regulated by the Food and Drug Administration (FDA) or the Center for Medicare and Medicaid Services (CMS) under the terms of CLIA. Physicians often struggle to find a suitable lab that performs the appropriate tests with acceptable analytical validity and turnaround time. By contrast, France, under the auspices of its National Cancer Institute, has implemented 28 regional molecular genetics testing centers that perform necessary molecular tests on tumor specimens for cancer patients throughout the country. Such centralized approaches have the potential to insure widespread access to standardized tests of acceptable quality, to provide uniform decision support tools to physicians to aid interpretation of test results, and to enable the capture of information on test utilization and patient outcomes that can inform both practice guidelines and healthcare policy.

While it remains to be proven conclusively that using molecular profiles to guide therapy produces superior patient outcomes, patients and physicians are increasingly interested in using such information to make clinical decisions. Drugs that target specific molecular aberrations might be available in a number of scenarios, including use within the labeled indication, off-label use of a marketed product, access to a drug within a clinical trial, or even compassionate use of a drug that is going through regulatory review. Reimbursement for offlabel use of expensive targeted therapies is a potential obstacle to patient access that could be addressed through innovative reimbursement models such as the Coverage with Evidence Development model available through CMS, wherein CMS agrees to reimburse the intervention if certain data collection goals are met that document the impact of the intervention on physician decision making or patient outcomes.

Underpinning all aspects of personalized cancer medicine must be sophisticated informatics systems that harness information from diverse sources to build rapid learning systems that both collate data and use sophisticated algorithms to learn from each patient. The CancerLinQ rapid learning system being developed by ASCO is one example of such a tool that has the potential to revolutionize how all stakeholders in the cancer community assemble and use information obtained from patients treated in real-world settings to guide clinical practice, regulatory decisions, and healthcare payment policy.

Richard L. Schilsky, M.D.

Dr. Schilsky earned his M.D. from the University of Chicago Pritzker School of Medicine in 1975. Following a residency in Internal Medicine at the University of Texas Southwestern Medical Center and Parkland Memorial Hospital, he received training in Medical Oncology and Clinical Pharmacology at the National Cancer Institute from 1977 to 1981. He then served as Assistant Professor of Medicine at the University of Missouri-Columbia School of Medicine from 1981-1984 when he returned to the University of Chicago. At the University of Chicago, Dr. Schilsky rose to the rank of Professor of Medicine (tenured) and served as Director of the University of Chicago Cancer Research Center (1991-99), as Associate Dean for Clinical Research (1999-2007) and as Chief of the Section of Hematology-Oncology (2009-2012). From 1995-2010, Dr. Schilsky also served as Chairman of the Cancer and Leukemia Group B, an NCI-sponsored national cancer clinical trials group.

An international expert in gastrointestinal malignancies and cancer pharmacology, he has 
served on a number of peer review and advisory committees for the NCI including as a member and chair of the NCI Board of Scientific Advisors and as a member of the Clinical and Translational Research Advisory Committee. Dr. Schilsky also served as a member and chair of the Oncologic Drugs Advisory Committee of the Food and Drug Administration. Dr. Schilsky has served as a member of the Board of Directors of the American Society of Clinical Oncology (ASCO) and of the Conquer Cancer Foundation of ASCO and as ASCO President 20082009. Effective February 28, 2013, Dr. Schilsky assumed responsibilities as Chief Medical Officer of ASCO.

\section{Using Functional Imaging and Novel Tracers to Accelerate Personalized Treatments}

Francois Benard, MD, FRCPC. BC Leadership Chair in Functional Cancer Imaging, UBC and $\mathrm{BC}$ Cancer Agency

Various imaging techniques are routinely used in the management of cancers for diagnosis, staging and treatment response monitoring. In recent years, numerous radiopharmaceuticals and imaging methods have been developed to probe the presence of various receptors and enzymes expressed in cancer cells or their surrounding microenvironment. Combined with classical morphological imaging techniques such as computed tomography and magnetic resonance imaging, radiolabeled probes offer unique opportunities to non-invasively detect the presence of molecular targets of interest in primary tumours and across metastatic sites. This provides unique opportunities to obtain in vivo phenotypes that can be used to stratify patients in various prognostic subgroups. In addition, many radiotracers are highly sensitive to cellular events that occur following therapy, and can provide rapid assessment of response that can enable physicians to rapidly alter treatment decisions based on the functional tumour response. It is envisioned that the combination of genomic predictors of drug sensitivity, combined with rapid response assessment will ultimately lead to improved care by limiting exposure to ineffective treatments that can cause significant undesirable effects.

\section{Francois Bénard}

Dr François Bénard completed his medical degree and a specialization in nuclear medicine at the Université de Sherbrooke. He obtained his research training in cancer imaging and positron emission tomography at the University of Pennsylvania. Upon his return to Canada, he started a clinical and research program in cancer imaging at the Universite de Sherbrooke and the first publically funded clinical PET imaging program in Canada. His research interests focus on the development of novel imaging probes and methods to improve the diagnosis and treatment response evaluation of cancer, with a particular interest on breast cancer. His research has been supported by the Canadian Institutes of Health Research, the National Sciences and Engineering Research Council, the National Institutes of Health and the Canadian Breast Cancer Foundation, among others. After relocating to British Columbia in 2008, Dr Bénard is now a Professor in the Department of Radiology at the University of British Columbia and a Distinguished Scientist at the BC Cancer Agency. He holds the BC Leadership Chair in Functional Cancer Imaging at UBC and BCCA, and is the Head of the Division of Nuclear Medicine in the Department of Radiology at UBC. 


\title{
Friday, June 14
}

\author{
SESSION 11:
}

\section{The BC Personalized Medicine Initiative}

\section{The BC Personalized Medicine Initiative}

Pieter R. Cullis, Department of Biochemistry and Molecular Biology, University of British Columbia, Vancouver

The advent of healthcare based on the unique molecular makeup of each individual and their disease, commonly termed "personalized medicine", will improve the safety, efficiency and effectiveness of healthcare and has potential for reduced per capita costs and a dramatically improved patient and provider healthcare experience. The $\mathrm{BC}$ Personalized Medicine Initiative (BCPMI) is an umbrella organization of the personalized medicine stakeholders and resources in $\mathrm{BC}$ that has the overarching mission of introducing technologies for personalized care into the $\mathrm{BC}$ health care system. The BCPMI will implement personalized medicine approaches into lead communities in a project-byproject manner. Projects will be sourced from advances in personalized medicine world-wide as well as through consultation with patients and health care practitioners. Projects will be prioritized on the basis of medical need, cost savings and tractability in consultation with Healthcare Authorities and the BC Ministry of Health. Project staff and facilities will be resourced from BC's existing technological, clinical testing and population delivery infrastructure. The BCPMI will manage these projects, focusing primarily on translation and implementation.

Near term deliverables of the BCPMI will include development and implementation of project selection processes, introduction of training programs for using genomic data to inform drug prescription practices as well as development of policy guidelines regarding handling of genomic information in BC. Intermediate term deliverables will be implementation of personalized medicine practices in lead communities, outcome assessments will determine whether full implementation across the $\mathrm{BC}$ health sector is warranted. In addition to province-wide implementation of validated personalized medicine practices, long term deliverables will be methods for addressing the social and ethical issues implicit in the introduction of personalized technologies into healthcare, the establishment of $\mathrm{BC}$ as an internationally recognized centre for the practice of personalized medicine and exploitation of the commercial potential of personalized medicine to bring economic benefits to BC.

\section{Pieter R. Cullis, Ph.D.}

Dr. Cullis and co-workers have been responsible for fundamental advances in the generation, loading and targeting of liposomal nanoparticulate (LNP) systems for intravenous delivery of conventional and genetic drugs. This work has contributed to three LNP products that have been approved by regulatory agencies in the U.S. and Europe for the treatment of cancer and its complications and five more that have finished Phase I clinical studies. Dr. Cullis cofounded The Canadian Liposome Company, Inex Pharmaceuticals (now Tekmira Pharmaceuticals), Northern Lipids Inc., Lipex Biomembranes Inc., and, most recently, AlCana Technologies and Precision NanoSystems. In addition, he co-founded and was Scientific Director of the Centre for Drug Research and Development (CDRD) 2004-2010. He has published over 290 scientific articles and is an inventor on over 40 patents. Dr. Cullis has received many awards, including the B.C. Science Council Gold Medal for Health Sciences in 1991, the Alec D. Bangham Award for contributions to liposome science and technology in 2000 and the B.C. Biotechnology Association award for Innovation and Achievement in 2002. He was elected a Fellow of the Royal Society of Canada in 2004, received the Leadership Award of the Canadian Society of Pharmaceutical Scientists in 2010 and was awarded the Prix Galien, Canada's premier prize for achievements in pharmaceutical R\&D, in 2011. 


\section{Implementation of Pharmacogenomics into Clinical Care Decision Making in BC}

Martin Dawes, MB.BS, PhD, DRCOG, FRCG. Royal Canadian Legion Professor \& Head for the Department of Family Practice at University of British Columbia

A family physician will diagnose 450 separate diseases in one year out of a total of 2,500 diagnoses. They will initiate therapy using 800 different drugs and prescribe a total 20,000 prescriptions per year. Initiation of therapy is complicated by the high prevalence of multimorbidity, multiple medications, and biophysical, dietary and alcohol variations. The knowledge needed to be a safe effective prescribing is so different from 50 years ago yet the technology and decision aids for prescribing in BC has hardly changed at all. With the lack of complex decision aids, and so few physicians using computerized order entry or electronic medical records it is not surprising that $12 \%$ of emergency room visits are due to drug adverse events. It has been estimated that this might be costing BC $\$ 49$ million annually. It is perfectly possible to have an effective clinical decision support tool that incorporates certain key features, and a panel of a several SNP's that would substantially reduce this iatrogenic problem. The Example of Warfarin has been tested in primary care and found to be feasible and randomized controlled trials are promising. The example of warfarin is useful as the metabolism of warfarin is significantly affected by two SNP's. Algorithms for control of this highly effective but potentially lethal commonly prescribed drug are available and very effective, and have been adjusted to incorporate this SNP information.

Examples of more complex prescribing support systems have not been adopted as they generally have interfered with the physician workflow rather than enabling it. The lack of clear options and costs for alternative therapeutic choices, an inability to identify NNT for outcomes, and the inability to display risk benefit trade offs to patients are all issues of previous systems that our team is addressing. Without an effective prescribing support system that includes pharmacogenomics results the harm and cost will only increase.

\section{Martin Dawes}

Martin Dawes is the Royal Canadian Legion Professor \& Head for the Department of Family
Practice at University of British Columbia since 2010. He was a family physician in Oxford starting practice in 1983. In 1992 following the completion of his $\mathrm{PhD}$ on weight gain in pregnancy, he helped develop a multi-disciplinary Masters programme in Evidence Based Health Care. He ran an NHS R\&D funded 10,000 patient cohort study on ambulatory blood pressure monitoring. In 2000, Prof Dawes became the Director of the UK Centre for EvidenceBased Medicine in Oxford. He moved to McGill University as the Head of the Department of Family Medicine in 2002. Prof Dawes is currently involved in multiple research projects including genomics, lifestyle interventions to prevent diabetes, stroke risk factors, colorectal cancer screening, and guidelines in primary care. He is program chair for the North American Primary Care Research Group, the department heads representative on the section of researchers of the College of Family Physicians, and on the steering group of the $\mathrm{BC}$ Personalized Medicine Initiative.

\section{Clinical Research in BC: Inegration and Synergizing Across the Clinical Research Spectrum}

Jim Russell, Professor, Department of Medicine, University of British Columbia, Vancouver

British Columbia Clinical Research Infrastructure Network (BCCRIN) was formed in April 2010 and aims to increase the quality, quantity and funding of clinical research in BC. BCCRIN's strategy focuses on several key areas: contract harmonization, professional development, quality systems, research methodology and technology, and business development. BCCRIN encompass both investigator-initiated clinical research and industrysponsored clinical trials. BCCRIN will maximize BC's current clinical research by focusing on six priorities: (i) a strategy for increased, faster patient recruitment and retention, (ii) systems that expedite clinical trials (i.e. faster, harmonized contract negotiations) (iii) professional development and methodological and technological support for researchers (iv) innovative trial design, technology, and science (adaptive trials, genomics, proteomics and personalized medicine), (v) better communication in $\mathrm{BC}$ and (vi) market externally to promote $\mathrm{BC}$ as a premier location for clinical trials aiming to increase investment by industry and other 
organizations.

Meetings with research leaders have lead to broad discussion and from that, five priority themes have emerged: 1. seamless vertical integration of clinical research processes across $\mathrm{BC} ; 2$. horizontal integration of clinical networks of health; 3 . focused on conditions of priority to the $\mathrm{BC}$ Ministry of Health; 4. for prevention of disease progression and complications; 5. while achieving cost savings for $\mathrm{BC}$.

BCCRIN's areas of scientific excellence are: 1 . Systematic literature reviews, evidence synthesis, \& decision modeling - foundational to relevance; 2 . Permission to contact - foundational to recruitment; 3. Registries \& clinical networks integrated with administrative databases (e.g. propensity scoring); 4 . Innovative trial design - Bayesian adaptive, pragmatic and policy trials; 5. Knowledge translation into practice; and 6. Health economics. I will present global developments in clinical research and the very recent results of a study of the economic impact of clinical research on the economy of $\mathrm{BC}$.

\section{James A. Russell, AB, MD, FRCPC}

Dr. Russell is a Professor of Medicine at the University of British Columbia (UBC), Principal Investigator in the James Hogg Centre for Cardiovascular and Pulmonary Research at St. Paul's Hospital (SPH), and a member of the UBC and SPH Division of Critical Care Medicine, all in Vancouver, BC, Canada.

Dr. Russell has over 350 publications and is on the Editorial Board of 5 journals. The two major current themes of his research are (1) the genomics and pharmacogenomics of septic shock and (2) vasopressin in septic shock. Dr. Russell's clinical research success in sepsis was recognized in an invited review in the New England Journal of Medicine (Russell JA. Management of sepsis. N Engl J Med 2006; 355 (16): 699 - 713.) Leading the VASST trial, he found that vasopressin decreased mortality in patients who had less severe septic shock ((Russell JA, et al. N Engl J Med 2008; 358: 877 - 887) and discovered a novel interaction of vasopressin infusion, corticosteroid treatment and mortality of septic shock (Russell et al. Crit Care Med 37(3):811-818, 2009.) The VASST study is cited in the 2008 and 2012 international sepsis treatment guidelines.

1. Genomics and Pharmacogenomics of Septic Shock: We study single nucleotide polymorphisms (SNP's) of key coagulation, inflammatory and innate immunity genes. We have found significant relationships of SNPs of protein C, IL-6, IL-10, vasopressinase (LNPEP), angiotensin associated protein (AGTRAP) and fibrinogen with increased risk of death. In contrast, genetic variants of key innate immune genes CD14, MBL, TLR-2 and TLR1 are associated with increased risk of severe infections (sepsis). We published a novel methods paper describing our multicentre 18,000 patient case matched study of genomic biomarkers for prediction of improved response to activated protein $\mathrm{C}$. We are doing GWAS studies in septic shock now.

2. Vasopressin in Septic Shock. We have published reviews, retrospective, prospective clinical and animal model studies of vasopressin in septic shock. I was Principal Investigator of a CIHRfunded multicentre, randomized controlled trial of vasopressin vs. norepinephrine in septic shock (VASST; Russell JA, et al. N Engl J Med 2008; 358: 877 - 887). We found that vasopressin decreased mortality in patients who had less severe septic shock. Polymorphisms of vasopressinase (LNPEP) were associated with increased clearance of vasopressin and increased mortality in septic shock. (Chest 139(5): 1042-1049, 2011). We continue studies of efficacy and safety of vasopressin and use of biomarkers to predict response to vasopressin.

\section{The Potential for Value for Money with Pharmacogenomics}

Carlo Marra, Faculty of Pharmaceutical Sciences, UBC, Vancouver, BC

Health care costs are increasing. Few health technologies have the potential to improve both health status and save costs to society. In my presentation, I will examine personalized medicine through the lens of sustainability and potential to reduce health care costs.

\section{Carlo Marra}

Dr. Carlo Marra completed a Bachelor of Science in Pharmacy at the University of British Columbia (UBC), a Doctor of Pharmacy at UBC, and a Doctor of Philosophy in Health Care and Epidemiology at UBC. Dr. Marra also completed a post-doctoral fellowship at the Arthritis Research Centre of Canada.

Dr. Marra is a Professor in the Faculty of Pharmaceutical Sciences at UBC. To read Dr. Marra's full biography, see UBC Pharmacy website. 


\section{Physician Education - An Important Factor for the uptake of Pharmacogenomics}

Jan Friedman, Department of Medical Genetics, UBC, Vancouver, BC

[Abstract not available]

\section{Jan Friedman}

Dr. Jan Friedman is a Professor of Medical Genetics at UBC. He is a clinical geneticist who holds an MD degree from Tulane University and $\mathrm{a} \mathrm{PhD}$ in Genetics from the University of Washington. Dr. Friedman's research has led to seminal advances in improving the diagnosis of neurofibromatosis (NF) by enumerating the complex and variable spectrum of its clinical features, and in formulating recommendations for genetic and clinical diagnosis that have led to enhanced standards of patient care. His key research discoveries of novel molecular and cellular hallmarks that distinguish types of neurofibromas, benign tumours that typically arise in these patients, are providing new insights into the pathogenesis and progression of NF. In the past decade, Dr. Friedman has been a pioneer in the development and application of cytogenetic and genomic tools to understand the genetic causes and clinical consequences, and improve diagnosis of intellectual disability syndromes. Dr. Friedman is also a recognized expert in teratology, with his recent focus on determining the risk for birth defects arising from maternal anti-depressant use during pregnancy which provides critical information that is essential for the development of regulatory guidelines for these medications. Dr. Friedman has won 17 awards for his research and several teaching awards. He has participated in many committees and strategic advisory groups at UBC and externally. Dr. Friedman has published more than 230 peerreviewed papers and numerous articles, book chapters and reports. Over the past 10 years, he has given more than 50 invited presentations. 


\title{
Poster Session 1
}

\author{
Tuesday, June 12 at 6:00 PM
}

through

Wednesday, June 13 afternoon coffee break 


\section{CSPS - Poster Session 1}

\section{Tuesday to Wednesday, June 11-12}

\section{Biomedical Sciences}

\section{Effect of Protein Kinase Inhibitors on the Activity and Expression of P-glycoprotein Drug Efflux Transporter}

Ruth M. Habte, Zhizhi Sun, Donald W. Miller. Department of Pharmacology and Therapeutics, Faculty of Medicine, University of Manitoba.

Purpose: Expression of P-glycoprotein (Pgp) drug efflux transporter in normal cells such as the brain endothelial cells that form the blood-brain barrier (BBB) has an important protective function limiting the exposure of the brain to potential neurotoxins. Recent studies demonstrating that Pgp can efflux beta amyloid from the brain, coupled with the reports of reduced expression and activity of Pgp in Alzheimer's and Parkinson's Disease, respectively support the important protective role of Pgp in the BBB. In addition, Pgp expression in the BBB also restricts the brain penetration of a wide variety of drugs. While much effort has been directed at identifying agents that can modulate Pgp function through inhibition of transporter activity or induction of Pgp expression through nuclear receptor activation, little is known about the impact of protein kinases on Pgp activity. The objective of this study was to perform an initial screening of a chemical library containing 360 Protein Kinase Inhibitors (PKIs), covering over 30 kinase families, to identify those particular kinase pathways that modulate Pgp activity and expression.

Methods: Studies were performed in MDCKMDR1 and MDCK-wt cells using accumulation of Rhodamine-123 (R123) as an index of Pgp functional activity. Accumulation studies using R123 were either done following acute (30-min) or chronic (24-hr) exposure to the various protein kinase inhibitors. Screening "hits" were defined as compounds altering R 123 exposure by $25 \%$ or more. In-cell westerns were performed on the hits from the chronic exposure studies to determine potential alterations in Pgp expression.

Results: There were 29 hits observed following acute exposure to the PKIs and 33 hits from the chronic exposure screening. Of the 29 hits observed in the acute functional study, only one was also a hit in the chronic functional studies. Furthermore, of the 33 PKIs that altered Pgp function in the chronic exposure screen, 4 PKIs caused an increased expression of Pgp while 1 PKI resulted in a decreased expression.

Conclusion: The present study identified several protein kinase pathways, that when inhibited with selective PKIs, could alter Pgp activity in MDCKMDR cells. As only 5 of the chronic exposure PKIs identified produced alterations in Pgp expression, the majority of the PKIs appear to be altering Pgp activity without changing expression levels of the transporter. These studies suggest that Pgp activity can be modulated with selective PKIs and that these agents may represent a new avenue for altering drug efflux transporter activity in target tissue.

Funds were provided by NSERC and University of Manitoba Graduate Studies.

\section{A Novel, Biocompatible and Multivalent Macromolecular Reversal agent for Clinically available Parenteral Anticoagulants}

Manu Thomas Kalathottukaren ${ }_{1}$, Rajesh A. Shenoi ${ }_{1}$, Benjamin F.L. Lai, ${ }_{1}$ Donald E. Brooks ${ }^{1,2}$, Cedric J. Carter $^{1}$, Louise A .Creagh ${ }^{3}$, Charles A. Haynes ${ }^{3}$ and Jayachandran N. Kizhakkedathu ${ }^{1,2}$.

Centre for Blood Research, Department of Pathology and Laboratory Medicine ${ }^{1}$, Department of Chemistry $^{2}$, and Department of Chemical and Biological Engineering ${ }^{3}$, University of British Columbia, Vancouver BC, Canada

Purpose: Parenteral anticoagulants such as unfractionated heparin (UFH), low molecular weight heparins (LMWHs) and fondaparinux play a vital role in the treatment and prophylaxis of thromboembolic disorders. In spite of well-known bleeding complications of anticoagulation therapy, 
high dose of UFH is administered to patients undergoing major invasive surgeries. Consequently, heparin reversal is a carefully monitored and mandatory post-operative procedure. Currently, protamine sulphate (PS) is the only approved UFH antidote. However, cardiovascular adverse reactions of PS and ineffectiveness in completely neutralizing LMWHs and fondaparinux are some major limitations. Therefore, there is an imperative need for a safe, effective and universal reversal agent for clinically available parenteral anticoagulants which would eventually reduce dependence on PS.

Methods: Polymeric antidotes were developed by modifying hyperbranched polyglycerol core with binding groups which elicit positive charges at physiological $\mathrm{pH}$ and polyethylene glycol chains to avert non-specific interaction with blood components. Antidotes were characterized by gel permeation chromatography, nuclear magnetic resonance and conductometric titrations. UFH and LMWHs neutralization by polymeric antidotes and biocompatibility was assessed by performing activated partial thromboplastin time assay in anticoagulated and normal human platelet poor plasma respectively. Biocompatibility was also assessed by performing erythrocyte aggregation, hemolysis and complement activation assays. Thromboelastography (TEG) and chromogenic factor Xa assay were performed to investigate the fondaparinux neutralization capability of antidotes in human whole blood and platelet poor plasma respectively. The thermodynamics of binding interactions between cationic polymeric antidotes and fondaparinux were studied by Isothermal titration Calorimetry (ITC).

Results:_Developed antidotes completely abrogated the in vitro anticoagulation effects of UFH and LMWHs over a broad concentration ranging from $0.025 \mathrm{mg} / \mathrm{mL}$ to $1 \mathrm{mg} / \mathrm{mL}$. In contrast, PS failed to completely reverse anticoagulation effects of LMWHs and showed anticoagulation effect above $0.1 \mathrm{mg} / \mathrm{mL}$. Polymeric antidote at $0.1 \mathrm{mg} / \mathrm{mL}$ completely normalized the TEG parameters of 1.2 IU fondaparinized blood and diminished $95 \%$ of anti-FXa activity of fondaparinux in chromogenic FXa assay. Antidotes exhibited excellent hemocompatibility compared to PS as they did not induce hemolysis, erythrocyte aggregation or activate the complement system. Thermodynamic parameters obtained from ITC experiments provided compelling evidence for multivalent interactions between fondaparinux and antidotes.

Conclusion: We have developed a novel, biocompatible, multivalent and efficient polymeric reversal agent capable of neutralizing in vitro anticoagulation effects of all clinically available parenteral anticoagulants. Further studies using murine bleeding and thrombosis models will confirm the in vivo anticoagulant reversing potential of developed antidotes.

\section{Suppression of Cardiac Myocyte Hypertrophy by Cannabinoid Receptors Involves AMP-activated Protein Kinase (AMPK)-Endothelial Nitric Oxide Synthase (eNOS) Crosstalk}

\author{
Yan Lu, ${ }^{1}$ Hope D. Anderson ${ }^{1,2}$. \\ ${ }^{1}$ Faculty of Pharmacy, University of Manitoba, \\ Winnipeg, Canada; ${ }^{2}$ Canadian Centre for Agri-Food \\ Research in Health and Medicine, St. Boniface \\ General Hospital Research Centre
}

Purpose: Endocannabinoids are bioactive lipids that signal through $\mathrm{CB} 1$ and $\mathrm{CB} 2$ cannabinoid receptors. Despite an effort to avoid the psychoactive side effects mediated by central $\mathrm{CB} 1$ receptors, we previously found that selective activation of CB2 receptors is not sufficient to prevent all aspects of cardiac hypertrophy. Thus, the objective of this study is to determine the effects of CB13, a peripherally-restricted agonist of $\mathrm{CB} 1 / \mathrm{CB} 2$ receptors, on cardiac myocyte hypertrophy.

Methods: The effects of CB-13 on endothelin-1 (ET-1)-induced hypertrophy were determined using cultured neonatal rat myocytes. Hypertrophic indicators included myocyte enlargement, protein synthesis by $[3 \mathrm{H}]$-leucine incorporation, and fetal gene expression by measuring brain natriuretic peptide (BNP) mRNA levels. Expression and activation of AMP-activated protein kinase (AMPK) and endothelial nitric oxide synthase (eNOS) were assessed by western blot of native and phosphorylated enzymes.

Results: CB13 suppressed cardiac myocyte hypertrophy by attenuating three distinct indicators: myocyte enlargement, [3H]-leucine incorporation and BNP expression. Endocannabinoids are known to signal in non-cardiac cells through AMPK, a sensor of cellular and whole body energy. Moreover, AMPK exerts inhibitory effects on hypertrophy. Therefore, we queried whether the anti-hypertrophic actions of CB13 were mediated by AMPK. Indeed, CB13 increased total expression and phosphorylation of AMPK. CB-13 also increased 
eNOS phosphorylation, which is an indicator that anti-growth signaling through nitric oxide might play a role. Finally, pretreatment with a chemical inhibitor of AMPK (compound C) attenuated the anti-hypertrophic actions of CB-13.

Conclusions: These findings suggest that agonism of $\mathrm{CB} 1$ and $\mathrm{CB} 2$ receptors by $\mathrm{CB} 13$, a synthetic endocannabinoid with poor brain-blood barrier penetration, prevents hypertrophy. This anti-growth effect of CB13 relies on AMPK signaling, and is associated with eNOS activation. This study suggests a cannabinoid-based treatment for heart disease remains a viable goal with therapeutic potential. Future studies that further investigate the ability of $\mathrm{CB}$ receptor agonists to inhibit cardiac hypertrophy are therefore warranted.

\section{Synthesis of Fluorescent Methyl Ketones as Inhibitors of Atg4B}

Thanh-Giau Nguyen; Robert N. Young

Department of Chemistry, Simon Fraser University, Burnaby, BC, Canada

Purpose: The goal of this research is to design an enzyme inhibitor capable of inhibiting Atg4B to provide direct information on the importance of autophagy in health and disease. Atg4B is a key cysteine protease which is believed to initiate autophagy by cleaving the carboxyl-terminal regions of three human Atg8 homologues, LC3, GABARAP, and GATE-16; an important reaction required for the formation of autophagosomes.

Method: We have developed a series of irreversible small molecule inhibitors of Atg4B that covalently modify the Atg4B enzyme. By measuring the rate of the modification one can estimate the rate of inactivation $\left(\mathrm{k}_{\text {inact }}\right)$ of the enzyme assuming the covalent modification occurs at the active site of the enzyme. The second order rate constant $k_{\text {inact }} / K_{I}$ can also be determined by this method and is a common parameter when reporting inhibition data.

Results: The rate of the modification was measured via LC/MS TOF. The second order rate constant $\mathrm{k}_{\text {inact }} / \mathrm{K}_{\mathrm{I}}$ was calculated for $\mathbf{T N}-\mathbf{3 3 8}$ from the slope of the plot of Rate of modification vs. Concentration of inhibitor and was calculated to be $2 \times 10^{-3} \mathrm{M}^{-1} \mathrm{~s}^{-1}$. Saturation kinetics could not be observed. Active site competition was confirmed by monitoring the decreased rate of modification in the presence of a known substrate. To date there are still no known reversible inhibitors of Atg4B. The development of this work could lead to a new enzyme occupancy assay for use within living cell cultures and would help identify inhibitors of Atg4B in vitro. The syntheses and inhibition kinetics of $\mathbf{T N}-\mathbf{3 3 8}$ and related analogues will be presented in a poster format.

\section{Cardioprotective Effects of Gnetol (a Stilbene Derivative) via AMP-activated Protein Kinase}

$\frac{\text { Bolanle Akinwumi, }}{{ }^{1}}{ }^{1}$ Neal Davies, ${ }^{1}$ Hope ${ }^{1}$ Faculty of Pharmacy, University of Manitoba, Winnipeg, Canada; ${ }^{2}$ Canadian Centre for Agri-Food Research in Health and Medicine, St. Boniface Hospital Research Centre, Winnipeg, Canada

Purpose: Gnetol, a stilbene derivative that occurs naturally in Gnetum, a group of gymospermous plants, exhibits structural similarity to resveratrol. Although resveratrol is known for its cardioprotective effects, the activities of other stilbene derivatives such as gnetol remain unknown.

Here, we tested the hypothesis that gnetol prevents cardiac myocyte hypertrophy. The objectives of this study were to determine first, the effects of gnetol on the development of hypertrophy, and second, the role that AMPK plays in the anti-hypertrophic actions of gnetol.

Methods: The effects of gnetol on endothelin-1induced hypertrophy were determined using primary neonatal rat myocytes. Hypertrophic indicators included myocyte size enlargement by computerassisted planimetry, de novo protein synthesis by Click-iT® AHA (L-azidohomoalanine) Alexa Fluor ${ }^{\circledR} 488$ Protein Synthesis HCS Assay kit, and fetal gene expression by quantitative PCR of brain natriuretic peptide (BNP) gene mRNA. Activation of AMPK by gnetol was detected by western blotting for phosphorylated AMPK (Thr 172).

Results: Gnetol prevented all hypertrophic indicators including cell size augmentation, increased AHA incorporation, and BNP gene expression. As resveratrol is known to signal through AMPK, a sensor of cellular and whole body energy status, we next queried whether AMPK might contribute to the anti-hypertrophic actions of gnetol. Indeed, (i) gnetol was shown to activate AMPK, and (ii) pretreatment with compound C (AMPK inhibitor,) attenuated the ability of gnetol to suppress hypertrophy. 
Conclusion: Collectively, these findings suggest that, at least in part through AMPK signaling, gnetol prevents cardiac myocyte hypertrophy. This study also suggests that gnetol might be a novel therapeutic stilbene-based treatment for heart disease. However, studies that further investigate the ability of gnetol to inhibit cardiac hypertrophy and elucidate underlying mechanisms are warranted.

\section{Combination Effects of Anti-Cancer Drugs and Flaxseed Lignans in Prostate Cancer Cells}

Yun-yun Di, Ed Krol \& Jane Alcorn.

Drug Discovery and Development Research Group, College of Pharmacy and Nutrition, University of Saskatchewan, Saskatoon, SK, Canada

Background: Castration resistant prostate cancer (CRPC) is a type of prostate cancer which is resistant to hormone-deprivation therapy (first-line therapy) and has a poor prognosis. The efficacy of single drug therapy has limited duration as CRPC eventually exhibits cross-resistance to a whole range of chemotherapeutic agents with different mechanisms of action.

Flaxseed is the richest source of lignan secoisolariciresinol diglucoside (SDG). Upon oral consumption, SDG is converted to its aglycone secoisolariciresinol (SECO) and further to the mammalian lignans by the intestinal microflora, of which enterolactone (ENL) is the most abundant. Systemically, the lignans primarily exists as glucuronide conjugates. The literature suggests flaxseed lignans are the putative bioactive components that mediate the beneficial effects against cancer. The aim of this study was to investigate whether flaxseed lignans potentiate the chemosensitivity of prostate cancer cells to existing and investigative prostate cancer chemotherapeutics.

Methods: Calcein AM cell viability assay was used to determine cell viability. GraphPad Prism was employed to produce $\mathrm{IC}_{50}$ curves following a four parameter nonlinear regression analysis. Statistical analysis of experimental data was performed using two-way ANOVA with Tukey's post hoc analysis. Significance was set at $\mathrm{p}<0.05$.

Results: Cell proliferation data suggested enterolactone glucuronide (ENL-Gluc) had no obvious cytotoxicity in both LNCap and PC-3 cell lines. The $\mathrm{IC}_{50}$ values of ENL and SECO in LNCap were $52 \mu \mathrm{M}(95 \% \mathrm{CI}, 47-59)$ and $324 \mu \mathrm{M}(95 \% \mathrm{CI}$,
260-403), respectively. The $\mathrm{IC}_{50}$ value of docetaxel alone was $936 \mathrm{pM}$ (95\% CI, 563-1556). The $\mathrm{IC}_{50}$ values were decreased to $374 \mathrm{pM}(95 \% \mathrm{CI}, 180-776)$ and $92 \mathrm{pM}$ (95\% CI, 35-241), when combined with $50 \mu \mathrm{M}$ SECO or ENL, respectively. Similar synergistic effects were observed between lignans and doxorubicin. Although $\mathrm{IC}_{50}$ values could not be calculated with the anti-cancer drugs abiraterone (ABI) and MDV3100 (MDV) in LNCap, their combination with $50 \mu \mathrm{M}$ SECO or ENL significantly decreased cell viability $(\mathrm{P}<0.0001)$.

Conclusions: Our data suggest that combination of SECO or ENL enhances the chemosensitivity of prostate cancer cells to anti-cancer drugs with known different mechanisms of action in vitro.

\section{Effect of Glucosamine on Arachidonic Acid Metabolite Formation under Inflammatory Condition}

Ali Aghazadeh-Habashi, Waheed Asghar, Fakhreddin Jamali.

Faculty of Pharmacy and Pharmaceutical Sciences, University of Alberta, Edmonton, Canada

Purpose: Arachidonic acid (AA) metabolism by cytochrome P450 (CYP) is an important pathway which is involved in formation of several mediators of different biological functions. In the vasculature and kidney, $\omega$-hydroxylation of AA generates 20hydroxyeicosatetraenoic acid (20-HETE) and its epoxidation results in regio- and stereospecific epoxyeicosatrienoic acids (EETs). It has been shown that inflammation alters the expression of CYP enzymes in different tissues. We hypothesized that inflammation changes tissue level of these eicosanoids, particularly in the heart, disrupt the balance between cardioprotective (EETs) and cardiotoxic (HETEs) metabolites while glucosamine $(\mathrm{GlcN})$ restores the balance.

Methods: Male Sprague-Dawley rats were randomly assigned to four groups $(n=4-5)$ : Controlplacebo, INF-placebo, Control-GlcN and INF-GlcN. On day zero control and inflamed (INF) animals received, saline or $0.2 \mathrm{ml}$ Mycobacterium Butyricum in Squalene $(50 \mathrm{mg} / \mathrm{mL})$ as tail base injection, respectively. The GlcN and placebo groups received daily oral dose of $160 \mathrm{mg} / \mathrm{kg} \mathrm{GlcN}$ or water, respectively. On day 16 placebo groups and on day 22 GlcN groups were euthanized and heart was harvested, kept at $-80^{\circ} \mathrm{C}$ until analyzed for AA metabolites using an HPLC-FL method. 
Results: 20-HETE level was significantly elevated by inflammation $(0.28 \pm 0.13$ vs $1.22 \pm 0.2 \mathrm{ng} / \mathrm{ml}$, control vs inflamed, respectively). Although total EETs level was not affected but the 20-HETE/EETs ratio was significantly higher in inflamed $(0.183 \pm 0.018)$ as compared to control $(0.099 \pm 0.046)$. GlcN treatment in control group did not change 20-HETE and EETs levels, but in INF groups the elevated level of HETE was reduced and 20-HETE/EET ratio was restored to that of controlplacebo group.

Conclusion: The anti-inflammatory effects of GlcN re-establish the disturbed 20-HETE/EETs balance due to inflammation. GlcN treatment reduces cardiotoxic (HETEs) and increases cardioprotective (EETs) eicosanoids levels in the heart. This suggests a cardioprotective potential for $\mathrm{GlcN}$ in inflammatory conditions such as rheumatoid arthritis.

\section{Effect of Glucosamine on Renin-Angiotensin System under Inflammatory Condition}

Ali Aghazadeh-Habashi, Waheed Asghar, Fakhreddin Jamali.

Faculty of Pharmacy and Pharmaceutical Sciences, University of Alberta, Edmonton, Canada

Purpose: Inflammation is one of the main contributing factors for cardiovascular complications particularly in rheumatoid arthritis. It is associated with the activation of the renin-angiotensin system (RAS). The main components of the RAS are two peptides, angiotensin (Ang) II and Ang (1-7), that are produced by the angiotensin converting enzyme (ACE) and ACE2, respectively. Ang II is a powerful vasoconstrictor, while Ang (1-7) counteracts the effects of Ang II as a vasodilatator. A balance between ACE and ACE2 is needed to regulate blood pressure, fluid, and electrolyte homeostasis. It's previously reported that in adjuvant arthritis (AA) rat heart inflammation disturbs the ACE2-ACE balance ${ }^{\dagger}$. We have hypothesized that through its anti-inflammatory properties, glucosamine (GlcN) counteract the effects of inflammation on the expression of ACE2 and restore the ACE2-ACE balance. This restoration will be translated to lower level of Ang II (cardiotoxic) and higher level of Ang (1-7) (cardioprotective).

Methods: Male Sprague-Dawley rats were randomly assigned to four groups $(\mathrm{n}=4-5)$ : Contplacebo, INF-placebo, Cont-GlcN and INF-GlcN.
On day zero control and INF animals received, saline or $0.2 \mathrm{ml}$ Mycobacterium Butyricum in Squalene $(50 \mathrm{mg} / \mathrm{mL})$ as tail base injection, respectively. The GlcN and placebo groups received daily oral dose of $160 \mathrm{mg} / \mathrm{kg} \mathrm{GlcN}$ or water, respectively. On day 16 placebo groups and on day $22 \mathrm{GlcN}$ groups were euthanized and plasma and heart was harvested, kept at $-80^{\circ}$ until analyzed for Ang peptide using ELISA kits.

Results: Inflammation significantly increased levels of heart Ang II and deceased Ang (1-7), hence, reduced the Ang (1-7):Ang II ratio. GlcN in INFGlcN restored the altered levels of Ang peptide to comparable levels of Cont-placebo group. Peptides level was not altered by GlcN use in control group.

\begin{tabular}{|c|c|c|c|}
\hline \multirow[b]{3}{*}{$\begin{array}{l}\text { Cont- } \\
\text { placebo }\end{array}$} & \multicolumn{3}{|c|}{ Plasma (fmol/mL) } \\
\hline & Ang(1-7) & AngII & 1-7/II \\
\hline & $439.67(56.66)$ & $42.35(11.70)$ & $9.49(4.58)$ \\
\hline $\begin{array}{l}\text { INF- } \\
\text { placebo }\end{array}$ & $225.44(75.65)^{*}$ & $125.27(13.11)^{*}$ & $5.38(2.37)^{*}$ \\
\hline \multirow{3}{*}{$\begin{array}{l}\text { Cont- } \\
\text { GlcN } \\
\text { INF- } \\
\text { GlcN }\end{array}$} & $358.29(36.20)^{* *}$ & $36.00(6.87) * *$ & $\begin{array}{l}7.88(3.35)^{*} \\
*\end{array}$ \\
\hline & $318.41(21.95)^{* *}$ & $55.79(4.69) * *$ & $\begin{array}{l}6.84(2.92) * \\
*\end{array}$ \\
\hline & \multicolumn{3}{|c|}{ Heart (fmol/g of tissue) } \\
\hline $\begin{array}{l}\text { Cont- } \\
\text { placebo }\end{array}$ & $274.79(44.82)$ & $36.07(6.81)$ & $7.82(1.34)$ \\
\hline $\begin{array}{l}\text { INF- } \\
\text { placebo }\end{array}$ & $127.89(20.48)^{*}$ & $55.96(9.90)^{*}$ & $2.33(0.53)^{*}$ \\
\hline $\begin{array}{l}\text { Cont- } \\
\text { GlcN }\end{array}$ & $220.44(30.62)^{* *}$ & $42.57(2.99)^{* *}$ & $\begin{array}{l}5.21 \\
(0.93) * *\end{array}$ \\
\hline $\begin{array}{l}\text { INF- } \\
\text { GlcN }\end{array}$ & $176.96(27.98)^{* *}$ & $39.62(7.87)^{* *}$ & $4.60(1.11)^{* *}$ \\
\hline
\end{tabular}

*Significantly different from Cont-Placebo, $* *$ significantly different from INF-placebo, $\mathrm{P}<0.05$

Conclusion: The anti-inflammatory effects of GlcN results in re-establishment of the disturbed ACE2ACE balance due to inflammation and reduce cardiotoxic peptide (Ang II) level while increases the level of cardioprotective peptide, Ang (1-7). This suggests a cardioprotective potential for $\mathrm{GlcN}$ in inflammatory conditions such as rheumatoid arthritis.

${ }^{\dagger}$ Hanafy S, Tavasoli M, Jamali F. Inflammation alters angiotensin converting enzymes (ACE and ACE2) balance in rat heart. Inflammation. 34:60913, 2011 


\section{Cytochrome P450 Metabolites of Arachidonic Acid in Rat Heart as Mediators of NSAIDs Induced Cardiovascular Risk in Adjuvant Arthritis Model of Inflammation}

Waheed Asghar, Ali Aghazadeh-Habashi, Fakhreddin Jamali.

Faculty of Pharmacy and Pharmaceutical Sciences, University of Alberta, Edmonton, Canada

Purpose: Arachodonic acid (AA) is a fatty acid component of the cell that undergoes oxidative metabolism by cyclooxygenase, lipoxygenase or cytochrome (CYP) enzymes. CYP converts AA into metabolites (eicosanoids) like epoxyeicosatrienoic acids (EETs) or hydroxyeicosatetraenoic acids (HETE). These eicosanoids are known for their effects on cardiovascular system. A hydroxylase CYP4A expressed in vasculature and renal arterioles and heart converts AA into 20-HETE that exerts prehypertensive and cardiotoxic effects. In contrast, (CYP) epoxygenases CYP2C11 converts AA into $14-15,11-12$ or 8-9 EETs which lowers the blood pressure reduce the infarct size and repair the damaged tissue. Studies have shown that cardiomayocytes can produce limited quantities of these eicosanoids but an increase in CYP4A expression and elevated 20 HETE levels are reported in hypertension, ischemia and infraction. In this study we examined the eicosanoids production in heart during inflammation and treatment with the non-steroidal anti-inflammatory drugs (NSAIDs).

Method: Sprague Dawley rats were divided into 2 main groups of healthy control and inflamed. Inflamed groups were injected with Mycobacterium butyricum in squalene in their tail base and after 12 days, when signs of arthritis emerged, inflamed group received daily oral doses of either rofecoxib $10 \mathrm{mg} / \mathrm{kg}$, meloxicam $0.5 \mathrm{mg} / \mathrm{kg}$, celecoxib 15 $\mathrm{mg} / \mathrm{kg}$ or flurbiprofen $5 \mathrm{mg} / \mathrm{kg}(\mathrm{n}=4$ each). After 7 treatment days, hearts were harvested and stored at $80^{\circ}$ until analyzed for AA metabolites using HPLCFL method.

Results: Inflammation resulted into significant increase in 20 HETE level in the heart compared to control $(0.30 \pm 0.10$ vs. $0.64 \pm 0.25 \mathrm{ng} / \mathrm{mg}$ of tissue $)$, rofecoxib (1.0 \pm 018$)$ and flurbiprofen $(0.64 \pm 0.38)$ also cause an increase. But meloxicam $(0.46 \pm 0.028)$ and celecoxib $(0.37 \pm 0.043)$ had no significant effect. Amongst epoxygenases metabolites 14-15 EET was elevated in inflammation and rofecoxib treatment $(0.42 \pm 0.14$ vs. $0.58 \pm 0.16$ and $0.71 \pm 0.13$ respectively) likewise, $11-12$ EET $(2.2 \pm 0.8$ vs
$4.4 \pm 0.5,7.0 \pm 0.8$ respectively).

Conclusion: The elevated 20-HETE and lower EETs (especially 14-15 EET) during inflammation suggests compromised heart condition making it more susceptible to ischemic heart injury. Some NSAIDs further aggravate the condition, which may be the reason that NSAIDs like rofecoxib and flurbiprofen have more cardiovascular consequences, compared to the other NSAIDs like meloxicam and celecoxib that has minimal or no significant effect on this indigenous mechanism in the heart.

\section{NSAIDs Induced Changes in Angiotensin II Receptor (AT1, AT2) and Angiotensin 1-7 Receptor (MASS) Protein Expression in the Heart in Adjuvant Arthritis Rat Model}

Waheed Asghar, Ali Aghazadeh-Habashi, Fakhreddin Jamali.

Faculty of Pharmacy and Pharmaceutical Sciences, University of Alberta, Edmonton, Canada

Purpose: Angiotensin II (Ang-II) is a potent vasoconstricting peptide produced by angiotensin converting enzyme (ACE) of the renin angiotensin system (RAS). It is reported to act on Ang-II type 1 (AT1) and Ang-II type 2 (AT2) receptors that are elevated under various cardiovascular conditions. AT1 receptors are involved in hypertension, arteriosclerosis, myocardial infraction and heart failure. AT2 receptors are expressed to counter AT1 receptors. In the meantime, there is a growing evidence for the involvement of Ang-1-7 and its receptor (MASS) to play a cardioprotective role in RAS. In this study we compared the expression of AT1, AT2 and MASS receptors in healthy control, inflamed and non-steroidal anti-inflammatory (NSAIDs) treated rat heart.

Method: Male Sprague Dawley rats were divided into 2 main groups of healthy control and inflamed. Inflamed groups were injected with Mycobacterium butyricum in squalene in their tail base and after 12 days, when signs of arthritis emerged, received daily oral doses of either rofecoxib $10 \mathrm{mg} / \mathrm{kg}$, meloxicam $0.5 \mathrm{mg} / \mathrm{kg}$, celecoxib $15 \mathrm{mg} / \mathrm{kg}$ or flurbiprofen 5 $\mathrm{mg} / \mathrm{kg}(\mathrm{n}=4$ each). After 7 treatment days, hearts were harvested and stored at $-80^{\circ}$ until analyzed for AT2 (40KDa), AT2 (40KDa), MASS (36kDa) and tubulin as loading control $(50 \mathrm{kDa})$.

Results: The expression of AT1 was significantly increased in the rat heart compared to healthy 
control in inflammation and rofecoxib treatment $(0.87 \pm 0.05$ vs. $1.1 \pm 0.13$ and $1.1 \pm 0.05$ respectively). Likewise, the AT2 expression was significantly increased in inflammation and treatment with rofecoxib and flurbiprofen $(1.1 \pm 0.12$ vs. $1.4 \pm 0.10$, $1.4 \pm 0.11$, and $1.9 \pm 0.19$ respectively). No significant effect was observed on AT1 or AT2 protein expression in meloxicam and celecoxib treated rat heart. Interestingly, Ang1-7 receptor (MASS protein) was significantly decreased in rat heart under inflammation $(0.8 \pm 0.05$ vs. $0.66 \pm 0.05)$ and with rofecoxib treatment $(0.50 \pm 0.073)$, however no significant effect was observed in meloxicam $(0.67 \pm 0.018)$, celecoxib $(0.75 \pm 0.086) \quad$ and flurbiprofen $(0.78 \pm 0.022)$ treatments.

Conclusion: Inflammation alters the expression of specific angiotensin receptors with increased AT1, AT2 and lower MASS receptor protein. This modulation of local RAS can result into increased cardiovascular risk during inflammation. Some NSAIDS like rofecoxib further enhance the AT1, AT2 expression and lower MASS receptor protein. This along with increased concentration of Ang-II may explain high cardiovascular risk associated with in rofecoxib treatment.

\section{Inhibition of PCSK9 Increases Survival in Human Septic Shock and Murine Models of Bacteremia}

Katherine Thain, Keith Walley, Yingjin Wang, James Russell and John Boyd.

University of British Columbia Critical Care Research Laboratories, James Hogg Research Centre, Vancouver, BC, Canada

Purpose: Significant interaction occurs between lipid metabolism and inflammation pathways, impacting the incidence and outcome of sepsis. Many Loss-of-Function (LOF) and Gain-ofFunction (GOF) variations in the Proprotein convertase subtilisin/kexin type 9 (PCSK9) gene have been correlated with altered LDL receptor densities on hepatic cells, with a concomitant decrease or increase in plasma LDL cholesterol levels, respectively. Loss-of-Function variations are associated with lower incidence of atherosclerosis and cardiovascular disease. We therefore tested the hypothesis that reduced PCSK9 function alters the systemic inflammatory response.

Methods: Using murine genetic Pcsk9 knock-out and pharmacologic inhibition strategies we measured physiological responses, cardiovascular function and inflammatory cytokines before and after administration of lipopolysaccharide $(20 \mathrm{mg} / \mathrm{kg}$ i.p.). In two cohorts of septic shock patients $(n=632$, $\mathrm{n}=589$ ) we genotyped known Loss-Of-Function (LOF) and Gain-Of-Function (GOF) single nucleotide polymorphisms (SNPs) and/or a tagging SNP of PCSK9. We tested for association with mortality, cardiovascular dysfunction and inflammatory cytokines.

Results: Pcsk9 null mice had significantly attenuated phenotypic and cardiovascular responses six hours after LPS administration, compared to wild-type mice (Activity index, $\mathrm{P}<0.001$; Body temperature,

$\mathrm{P}<0.001$; Mean arterial pressure, $\mathrm{P}=0.017$; Ejection fraction, $\mathrm{P}=0.019)$ as well as reduced plasma cytokine concentrations: TNF $\alpha(\mathrm{P}=0.018)$, IL6 $(\mathrm{P}=0.004)$, IL-10 $(\mathrm{P}=0.003)$, JE $(\mathrm{P}=0.006)$ and MIP2 $(\mathrm{P}=0.019)$. These beneficial phenotypic responses of mice were replicated after pharmacologic inhibition of Pcsk9 using berberine (Activity index, $\mathrm{P}=0.001$; Body temperature, $\mathrm{P}=$ 0.004).

In human septic shock patients, PCSK9 LOF variants were significantly associated with decreased 28-day mortality compared to patients without LOF variants (Log-Rank test, $\mathrm{P}=0.0037)$, even after adjusting for potentially confounding covariates (Odds Ratio 0.64, 95\% Confidence Interval 0.46$0.89, \mathrm{P}=0.009)$. There was a directionally opposite effect in patients with GOF variants. In addition, patients with LOF variants had a significantly blunted cytokine response compared to patients with GOF variants: TNF $\alpha(\mathrm{P}=0.061)$, IL6 $(\mathrm{P}=0.076)$, IL10 $(\mathrm{P}=0.009), \mathrm{MCP} 1(\mathrm{P}=0.043)$ and IL8 $(\mathrm{P}=$ $0.035)$.

Conclusion: The reduction of PCSK9 activity in both mice and humans reduces the inflammatory response and improves outcome in septic shock. Pharmacologic inhibition of PCSK9 could be beneficial in sepsis and other acute inflammatory processes. 


\section{Evaluating Methods to Modulate Levels of Valproyl-1-O-Glucuronide in Sandwich- Cultured Rat Hepatocytes Treated with Valproic Acid}

Jayakumar Surendradoss, Thomas K. H. Chang, and Frank S. Abbott.

Faculty of Pharmaceutical Sciences, The University of British Columbia, Vancouver, BC, Canada

Purpose: Valproic acid (VPA) therapy is associated with a rare, but fatal, idiosyncratic hepatotoxicity, the mechanism for which is unknown. Glucuronidation of VPA to valproyl-1-O-acyl glucuronide (VPA-G), a major metabolite in rats and humans, has been linked to increased plasma and hepatic levels of $15-\mathrm{F}_{2 \mathrm{t}}$-isoprostanes (a marker for lipid peroxidation) in rats. As part of our research efforts to investigate the role of VPA-G in VPA hepatotoxicity, the present study evaluated three approaches to modulate the levels of VPA-G in sandwich-cultured rat hepatocytes, namely: 1) inhibiting VPA-G efflux by using chemical inhibitors of efflux transporters; 2) inhibiting VPA$G$ formation using borneol (a known inhibitor of glucuronidation); and 3) increasing VPA-G formation by using various known inducers of uridine diphospho-glucuronosyltransferases (UGTs). Methods: Freshly isolated rat hepatocytes were cultured in a Matrigel ${ }^{\mathrm{TM}}$-sandwich configuration. To inhibit VPA-G efflux or VPA glucuronidation, hepatocytes, after $120 \mathrm{~h}$ culture, were pretreated with a chemical inhibitor or DMSO (vehicle) for 30 minutes, prior to $24 \mathrm{~h}$ treatment with VPA. For the experiments involving UGT induction, hepatocytes, after $48 \mathrm{~h}$ of culture, were pretreated with a known UGT inducer or vehicle for $72 \mathrm{~h}$, followed by $24 \mathrm{~h}$ VPA treatment. VPA-G levels were quantified using a validated UHPLC-MS-MS assay.

Results: Following $1 \mathrm{mM}$ VPA treatment, VPA-G levels in the culture supernatants increased linearly for $24 \mathrm{~h}$. VPA-G levels at $24 \mathrm{~h}$ increased over a VPA concentration range of 0.03 to $3 \mathrm{mM}$, appeared to plateau from 3 to $10 \mathrm{mM}$ VPA, and then declined at concentrations $\geq 20 \mathrm{mM}$ VPA. Attempts to inhibit VPA-G efflux by using benzbromarone, prazosin, MK571, or bromosulfalein did not enhance the intracellular levels of VPA-G, which could be due to the cytotoxicity of these chemicals or their inhibition of VPA uptake. Borneol up to $500 \mu \mathrm{M}$ did not attenuate the levels of VPA-G. Various known inducers of UGTs such as 3-methylcholanthrene, $\beta$ naphthoflavone, quercetin, L-sulforaphane, tert- butylhydroquinone, trans-stilbene oxide, phenobarbital, pregnenolone-16 $\alpha$-carbonitrile, dexamethasone, clofibrate, and ritonavir were evaluated for their effects in increasing VPA-G levels. Only $\beta$-naphthoflavone and L-sulforaphane were effective, and $\beta$-naphthoflavone at $20 \mu \mathrm{M}$ concentration produced the maximal increase (2fold) in supernatant levels of VPA-G.

Conclusion: Among the three approaches evaluated, pretreatment with UGT inducers such as $\beta$ naphthoflavone and L-sulforaphane was alone effective in modulating VPA-G levels in our sandwich-cultured rat hepatocyte model. The toxicological significance of a $\beta$-naphthoflavone- or L-sulforaphane-mediated increase in VPA-G levels is under investigation. [Supported by CIHR and MSFHR]

\section{Clinical Sciences and Pharmacy Practice}

\section{Canadian Values, Attitudes and Willingness to Pay for Expensive Medications for Rare Diseases}

Shirin Rizzardo and Larry Lynd.

Faculty of Pharmaceutical Sciences, University of British Columbia, Vancouver, British Columbia, Canada

Purpose: Personalized medicines, particularly those for rare or orphan diseases, is an area of rapid development often associated with much higher prices than those for common diseases. The potential financial burden and opportunity cost of treating patients with rare diseases is therefore significant. As government health care budgets are limited, it is important to understand whether Canadians would altruistically prioritize a rare condition over the efficiency of using resources to benefit more people. The objective of this study was to determine how Canadian society values the treatment of rare over common diseases, willingness to accept the opportunity costs associated with funding rare diseases, and maximum willingness to pay (WTP).

Methods: A cross-sectional survey of the Canadian public was employed using a web based questionnaire. Respondents chose to fund treatment and allocate limited resources to either a rare or 
common disease, and preferences were elicited under both equal and higher rare disease treatment cost. Participants also rated five statements regarding rare disease equity attitudes. WTP was determined using a variation of the payment card method where respondents were presented either high or low initial price ranges. Respondents were also randomized to either high or low drug treatment efficacy.

Results: Data on 100 pilot respondents indicate strong agreement with the statements pertaining to rare disease equity. $57 \%$ of participants strongly agreed and $19 \%$ agreed with the statement "Everyone should have equal access to health care regardless of cost". When treatment cost was equal, $37 \%$ of subjects chose to treat the common disease, $35 \%$ the rare disease and $28 \%$ were indifferent. When the rare disease was more expensive to treat, the results were $23 \%, 53 \%$ and $24 \%$ respectively. WTP for high efficacy and a lower payment-card range ranged from $\$ 2500$ to over $\$ 1$ million, with an average of $\$ 238,000$. For the lower efficacy scenario, WTP averaged $\$ 99,000$ when randomized to lower payment ranges and $\$ 173,447$ in the higher ranges.

Conclusion: Although Canadians feel positively towards statements pertaining to rare disease equity, preliminary data indicates no preference for rarity at the expense of common conditions. Additionally, the WTP varied depending on the treatment efficacy and the price ranges respondents were initially shown. The current costs for rare disease treatments, which are as high as $\$ 600,000$ annually per patient, appear to exceed the societal WTP, particularly given the low or unknown efficacy associated with these treatments.

\section{Polymorphism of V1b Receptor is Associated with Increased Risk of Serious Adverse Events during Norepinephrine Infusion in Septic Shock}

James A. Russell, Nattachai Anantasit, John Boyd, Keith Walley.

University of British Columbia, Vancouver BC, Canada

Purpose: Ischemic serious adverse events (SAEs) associated with vasopressin (AVP) or norepinephrine (NE) infusion in patients with septic shock can be difficult to predict. Polymorphisms (SNPs) of candidate genes of the AVP and NE pathways and/or plasma AVP levels could predict SAEs in such patients.

Hypothesis: SNPs of AVP pathway and of NE pathway and plasma AVP levels are associated with increased risk of SAEs during AVP and NE infusions in human septic shock.

Methods: We studied 597 patients from the VASST trial of AVP vs. NE in septic shock. Patients in septic shock (NE $>5 \mathrm{ug} / \mathrm{min}$ for 6 hours) were randomized to blinded infusions of 0.01-0.03 units $/ \mathrm{min}$ AVP or $5-15 \mathrm{ug} / \mathrm{min} \mathrm{NE}$ in addition to open label NE. For the AVP pathway, we genotyped 248 SNPs in AVP and AVP receptor genes (AVPR1A, AVPR1b, AVP), vasopressinase (LNPEP) and oxytocin receptor (OXTR). For the NE pathway, we genotyped 20 SNPs in AGTRAP and ADR genes. We identified patients who had SAEs and tested for association of SNPs with presence of SAEs using Armitage trend test for additive genetic model. We measured plasma AVP at baseline, 6, 24, 72 hours and 7 days and calculated area under the curve of AVP level (AUC of AVP level) in a subset of patients $(n=88)$ and tested for association of maximum plasma AVP level and AUC of AVP level with SAEs.

Results: Patients who had SAEs had significantly higher 28-day mortality than patients without SAEs (56\% vs $31.5 \%$, respectively, $p<0.001$ ). Patients with SAEs required a significantly higher maximum dose of NE than patients without SAEs (SAE: median $22.4 \mathrm{ug} / \mathrm{min}$ in SAE; no SAE $16.0 \mathrm{ug} / \mathrm{min}, \mathrm{p}$ $<0.05$ ). The $1^{\text {st }}$ day (SAE: mean lactate $2.8 \mathrm{mmol} / \mathrm{L}$; no SAE: $2.2 \mathrm{mmol} / \mathrm{L}$ ) and maximum plasma lactate levels (SAE: $3.9 \mathrm{mmol} / \mathrm{L} \mathrm{SAE}$; no SAE: $2.8 \mathrm{mmol} / \mathrm{L}$ ) were significantly higher in patients with SAEs than without SAEs $(p<0.05)$. After adjusting for clinical risk factors (age, severity of shock based on baseline dose of open label NE, APACHE II, and platelet count (marking DIC), rs28418396 of AVPR1b was significantly $(\mathrm{p}<0.05)$ associated with SAEs in the NE group. There was no association of maximum plasma AVP level or AUC of AVP level with SAEs.

Conclusions: Patients who have SAEs on vasopressin or norepinephrine have much higher mortality than patients without SAEs. Patients with the minor allele of rs28418396 of AVPR $1 \mathrm{~b}$ have a significantly increased risk of SAEs during NE infusion for treatment of septic shock. The mechanism of this association requires investigation. 


\section{Pharmaceutical \& Analytical Chemistry}

\section{1,4-Diaryl-substituted Triazoles as Cyclooxygenase-2 Inhibitors: Synthesis, Biological Evaluation and Molecular Modeling Studies}

Jatinder Kaur, Atul Bhardwaj, Sai Kiran Sharma and Frank Wuest.

Department of Oncology, University of Alberta, Edmonton, Alberta, Canada

Purpose: Nonsteroidal anti-inflammatory drugs (NSAIDs) have been widely used for the relief of pain, fever and inflammation. NSAIDs act by inhibiting the cyclooxygenase (COX) catalyzed biotransformation of arachidonic acid to prostaglandins, prostacyclin, and thromboxane A2. COX enzyme exists in two isoforms viz. COX-1 and COX-2; among which consecutively expressed COX-1 isoform is involved in homeostatic functions of body, whereas COX-2 is an inducible isozyme responsible for the production of inflammatory prostaglandins. The classical non-selective NSAIDs (aspirin, ibuprofen and indomethacin), inhibits both COX-1 and COX-2 isozymes resulted in gastrointestinal (GI), ulcerogenic, hepatic and renal toxicity. The purpose of this study was to synthesize a new group of anti-inflammatory agents as selective COX-2 inhibitors and investigate the effect of their substituents in controlling the activity profile.

Methods: A novel group of 1,4-diaryl-substituted triazoles were designed and synthesized by introducing cyclooxygenase-2 (COX-2) pharmacophore $\left(\mathrm{SO}_{2} \mathrm{NH}_{2}\right)$ on one ring and $\mathrm{H}, \mathrm{F}, \mathrm{Cl}$, $\mathrm{CH}_{3}$ or $\mathrm{OCH}_{3}$ substituent on the other aryl ring using $\mathrm{Cu}$ (II)-catalyzed click chemistry. The effect of size and flexibility of the molecule on COX-1/COX-2 inhibitory activity was determined by increasing the size of linker chain $\left[\left(-\mathrm{CH}_{2}\right)_{\mathrm{n}}\right.$ where $\left.\mathrm{n}=0,1,2\right]$. The COX-1/2 inhibitory activity and selectivity index was evaluated by using fluorescent $\mathrm{COX}-1 / \mathrm{COX}-2$ inhibitor screening assay.

Results: In vitro COX-1/COX-2 isozyme inhibition studies showed that all compounds are more potent inhibitors of COX-2 isozyme $\left(\mathrm{IC}_{50}=0.17-28.0 \mu \mathrm{M}\right.$ range) than COX-1 isozyme $\left(\mathrm{IC}_{50}=21.0->100 \mu \mathrm{M}\right.$ range). Within this group of 1,4 diaryl-substituted triazoles, the compound 4-\{2-[4-(4-Chloro-phenyl)$[1,2,3]$ triazol-1-yl]-ethyl $\}$-benzenesulfonamide was emerged as most potent $\left(\mathrm{COX}-1 \quad \mathrm{IC}_{50}=>100 \mu \mathrm{M}\right.$, COX-2 $\left.\mathrm{IC}_{50}=0.17 \mu \mathrm{M}\right)$ and selective COX-2 inhibitor (SI > 588). Molecular docking studies in the active site of COX-1 and COX-2 isozymes provided complementary theoretical support for the experimental data obtained.

Conclusions: A novel class of 1, 4-diaryl-substituted triazoles have been synthesized and identified as inhibitors of COX isozymes. In vitro $\mathrm{COX}-1 / \mathrm{COX}-2$ inhibition studies showed that this new class of 1,4diaryl-substituted triazoles inhibit COX-2 isozyme selectively. From experimental structure-activity data and molecular docking it is concluded that with increase in length of linker chain, there is an enhancement in molecular interactions between the substituents of compound and secondary pocket of COX-2 site residues.

\section{Synthesis and Bio-evaluation of Fluorescent Cyclooxyegenase-2 Inhibitors as Cancer Imaging Agents}

Atul Bhardwaj ${ }^{1,}{ }^{2}$, Jatinder Kaur ${ }^{1,2}$, Sai Kiran Sharma $^{1,}{ }^{2}$, Zhangjian Huang ${ }^{1}$, Frank Wuest ${ }^{1,2}$, Edward E. Knaus ${ }^{1}$

${ }^{1}$ Faculty of Pharmacy and Pharmaceutical Sciences, University of Alberta, Edmonton, AB, Canada; ${ }^{2}$ Department of Oncology, University of Alberta, Edmonton, AB, Canada

Purpose: The cyclooxygenase- 2 isozyme (COX-2) is a well known pharmaceutical target for the treatment of inflammation. Recent advances indicate that over-expression of the COX-2 isozyme is associated with a variety of human cancers (colon, breast, prostate, hepatocellular carcinomas). Furthermore, the successful use of several nonsteroidal anti-inflammatory drugs for cancer prevention validates the involvement of the COX-2 in cancer progression. This correlation between COX-2 over-expression and cancer progression makes the COX-2 isozyme an attractive therapeutic target for the prevention and detection of cancer. The purpose of this study is to design "hybrid COX2 inhibitor-fluorescent conjugates" comprised of a fluorescent structure attached to a COX-2 inhibitory compound which can serve as potential COX-2 imaging fluorescence probes for the detection of cancer.

Methods: A series of hybrid fluorescent conjugates were synthesized, purified and characterized wherein the COX inhibitors ibuprofen, (S)-naproxen, acetyl 
salicylic acid, a chlororofecoxib analog and celecoxib were coupled via a linker group to a variety of fluorophores. In-vitro COX-1/2 inhibitory activities and selectivity indexes were determined using COX-assay kits. Using COX-2 overexpressing colon cancer cells, the most promising compounds were investigated as fluorescent COX-2 imaging agents.

Results: Amongst all investigated compounds, the ibuprofen-acridone conjugate and celecoxib-dansyl conjugate showed the most potent and selective COX-2 inhibition, but their fluorescence emission properties were not suitable for fluorescent imaging of cancer cells that over-express the COX-2 isozyme. Ultimately, a celecoxib-rhodamine $\mathrm{B}$ conjugate that exhibited moderate $\mathrm{COX}-2$ potency $\left(\mathrm{COX}-2 \mathrm{IC}_{50}=3.9 \mu \mathrm{M}\right)$ having the best fluorescence emission was identified as the most promising biomarker for fluorescence imaging.

Conclusion: Organic synthesis of a new group of hybrid fluorescent conjugates was achieved for bioevaluation. Structure-activity data acquired showed that the ibuprofen, (S)-naproxen and acetyl salicylic acid acridone conjugates, unlike the parent nonselective COX-1/COX-2 inhibitory drug, exhibited COX-2 selective inhibition. The ibuprofen/celecoxib-dansyl conjugates identified as selective COX-2 inhibitors and their fluorescence emission was significantly higher than those of the acridone conjugates, but lower than that for the celecoxib-rhodamine B conjugate which showed the highest, and most suitable, fluorescence emission. The celecoxib-rhodamine $\mathrm{B}$ conjugate emerged as the most promising $\mathrm{COX}-2$ fluorescent imaging probe in colon cancer cells.

\section{Simultaneous Determination of Bioactive Eicosanoids by Simple, Sensitive, Reliable and Cost-effective Reversed-Phase HPLC Method Using Fluorescence Detection}

Ali Aghazadeh-Habashi, Waheed Asghar and Fakhreddin Jamali

Faculty of Pharmacy and Pharmaceutical Sciences, University of Alberta, Edmonton, AB, Canada

Purpose: Eicosanoids, as arachidonic acid (AA) metabolites, influence a wide range of biological processes. Recently, their role in modulation of inflammation put them in the center of attention for many research areas, including cardiovascular and cancer research. Estimation of plasma or tissue level is important for understanding their role in physiological and pathophysiological conditions. In our laboratory, a reported LC-MS method demonstrated low sensitivity; hence, in-vitro microsomal enzymes incubation with AA was required. In addition, the method showed poor reliability. The objective of this work was to introduce an improved assay based on an earlier reported method.

Method: Using 16-Hydroxyhexadecanoic acid as internal standard, and 2-(2,3-naphthalimino)ethyl trifluoromethanesulfonate as fluorescent labeling agent, 13 derivatives of eicosanoids including 20hydroxyeicosatetraenoic acids (HETEs) and epoxyeicosatrienoic acids (EETs) were extracted by solid phase cartridge (HLB) and separated using gradient combination of acetonitrile: water: formic acid on C18 reveres-phase HPLC column followed by fluorescence detection (excitation at $260 \mathrm{~nm}$ and emission at $396 \mathrm{~nm}$ ).

Results: Standard curves for each of the eicosanoids were generated using standard solutions with known amount (range $0.1-25 \mathrm{ng}, \mathrm{r}^{2}=0.98$ to 0.99). The limits of detection and quantification for standard solutions diluted from $2.5 \mu \mathrm{g} / \mathrm{ml}$ ranged from 1-10 pg and 5-60 pg, respectively. This enabled us to measure the basal level of these metabolites without using complicated incubation process. Comparing to LC-MS method, intra-day and interday variability of this method for the same concentrations were much lower $(124 \%$ vs $16.8 \%$, respectively). It was successfully applied to determine the tissue level of eicosanoids in control and inflamed rats.

Conclusion: The assay was easy, sensitive, reliable and inexpensive as compared with LC-MS method. As the relative ratio between eicosanoids is more important than their individual levels, the simultaneous determination of eicosanoids will facilitate study of AA pathways in different disease state. 


\section{Pharmacokinetics \& Pharmacodynamics}

\section{Efficacy and Toxicity of Novel Oral Lipid- based Formulation of Amphotericin B (iCo- 010) in a Rat Model of Invasive Candidiasis}

$\underline{\text { Fady Ibrahim }}^{1}$, Pavel Gershkovich ${ }^{1}$, Olena Sivak ${ }^{1}$, Ellen K. Wasan ${ }^{1,2}$, Karen Bartlett ${ }^{3}$, Kishor M. Wasan ${ }^{1}$.

${ }^{1}$ Faculty of Pharmaceutical Sciences, The University of British Columbia, Vancouver, BC, Canada, ${ }^{2}$ School of Health Sciences, British Columbia Institute of Technology, Burnaby, BC, ${ }^{3}$ Faculty of Environmental and Occupational Health, The University of British Columbia, Vancouver, BC.

Purpose: To assess the in vivo antifungal activity of the novel oral iCo-010 lipid-based formulation of Amphotericin B (AmB) in a rat model of invasive candidiasis.

Methods: Rats were infected with Candida albicans strain ATCC 18804 by injecting $1 \times 10^{8}$ colony forming units (CFU) per animal through the cannulated jugular vein; 48 hours later, the animals were assigned either to the control untreated group, the AmBisome treated group at $5 \mathrm{mg} / \mathrm{kg}$ QD for two consecutive days, or the oral $\mathrm{AmB}$ iCo- 010 treated groups at doses of $0.5,1,2.5,5$ and $10 \mathrm{mg} / \mathrm{kg}$ TID over two consecutive days. The animals were sacrificed 12 hours following the completion of the treatment. The blood and the organs of liver, heart, lungs, kidneys, spleen and brain were harvested. The antifungal activity was assessed by determining the CFU counts in the organ homogenates and plasma.

Results: There was a linear relationship between the antifungal activity in renal tissues and the administered dose level of oral iCo-010. There was no significant difference in the reduction of the fungal CFU count in the tissues between the AmBisome ${ }^{\circledR}$ treatment group and the oral iCo-010 groups except in the spleen and the liver. Moreover, the plasma creatinine levels were not significantly different among the control and all the treatment groups.

Conclusion: Oral iCo-010 is not nephrotoxic and is a promising oral treatment for invasive candidiasis especially in the kidneys over the two days treatment regimen.

\section{Pharmacokinetics of a Novel Lipid Based and Tropically Stable Formulation of Amphotericin B (iCo 010) following Oral Administration to Rats}

$\underline{\text { Fady Ibrahim }}^{1}$, Pavel Gershkovich ${ }^{1}$, Olena Sivak ${ }^{1}$, Ellen Wasan $^{2}$, Kishor M. Wasan ${ }^{1}$

${ }^{1}$ Faculty of Pharmaceutical Sciences, University of British Columbia, Vancouver, Canada; ${ }^{2}$ School of Health Sciences, British Columbia Institute of Technology, Burnaby, Canada

Purpose: To assess the pharmacokinetics and tissue distribution profiles of amphotericin B (AmB) from a novel lipid-based formulation after oral administration to rats.

Methods: The novel lipid-based formulations (iCo010) was previously developed using Peceol, Gelucire44/14 (50:50, v/v) and vitamin-E TPGS. The formulation was dispersed in simulated intestinal fluid (SIF) to determine its particle size. The jugular veins of Sprague Dawley rats were cannulated $(\mathrm{n}=6 \mathrm{each})$ and were given oral iCo-010 at a dose of $10 \mathrm{mg} / \mathrm{kg}$. Blood samples were withdrawn at 1, 2, 3, 4, 5, 6, 8, 10, 12, 24, 48 and 72 $\mathrm{hr}$ post-dose. At the last time point, the animals were sacrificed and the organs of spleen, liver, kidney, lung, heart and brain were collected for $\mathrm{AmB}$ quantification by using a validated HPLC method. The plasma pharmacokinetics parameters were derived by using a non-compartmental model.

Results: The particles of the dispersed iCo-010 in SIF had a unimodal distribution with a size of 360 $\mathrm{nm}$. The plasma concentration of $\mathrm{AmB}$ increased slowly to reach a $\mathrm{C}_{\max }$ of $75 \mathrm{ng} / \mathrm{ml}$ after $9 \mathrm{hr}$ (Figure 1). The disappearance of $\mathrm{AmB}$ from plasma was slow and $\mathrm{AmB}$ was still detected up to the last sampling point with mean residence time of $63 \mathrm{hr}$. The AUC of iCo-010 was $2808 \pm 407 \mathrm{hr} . \mathrm{ng} / \mathrm{ml}$ after $72 \mathrm{hr}$. The kidney and the lung exposure was comparable ( $210 \pm 52$ and $171 \pm 51 \mathrm{ng} / \mathrm{g}$ tissue weight) and higher than that of the spleen and the liver ( $59 \pm 19$ and $46 \pm 20 \mathrm{ng} / \mathrm{g}$ tissue weight). There was no detectable AmB in the brain and heart tissues.

Conclusion: The pharmacokinetics of the oral lipid based formulation (iCo-010) suggests that the absorption of $\mathrm{AmB}$ from the oral formulation was enhanced to show detectable levels in plasma and the harvested tissues. High accumulation in tissues with daily dosing is expected to reach high steady state concentration which could have a therapeutic effect. 


\section{Agonism of Human Pregnane $X$ Receptor by Rilpivirine and Etravirine: Comparison with First Generation Non-nucleoside Reverse Transcriptase Inhibitors}

Devinder Sharma ${ }^{1}$, Aik Jiang Lau', Matthew A. Sherman $^{2}$, and Thomas K. H. Chang ${ }^{1}$

${ }^{1}$ Faculty of Pharmaceutical Sciences, The University of British Columbia, Vancouver, British Columbia, Canada and ${ }^{2}$ Triangle Research Labs, LLC, Research Triangle Park, NC, USA

Purpose: Pregnane $X$ receptor (PXR) is a member of the superfamily of nuclear receptors that regulate the expression of various genes controlling diverse biological functions. Rilpivirine and etravirine are the United States Food and Drug Administration approved second generation non-nucleoside reverse transcriptase inhibitors indicated for the treatment of human immunodeficiency virus-1 infection. Among the first generation non-nucleoside reverse transcriptase inhibitors, efavirenz $(10 \mu \mathrm{M})$ and nevirapine $(50 \mu \mathrm{M})$ are reported to activate PXR. However, the mechanism of PXR activation by these drugs is still unknown. Furthermore, there is no direct experimental evidence on whether rilpivirine or etravirine affect the transcriptional activity of PXR. Therefore, the present study systematically investigated the effects of second and first generation non-nucleoside reverse transcriptase inhibitors on the activity of PXR, including the mechanism of activation.

Method: PXR activation was assessed in transiently transfected HepG2 cells. Mechanistic studies were carried out using techniques such as reporter gene assays, competitive ligand-binding assay, timeresolved fluorescence resonance energy transfer, confocal microscopy, and mammalian two-hybrid assays. PXR target gene expression was quantified in primary cultures of human hepatocytes.

Results: In the transiently transfected HepG2 cells, rilpivirine $(0.5-10 \mu \mathrm{M})$, etravirine $(0.5-10 \mu \mathrm{M})$, and efavirenz ( 5 and $10 \mu \mathrm{M}$ ), but not nevirapine or delavirdine, activated human, mouse, and rat PXR. Results from mechanistic studies indicated that rilpivirine, etravirine, and efavirenz, but not nevirapine or delavirdine, bound to the ligandbinding domain of hPXR, as assessed by a transactivation assay and by a competitive ligandbinding assay using time-resolved fluorescence resonance energy transfer; triggered nuclear translocation of a green fluorescence protein-tagged hPXR, as visualized by confocal imaging; and recruited steroid receptor coactivator-1 (SRC-1), SRC-2, and SRC-3 to hPXR, as demonstrated by mammalian two-hybrid assays. Rilpivirine, etravirine, and efavirenz, but not nevirapine or delavirdine, increased human PXR target gene (CYP3A4) expression in primary cultures of human hepatocytes.

Conclusion: Select non-nucleoside reverse transcriptase inhibitors activate rodent and human PXR. Rilpivirine, etravirine, and efavirenz, but not nevirapine or delavirdine, are agonists of human PXR and inducers of CYP3A4.

\section{Pharmacometrics of Gnetol: A Resveratrol Analogue from Asian Medicinal Plants}

Stephanie E. Martinez $^{1}$, Connie M. Remsberg ${ }^{2}$ and Neal M. Davies ${ }^{1}$

${ }^{1}$ Faculty of Pharmacy, University of Manitoba, Winnipeg, Manitoba, Canada; ${ }^{2}$ Division of Clinical Pharmacology and Experimental Therapeutics, School of Medicine, University of California San Francisco, San Francisco, California, USA

Purpose: To evaluate the bioavailability and content analysis of gnetol in plant products reported to contain gnetol using a previously validated analytical assay ${ }^{1}$ and to examine the pharmacocological properties of gnetol in in vitro models including anti-inflammatory, anti-diabetic, anti-adipogenesis and anti-cancer activity.

Methods: A validated RP-HPLC method to quantify gnetol in biological fluids was used to determine the bioavailability of the stilbene in rats as well as gnetol content analysis in Gnetum gnemon products. Male Sprague-Dawley rats were cannulated and dosed either intravenously with gnetol in 1\% DMSO in PEG $600(10 \mathrm{mg} / \mathrm{kg})$ or orally with gnetol in PEG $600(100 \mathrm{mg} / \mathrm{kg})$. Serum and urine samples were collected over a $120 \mathrm{~h}$ period. Various methanolic extractions of $G$. gnemon products were carried out for quantification of gnetol. Gnetol's effect on cell viability in breast, hepatic and prostate cancer cell lines and in colorectal cancer cell lines with or without inflammatory stimulus was assessed. Alphaamylase and alpha-glucosidase inhibition was evaluated using simple colorimetric assays. The possibility of dual cylooxygnease ( COX)-1 and-2, lipoxygenase (LOX) and adipogenesis inhibition of gnetol were assessed via commercially available assay kits. Significance was set at $\mathrm{P}<0.05$ for all statistical testing. 
Results: After oral and intravenous administration, gnetol was detected in both serum and urine as the parent compound and as a glucuronidated metabolite. The bioavailablity of gnetol was determined to be $6 \%$. Gnetol is rapidly glucuronidated and is excreted in urine and via nonrenal routes. Gnetol was found to exist as an aglycone and as a glycoside in G. gnemon products. Gnetol showed concentration dependent cell viability in cancer cell lines with greatest activity in colorectal cancer and potent COX-1 and weak COX-2 and LOX activities along with limited reduction in inflammation via the COX pathway. Gnetol also possessed concentration dependent alpha-amylase, alpha-glucosidase, and adipogenesis activities.

Conclusion: Gnetol primarily exists in nature as a glycoside. Gnetol appears to possess pharmacological activities include concentration dependent anti-cancer, anti-diabetic, antiadipogenesis and COX/LOX inhibitory activities. Pharmacokinetic studies of gnetol confirm it is poorly orally bioavailable, rapidly undergoes Phase II metabolism, and is excreted via renal and nonrenal routes.

References: ${ }^{1}$ Remsberg CM, et al. 2011. Highperformance liquid chromatography assay of gnetol in rat serum and application to pre-clinical pharmacokinetic studies. J Pharm Biomed Anal; 54:878-81.

\section{Pharmacokinetics of Tulathromycin, a Macrolide Antibiotic, in North-American Bison Following Mass Spectrometric Analysis}

$\underline{\text { Kali Bachtold }}^{\mathrm{a}}$, Jane Alcorn' ${ }^{\mathrm{a}, \mathrm{b}}$, Murray Woodbury ${ }^{\mathrm{b}}$, Johanna Matus ${ }^{\mathrm{c}}$, Joe Boison ${ }^{\mathrm{c}}$.

College of Pharmacy and Nutrition, University of Saskatchewan, Saskatoon, Saskatchewan, Canada; Western College of Veterinary Medicine, University of Saskatchewan, Saskatoon, Saskatchewan,

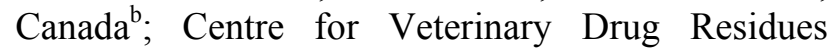
(CVDR), Canadian Food Inspection Agency, Saskatoon, Saskatchewan, Canada ${ }^{c}$.

Purpose: Tulathromycin is a macrolide antibiotic approved for use in treating bovine and swine respiratory disease. For bison, off-label use of tulathromycin occurs and studies are needed in order to determine the proper dosage regimen in this species. The purpose of our study was to assess the pharmacokinetics of tulathromycin in North-
American bison following a single $2.5 \mathrm{mg} / \mathrm{kg}$ subcutaneous injection $(\mathrm{n}=10)$ of tulathromycin (Draxxin) to provide important information regarding an appropriate dosage regimen for bison.

Method: Serial blood samples were collected at baseline and up to 25days post-injection. A quantitative analytical method for measuring tulathromycin in bison serum was validated according to international guidelines. Samples were extracted by solid-phase extraction with a weak cation exchange cartridge (Bond Elut-CBA). Cartridges were thoroughly washed in a series of steps before elution with methanol containing 2\% formic acid. Chromatography was performed by gradient elution using a Poroshell $\mathrm{C} 18$ column $(2.1 \mathrm{x}$ $50 \mathrm{~mm}, 2.7 \mu \mathrm{m})$. The mobile phase consisted of A: 5 $\mathrm{mM}$ Ammonium Formate containing $0.1 \%$ formic acid, and B: methanol. Electrospray ionization, operated in positive ionization mode, was used to detect for the $\mathrm{M}+2 \mathrm{H}^{2+}$ ion, $\mathrm{m} / \mathrm{z}$ 403.95, of tulathromycin. Pharmacokinetic parameters were estimated from each individual bison serum concentration-time data by non-compartmental methods using GraphPad Prism.

Results: Pharmacokinetic parameter estimates are reported in Table 1.

Table 1: Mean and standard deviation of each PK parameter following a $2.5 \mathrm{mg} / \mathrm{kg}$ subcutaneous injection of tulathromycin in 10 bison.

\begin{tabular}{|c|c|c|}
\hline PK parameter & $\begin{array}{l}\text { Mean } \\
(n=10)\end{array}$ & SD \\
\hline $\mathrm{k}\left(\mathrm{hr}^{-1}\right)$ & 0.0033 & 0.0006 \\
\hline $\begin{array}{l}\text { AUC } \\
(\mathrm{ng} * \mathrm{hr} / \mathrm{mL}) \\
\mathrm{Cl} / \mathrm{F}(\mathrm{L} / \mathrm{hr} / \mathrm{kg})\end{array}$ & $\begin{array}{l}\mathbf{9 3 4 1} \\
0.35\end{array}$ & $\begin{array}{l}\mathbf{5 0 8 6} \\
0.18\end{array}$ \\
\hline $\mathrm{V}_{\mathrm{d}} / \mathrm{F}(\mathrm{L} / \mathrm{kg})$ & 111 & 66.2 \\
\hline $\mathrm{t}_{1 / 2}$ (days) & 8.9 & 1.8 \\
\hline $\mathrm{C}_{\max }(\mathrm{ng} / \mathrm{mL})$ & 195 & 157 \\
\hline $\mathrm{t}_{\max }(\mathrm{hrs})$ & $4.2 *$ & 4.6 \\
\hline
\end{tabular}

$*$ Median $=1.04 \mathrm{hrs}$

Conclusion: Bison exhibited extensive interindividual variation in tulathromycin pharmacokinetics following a single subcutaneous injection. Maximal serum concentrations were lower in bison, when compared cattle, while half-lives were longer in bison, compared to cattle. Pharmacokinetic data may suggest a need to increase the size of dose used in bison. However, tissue distribution studies will assist in determining whether a cattle-based dosage regimen is inadequate 
in bison.

\section{First-In-Human Clinical Program Design for New Entities: a Comparison Between the Traditional Linear Approach and the Integrated Multiple Parts Approach}

Mira Francis, Ingrid Holmes, Eric Legault, Eric Sicard and Marc Lefebvre

Algorithme Pharma Inc., Laval, Quebec, Canada

Purpose: A comparison between 2 different approaches to design first in human (FIH) clinical programs for the assessment of safety and pharmacokinetics (PK) of new chemical entities: (1) the traditional linear approach of multiple studies, and (2) the integrated multiple parts approach.

Methods: The present analysis is conducted over 2 Phase I FIH programs aiming the following investigations: (1) Safety and PK in Single Ascending Doses (SAD), (2) Safety and PK in Multiple Ascending Doses (MAD), and (3) Effect of food in a 2-way crossover design. Each of the SAD and MAD cohorts included 8 healthy subjects $(6$ active: 2 placebo), the food effect included either 10 or 12 subjects. FIH Program 1 followed the traditional linear approach where each of the 3 studies was designed in a separate protocol, using fixed dose levels established following completion and data analysis of the previous study. FIH Program 2 followed the integrated approach where the multiple study parts were designed simultaneously within the same protocol prior to initiation of the clinical program. Additionally an adaptive approach was considered in the design to allow optional dose adjustment during the study conduct, based on the results observed from the completed parts.

Results: Both FIH Programs were completed successfully and considered to be conducted with good tolerability of the study drugs in healthy subjects. In the FIH Program 1, 7 SAD cohorts and 6 MAD cohorts were completed together with the food effect study sequentially over a period of 15 months in total. In the FIH Program 2, 5 SAD cohorts and 7 MAD cohorts were completed in parallel together with the food effect study over a period of 6.5 months. In addition, the adaptive approach offered design flexibility to investigate new dose levels in the SAD part and adapt the dosing regimen for MAD cohorts 6 and 7 based on results observed in ongoing cohorts. Finally, the FIH Program 2 included a prescheduled Proof-of-concept patient arm that could be initiated immediately following the $7^{\text {th }}$ MAD cohort and was completed within 2.5 months, for a total of 9 months for the FIH Program 2.

Conclusion: During early stage clinical development of new entities, the integrated multiple parts design approach primarily overcomes the long delay challenge observed in the traditional linear approach, thus allowing an expedited entry into Phase II.

\section{Stereoselective Pharmacokinetics of Nebivolol in the Rat}

Forugh Sanaee $^{1}$, Daniel Valente Neves ${ }^{2}$, Vera Lucia Lanchote $^{2}$ and Fakhreddin Jamali ${ }^{1}$

${ }^{1}$ Faculty of Pharmacy and Pharmaceutical ScienceS, University of Alberta, Edmonton, Alberta, Canada, ${ }^{2}$ Faculdade de Ciências Farmacêuticas de Ribeirão Preto; Universidade e São Paulo, Ribeirão Preto, Brazil

Purpose: Nebivolol is a third generation betablocker, a racemate of $d$ and 1 enantiomers, highly selective $\beta 1$ adrenoceptor antagonist and $\beta 3$ adrenoceptor agonist which goes through a significant presystemic metabolism mainly in the gut. The objective of this work was to investigate the stereospecific pharmacokinetics of the drug following different routes and to determine the factors which affect the stereoselective pharmacokinetics of nebivolol.

Method: Male Sprague-Dawley rats $(400 \pm 10 \mathrm{~g})$ were cannulated in the right jugular veins. Single 1 $\mathrm{mg} / \mathrm{kg}$ i.v. or i.p. ( $\mathrm{n}=8 /$ group) and $2 \mathrm{mg} / \mathrm{kg}$ oral $(n=10$, via gastric gavage) doses were administered. Following i.v. injection, the cannula was washed with normal saline before the first blood sample collection. Serial blood samples $(200 \mu \mathrm{L})$ were collected prior and up to $24 \mathrm{~h}$ post-dose. In another group of rats $(n=3)$, excised rat intestine segments were everted, suspended in cold Kerbs-Henesleit bicarbonate buffer at $37^{\circ} \mathrm{C}$ and samples collected from both serosal and mucosal sides. To investigate possibility of stereoselective protein binding, serum samples were incubated at $37^{\circ} \mathrm{C}$ for $1 \mathrm{~h}$ with nebivolol and then transferred to Centrifree Ultrafiltration for ultrafiltration at $2000 \mathrm{~g}$ for $1 \mathrm{~h}$. Filtrate and nonfiltrate nebivolol concentrations were measured by using a stereospecific HPLC method. The fraction unbound, fu, was determined 
as $\mathrm{fu}=\mathrm{Cu} / \mathrm{Ct}$, where $\mathrm{Cu}$ is the unbound concentration and $\mathrm{Ct}$ is the total concentration.

Results: Nebivolol pharmacokinetics was stereoselective following various routes of drug administration; the AUC of d-nebivolol was significantly higher than 1-nebivolol. Breakdown of nebivolol in the presence of everted intestine was not stereoselective (\% lost; d-nebivolol: 47.48 \pm 12.41 ; 1nebivolol: $49.86 \pm 6.24)$. On the other hand serum binding of nebivolol was stereoselective; fu: $1>d$.

Conclusion: The stereoselective binding of nebivolol enantiomers to serum proteins is the main reason behind observed stereoselectivity in the drug pharmacokinetics.

\section{Drug Delivery \& Pharmaceutical Technology}

\section{5. ${ }^{111}$ In Labeled Gold Nanoparticles Conjugated to Trastuzumab ( ${ }^{111}$ In-Au-T) Selectively Target HER-2 Overexpressed Breast Cancer Cells and Cause DNA Double Strand Breaks}

Kaiyu Yang, Zhongli Cai, Niladri Chattopadhyay, Raymond M. Reilly

Department of Pharmaceutical Sciences, Leslie Dan Faculty of Pharmacy, University of Toronto, Ontario, Canada

Background: Trastuzumab is a monoclonal antibody that can selectively bind to the human epidermal growth factor receptor-2 (HER2), which is overexpressed in $20-25 \%$ of breast cancers (BC). Our previous studies showed that ${ }^{111}$ In labeled gold nanoparticles conjugated with trastuzumab $\left({ }^{111} \mathrm{In}\right.$ $\mathrm{Au}-\mathrm{T}$ ) were retained in HER2 overexpressed $\mathrm{BC}$ tumours in mice after intratumoral injection. The purpose of this study was to examine the induction of DNA DSB in HER2 overexpressed BC cells by ${ }^{111} \mathrm{In}-\mathrm{Au}-\mathrm{T}$ and its dependence on HER 2 expression of the cells.

Method: Three BC cell lines with different HER2 expression: SK-BR-3 (1.34 $\pm 0.34 \times 10^{6}$ HER2/cell), MDA-MB-361 (5.1 $\pm 1.7 \times 10^{5}$ HER2/cell) and MCF$7\left(1 \times 10^{4}\right.$ HER $2 /$ cell $)$, were treated with $30 \mathrm{~nm}$ gold nanoparticles (AuNPs) conjugated to trastuzumab and ${ }^{111} \mathrm{In}\left({ }^{111} \mathrm{In}-\mathrm{Au}-\mathrm{T}\right)$, trastuzumab alone $(\mathrm{Au}-\mathrm{T})$, or ${ }^{111}$ In alone $\left({ }^{111} \mathrm{In}-\mathrm{Au}\right)$. The $\gamma-\mathrm{H} 2 \mathrm{AX}$ assay was used to evaluate DSBs in $\mathrm{BC}$ cells. Cell fractionation and dark field microscopy were applied to quantitatively measure and qualitatively visualize the uptake of AuNPs in BC cells, respectively.

Results: ${ }^{111} \mathrm{In}-\mathrm{Au}-\mathrm{T}$ caused 11 times more DNA DSBs in SK-BR-3 cells and 5 times more DNA DSBs in MDA-MB-361 cells than in MCF-7 cells. All three cell types treated with ${ }^{111} \mathrm{In}-\mathrm{Au}$ and $\mathrm{Au}-\mathrm{T}$ did not exhibit significantly higher DNA DSBs compared to the group without treatment $(\mathrm{P}<0.05)$. Cell fractionation showed that ${ }^{111} \mathrm{In}-\mathrm{Au}-\mathrm{T}$ is internalized 51 times more into the cell cytoplasm than ${ }^{111} \mathrm{In}-\mathrm{Au}$ in SK-BR-3 cells, and 10 times more than in MDA-MB-361 cells. Dark field microscopy confirmed that ${ }^{111} \mathrm{In}-\mathrm{Au}-\mathrm{T}$ were able to translocate into the cytoplasm of HER2 overexpressed BC cells. Conclusion: ${ }^{111} \mathrm{In}-\mathrm{Au}-\mathrm{T}$ selectively targets HER2 overexpressed $\mathrm{BC}$ cells and causes DNA DSBs. These results suggest the potential of this agent to decrease the survival of the HER 2 overexpressed BC cells, which warrant future study.

Acknowledgement: Kaiyu Yang is an awardee of the National Summer Student Research Program Awards to Present Research Findings sponsored by GlaxoSmithKline Inc.

\section{Role of Stereoregularity in the Stability of Polymeric Micelles and their Release Profiles}

Hoda Soleymani, Mohammadreza Vakili, Afsaneh Lavasanifar

Faculty of Pharmacy and Pharmaceutical Sciences, University of Alberta, Edmonton, Canada

Purpose: Polymeric micelles have been the focus of much interest in pharmaceutical research due to a wide variety of potential applications in biomedical field such as application in solubilization of poorly water soluble drugs and utilization for sustained as well as targeted drug delivery. A common problem with polymeric micellar systems is the premature drug release after systemic administration. This occurs either because the drug cannot be kept within the carrier or because the polymeric micelle cannot retain its integrity and disintegration happens upon introduction to infinite dilution after systemic administration. The objective of this research was to investigate the role of seteroregularity in the core structure of polymeric micelles in enhancing the kinetic stability and modifying the pattern of drug release from these nanocarriers.

Methods: Di-block copolymers composed of poly(ethylene oxide) (PEO), poly(L-lactide) 
(PLLA), poly(D/L-lactide) (PD/LLA) and poly(D, L- lactide) 50:50 ratio of L-lactide and D-Lactide as a racemic mixture (abbreviated as PEO-PLLA, PEOPD/LLA and PEO-PDLLA 50-50, respectively) were synthesized using MePEO (5000 Da) as initiator, L-lactide (LA), meso D/L-lactide (D/LLA) and 50:50 ratio of L-lactide and D-Lactide as the monomers and stannous octoate as catalyst. The synthesis of the di-block copolymers was pursued by two different methods bulk and solution polymerization. Polymers and micelles were characterized for their chemical structure using ${ }^{1} \mathrm{H}$ NMR, thermal properties using Differential Scanning Calorimetry (DSC), morphology using Transmission Electron Microscopy (TEM) and size using Dynamic Light Scattering (DLS). The effect of stereoregularity on the kinetic stability of polymeric micelles and release rate of loaded model drug, i.e., nimodipine, from the micellar carrier was investigated.

Results: From the synthesized block copolymers, only PEO-PLLA prepared by bulk and solution methods have shown crystallization and melting points for the core-forming block based on the DSC results. The degree of crystalinity appeared to be higher for block polymers synthesized through solution polymerization ( $\mathrm{H}$ crystallization of 16.60 versus $9.54(\mathrm{~J} / \mathrm{g})$ for solution versus bulk PLLAs, respectively). In line with this observation, micellar structures of PEO-PLLA showed an enhanced kinetic stability in comparison with other structures when exposed to sodium lauryl sulfate. The rate of drug release and its relationship with stereoregularity of the core structure appeared to be influenced by the level of drug loading levels. For polymeric micelles with high drug loading, the highest accumulative drug release was observed from the most stereoregular polymer (PEO-PLLA) and the lowest rate of drug release was seen from PEO-PDLLA 50:50. However, in the case of polymeric micelles with low drug loading no difference was observed between polymeric micelles with various core stereo-regularity.

Conclusion: The results indicate the influence of stereo-regularity in block copolymer structure on micellar stability and pattern of drug release. Although introducing a stereoregular block resulted in enhancing the kinetic stability of polymeric micelles, it didn't translate to the slow rate of drug release from the carrier.

\section{In Silco Modelling (Gastroplus ${ }^{\mathrm{TM}}$ ) to Overcome Pharmacogenomic Variation in Humans using Different Dextromethophan Dosage Forms}

Muhammad K Sarfraz, ${ }^{1}$ M. Almukainzi, ${ }^{1}$ and R. Löbenberg ${ }^{1}$ *

${ }^{1}$ Faculty of Pharmacy and Pharmaceutical Sciences, University of Alberta, Edmonton, Alberta, Canada

Purpose: Physiological based pharmacokinetic in silico modeling has become an integral tool in formulation development. The purpose of this study was to investigate how modeling can assist the formulation scientist in developing a controlled release dosage form for drugs, which undergo extensive (EM) or poor metabolism (PM). Dextromethophan (DM) was selected as a model drug because its metabolism is sensitive to pharmacogenomic variations. Literature suggested that drug delivery might be able to overcome the differences between EM and PM. Physiologically based simulations were used to test this suggestion.

Methods: A predictive model was generated using various physiological and pharmacokinetic parameters from literature data. Simulations were performed using a $30 \mathrm{mg}$ immediate release (IR) tablet model with or without co-administration of quinidine $(25 \mathrm{mg}, 50 \mathrm{mg} \& 75 \mathrm{mg}$ ) as enzyme inhibitor. After validation of the predictive model simulations were performed with zero order release tablets $\left(\mathrm{F}_{1}\right)$, first order sustained release tablets $\left(\mathrm{F}_{2}\right)$, an immediate release $(35 \%$ in $30 \mathrm{~min}$ ) followed by the zero order release tablets $\left(\mathrm{F}_{3}\right)$ and an immediate release $(70 \%$ in $30 \mathrm{~min})$ followed by zero order release tablets $\left(\mathrm{F}_{4}\right)$.

Results: There was a significant difference between EM and PM in all simulations. The IR showed a fast onset, short $\mathrm{T}_{\max }$ and highest $\mathrm{C}_{\max }$, compared to all other dosage forms in both the EM and PM. The

$\mathrm{AUC}_{0-24}$ was similar for all dosage forms for the EM and PM respectively. The co-administration of quinidine showed a gradual increase in plasma drug concentrations with increasing doses, however the effect was more pronounced in EM than in PM. There was gradual increase in $\mathrm{C}_{\max }$, decrease in $\mathrm{T}_{\max }$ and comparable $\mathrm{AUC}_{0-24}$ as the formulation release profile was altered from the $F_{1}, F_{2}, F_{3}$ and $F_{4}$ tablets, respectively. The formulations were able to alter the drug plasma profiles but did not impact the difference in the observed drug plasma profiles between the EM and PM.

Conclusion: In silico modeling assist the 
formulation scientist to optimize the release properties of a drug from a dosage form to reach a desired drug plasma profile. However, the study showed that drug delivery cannot address the differences between EM and PM which were due to pharmacogenomic variations.

\section{Effect of Disodium Ascorbyl Phytostanol Phosphates on ABC-transporter within Caco- 2 cells and the Potential Application as Enhancer of Chemotherapeutic Agents}

Kristina Sachs-Barrable and Kishor M. Wasan

Faculty of Pharmaceutical Sciences, University of British Columbia, B.C., Canada.

Purpose: Multi-drug resistance is a major problem in cancer therapy. Increased levels of $m d r-1$ gene product or its RNA have been associated with poor prognosis in a number of human tumor studies.

The purpose of this study was to investigate the effect of disodium ascorbyl phytostanol phosphate (DAPP) on $m d r-1$ gene expression and its protein, Pglycoprotein (P-gp) in Caco-2 cells, a human colon carcinoma cell line which mimics the small intestinal villus epithelium and is widely used to study intestinal drug permeability and absorption.

Disodium ascorbyl phytostanol phosphate, an amphipathic analogue of phytostanol, represents a new class of cholesterol-lowering agents.

Method: The effects of DAPP on the regulation of $m d r-1$ gene, P-glycoprotein expression as well as functionality of P-glycoprotein in Caco-2 cells, were determined via RT-PCR, Western Blot and bidirectional transport studies respectively. Caco-2 cells were treated for 7 days with increasing and non-toxic concentrations of DAPP or media as control. Bi-directional transport of Rhodamine123, a fluorescent P-gp substrate, was measured in a Transwell setting. $100 \mathrm{M}$ Verapamil was used as control for P-gp inhibition. Cells were cultured on a semi-permeable membrane which is placed between the apical and basolateral chamber. TEER values were measured before and after treatments to assure the integrity of the cell monolayer. Absorptive and secretory transport was determined by replacement experiments and fluorescent was measured (excitation: $485 \mathrm{~nm}$, emission: 530nm).

Results: We observed a significant down-regulation of $m d r-1$ m-RNA (e.g. $38.5 \pm 0.17 \%$ decrease vs. control for $10 \mu \mathrm{M}$ DAPP and $61.2 \pm 0.25 \%$ versus control for $5 \mu \mathrm{M}$ DAPP; $\mathrm{n}=6, \mathrm{P} *<0.05$ ) within Caco-
2 cells. Western Blot analysis of P-glycoprotein expression showed that changes in $m d r-1$ gene expression lead to correlating changes in P-gp protein expression. This down-regulation of Pglycoprotein also resulted in a decreased activity of P-glycoprotein compared to untreated control.

Conclusions: These findings suggest that DAPP not only has cholesterol-lowering and antiatherosclerotic properties but also decreases drug efflux and reverses multi-drug resistance.

Here we show a potential candidate for enhancing the effect of chemotherapeutic agents by reversing multi-drug resistance and decreasing drug efflux. Therefore DAPP might improve the prognosis for cancer patients.

Funding was provided by Canadian Institutes for Health Research (CIHR).

\section{Development and Characterization of Tacrolimus-Loaded PLGA Nanoparticles}

Aws Alshamsan ${ }^{1,2,3}$, Mohd. Abul Kalam ${ }^{1}$, Mohamed Badran $^{1}$, Abdullah Al-Omrani ${ }^{1}$, Ziyad Binkhathlan ${ }^{1}$, Ibrahim Aljuffali ${ }^{1}$, and Mohammed Alghonaim ${ }^{2}$

${ }^{1}$ Nanomedicine Research Unit, Department of Pharmaceutics, College of Pharmacy, King Saud University, Riyadh, Saudi Arabia; ${ }^{2}$ Prince Salman Bin Abdulaziz Chair for Kidney Disease King Saud University, Riyadh, Saudi Arabia; ${ }^{3}$ National Institute for Nanotechnology (NINT-NRC), University of Alberta, Edmonton, AB, Canada

Purpose: In order to reduce tacrolimus-associated nephrotoxicity, and to enhance the drug stability, pharmacokinetic and biodistribution profile, and to enhance preferential targeting of tacrolimus to dendritic cells (DCs), the drug was encapsulated in PLGA nanoparticles (NPs) and evaluated for different characterization parameters.

Methods: Emulsification-diffusion method was used to prepare the drug-loaded PLGA NPs. An organic phase consisting of polymer (PLGA 1\% $\mathrm{w} / \mathrm{v})$ and tacrolimus $(1 \mathrm{mg} / \mathrm{ml})$ dissolved in dichloromethane $(10 \mathrm{ml})$ was added to an aqueous phase containing polyvinyl alcohol (PVA) with and without poloxamer-188 (1\% w/v) and Tween-80 $(0.1 \% \mathrm{w} / \mathrm{v})$, and emulsified by homogenization $(21,500 \mathrm{rpm}, 10 \mathrm{~min})$. Water addition under continuous stirring for $3 \mathrm{~h}$ allowed for dichloromethane evaporation and suspension formation. Then the final product was obtained by washing through repeated centrifugation $(12,000$ 
rpm, $30 \mathrm{~min}$ ), re-dispersion and freeze-drying. Dynamic light scattering was used to measure particle size, while NP morphology was observed by scanning electron microscopy (SEM). The drug levels were measured by HPLC. Drug encapsulation efficiency (EE) and drug loading capacity of PLGA was calculated by determining the amount of nonencapsulated tacrolimus in the supernatant, against the total amount of drug added to the formulation.

Results: The prepared tacrolimus-loaded PLGA-NP had a spherical shape with a smooth surface and solid dense structure. The DLS measurement showed that the tacrolimus-loaded PLGA-NPs of about $422 \mathrm{~nm}$ in size with ideal morphology were successfully prepared by the emulsification-diffusion method. The surfactant concentrations from $0.5 \%$ to $2 \%(\mathrm{w} / \mathrm{v})$ of PVA in the external phase were used to evaluate the effect of surfactant concentration on particle size and the mean sizes of NPs were maintained in the range of 400 to $570 \mathrm{~nm}$. Our results showed that the smallest particle size and the highest drug entrapment efficiency were found at $1 \%(\mathrm{w} / \mathrm{v})$ of PVA with $1 \%(\mathrm{w} / \mathrm{v})$ poloxamers- 188 concentration. At this PVA concentration, the mean particle size and polydispersity index (PI) of PLGANPs was $422.56 \pm 41.15 \mathrm{~nm}$ and $0.143 \pm 0.0312$ respectively, while the drug EE and drug loading efficiency for PLGA-NP was $83.07 \pm 0.32 \%$ and $7.82 \pm 0.015 \%(83 \mu \mathrm{g} / \mathrm{mg})$, respectively. From these results, the optimal concentration was determined to be $1 \%(\mathrm{w} / \mathrm{v})$ of PVA.

Conclusion: Tacrolimus-loaded PLGA-NPs with diameters of about $422 \mathrm{~nm}$ could be prepared easily and are reproducible by the emulsification-diffusion method. Their drug EE and drug loading efficiency was about $83 \%$ and $7.8 \%$, respectively.. Acknowledgement: AA was supported by the grant (11 NAN 1946) from the National Plan for Science and Technology (NPST), King Saud University.

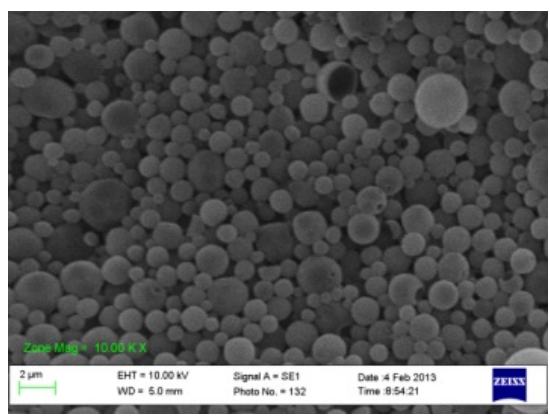

SEM image of tacrolimus loaded PLGA-NPs
Effect of PVA concentration (\%, w/v) on particle size and size distribution (Mean $\pm \mathrm{SD}$ )

\begin{tabular}{|c|c|c|c|}
\hline \multirow[t]{5}{*}{$\begin{array}{l}\text { Tacroli } \\
\text { mus } \\
\text { loaded } \\
\text { PLGA- } \\
\text { NPs }\end{array}$} & $\begin{array}{l}\text { PVA } \\
\text { concent } \\
\text { rations } \\
(\%, \\
w / v)\end{array}$ & $\begin{array}{l}\text { Particle } \\
\text { size }(\mathbf{n m})\end{array}$ & $\begin{array}{l}\text { Polydispersity } \\
\text { Index }\end{array}$ \\
\hline & 0.5 & $\begin{array}{l}570.36 \pm \\
37.41\end{array}$ & $0.2053 \pm 0.0406$ \\
\hline & 1.0 & $\begin{array}{l}422.56 \pm \\
41.15\end{array}$ & $0.1430 \pm 0.0312$ \\
\hline & 1.5 & $\begin{array}{l}543.26 \pm \\
37.63\end{array}$ & $0.1013 \pm 0.0376$ \\
\hline & 2.0 & $\begin{array}{l}569.51 \pm \\
15.19\end{array}$ & $0.2033 \pm 0.0688$ \\
\hline
\end{tabular}

30. Stromal Depletion and Suppression of Metastases in Breast Cancer Models with a Docetaxel-carboxymethylcellulose Nanoparticle

M. J. Ernsting ${ }^{1}$, A. Roy ${ }^{1}$, M. Murakami ${ }^{1}$, E. Undzys $^{1}$, N. Holwell ${ }^{1}$, and S.D. Li ${ }^{1,2}$.

${ }^{1}$ Ontario Institute for Cancer Research, Toronto, ON, Canada; ${ }^{2}$ Leslie Dan Faculty of Pharmacy, University of Toronto, Toronto, ON, Canada

Purpose: Stromal cells, integral components of the tumor microenvironment, promote tumor survival, progression and metastasis. Depletion of tumor stroma is considered to be an effective approach for cancer therapy, but success has been limited. It has already been established that treatment with Cellax, a polymeric conjugate of docetaxel (DTX) and carboxymethylcellulose, resulted in improved antitumor efficacy and reduced side effects compared to native DTX. We further studied the intratumoral distribution of Cellax, its impact on tumor microenvironment and its effect on metastases.

Methods: Cellax was synthesized as reported earlier (Ernsting et al. Bioconjug Chem 2011). Orthotopic tumors were generated by inoculating 4T1 cells $(1 \mathrm{x} 106)$ in the mammary fat pad of female $\mathrm{Balb} / \mathrm{c}$ mice. Intratumoral pharmacodynamic and distribution studies: Tumor bearing mice were treated with Cellax (170 mg DTX/kg) and were sacrificed $6,16,24,72$ and $168 \mathrm{~h}$ after treatment. Tumor sections were fixed, stained for $\alpha$-smooth muscle actin [SMA, a marker for cancer associated fibroblast (CAF)] and with $\mathrm{H} \& \mathrm{E}$ and the images 
were analyzed for total tumor area, non-viable component, and $\alpha$-SMA stromal coverage. The stromal uptake of Cellax was analyzed by treating a group of mice with Cellax containing fluorescent DiI. The animals were sacrificed $24 \mathrm{~h}$ after treatment, fixed tumors were stained for $\alpha$-SMA $+\mathrm{CAF}$ and the co-localization of CAF with Cellax-DiI was analyzed. Efficacy study: Tumor bearing mice were treated with the MTD of Cellax (170 mg DTX $/ \mathrm{kg})$, native DTX (40 mg DTX/kg), Nab-paclitaxel (50 mg $\mathrm{PTX} / \mathrm{kg}$ ) or saline through i.v. route. Six days post therapy, mice were i.v. injected with FITC-lectin for determination of tumor perfusion and tumor interstitial fluid pressure (IFP) was measured, and the primary tumors were resected, fixed and stained for CD31 (blood vessels) and for $\alpha$-SMA. On day 13, mice were treated with a second round of therapy, and on day 20 the entire cohort was sacrificed, and lung tissues were harvested for histological analysis of metastases.

Results: CAFs were found to be the primary target of Cellax as $85 \%$ of DiI labelled Cellax particles were internalized by them. Cellax treatment resulted in rapid (16 $\mathrm{h}$ after injection) and continuous reduction in $\mathrm{CAF}$ which became almost undetectable after 1 week. Significant death of the tumor cells occurred only after complete $\alpha$-SMA stromal depletion. The Cellax induced CAF reduction was found to be significantly higher compared to Nabpaclitaxel or DTX, which showed no significant effect. Perfusion also increased significantly with Cellax treatment ( $>60$-fold) compared to DTX and Nab-paclitaxel. A $\sim 3$ fold reduction in IFP was seen in Cellax treated tumors compared to other treatments, which showed no significant change compared to control.

Cellax treatment also resulted in a significant reduction in lung metastases. While $90 \%$ and $86 \%$ of mice treated with DTX and Nab-paclitaxel showed tumor nodules in the lung, only $40 \%$ Cellax treated mice presented with lung nodules. A 6.7 fold less tumor burden was found in the lung sections of the Cellax treated mice compared to other taxane treatments which showed no significant difference from the control group.

Conclusion: Cellax therapy has a significant impact on tumor stroma, an effect associated with increased tumor perfusion, decreased IFP, and reduced metastases compared to native DTX and Nabpaclitaxel.

\section{Effect of Gemini Surfactant on Amyloid Beta Aggregation}

Mehrnoosh Bahmani and Shawn Wettig. School of Pharmacy, University of Waterloo, Waterloo, Ontario, Canada

Purpose: Alzheimer's disease (AD) is a progressive dementia affecting cognition, behavior, and functional status and there is no cure which exists to it. In $\mathrm{AD}, \mathrm{A} \beta$ forms a conformation that is neurotoxic for neuronal cells in the brain. Therefore, molecules with the ability of preventing $A \beta$ aggregation could be effective in $\mathrm{AD}$ treatment. Gemini surfactant (GS) molecules consist of two hydrophilic heads separated by a covalently bound spacer and two hydrophobic tails. Their structure gives rise to a number of unique properties, including low critical micelle concentrations, the ability to form multiple types of aggregates (governed primarily by the nature of the spacer group) and enhanced ability to bind to polymers, all of which are important with respect to the ability of these compounds to solubilize very hydrophobic materials such as $A \beta$. The aim of this study was to examine various GS structures to help us to understand their interaction with $\mathrm{A} \beta$ and the influence of spacer group and tail length in $A \beta$ disassembly.

Method: We employed GS with a tail 12 carbon atoms in length and spacer groups with different hydrophilicities: $\left(-\mathrm{CH}_{2}-\mathrm{CH}_{2}-\mathrm{O}\right)_{\mathrm{m}},\left(-\mathrm{CH}_{2}\right)_{\mathrm{m}}, \mathrm{N}\left(\mathrm{CH}_{2}\right)_{\mathrm{m}}$, $\mathrm{OH}\left(\mathrm{CH}_{2}\right)_{4}$ and $(\mathrm{OH})_{2}\left(\mathrm{CH}_{2}\right)_{4}$. Isothermal titration calorimetry and dynamic light scattering have been employed to observe the gemini-A $\beta$ interactions. All experiments were performed at room temperature.

Results: data analysis revealed extensive rearrangement of $\mathrm{A} \beta$ and gemini surfactant during the interaction. The results are attributed to the changes in both the length and composition of the spacer group.

Conclusion: Gemini surfactants are observed to complex with $\mathrm{A} \beta$, increasing its solubility. The manner in which the interaction takes place is strongly dependent upon the size and composition of the spacer group, indicating the importance of surfactant head group - peptide interactions. 


\section{Evaluation of the Cholesterol Lowering Plant Sterols using an in vitro Lipolysis Model}

Jinying Zhao ${ }^{1}$, Pavel Gershkovich ${ }^{2}$, and Kishor M. Wasan $^{1}$

${ }^{1}$ Faculty of Pharmaceutical Sciences, The University of British Columbia, Vancouver, BC, Canada; ${ }^{2}$ School of Pharmacy, The University of Nottingham, Nottingham, UK

Purpose: Numerous studies have demonstrated that plant sterols and their analogues lower blood cholesterol levels and reduce the risk of coronary heart disease. However, the mechanism of action is still poorly understood. In this work, an in vitro lipolysis model was used to evaluate the effects of two well reported cholesterol lowering plant sterols: stigmastanol and disodium ascorbyl phytostanol phosphate (DAPP) on intestinal processing of cholesterol

Method: Stigmastanol is a lipophilic phytosterol that was added into the lipolysis system as 1) powder; 2) stigmastanol formulation (wetted by Tween 80 and suspended in $2 \%$ sodium carboxymethyl cellulose solution). DAPP is a modified hydrophilic phytostanol that was added as a viscous solution. For the in vitro lipolysis experiments, radiolabeled cholesterol and cold peanut oil were added to $35.5 \mathrm{ml}$ digestion buffers mimicking both the fasted and fed state intestinal conditions. After the plant sterols were added, the pancreatic enzyme was added to initiate the lipolysis process, and a stat titrator was maintaining $\mathrm{pH} 7.4$ with constant stirring. Following the completion of the lipolysis reaction, samples of the digestion buffer were ultra-centrifuged The radioactivity of cholesterol in oil, aqueous and sediment phases were then determined by scintillation counter and calculated to show the percentage cholesterol distribution between phases.

Results: Stigmastanol powder had no effect on cholesterol intra-luminal processing in both fasted and fed states. Stigmastanol formulation changed the cholesterol distribution significantly $(p<0.05)$ in both states $(22 \%$ reduction in aqueous phase in fasted state: $8 \%$ reduction in fed state) by redistributing cholesterol into oil phase and sediment phase. Disodium ascorbyl phytostanol phosphate (DAPP) redistributed cholesterol from aqueous phase $(24 \%$ reduction in fasted state; $4 \%$ reduction in fed state) to sediment phase $(\mathrm{p}<0.05)$ suggesting its possible higher efficiency compared to stigmastanol. A significant reduction of the $\mathrm{NaOH}$ used titrating free fatty acids produced during the process was also observed for DAPP $(0.73 \pm 0.09 \mathrm{ml}$ vs. Control: $0.89 \pm 0.07 \mathrm{~m}, \mathrm{p}<0.05)$.

Conclusion: The in vitro lipolysis results revealed valuable mechanistic information about the two cholesterol absorption inhibitors. Formulation is found to play an important role for lipophilic stigmastanol. DAPP's cholesterol lowering ability may be related to its potential role in intestinal triglyceride hydrolysis.

Funding for this project was kindly provided by Canadian Institute of Health Research (CIHR). This was previously presented at AAPS Annual Meeting October 2012 in Chicago IL USA.

\section{In Vivo Degradation Biodistribution and Biocompatibility of Biodegradable Hyperbranched Polyglycerols in Mice}

Rajesh A. Shenoi, Benjamin F.L. Lai, Muhammad Imran ul-haq and Jayachandran N. Kizhakkedathu*. Centre for Blood Research and Department of Pathology and Laboratory Medicine, University of British Columbia, Vancouver BC, Canada

Purpose: Hyperbranched polyglycerols (HPGs), due to their multifunctionality, excellent biocompatibility and ability to control the plasma half life have recently been explored as scaffolds for drug delivery, bioconjugation and imaging. However the non-biodegradable nature of HPGs results in accumulation of high molecular weight polymers in vital organs that may limit their therapeutic utility. The purpose of the present study was to develop high molecular weight biodegradable HPGs (BHPGs) and investigate their degradation behavior and biodistribution in mice.

Methods: We synthesized main chain degradable BHPGs containing acid cleavable ketal groups by anionic ring opening polymerization of glycidol with ketal group containing epoxide monomers. The biocompatibility of BHPGs and their degradation products was evaluated using blood coagulation, complement and platelet activation, erythrocyte aggregation, hemolysis and cell viability assays. We also studied the $\mathrm{pH}$ dependent degradation of BHPGs in vitro in different buffers using nuclear magnetic resonance spectroscopy. The in vivo degradation, biodistribution and clearance of tritiumlabeled BHPG were investigated by intravenous administration in female Balb/C mice and the results were compared with those of non-degradable HPGs. 
Results: BHPGs exhibited controlled degradation profiles in vitro depending on the $\mathrm{pH}$ and temperature. BHPGs and their degradation products showed excellent blood and cell compatibility profiles even at high concentrations $(5 \mathrm{mg} / \mathrm{mL})$ based on various analysis methods. When administered intravenously in mice, the plasma half life of BHPG of molecular weight $100 \mathrm{kDa}$ was $2.7 \pm 0.3 \mathrm{~h}$ compared to the $39.2 \pm 8.9 \mathrm{~h}$ for nondegradable HPG of similar molecular weight. This demonstrated the in vivo degradation of BHPGs into low molecular weight fragments and their rapid clearance from circulation. This was further supported by the very low tissue accumulation $(<0.5 \%)$ and substantial urinary and fecal clearance $(82 \%)$ exhibited by BHPG. Due to the excellent biocompatibility, controlled degradation and multifunctional nature of the biodegradable HPGs, we are currently exploring their use as drug delivery vehicles and imaging agents.

Conclusion: We demonstrated for the first time the in vivo degradation and biodistribution of water soluble main chain degradable multifunctional high molecular weight BHPGs. The excellent biocompatibility and the in vivo degradation and clearance of BHPGs have the potential for the development of multifunctional drug delivery systems.

\section{Development and Characterization of a Novel Intravaginal Nanomedicine for the Targeted Delivery of Saquinavir to CD4+ T-Cells}

Alicia Dash, Sidi Yang, Yufei Chen, Kaien Gu, Casey Sayre, Neal Davies, and Emmanuel A. Ho. Laboratory for Drug Delivery and Biomaterials, Faculty of Pharmacy, University of Manitoba, Winnipeg, Manitoba, Canada

Purpose: Despite successful HIV prevention strategies such as condom use, monogamy, and abstinence, HIV is a disease that has affected over 65,000 Canadians in 2009, with over 4,000 new HIV infections occurring each year in Canada. Biologically, women are twice more likely to become infected with HIV through unprotected heterosexual intercourse. The goal of this study was to develop and characterize an intravaginal nanomedicine for the active delivery of saquinavir (SQV) to CD4+ immune cells as a strategy to protect and reduce HIV infection.

Methods: SQV-encapsulated nanoparticles (SQV-
NPs) were prepared from poly(lactic-co-glycolic acid) (PLGA) and conjugated to anti-CD4 antibody. Dynamic light scattering was used to determine particle size and zeta potential. Drug release studies were performed in PBS buffer ( $\mathrm{pH} 4.6$ ) at $37{ }^{\circ} \mathrm{C}$ on a rotary shaker and quantitated using high performance liquid chromatography (HPLC). Cell targeting studies were performed using the T-cell line Sup-T1 and cytotoxicity studies were evaluated in the vaginal epithelial cell line VK2/E6E7.

Results: Antibody-conjugated SQV-NP (SQV-NP$\mathrm{Ab})$ had an encapsulation efficiency of $74.4 \pm 3.7 \%$ and antibody conjugation efficiency of $80.95 \pm 1.105 \%$. Over $77 \%$ of total loaded SQV was released from NPs over 13 days. NPs were rapidly taken up by Sup-T1 cells with more than a two-fold increase observed in the intracellular level of SQV when delivered by SQV-NP-Ab compared to control $1 \mathrm{hr}$ post-treatment. No cytotoxicity was observed when vaginal epithelial cells were treated for $24 \mathrm{hr}$ with drug-free NPs $(1 \mathrm{mg} / \mathrm{mL})$.

Conclusions: Overall, we have described an intravaginal nanomedicine that is non-toxic and can specifically deliver SQV into CD4+ immune cells. This platform demonstrates utility in its application as a microbicide for the prevention of HIV and other sexually transmitted infections.

Acknowledgement: Alicia Dash is an awardee of the National Summer Student Research Program Awards to Present Research Findings sponsored by GlaxoSmithKline Inc.

\section{Nanoparticle-based Gel for the Intravaginal Targeted Delivery of siRNA to Immune Cells of the Mucosa}

Sidi Yang, Jijin Gu, and Emmanuel A. Ho. Laboratory for Drug Delivery and Biomaterials, Faculty of Pharmacy, University of Manitoba, Winnipeg, Manitoba, Canada

Purpose: The main purpose of this study is to develop and characterize an intravaginal nano-based drug delivery system for the targeted delivery of siRNA to CD4+ immune cells. The intravaginal drug delivery system is designed to deliver single or multiple siRNA sequences for the targeted knockdown of viral genes or host factors as a potential pre-exposure prophylaxis for HIV-1 infection.

Methods: Non-specific siRNA was used as a model drug for the study of our drug delivery system. 
siRNA was first condensed by polyethyleneimine (PEI) and then encapsulated into nanoparticles (NPs) by a double-emulsion evaporation method using the biodegradable di-block copolymer, poly(lactic-coglycolic acid)- polyethylene glycol (PLGA-PEG). NPs were conjugated to anti-human anti-CD4 antibody via the activation of NHydroxysuccinimide and 1-ethyl-3-(3dimethylaminopropyl)carbodiimide. Resulting antibody-conjugated NPs (NP-Ab) were then formulated into a $1 \% \mathrm{HEC}$ vaginal gel.

Results: siRNA NPs showed a uniform particle size of $269 \pm 1.4 \mathrm{~nm}$ and a zeta-potential of $-47.59 \pm 1.42$ $\mathrm{mV}$. Encapsulation efficiency of siRNA was improved from $58.4 \%$ to $81.7 \%$ via the inclusion of PEI at an N/P ratio of $6: 1$. NPs showed a sustained release profile, with approximately $3.18 \pm 0.32 \%$ of siRNA released over 5 days $(\sim 0.5 \%$ per day with no significant burst release observed). There was a positive correlation between the amount of antibody added and the amount of antibody conjugated to the NPs. siRNA-loaded NP-Ab achieved >3-fold increase in the intracellular accumulation of siRNA in the T-cell line Sup-T1 compared to unconjugated NPs. Vaginal gel consisting of 1\% HEC and loaded with NP-Ab showed a non-Newtonian shearthinning behavior and the viscosity of the NP-Ab loaded gel was comparable to over-the-counter lubricant gel products. Both the drug-free NPs (1000 $\mu \mathrm{g} / \mathrm{mL})$ and the $1 \%$ HEC placebo gel $(200 \mathrm{mg} / \mathrm{mL})$ had no significant impact on the viability of the vaginal epithelial cell line VK2/E6E7 after $24 \mathrm{~h}$ exposure.

Conclusions: Our research group has developed a novel intravaginal nano-based drug delivery system for the active delivery of siRNA to CD4+ immune cells. siRNA can be efficiently encapsulated into PLGA-PEG NPs with desirable particle size for intravaginal delivery and sustained drug release. NP$\mathrm{Ab}$ can significantly increase the intracellular delivery of siRNA into CD4+ immune cells when compared to unconjugated NPs. NP-Ab can be formulated into a gel dosage form that is comparable to marketed vaginal gel products. Both of the drugfree NPs and the 1\% HEC placebo gel are non-toxic to vaginal epithelial cells.

\section{An Innovative Two-Component Intravaginal Ring for Sustained Protein Delivery}

Yufei Chen, Roien Ahmadie, Nathan Baart, and Emmanuel A Ho.

Laboratory for Drug Delivery and Biomaterials, Faculty of Pharmacy, University of Manitoba, Winnipeg, Manitoba, Canada

Purpose: In the absence of an HIV vaccine, development of microbicides (products applied intravaginally for the prevention of HIV transmission) has been of great interest. As a result, developing a strategy that can induce vaginal mucosal immunity may be effective in protecting against sexually transmitted infections. The goal of this study was to develop and characterize a novel two-component intravaginal ring (tIVR) drug delivery system for the sustained release of proteins (>14 days).

Method: The first component of the tIVR (IVR body) was fabricated from medical grade polyether urethane using hot melt injection molding. The second component of the tIVR (capsules) was fabricated from silicone using solvent casting. Various excipients were mixed with BSA at different weight ratios to form semi-solid mixtures, which were then loaded into the capsules and sealed with a semi-permeable membrane. In vitro release studies were performed by incubating the capsules in $5 \mathrm{~mL}$ of $0.1 \mathrm{M}$ potassium phosphate buffer $(\mathrm{pH} 4)$ at $37^{\circ} \mathrm{C}$ and $160 \mathrm{rpm}$ for 20 days. Quantitation of BSA release was performed using a gradient reversephase HPLC method. In vitro cytotoxicity was evaluated in the vaginal epithelial cell line Vk2/E6E7 using protein-free capsules and tIVR segments over 30 days. The levels of proinflammatory cytokine (IL-1 $\beta$, IL-6 and IL-8) production were quantitated via ELISA. Thermal stability studies were carried out using various osmolytes, as protein stabilizers, mixed with BSA at different molar ratios and incubated in vaginal fluid simulant ( $\mathrm{pH} 4.2)$ at $60{ }^{\circ} \mathrm{C}$ for 28 days. Tris-Tricine SDS-PAGE and native-PAGE were utilized for the detection of BSA aggregation/degradation.

Results: The rate of BSA release from the capsules was affected by the viscosity of the excipient and the type of semi-permeable membrane used. Controlled and sustained release of BSA $(\sim 0.5 \mu \mathrm{g} / \mathrm{mL} /$ day $)$ was observed using a high viscosity non-ionic excipient at a BSA:excipient ratio of 1:2.5 (w/w) over 2 weeks. No cellular toxicity or significant cytokine production was observed when vaginal epithelial 
cells were exposed to the protein-free capsule and tIVR segment for 30 days. In acidic and heatstressed environments, the naturally occurring osmolyte trimethylamine $\mathrm{N}$-oxide was capable of stabilizing BSA.

Conclusions: We have developed an innovative two-component ring device (tIVR) that is capable of providing controlled and sustained release of BSA over 14 days, and can stabilize BSA in acidic and heat-stressed environments. This novel platform demonstrates potential utility for the sustained induction of vaginal mucosal immunity against sexually transmitted infections.

\section{Enhanced Teatment of Lung Metastasis of Triple Negative Breast Cancer by Doxorubicin-mitomycin C Co-loaded Polymer Lipid Nanoparticles}

$\underline{\text { Preethy Prasad }^{1}}$, Ping Cai ${ }^{1}$, Andrew M. Rauth ${ }^{2}$, Xiao $\mathrm{Yu} \mathrm{Wu}$.

${ }^{1}$ Department of Pharmaceutical Sciences, Leslie Dan Faculty of Pharmacy, University of Toronto, Toronto, Ontario, Canada; ${ }^{2}$ Division of Applied Molecular Oncology, Ontario Cancer Institute, Toronto, Ontario, Canada

Background: Triple negative, a subtype of breast cancer accounts for about $15 \%$ for breast cancer and is known for its aggressive characteristics leading to metastases. Treatment of triple negative breast cancer is a big challenge due to its aggressiveness, poor prognosis and lack of therapeutic target due to absence of receptor proteins. Our laboratory has developed doxorubicin (Dox) - mitomycin C (MMC) co-loaded stealth polymer lipid hybrid nanoparticles (DMsPLN) and demonstrated anti-cancer synergy in vitro and high efficacy in vivo. The purpose of the study is to evaluate the biodistribution, in vivo efficacy and safety of DMsPLN in a lung metastatic human breast cancer model.

Method: Lung metastasis of breast tumor was established using MDA-MB 231-luc-D3H2LN, a luciferase expressing cell line that was derived from spontaneous lymph node metastasis. The cells were injected via tail vein to develop lung metastasis in SCID mice. The biodistribution and tumor accumulation of the nanoparticle were examined by whole animal optical imaging using near infrared fluorescence labeled nanoparticles. The efficacy and systemic toxicity of DMsPLN were evaluated against clinically used doxorubicin (Dox). To determine the therapeutic efficacy and toxicity, DMsPLN and Dox were administered intravenously at various Dox dose. Tumor size was measured as function of time to determine therapeutic efficacy of the treatment and systemic toxicity was monitored by repeated measurement of body weight.

Results: A metastatic breast tumor model was successfully developed using the MDA-MB 231-lucD3H2LN which allowed for non-destructive monitoring of tumor growth and metastases using bioluminescence imaging. Whole animal imaging demonstrated the localization of the fluorescent nanoparticles in the metastatic breast cancer site. Treatment with Dox $(10 \mathrm{mg} / \mathrm{kg})$ resulted in severe total body weight loss over $20 \%$ which is ruled as a toxic endpoint. However, the DMsPLN $(10 \mathrm{mg} / \mathrm{kg}$ equivalent Dox dose) group did not show any systemic toxicity. Treatment with DMsPLN at various Dox dose resulted in a reduction in tumor size compared to the saline and Dox treated groups.

Conclusion: DMsPLN demonstrated enhanced efficacy and reduced toxicity over free drug in aggressive mouse models metastatic human breast cancers. Therefore, DMsPLN may provide clinically relevant, more aggressive anti-cancer interventions.

\section{Design of Progesterone Binding Nano- Carriers for the Treatment of Alzheimer's Disease}

Mahsa Alizadeh Noghani ${ }_{1}$ Donald E. Brooks ${ }_{1,2}$, and Jayachandran N. Kizhakkedathu ${ }_{1,2}$.

Centre for Blood Research, Department of Chemistry $_{1}$, Department of Pathology and Laboratory Medicine ${ }_{2}$; University of British Columbia, Vancouver BC, Canada

Purpose: Alzheimer's disease (AD) is characterized clinically by slow progressive intellectual decline resulting in psychological and social dependence, ultimately leading to dementia and death. Severe head trauma, acute infection, and excessive use of drugs and alcohol have been proved as capable precipitating dementia syndromes in several case reports. Traumatic brain injury (TBI) has been proved as an established risk factor of Alzheimer's disease. Historically, progesterone promotes recovery from moderate TBI. However, the utility of progesterone as a TBI treatment is severely hampered by its near total insolubility in water due to its hydrophobicity contributes to the inability to rapidly administer progesterone after injury. 
Development of progesterone encapsulated HPG based biocompatible nanocarriers (dHPG-Pro) will significantly enhance the solubility, stability and bioavailability of progesterone.

Methods: We have synthesized a hydrophobic core containing HPG protected by Methoxy Polyethylene Glycol (MPEG) to enable drug binding as well as enhancing the solubility of the drug and stability of the formulation. Polymeric system was developed by modifying hyperbranched polyglycerol core with binding alkyl chains which increase the hydrophobicity in order to provide the system with higher drug encapsulation. dHPG systems were characterized by Gel Permeation Chromatography and Nuclear Magnetic Resonance. Progesterone binding and releasing from the polymeric pocket was determined by using Reversed Phase HPLC. Progesterone detection was performed using ultraviolet detection at a wavelength of $249 \mathrm{~nm}$ by measuring the drug's highest absorbance and its concentration. Biocompatibility and cytotoxicity of the drug-polymer system will be measured by using standard blood coagulation in vitro assays including Prothrombolin Time and Activated Partial Thromboplastin Time and Thromboelastography (TEG).

Results: Polymeric vehicle with different incorporation of hydrophobic alkyl chains and hydrophilic MPEG chains have shown different capacity of drug loading and stability of the whole system. Higher amount of alky chains shows stronger and more stable drug binding whereas incorporation of more hydrophilic MPEG chains in the system have been developed more and longer stability of the drug delivery system in buffer system. The amount of hydrophobic and hydrophilic parts of the system should be in balance in order to prevent any kind of aggregation and instability of drug in the system for longer time, respectively.

Conclusion: Progesterone has been identified to increase the secretion of one of the most established genetic risk factors of Alzheimer's disease from the brain cells called glia. As a result, offering a solution in administration of progesterone as a TBI treatment and $\mathrm{AD}$ applications has been highly important. Based on hydrophobic dHPGs, we have developed a novel and highly innovative nanoparticulate drugdelivery vehicle to encapsulate progesterone which would significantly improve its solubility, bioavailability and stability.

\section{Chitosan Coated Nanostructured Lipid Carriers Containing Dexamethasone Acetate: Development and PhysicalCchemical Characterization}

Bruna Barbosa, Juliana Denise Conte, Raimar Löbenberg, Nadia Bou-Chacra.

Faculty of Pharmaceutical Sciences, University of Sao Paulo, Brazil. Faculty of Pharmacy and Pharmaceutical Science, University of Alberta, Edmonton, Alberta, Canada

Purpose: The conventional ophthalmic preparations have reduced residence time in the ocular region as a result of the protective mechanisms of the eye. In addition, the cornea acts as a barrier contributing to the reduced concentration of the drug in the organ. Thus, these products have low bioavailability. These limitations require patient adherence to treatment regimen with multiple administrations per day and substantial loss of the instilled material. The purpose of this work was to develop and characterize a chitosan coated nanostructured lipid carrier (CSNLC) containing dexamethasone acetate which represents a therapeutic opportunity for ocular drug delivery.

Methods: The NLC was formulated using 12.0\% $(\mathrm{w} / \mathrm{w})$ cetyl palmitate (CP), $8.0 \% \quad(\mathrm{w} / \mathrm{w})$ capric/caprylic triglycerides (CCP), $5.0 \%(\mathrm{w} / \mathrm{w})$ tween ${ }^{\circledR} 80,3.0 \%(\mathrm{w} / \mathrm{w})$ lutrol ${ }^{\circledR}, 0.5 \%(\mathrm{w} / \mathrm{w})$ soy lecithin (SL), $2.0 \%(\mathrm{w} / \mathrm{w})$ sodium dodecyl sulphate (SDS) and $0.1 \%(\mathrm{w} / \mathrm{w})$ dexamethasone acetate and obtained by high pressure homogenization (HPH). An aqueous surfactant solution of tween ${ }^{\circledR}$ 80, SDS and lutrol ${ }^{\circledR}$ was slowly added to the lipid phase $(\mathrm{CP}$, $\mathrm{CCP}$ and SL) at $10{ }^{\circ} \mathrm{C}$ above the lipid melting temperature. The formulation was mixed for $1 \mathrm{~min}$ at $8000 \mathrm{rpm}$ using the Ultra-Turrax ${ }^{\circledR}$ (IKA, model $\mathrm{T} 25)$. The hot nanoemulsion obtained was processed using a high pressure homogenizer (GEA Niro Soavi, model PANDA) for three cycles at 500 bar. CS- NLC was obtained by dissolving $0.5 \% \mathrm{w} / \mathrm{v}$ of chitosan (CS) in the nanoparticle suspension under moderated magnetic stirring for one hour. Measures of mean diameter, polydispersity index (PI) and zeta potential (ZP) were performed on Zetasizer Nano $Z S ®$. The encapsulation efficiency was evaluated using spectrophotometer at $240 \mathrm{~nm}$.

Results: The nanoparticles presented mean diameter of $120.7 \pm 22 \mathrm{~nm}$, PI equal to 0.012 and ZP $-33.2 \pm 9.0$ $\mathrm{mV}$. The efficiency of encapsulation rate was $97.4 \%$. After the coating procedure, the mean diameter, the PI and the ZP were changed to respectively $290 \pm 35$ 
$\mathrm{nm}, 0.302$ and $+25.80 \pm 7.0 \mathrm{mV}$. As expected, the CS-NLC presented larger mean diameter and an inversion of the surface charge which indicated the coating efficiency.

Conclusion: The system developed in this study showed interesting properties and therefore it can be proposed as promising carrier to improve the therapeutic efficacy of ophthalmic preparations containing dexamethasone acetate.

\section{Lipid Nanoparticles Containing siRNA Synthesized by Microfluidic Mixing Exhibit an Electron-Dense Nanostructured Core}

Alex K. K. Leung ${ }^{1}$, Ismail M. Hafez ${ }^{1}$, Svetlana Baoukina $^{2}$, Nathan M. Belliveau, ${ }^{3}$, Igor V. Zhigaltsev $^{1}$, Elham Afshinmanesh ${ }^{2}$, D. Peter Tieleman $^{2}$, Carl L. Hansen ${ }^{4}$, Michael J. Hope ${ }^{5}$ and Pieter R. Cullis ${ }^{1}$.

${ }^{1}$ Department of Biochemistry and Molecular Biology, University of British Columbia, Vancouver, Canada; ${ }^{2}$ Department of Biological Sciences and Institute for Biocomplexity and Informatics, University of Calgary, Calgary, Canada; ${ }^{3}$ Precision NanoSystems, Vancouver, Canada; ${ }^{4}$ Department of Physics and Astronomy, University of British Columbia, Vancouver, Canada; ${ }^{5}$ AlCana Technologies, Vancouver, Canada

Purpose: Lipid nanoparticles (LNP) containing ionizable cationic lipids are the leading systems for enabling therapeutic applications of siRNA, however the structure of these systems has not been defined. Interestingly, siRNA encapsulation efficiency of LNPs produced by microfluidic mixing routinely approaches $90 \%$, a result that is difficult to reconcile with a bilayer model for these LNPs. Here we examine the structure of LNP siRNA systems containing DLin-KC2-DMA (an ionizable cationic lipid), phospholipid, cholesterol and a polyethylene glycol (PEG) lipid formed using a rapid microfluidic mixing process.

Methods: Lipid nanoparticles (LNP) were produced by mixing lipids in ethanol with equal volumes of siRNA in aqueous buffer using a herring bone micromixer. Encapsulation efficiency of siRNA was measured using the commercially available RiboGreen RNA Assay Kit. The structure of LNPs was determined using cryo-transmission electron microscopy (cryo-TEM), ${ }^{31} \mathrm{P}$ NMR, membrane fusion assays, density measurements and molecular modeling.

Results: Cryo-TEM results clearly indicate these LNP siRNA systems have a solid interior lipid core in stark contrast to that of a bilayer system. Results from ${ }^{31} \mathrm{P}$ NMR, membrane fusion assay and density measurements suggest the LNPs are made up of a core that contains siRNA duplexes complexed to cationic lipid and that the interior core also contains phospholipid and cholesterol. Consistent with experimental observations, molecular modeling calculations indicate that the interior of LNP siRNA systems exhibits a periodic structure of aqueous compartments, where some compartments contain siRNA.

Conclusions: It is concluded that LNP siRNA systems formulated by rapid mixing of an ethanol solution of lipid with an aqueous medium containing siRNA exhibit a nanostructured core. The results give insight into the mechanism whereby LNP siRNA systems are formed, provides an understanding of the high encapsulation efficiencies that can be achieved and inform methods of constructing more sophisticated LNP systems.. 


\section{CC-CRS Posters - Session 1}

\section{Tuesday to Wednesday, June 11-12}

\section{A Bilayer Hydrogel System with Bioinspired Mucoadhesion for Buccal Drug Delivery}

$\underline{\text { Jinke Xu }}^{1}$, Satu Strandman ${ }^{2}$, Julian X.X. Zhu ${ }^{2}$, Jake Barralet $^{3}$ and Marta Cerruti ${ }^{1,3}$.

${ }^{1}$ Department of Mining and Materials Engineering, McGill University, Montreal, Canada; ${ }^{2}$ Department of Chemistry, Université de Montréal, Montreal, Canada; ${ }^{3}$ Faculty of Dentistry, McGill University, Montreal, Canada.

Purpose: Buccal drug delivery is an attractive administration method which has no presystemic clearance compared to gastrointestinal tract drug delivery, avoids the first-pass elimination in the liver during systemic circulation, and prolongs localized drug effect. Good mucoadhesion of the systems can prolong their residence time on site, allowing sustained release of drugs. In this study, we developed catechol-chitosan/genipin (Cat-CS/GP) hydrogel system inspired by Dopa-enriched marine mussel adhesive protein. Cat-CS/GP system has shown enhanced mucoadhesion and achieved sustained release of model drugs.

Methods: Catechol functional groups were covalently bonded to chitosan by EDC coupling method of chitosan and hydrocaffeic acid, with two catechol contents of $6 \%$ and $14 \%$. Hydrogel was prepared by crosslinking Cat-CS with GP. A protective layer made in ethyl cellulose was prepared to prevent drug release to saliva. Rheological behavior of Cat-CS/GP hydrogel was tested by a time sweep up to $12 \mathrm{~h}$ (cone/plate steel geometry $\left(\Phi 40 \mathrm{~mm}, 2^{\circ}\right)$. Acetaminophen and nicotine as model drugs were loaded into the hydrogels respectively. Drug release was quantified in vitro by UV-vis spectrophotometry. Mucoadhesion was evaluated by measuring detachment time of the hydrogel from pig buccal mucosa surface in PBS (pH 6.8), at $300 \mathrm{rpm}$ continuous stirring. In vivo study was conducted in rabbit, by attaching drug-loaded bilayer hydrogel to the buccal mucosa. Blood samples were collected at certain time points, followed by HPLC quantification of drug concentration in the serum.
CS crosslinked by GP hydrogels (CS/GP) were used as controls.

Results: The gelation of both CS/GP and Cat$\mathrm{CS} / \mathrm{GP}$ hydrogels reached to equilibrium after $12 \mathrm{~h}$ at $37^{\circ} \mathrm{C}$. Cat-CS/GP showed higher G' and G" than $\mathrm{CS} / \mathrm{GP}$, indicating Cat-CS/GP is stronger than CS/GP. Cat-CS/GP significantly enhanced the adhesion time at pig buccal mucosa in PBS (Fig.1). The sustained release of acetaminophen was achieved in both hydrogel systems up to 2 hours. Other in vitro and in vivo studies are ongoing.

Conclusion: Catechol-induced CS hydrogel system has enhanced mucoadhesion in comparison to unmodified system. Cat-CS/GP increases the residence time at the buccal mucosa and shows sustained release of model drugs, and thus is a promising candidate for buccal drug delivery.
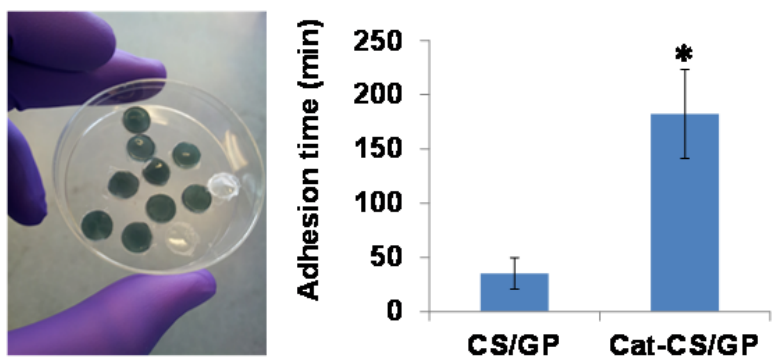

Figure 1. Adhesion time of hydrogels on pig buccal mucosa in PBS pH 6.8.

\section{Development of Bone-Seeking Magnetic Nanoparticles as MRI Contrast Agents for Imaging Bone Metabolic Activity}

Arash Panahifar ${ }^{1}$, Morteza Mahmoudi ${ }^{2,3}$, Michael R. Doschak $^{1,4^{*}}$

${ }^{1}$ Faculty of Pharmacy \& Pharmaceutical Sciences, University of Alberta, Edmonton, Alberta, Canada; ${ }^{2}$ National Cell Bank, Pasteur Institute of Iran, Tehran, Iran; ${ }^{3}$ Nanotechnology Research Centre, Faculty of Pharmacy, Tehran University of Medical Sciences, Tehran, Iran; ${ }^{4}$ Department of Biomedical Engineering, Faculty of Medicine, University of Alberta, Edmonton, Alberta, Canada

Purpose: Thousands of radioactive bone scans are 
performed daily around the globe to diagnose bone disease. While this method provides informative functional images to aid in diagnosis, the poor spatial resolution and lack of anatomical insight limits its application to qualitative information. Moreover, this procedure exposes the patient to ionizing radiation which may be contraindicated in certain clinical situations. Hence, the goal of this project was to develop a non-ionizing magnetic resonance imaging (MRI) bone tracer, capable of producing images of similar sensitivity and at the same time, offering greater resolution in both anatomical and functional imaging whilst avoiding the application of ionizing radiation.

Methods: In this research, Superparamagnetic Iron Oxide Nanoparticles (SPIONs) were synthesized using a microemulsion method in order to serve as an MRI contrast agent. The synthesized SPIONs were modified by addition of citric acid to introduce surface $\mathrm{COOH}$ group. After $\mathrm{COOH}$ modification, by employing a zero-length cross linker, SPIONs were conjugated with $\mathrm{NH}_{2}$-terminal bisphosphonate (e.g. Alendronate) by using NHS (Nhydroxysuccinimide) and EDC (N-Ethyl-N'[3(dimethylamino)propyl]carbodiimide

hydrochloride) to impart bone-targeting affinity. After conjugation, the novel MRI-visible bone tracer was characterized by various analytical techniques, such as FT-IR, X-ray photoelectron spectroscopy (XPS), and zeta-potential measurement to characterize the successful binding of bisphosphonate to SPIONs. Transmission electron microscopy (TEM) and dynamic light scattering (DLS) were also used to evaluate the size and morphology of the SPIONs after each step. The final product were tested for hydroxyapatite binding affinity and compared with unmodified SPIONs.

Results: The SPIONs synthesized with this method showed a relatively narrow size distribution with average size of $17 \mathrm{~nm} \pm 5.95$ under TEM. Successful conjugation of Alendronate to carboxylic acid groups of modified SPIONs was confirmed by presence of phosphorus peak on XPS spectra which was attributable to attachment of the bisphosphonate. Moreover, formation of covalent amide bond was witnessed in FT-IR spectra. In-vitro binding studies of our novel bone tracer have shown binding affinity of up to $65 \%$ for hydroxyapatite, the principal mineral of bone.

Conclusion: Similar to ${ }^{99 \mathrm{~m}}$ Technetium medronate, our novel contrast agent uses bisphosphonates to impart bone-seeking properties, but replaces the former radioisotope with SPIONs which enables their subsequent detection using MRI. In this work, we employed a relatively simple and cost-effective method to conjugate $\mathrm{NH}_{2}$-terminal bisphosphonates covalently to SPIONs for future use as non-ionizing dynamic contrast agents in the MRI imaging of bone turnover.

\section{Highly Elastic and Degradable Poly(N- isopropylacrylamide)-Magnetite Nanoparticle Composite Hydrogels for Controlled Drug Delivery}

Scott B. Campbell and Todd Hoare.

Department of Chemical Engineering, McMaster University, Hamilton, Ontario, Canada

Purpose: Injectable, degradable, in situ-gelling magnetic composite hydrogels with highly elastic mechanical properties have the potential to be utilized as drug delivering scaffolds in vivo. The development of composite materials that could withstand moderate compressive or shear forces in the body and deliver externally-controlled bursts the API of interest could be highly beneficial for biomedical applications.

Methods: The composites are fabricated by the in situ gelation of solutions of superparamagnetic iron oxide nanoparticles (SPIONs) coated with hydrazide-functionalized PNIPAM (12 wt $\%)$ and aldehyde-functionalized dextran (varying contents), with the API dissolved in both solutions. The hydrazide and aldehyde groups condense to form hydrolytically degradable hydrazone cross-linking bonds, forming a bulk hydrogel with the entrapped drug within it. Due to the thermosensitive and superparamagnetic components of these hydrogels, an external oscillating magnetic field (OMF) could simultaneously heat the SPIONs, deswell the composites, and encourage burst release of drug from the composite materials.

Results: The composite hydrogels were shown to have high water contents, possess $5 \mathrm{wt} \%$ SPIONs, and are hydrolytically degradable, completely degrading over a period of $\sim 8$ months in physiological conditions. Importantly, these materials exhibit extremely high elasticities, behaving more like elastomers than typical hydrogels, with storage moduli 12-20-fold higher than their corresponding hydrogel-only materials. The composites are also able to return to their original shape after several compressive cycles, potentially allowing for their use in regions of the 
body that experience frequent stresses. The materials exhibited pulsatile controlled release, where OMF pulses applied to the composites resulted in a significantly increased rate of bupivacaine release $(163 \pm 24 \%)$ immediately following the pulse. This suggests the utility of these materials particularly for pulsatile release of drugs whose minimal inhibitory concentration (MIC) lies between the non-pulsed and pulsed release rates. Furthermore, the composites and its individual components do not exhibit significant cytotoxicity in vitro or chronic inflammation in vivo.

Conclusion: The demonstrated externallytriggerable drug delivery potential of these magnetic thermosensitive materials upon the application of an OMF provides as a significant advantage over many current SPION-containing materials for biomedical use. Additionally, the highly elastic nature of these composite hydrogels, along with their low in vitro cytotoxicity and lack of in vivo chronic inflammation, suggest that these drug delivering systems could be used for a wider variety of applications than typical hydrogel materials.

\section{Development of an Analytical Method for the Simultaneous Quantification by LC-MS/MS of 8 Standard Drugs used in Permeability Assays}

Marie-Eve Leclaire, Sarra Zaraa, Isabelle Marcotte, and Grégoire Leclair.

Faculty of Pharmacy, Université de Montréal, Montreal, QC

Purpose: Permeability assays such as Caco-2 and PAMPA must be verified and calibrated using known control drugs in the four classes of the biopharmaceutical classification system. However, these assays are time-consuming and expensive. Therefore, an efficient approach is to concurrently analyse the permeability of pooled control standards. Nevertheless, the simultaneous quantification is difficult because of their different physico-chemical properties. The objective of this study was to develop an analytical method for the simultaneous quantification by LC-MS/MS of a pool of 8 standard drugs used in permeability assays.

Methods: Chromatography analyses were performed using an Agilent 6400 series triple quadrupole LC-MS equipped with an electrospray ionization source (ESI). All usual chromatography and detection parameters were optimized in order to achieve the best separation, specificity and signal quality. Then, the method was validated according to linearity, lower limit of detection (LLOD), lower limit of quantification (LLOQ), selectivity and sensitivity.

Results: Samples were analyzed by LC-ESI-MS/MS in positive and negative modes with a $\mathrm{C} 18$ column (Hypersil Gold Aq, $50 \times 3 \mathrm{~mm}, 5 \mu \mathrm{m}$ ). The injection volume was $5 \mathrm{uL}$ and $10 \mu \mathrm{L}$ for positive and negative ions, respectively. The mobile phase gradient was formed using $0,2 \%$ formic acid in water (A) and $0.2 \%$ formic acid in acetonitrile (B) $(0$ $\min , 100: 0 \mathrm{~A}: \mathrm{B} ; 1 \mathrm{~min}, 100: 0 \mathrm{~A}: \mathrm{B} ; 3 \min 50: 50$ A:B; 3,5 min 100:0 A:B; 6 min 100:0 A:B). Samples were quenched with $15 \%$ acetonitrile to improve the peak shape. Linearity, LLOQ and LLOD for the 8 control drugs were determined (Table). Selectivity and sensitivity experiments are ongoing and these results will be presented at the meeting.

\begin{tabular}{llll}
\hline Molecule & $\begin{array}{l}\text { Linearity } \\
(\boldsymbol{\mu} \boldsymbol{M})\end{array}$ & $\begin{array}{l}\text { LLOQ } \\
(\boldsymbol{\mu} \boldsymbol{M})\end{array}$ & $\begin{array}{l}\boldsymbol{L L O D} \\
(\boldsymbol{\mu} \boldsymbol{M})\end{array}$ \\
\hline Antipyrine & $0.016-10$ & 0.08 & 0.016 \\
Atenolol & $0.08-10$ & 0.08 & $0.016<\mathrm{x}$ \\
CBZ & $0.08-50$ & $0.016<\mathrm{x}$ & 0.016 \\
Ketoprofen & $0.08-50$ & 0.08 & $0.016<\mathrm{x}$ \\
Propranolol & $0.016-10$ & 0.016 & 0.0032 \\
Verapamil & $0.0032-10$ & 0.0032 & 0.00064 \\
Furosemide & $0.08-10$ & 0.08 & 0.016 \\
HCT & $0.4-10$ & 0.4 & 0.08 \\
\hline
\end{tabular}

Conclusion: The range of linearity and LLOQ were in the range of concentrations required by permeability assays. Furthermore this method provided sufficient specificity to perform the concurrent evaluation of the 8 proposed standard drugs. Complete validation is ongoing to comply to the Guidance for Industry: Bioanalytical Method Validation (Health Canada, 2001).

\section{The Long Term Stabilization of Chitosan/DNA Polyelectrolyte Complexes for Gene Delivery}

Daniel Veilleux, Marc Lavertu and Michael D. Buschmann.

Biomedical and Chemical Engineering, Ecole Polytechnique de Montreal, Montreal, Quebec, Canada

Purpose: Although chitosan (CS), a biocompatible 
cationic polymer, has shown great potential for gene delivery in vitro and in vivo through formation of polyelectrolyte complexes with nucleic acids, the stability of these colloidal formulations is limited. Lyophilization, or freeze-drying (FD), is a process by which stability of pharmaceutical formulations may be increased. Formulations to be freeze-dried must however be optimized to ensure the biological activity and integrity of rehydrated therapeutic agents.

Methods: CS/DNA nanoparticles were prepared using $10 \mathrm{kDa} \mathrm{CS}$ and the plasmid eGFPLuc (6400 bp) as reporter gene. Dynamic Light Scattering (DLS), Nanoparticle Tracking Analysis (NTA), and Scanning Electron Microscopy (SEM) were used to assess the size, polydispersity (PDI), and morphology of CS/DNA nanoparticles, formulated with or without excipients, following or not FD and rehydration at various concentrations. Transfection efficiency of formulations was quantified in vitro in a HEK293 cell line, measuring expression of reporter genes eGFP and Luciferase in flow cytometry and luminometry respectively.

Results: DLS measurements showed that specific formulations prevented particle aggregation following FD and rehydration. Formulations could be optimized to permit increasing nanoparticle concentration up to 20-fold upon rehydration (Rh20X) of FD cakes in lower volumes, while achieving nearly physiological $\mathrm{pH}$ and tonicity. Optimised Particle hydrodynamic diameters, prior to or after $\mathrm{Rh} 20 \mathrm{X}$, ranged from 125 to $235 \mathrm{~nm}$, with low PDI values (0.15 to 0.25$)$. ESEM observations revealed a spherical morphology of optimised nanoparticle formulations. In vitro studies showed that fresh or FD formulations rehydrated to equal volume, had similar transfection efficiencies $(\geq$ $50 \%$ ), while a slight decrease was seen (30 to $45 \%$ ) upon rehydration to $20 \mathrm{X}$ the original concentration. Luciferase expression levels were not affected by FD or rehydration processes.

Conclusion: These novel lyophilisation procedures show promise in permitting greater applicability, increased dose and improved storage properties for these nanoparticle gene delivery systems. Characterization of these systems during accelerated and long term stability studies should provide more insight and progress towards eventual commercialization.

\section{Self-Assembling MMP-2 Cleavable Hydrogel Drug Delivery Systems}

Kyle Koss and Larry D. Unsworth.

Dept. of Chemical and Materials Engineering, University of Alberta, Edmonton, AB, Canada; NanoLife, National Institute for Nanotechnology, NRC, Edmonton, AB, Canada.

Purpose: Peptides are the fastest growing segment of the pharmaceutical industry and are considered the ideal therapeutic: specific, potent, small enough for diffusion, etc. That said, they are easily digested and have a short half-life in plasma; making systemic delivery difficult. Self-assembling peptide $(\mathrm{RADA})_{4}$ are a novel class of biocompatible peptides that, upon injection, can assemble into a hydrogel nanofiber (NF) matrix that may act as a reservoir for releasing a variety of molecules. Moreover, synthesizing peptide therapeutics directly to $(\mathrm{RADA})_{4}$ may afford protection from circulating proteases. Utilizing the spatiotemporal profile of tissue resident enzymes provides an 'on-demand' release strategy. Understanding the matrix selfassembly and the release of bound therapeutics are vital for clinical application. To this end, NF morphology and fractal dimension will be studied using transmission electron microscopy (TEM) and degradation of (RADA) $)_{4}$ based hydrogels with matrix metalloproteinase-2 (MMP-2) cleavable bonds will be observed using mass spectrometry (MADLI).

Methods: Peptides (RADA) ${ }_{4}-\mathrm{GG}-\mathrm{GPQG}+\mathrm{IASQ}$ (CS1) and (RADA) ${ }_{4}$-GG-GPQG+PAGQ (CS2), known for their respective high and low MMP-2 sensitivity, were employed; ' + ' denoting the scissile bond. To assure NF formation, TEM was performed on $0.5 \% \mathrm{wt} / \mathrm{v}$ mixtures of $25 \%, 50 \%$, and $75 \%$ $(\mathrm{RADA})_{4}$ with either CS1 or CS2 peptides. Growth was observed at $0,1,2,4,6$ and $24 \mathrm{hr}$ to determine self-assembly morphology. Hausdorff fractal analysis was performed on these images using Matlab $^{\circledR}$. MALDI was used to enzymatic activity through product formation upon incubating the peptide matrices with $40 \mathrm{nM}$ active MMP- 2 at $37^{\circ} \mathrm{C}$ for three weeks.

Results: Varying NF complexes were present in all samples, where Figure 1 illustrates this for $24 \mathrm{hr}$ growth. All growth periods preceding $24 \mathrm{hrs}$ show NF growth with relatively less bundle development. All Hausdorff fractal dimensions reached a maximum after two hours; the highest ranging within $1.7-1.8$, as calculated from the pure peptide 
groups. MMP-2 cleavage of the NF matrix was observed with formation of the product (RADA) $4^{-}$ GG-GPQG using MADLI at a $2125.1 \mathrm{~m} / \mathrm{z}$ peak. Peaks at $2525.2 \mathrm{~m} / \mathrm{z}$ for CS1 and $2478.8 \mathrm{~m} / \mathrm{z}$ for CS2 groups.

Conclusion: NF matrices were present in all samples. Fractal matrix patterns were apparent after two hours for all samples, suggesting growth stability. These NFs form diverse morphologies, but there is no evidence to suggest that some peptides are being excluded from NF formation. Despite these differences in morphologies, preliminary results show expected product formation upon MMP-2 digestion. Quantitative analysis of product formation needs to be conducted.

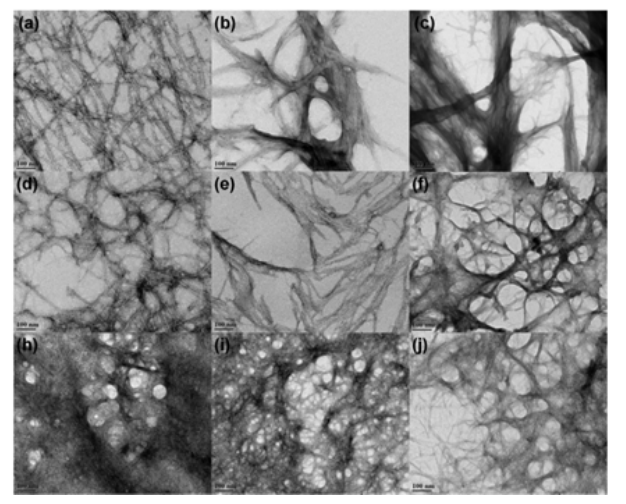

Figure 1. TEM images at 110,000X magnification of (a) (RADA), (b) CS1, (c) CS2, CS1 doped with (d) 25\%, (e) $50 \%$, (f) $75 \%$ (RADA), and CS2 doped with (h) $25 \%$, (i) $50 \%$, (j) $75 \%$ (RADA).

\section{Intrinsic and Extrinsic Parameters Affecting Efficiency and Toxicity of Chitosan-siRNA Nanoparticles for Gene Silencing}

\author{
Mohamad-Gabriel Alameh ${ }^{1}$ Michael D. \\ Buschmann $^{1}$ and Abderrazzak Merzouki ${ }^{1}$. \\ Institute of Biomedical Engineering, Department of \\ Chemical Engineering, Ecole Polytechnique de \\ Montréal, Montréal, Canada
}

Purpose: Chitosan (CS) is a promising biopolymer for the delivery of small interfering RNA (siRNA). Reports attempting to identify its optimal physicochemical parameters for siRNA delivery were inconclusive. In an attempt to determine the influence of intrinsic and extrinsic parameters and their coupling effects on chitosan transfection efficiency (TE), a design of experiment approach
(DoE) was used to screen a library of nanoparticles with different bio-nano interfaces.

Methodology: CS-siRNA nanoparticles targeting the enhanced Green Fluorescent Protein (eGFP) were formed by manual mixing and characterized for their size, morphology and polydispersity index by Dynamic Light Scattering (DLS) and Scanning Electron Microscopy. Encapsulation efficiency and temporal stability $(<20 \mathrm{~h})$ was evaluated at different $\mathrm{pH}(6.5-8)$ using a fluorometric quantification assay. Gene silencing efficiency in different media compositions and at different $\mathrm{pH}$ (6.5 and 7.2) was assessed in the H1299 cell line by measuring eGFP knockdown relative to non-treated cells by flow cytometry and quantitative PCR. Nanoparticle toxicity was measured using the Alamar blue ${ }^{\circledR}$ assay.

Results: DLS measurements demonstrated positive and strong correlation between size and molecular weight (MW) with nanoparticle diameter ranging between 55-250 nm. $\zeta$-potential correlated with chitosan degree of deacetylation (DDA) and the ratio to siRNA (N:P) (Figure 1). Nanoparticles were spherical by SEM, a shape promoting uptake and decreased cytotoxicity. Encapsulation efficiency decreased with increasing $\mathrm{pH}$ (Figure 2) owing to nanoparticle instability in such buffers where $\mathrm{pH}$ above chitosan $\mathrm{pKa}_{6.7}$ leads to chitosan deprotonation. Nanoparticle stability was increased with increasing MW, DDA and N:P ratio (Figure 2). Most importantly, our data show that in nearphysiological $\mathrm{pH}$, complete siRNA encapsulation and particle stability is maintained for at least $20 \mathrm{~h}$ at low N:P ratio of 5. Silencing efficiency reached $85 \%$ with high DDA (Figure 3). Cytotoxicity was found to increase with increasing DDA and $\mathrm{N}: \mathrm{P}$ ratios (increased $\zeta$-potential) therefore hindering the application of high N:P based formulations proposed previously.

Conclusion: Taken together our results suggest a distinct dependence on chitosan parameters for efficient siRNA delivery versus previous studies delivering plasmid DNA. Our results also indicate the importance of extrinsic parameters such as $\mathrm{pH}$, serum and media composition in promoting effective siRNA delivery. Ongoing studies and modelling of our data suggest that novel and optimized formulations may possess appropriate properties to permit specific applications of these effective and non toxic reagents. 


\section{Poster Session 2}

\section{Wednesday, June 12, 5:00 PM through Thursday, June 13}




\section{CSPS Posters - Session 2}

\section{Wednesday to Thursday, June 12-13}

\section{Biomedical Sciences}

\section{Targeting Intracellular Cholesterol Synthesis in Castration-resistant Prostate Cancer Cells}

Jenny Hanbi Kim ${ }^{1}$, Kishor M. Wasan ${ }^{1}$.

${ }^{1}$ Faculty of Pharmaceutical Sciences, The University of British Columbia, Vancouver, BC, Canada

Purpose: This study assesses the in vitro efficacy of Simvastatin in inhibiting 3-hydroxy-3methylglutaryl-coenzyme A (HMG-CoA) reductase in $\mathrm{C} 4-2$ and $\mathrm{LNCaP}$ cells.

Methods: C4-2 and LNCaP cells were grown in RPMI 1640 media without phenol red supplemented with $5 \%$ charcoal stripped fetal bovine serum (FBS) and $1 \%$ penicillin-streptomycin at $37^{\circ} \mathrm{C}$ in a humidified, $5 \% \mathrm{CO}_{2}$ environment. Cells were seeded at a density of $1.6 \times 10^{4}$ in 24 -well plates or $5 \times 10^{3}$ in 96 -well plates pre-treated with poly-L-lysine. 48 hours after seeding, cells were treated with Simvastatin at concentrations of 10,50 , or $80 \mathrm{uM}$ with negative, vehicle, and positive controls for 48 hours. Cell toxicity was determined by lactate dehydrogenase (LDH) assay and cell viability was analyzed by CellTiter $96 \AA$ Cell Proliferation MTS assay. The dose-dependent suppression of HMG$\mathrm{CoA}$ reductase was analyzed by incorporation of ${ }^{14} \mathrm{C}$-acetic acid followed by radioisotope detection using thin layer chromatography and phosphour screen exposure while the protein expression levels were qualitatively determined by Western blot analysis. The cholesterol and prostate specific antigen (PSA) levels were quantified using Amplex Red Assay and ELISA kit respectively.

Results: The $\mathrm{IC}_{50}$ cytotoxicity values of Simvastatin were $70 \mathrm{uM}$ and $10 \mathrm{uM}$ for $\mathrm{C} 4-2$ and $\mathrm{LNCaP}$ cells respectively. A single 48 hour Simvastatin treatment with $10 \mathrm{uM}$ Simvastatin was sufficient to reduce the HMG-CoA reductase activity to $<10 \%$, relative to the Negative Control in both C4-2 and LNCaP cells. Inhibition was sufficient to significantly decrease the intracellular cholesterol concentration from $14.38 \pm$ $3.97 \mu \mathrm{g} / \mu \mathrm{g}$ protein for Negative Control to $3.12 \pm$
$0.93 \mu \mathrm{g} / \mu \mathrm{g}$ protein for $50 \mathrm{uM}$ Simvastatin treated C42 cells, $(n=6$, mean \pm SEM, $p<0.05)$. No significant differences were observed in the PSA concentrations between the treatment groups for both cell lines.

Conclusion: This study supports the use of Simvastatin as an effective treatment for in vitro inhibition of HMG-CoA reductase in $\mathrm{C} 4-2$ and LNCaP cells for assessing intra-cellular cholesterol regulation. This technique, in conjunction with scavenger receptor class B type I inhibition, will be conducted in the future to investigate the inhibition of multiple intra-cellular cholesterol regulatory pathways.

Funding provided by the Canadian Institutes of Health Research and the Vancouver Prostate Centre.

\section{Endothelial Heparanase Secretion Induced by High Glucose Amplifies Fatty Acid Delivery to Cardiomyocytes}

Andrea Wan, Dahai Zhang, Brian Rodrigues.

Faculty of Pharmaceutical Sciences, University of British Columbia, Vancouver, British Columbia, Canada

Purpose: Diabetes is a growing pandemic characterized by hyperglycemia when the pancreas is unable to produce insulin or the body becomes resistant to insulin. Chronically, a plethora of complications are evident in patients with diabetes, with cardiovascular disease being of preeminent importance. Specifically, atherosclerosis compromises the competence of the heart to pump, and is a leading cause of morbidity and mortality. Interestingly, prior to this diagnosis, undetected metabolic changes have likely begun and can induce cardiomyocyte death well before atheroscleroticrelated heart damage. In a normal individual, the heart's energy demand is supplied by glucose and fatty acid (FA) metabolism at $30 \%$ and $70 \%$ respectively. Following diabetes, this percentage skews towards exclusive FA utilization (95-99\%) to meet the heart's energy needs. This metabolicswitching is regulated by lipoprotein lipase (LPL), an enzyme that breaks down circulating fats into 
useable FA. LPL, produced in cardiomyocytes, is transported across the endothelial cell (EC) to the coronary lumen where it shows its action. VEGF enhances EC permeability and could increase the transport of LPL (towards the lumen) and FA (towards the cardiomyocyte) to promote cardiac cell death.

Hypothesis: We hypothesize that in response to diabetes, VEGF is essential for amplifying FA delivery to the cardiomyocyte.

Methods and Results: Bovine coronary artery EC were incubated in high glucose (HG, 25mM). Following 30 minutes of incubation, the medium was collected and termed EC conditional medium (ECCM). ECCM demonstrated higher amounts of heparanase, an enzyme responsible for degrading heparan sulfate proteoglycans (HSPG). HSPG are cell-surface anchors to which VEGF and LPL are bound. Interestingly, incubating cardiomyocytes with ECCM caused robust release of LPL and VEGF. Furthermore, we observed that VEGF influences EC permeability by phosphorylating and activating sarcoma tyrosine kinase (SRC) and hence, VEGF in ECCM is likely responsible for increasing LPL permeability and its subsequent transport towards the lumen.

Conclusion: Our data suggests that HG causes substantial secretion of heparanase from EC to release LPL and VEGF from the cardiomyocyte surface. Given the function of VEGF to increase vascular permeability, this heparanase-VEGF axis could potentially amplify FA delivery and utilization by the diabetic heart. By manipulating this pathway, we can reduce FA transport towards the cardiomyocyte, minimizing the cardiovascular complications associated with diabetes.

Acknowledgement: Andrea Wan is an awardee of the National Summer Student Research Program Awards to Present Research Findings sponsored by GlaxoSmithKline Inc.

\section{Multi-disease Animal Model for Examining the Relationship Between Stroke and Rheumatoid Arthritis}

Nelson Pearce and Noriko Daneshtalab.

School of Pharmacy, Memorial University of Newfoundland and Labrador, St. John's, NL

Introduction: In rheumatoid arthritis (RA) subjects, the incidence of stroke is significantly higher than the normal population however, the mechanism for stroke development in RA remains unclear. Currently no ideal animal model exists to examine the co-existence of the two disease states. The aim of our work was to establish a multi-disease animal model that displays both hypertension (a risk for stroke) and RA.

Materials and Methods: Spontaneously Hypertensive Rats (SHR) fed a Japanese high salt diet $(4 \% \mathrm{NaCl}$; to induce hypertension) were injected with $0.5 \mathrm{~mL}$ of either saline or Complete Freud's Adjuvant (CFA; to induce adjuvant arthritis [AA]) in hind paw. Sprague Dawley Rat (SDR) and stroke prone SHR (SHRsp) strains were used as positive control for AA and hypertensive stroke respectively. Blood pressures were monitored weekly. The limbs were monitored for signs of inflammation and swelling using caliper and water displacement measurements, and by visual examination and arthritic index scoring.

Results: Preliminary results indicate SHRs injected with CFA developed significant inflammation, increase in paw volume, and increase in arthritic index score, comparable to those seen in SDRs with AA. SHRs fed a high salt diet also displayed increased blood pressure, as previously established with SHRsp on high salt. SHRs and SHRsps injected with saline did not display signs of inflammation or paw swelling.

Conclusion: A multi-disease model displaying characteristics of hypertension and rheumatoid arthritis was successfully produced. Further development of this model may allow for characterization of the cerebrovascular changes that may potentially lead to stroke development in hypertensive and arthritic states. This information would be crucial in identifying suitable treatment options for patients with RA who also suffer from hypertension in order to circumvent occurrence of stroke.

Acknowledgement: Nelson Pearce is an awardee of the National Summer Student Research Program Awards to Present Research Findings sponsored by GlaxoSmithKline Inc. 


\section{Non-Canonical Function of Telomerase Reverse Transcriptase in the Protection Against Genotoxic Events}

Helen B. Fleisig, Kyle R. Hukezalie, Rafael C. Zhao and Judy M. Wong.

Faculty of Pharmaceutical Sciences, University of British Columbia, Vancouver, BC

Purpose: Up-regulation of telomerase is observed in $>85 \%$ of cancers. Initial studies indicated that the role of telomerase is to maintain telomere length, however, the proposed roles of telomerase in cancer cell fitness and survival has expanded in recent years to include effects on chromatin remodeling and DNA damage responses. Many of these pro-survival responses appear to be independent of telomerase's role in telomere maintenance. The aim of the present study is to investigate the mechanism of these non-canonical telomerase activities.

Methods: Alternative Lengthening of Telomeres (ALT) cells are telomerase-negative human transformed cells that employ a recombination-based mechanism for telomere synthesis. Using ALT cells forced to stably express telomerase functional variants, we examined the effect of telomerase expression on cell survival after transient exposure to genotoxic agents.

Results: ALT cells expressing wild-type telomerase reverse transcriptase (TERT) displayed an increased resistance to the cytotoxic effects of the DNA damaging agents, etoposide and cisplatin. TERTexpression promotes cell viability following the induction of DNA damages but may lead to a decrease in cell division fidelity. Examination of various TERT mutants revealed dissociation-ofactivities-at-telomeres mutants and the catalyticallydefective versions of TERT did not contribute to increased cellular resistance against these agents. In contrast, one of the RNA-binding defective TERT mutant displayed similar levels of cellular resistance against etoposide as compared to cells expressing wild-type TERT.

Conclusion: Our study supports a telomere synthesis independent role for TERT in enhanced survival during cytotoxic events.

\section{Characterization of Ribosomal RNA Pseudouridine Modification and Ribosomal Protein Translation in Telomerase-rescued X- linked Dyskeratosis Congenita Cells}

Naresh R Thumati ${ }^{1}$, Xi-Lei Zeng ${ }^{1}$, Hilda $\mathrm{Au}^{2}$, Christopher Jang ${ }^{2}$, Eric Jan ${ }^{2}$ and Judy MY Wong ${ }^{1}$.

${ }^{1}$ Faculty of Pharmaceutical Sciences, ${ }^{2}$ The Department of Biochemistry and Molecular Biology, Faculty of Medicine, University of British Columbia, Canada

Purpose: $\mathrm{X}$-linked dyskeratosis congenita (X-DC) is a telomere maintenance disorder, characterized by the decrease in stability of telomerase RNA. X-DC is caused by mutations in the housekeeping gene $D K C-1$, coding for the nucleolar protein dyskerin. An obligate member of the telomerase holoenzyme complex, dyskerin is also the pseudouridinylase responsible for site-specific modifications of ribosomal RNA (rRNA) and small nuclear RNA (snRNA). Alternate theory posits that ribosomal dysfunction, not short telomeres, leads to the clinical manifestations of X-DC. In our present study, we investigated the alternate hypothesis of ribosomal dysfunction in X-DC cells.

Method: Using five X-DC patient cell lines, corrected for telomere maintenance deficiency, we assessed the effects of mutant dyskerins on rRNA pseudouridine modification and ribosomal protein translation. We measured the ribosomal RNA pseudouridine modifications, biogenesis and maturation with cell-based assays. Protein translations were measured with pulse-chase labeling under normal cell growth conditions, or after the induction of cellular stress. Finally, internal ribosomal entry site (IRES) dependent protein translations were measured using a cell-free IRESreporter assay.

Results: Stability of mature rRNA and the kinetics of rRNA maturation were not affected by the X-DCassociated dyskerin mutations. We detected a small but reproducible decrease in total pseudouridine levels of mature rRNA in two X-DC models. These reductions in pseudouridine modifications did not lead to any discernable differences between WT and $\mathrm{X}$-DC protein-translation rates under normal cell growth, or after stress-induction. IRES-dependent reporter protein translations were not significantly different between WT and X-DC ribosomes under our assay conditions.

Conclusion: Mutant dyskerins affect steady state accumulation of pseudouridine in mature rRNA in a 
manner that is X-DC genotype-specific. These XDC specific pseudouridine modification defects may exacerbate the telomere attrition rate. We conclude that telomere dysfunction is the primary and only unifying disease etiology of X-DC, and propose that the variable clinical presentation of X-DC could be dyskerin-genotype-dependent.

\section{Effect of Acute Exercise on Pharmacokinetics of Diltiazem in a Freely Moving Rat Model}

Pollen K.F. Yeung and Tanya Marcoux.

${ }^{a}$ Pharmacokinetics and Metabolism Laboratory, College of Pharmacy and Department of Medicine, Dalhousie University, Halifax, NS, Canada

Purpose: Exercise is increasingly used to enhance health in complimentary medicine. The objective of the research is to study the effect of acute exercise on pharmacokinetics of diltiazem (DTZ).

Methods: Sprague Dawley rats (SDR) with a carotid artery catheter weighing between 250 and $300 \mathrm{~g}$ were used. Each rat was housed in a freely moving caging environment with free access to drinking water. In the exercise group $(\mathrm{n}=8)$, each rat received $5 \mathrm{mg} / \mathrm{kg}$ of DTZ twice daily for 4 doses by subcutaneous (sc) injection. One hour after the last injection, the SDR was exercised on a research treadmill for 15 minutes at a speed of $10 \mathrm{~m} / \mathrm{min}$ and $5 \%$ grade. Blood samples were collected at 0 (before the last dose), and at 0.25, 1, 1.2, 1.5, 2, 3, 4, 5 and 6 hours after the last dose for measurement of plasma concentrations of DTZ by a validated HPLC. A separate group received the same dosage of DTZ but without the exercise was used as control ( $\mathrm{n}=$ 14). Plasma concentration-time data were fitted to a 2-compartment open model following a $1^{\text {st }}$ order input (Rstrip II ${ }^{\circledR}$, Micromath, St Louis, MO, USA), and pharmacokinetic data calculated between the exercise and control groups were considered significant at $\mathrm{p}<0.05$ (Student $t$-test).

Results: Exercise decreased maximum plasma concentrations (Cmax) of DTZ from $1812 \pm 1477$ to $654 \pm 191 \mathrm{ng} / \mathrm{mL}^{*}$ and time to Cmax (tmax) from $0.32 \pm 0.09$ to $0.22 \pm 0.10 \mathrm{~h}^{*}$, increased systemic clearance $(\mathrm{CL})$ from $4.49 \pm 2.13$ to $9.04 \pm 2.76$ $\mathrm{L} / \mathrm{h} / \mathrm{kg}^{*}$ and volume of distribution at steady state (Vdss) from $4.87 \pm 2.14$ to $9.17 \pm 1.68 \mathrm{~L} / \mathrm{kg}^{*}\left({ }^{*} \mathrm{p}<\right.$ 0.05 for all).

Conclusion: A brief exercise shortly after DTZ injection increased absorption rate, Vdss and CL. The effect of exercise on pharmacokinetics of therapeutic agents warrant further study (Supported in part by CIHR, Nova Scotia Health Research Foundation and Dalhousie Pharmacy Endowment Foundation).

\section{Protein Expression Changes of Nerve Growth Factor (NGF) During the Inflammatory Pre- demyelinating Stages of Experimental Autoimmune Encephalomyelitis (EAE): Implications in Multiple Sclerosis (MS)}

Crystal May R. Acosta ${ }^{1}$, Claudia Cortes $^{1}$, and Michael P. Namaka ${ }^{1,2,3}$.

1 Faculty of Pharmacy, University of Manitoba; ${ }^{2}$ Faculty of Medicine, University of Manitoba; ${ }^{3}$ Manitoba Institute of Child Health, University of Manitoba, Winnipeg, Manitoba

Purpose: Multiple sclerosis (MS) is a disease of the central nervous system characterized by inflammation, demyelination, and neurodegeneration. Studies involving nerve growth factor (NGF) have gained considerable interest due to its ability to reduce immune-mediated myelin damage. NGF exists as two predominant isoforms: proNGF (pNGF, 25 and $32 \mathrm{kDa}$ ) and mature NGF (mNGF, $13 \mathrm{kDa}$ ). However, the importance of the biological activity of the various isoforms in regards to recovery during the inflammatory stage of disease remains unknown. The aim of this study was to examine pNGF protein expression changes in the EAE rat model during the inflammatory disease phase. We hypothesize that an increase in $p N G F$ protein in the dorsal root ganglion (DRG) and/or spinal cord (SC) correlates with neurological recovery during the inflammatory pre-demyelinating stage of EAE.

Methods: The EAE myelin basic protein Lewis rat model was used to study changes in pNGF protein expression. Neurological disability scores (NDS) were recorded for correlation against pNGF protein. DRG and SC tissues were harvested every 3 days up to 24 days post induction (dpi). Enzyme-linked immunosorbant assay (ELISA) was performed to quantify the $25 \mathrm{kDa}$ pNGF isoform. Western blot (WB) was performed to quantify various pNGF isoforms.

Results: EAE NDS peaked 13 dpi with animals recovering by 18 dpi. EAE DRG ELISA identified a significant increase in $25 \mathrm{kDa}$ pNGF $21 \mathrm{dpi}$ that could not be linked to neurological recovery. EAE SC ELISA identified a significant increase in $25 \mathrm{kDa}$ 
pNGF 12 dpi that correlated with peak NDS. EAE DRG WB analysis revealed no specific changes that could be linked to neurological recovery. EAE SC WB analysis revealed an increase in $25 \mathrm{kDa}$ pNGF 15-18 dpi and $37 \mathrm{kDa}$ pNGF 6-9 dpi that correlates with neurological recovery.

Conclusions: This research confirms the importance of the biological activity of the $25 \mathrm{kDa}$ pNGF isoform in neurological recovery during the inflammatory disease stage. We believe the elevated SC $37 \mathrm{kDa}$ pNGF isoform at 6-9 dpi is cleaved to produce the elevation of the biologically active 25 $\mathrm{kDa}$ pNGF isoform seen 12 dpi. DRG pNGF isoforms do not appear to be involved in repairing EAE neurological deficits.

\section{Characterization of Xenobiotic-Metabolizing Enzyme Expression, at the Protein Level, in Adult Rat Testis}

Ravindranath Reddy Gilibili ${ }^{1}$, A. Wayne Vogl $^{2}$, Thomas K. H. Chang ${ }^{1}$, and Stelvio M. Bandiera ${ }^{1}$.

${ }^{1}$ Faculty of Pharmaceutical Sciences and ${ }^{2}$ Faculty of Medicine, The University of British Columbia, Vancouver, British Columbia.

Purpose: Relatively little is known about the expression of various xenobiotic-metbolizing enzymes (XME), such as cytochrome P450s (CYP) and microsomal epoxide hydrolase $(\mathrm{mEH})$, at protein level, in rat testis. These enzymes are expressed in liver and many other organs and are known to play important role in the oxidative biotransformation of various endogenous and exogenous compounds. Some xenobiotics such as benzo[a]pyrene are procarcinogenic and metabolised into reactive intermediates, which possess genotoxic and carcinogenic activities. Formation of these reactive metabolites in the testis could pose severe adverse effect on steroidogenesis and germ cell development.

Methods: In the present study, we characterized the expression of various XMEs in adult rat testis using immunoblot and immunohistochemical analyses. Testicular microsomes, prepared from adult male Sprague-Dawley rats, were separated using SDSPAGE and electrophoretically transferred onto membranes and probed with different antibodies. Immunohistochemical analysis was performed using tissue sections prepared from frozen rat testis and probed with antibodies specific to CYP1B1, CYP2A1, CYP17A1, NADPH-cytochrome P450 reductase and $\mathrm{mEH}$.

Results: Immunoblot results indicated that CYP1B1, CYP2A1, NADPH-cytochrome P450 reductase, and $\mathrm{EH}$ were expressed in testicular microsomes isolated from adult rats. By comparison, CYP1A1, CYP1A2, CYP2B1, CYP2E1, CYP2D1, CYP2D2, CYP2C6, CYP2C7, CYP2C11, CYP2C12, CYP2C13, CYP3A1, CYP3A2, CYP4A1, CYP4A2 and CYP4A3 were not detected in the testicular microsomal samples. To corroborate these results, tissue sections were prepared from frozen adult rat testis and probed with antibodies to CYP1B1, CYP17A1, CYP2A1, NADPH-cytochrome P450 reductase and $\mathrm{mEH}$. Fluorescent staining indicated that CYP1B1, CYP2A1 and CYP17A1 were expressed in interstitial cells, which are comprised mainly of Leydig cells, but not in seminiferous tubules. In contrast, $\mathrm{mEH}$ and NADPH-cytochrome P450 reductase were expressed in both interstitial cells and in seminiferous tubules.

Conclusion: CYP1B1, CYP2A1, CYP17A1, mEH and NADPH-cytochrome $\mathrm{P} 450$ reductase were detected in rat testis and their expression was confined to interstitial cells (CYP1B1, CYP2A1, CYP17A1, $\mathrm{mEH}$ and NADPH-cytochrome P450 reductase) and seminiferous tubules (mEH and NADPH-cytochrome P450 reductase).

Note: This abstract was presented at $52^{\text {nd }}$ Annual Meeting of Society of Toxicology, March 10-13, 2013, San Antonio, Texas, USA.

\section{Screening for Inhibitors of the Cancer Related Enzyme Atg4B}

Lubomir L. Vezenkov, Suzana Kovacic, Robert N. Young.

Simon Fraser University, Burnaby, BC, Canada

Objective: Autophagy is a biological process responsible for the bulk degradation of organelles and proteins and is essential for cellular maintenance and viability. It is believed that cancer cells can use autophagy to survive ionizing radiation and metabolic stress, possibly by removing damaged organelles, which could protect them against apoptosis. The Atg4B enzyme plays a key role in autophagy by both processing and deconjugating the LC-3 protein which is the main component of the autophagosome vesicles. The first aim of our study was to develop different assays to follow the Atg4B enzymatic activity. Next we planned to use those assays in order to determine selective inhibitors of 
the Atg4B enzyme. Finally those inhibitors will be improved by SAR and tested in vitro and in vivo, thus giving us a better understanding of the implication of autophagy in cancer.

Methods: The first assay that we developed was based on the observation of the LC-3 cleavage by the Atg4B enzyme, by LC-MS techniques. While this method is somewhat slow it has the advantage to be very accurate and not prone to artefacts. Next we developed a small latent fluorophore substrate for the Atg4B enzyme. This substrate was used in fluorescence monitoring assay that was suitable for HTS. Moreover scale up of such substrate was easy and cost effective. To test the inhibition of the Atg4B enzyme in more complex biological media we have developed an in vitro assay based on the stable expression of the LC-3 coupled to a green fluorescent protein in cells.

Results and Conclusion: Combination of the aforementioned techniques was used to screen libraries of synthetic compound in cellulo and on the isolated Atg4B enzyme. This study led to the discovery of compounds that are able to inhibit the autophagy process in cells. We are currently working on improving those compounds by SAR. The most potent compounds will be tested in vivo and they will hopefully let us to better understand the implications of autophagy. Combination of established anti-cancer drugs with autophagy inhibitors might sensitize resistant cancer cell lines, which is one of the biggest current challenges in science.

\section{Cross-cancer Profiling of Molecular Alterations within the Human Autophagy Interaction Network}

Chandra Lebovitz ${ }^{1,2}$, Gordon Robertson ${ }^{1}$, Ryan Morin $^{1,2}$, Rodrigo Goya ${ }^{1}$, Marco Marra ${ }^{1}$, Sharon Gorski $^{1,2}$.

${ }^{1}$ British Columbia Cancer Agency, Genome Sciences Centre, Vancouver, Canada; ${ }^{2}$ Simon Fraser University, Department of Molecular Biology and Biochemistry, Burnaby, Canada

Purpose: Macroautophagy (or autophagy), a catabolic cellular process that provides nutrients and energy through lysosomal degradation of bulk cytoplasm in autophagosomes, is integral to the health of most eukaryotic cell types. Because cancer cells may exploit elevated autophagy to survive in low-nutrient conditions and to escape the effects of chemotherapy, autophagy is under investigation as a novel anticancer target in clinical trials. However, our understanding of the mechanisms by which cancer may manipulate the autophagy pathway to enhance disease progression is in its infancy. Our overall objective is to profile the association of molecular alterations in autophagy genes and regulators with various cancers and to investigate their functional relevance with respect to disease progression.

Methods: To explore the mutational landscape of autophagy in human cancer, we queried publically available somatic mutations identified from matched tumor and normal genomes and exome sequence data by The Cancer Genome Atlas consortium, for 214 autophagy-associated genes curated from the literature, across 14 cancer types. We further investigated tumor-associated gene expression changes by identifying differentially expressed (DE) genes between matched tumor and normal transcriptomes for 6 cancer types, and examined whether unsupervised hierarchical clustering on DE gene levels was able to distinguish between tumor and normal samples. Finally, we performed unsupervised consensus clustering to assess whether autophagy-associated gene expression could stratify patient groups based on overall patient survival.

Results: Somatic mutation analysis | Across the 14 cancer types examined, numerous autophagyassociated genes had tumor-specific nonsynonymous single nucleotide variants, with mutation frequencies per gene ranging from $<1 \%$ to $14 \%$ of patients, depending on cancer type. However, for the 4 cancer types for which we have assessed selective pressure to date, no gene has shown significant positive selection pressure for mutation.

Expression analyses | Differential gene expression analysis of RNA-seq data for tumors versus matched normal tissues identified sets of significantly upregulated and down-regulated autophagy-associated genes in all cancer types tested, and, with minor exceptions, hierarchical clustering on these genes successfully grouped tumor and normal samples together. DE core autophagy genes included: MAP1LC3C [breast (BRCA), kidney (KIRC) and lung squamous cell (LUSC) carcinoma], GABARAPL1 (BRCA and KIRC), and ATG4D (LUSC). The majority of DE autophagy-associated genes were known or potential autophagy regulators or autophagy pathway interactors. For 4 cancer types, unsupervised consensus clustering on autophagy-associated gene levels identified groups 
of patients with significant differences in overall survival.

Conclusion Results from this study suggest that autophagy-associated genes are not targets of somatic mutation in human cancer, but that differential gene expression of known and potential regulators of autophagy may contribute to the modulation of autophagy in tumors. Further identification of disease-related biological commonalities in patients grouped into discrete categories for overall survival by autophagyassociated gene level may help dissect autophagy's functional role in the progression of cancer in patients.

\section{Clinical Sciences \& Pharmacy Practice}

\section{Implementation of Pharmacogenomics (PGx) Testing in Community Pharmacy: A Pilot Project in Montréal, Québec}

Anick Dubois, Center of Excellence in Personalized Medicine (Cepmed), Montreal Heart Institute, Montréal, Québec, Canada

Purpose: Genetic variations in genes encoding drug response are involved in mostly half of adverse events or non-response to drugs. Pharmacogenomics testing (PGx) has the potential to prevent nonresponse or the occurrence of adverse events preemptively. Implementation studies in the U.S. have demonstrated that PGx testing is beneficial in community pharmacy for selected drugs. Given their expertise in pharmacotherapy, pharmacists are well positioned to play a leading role in the implementation of $\mathrm{PGx}$ and contribute to the education of patients and their physicians. In collaboration with a Canadian pharmacy chain, the Centre of Excellence in Personalized Medicine and the Beaulieu-Saucier PGx Center, both located at the Montreal Heart Institute, are developing an innovative pilot project to implement PGx testing in Québec community pharmacies, a first in Canada. The main objectives of the project are to assess the feasibility of using PGx results in a communitysetting to guide prescription and to define the optimal framework of implementation (including PGx training).
Methods: The first step is to select drugs for which PGx guided-prescription will be useful in community pharmacy and develop associated guidelines for prescription adjustment. We did a systematic review of all the current guidelines and existing PGx implementation studies protocol to define criteria and parameters that will be important for the community pharmacy context. As a second step, 50 pharmacies will be recruited. Pharmacists and physicians will be trained (accredited CME) prior to study initiation. The return of genetic results (metabolism status) will be transmitted to pharmacists and physicians via a computer interface with recommendations for treatment. The adoption of tests and recommendations made will be quantified (number of tests offered vs performed and of therapy adjusted).

Results: We have identified 11 drugs that are ready to be implemented in community pharmacies and we are developing guidelines according to: the level of evidence and clinical relevance of genetic influence on drugs response; statistics on most common disease and prescribed drugs in Québec; turn-around time of testing vs prescription duration; possibility of clear guidelines and interventions to be made (therapy adjustment); existing workflow and feasibility of changes if offering PGx testing. In terms of recruitment, 26 pharmacies have been recruited to date.

Conclusion: The results of this study will provide a framework for optimal PGx implementation in community pharmacies and guide change in practice towards a more efficient decision making.

\section{An Evaluation of Hypertension Self- Management Applications for the iPhone}

Darlene Korn and Mark Makowsky.

Faculty of Pharmacy and Pharmaceutical Science, University of Alberta, Edmonton, Alberta, Canada

Purpose: The emergence and proliferation of digital devices like smart phones and tablet computers and their associated applications (Apps) have the potential to become valuable self-management support tools in the management of chronic disease. Our objective was to characterize currently available iPhone Apps that support hypertension selfmanagement and provide guidance to clinicians and patients about the most clinically useful apps.

Method: We conducted a systematic review of free and paid English Language iPhone Apps by 
searching the iPhone App Store, with the keywords blood pressure and hypertension. To qualify, the app had to have the capability to record blood pressure measurements over time. We excluded apps marketed towards patients with other disease states (e.g., diabetes or chronic kidney disease). We extracted key features, functionalities, and user ratings. We performed a content analysis of user reviews to summarize the domains on which users rated the quality of the app.

Results: Our search yielded 262 apps and after full review, we included 25 of the 31 free apps, and 33 of the 53 paid apps. Key features of available apps included: medication tracking, reminders, sharing capabilities, diet tracking, salt intake, exercise tracking, weight tracking, and lab values. Several allowed graphical display of blood pressure readings and ability to average the most recent blood pressure readings. A total of 8 apps were rated four stars or above. Customers valued the ability to observe the trend in their blood pressure graphically and share these with their physician. Few apps incorporated information about hypertension. Of those that did, none referred to the Canadian recommendations.

Conclusion: While currently available blood pressure tracking apps do not align with Canadian Hypertension recommendations, we suggest that a combination of the two apps: Heart Pal by Delta Works (upgraded version) and MyDashDiet by FreshObjectSoftware, would offer functionalities that clinicians can recommend as useful selfmanagement tools to optimize therapy for patients.

Acknowledgement: Darlene Korn is an awardee of the National Summer Student Research Program Awards to Present Research Findings sponsored by GlaxoSmithKline Inc.

\section{Synthesis of Inhibitors of a Streptococcus Pneumoniae Virulence Factor}

Isaac K. Seo, Samy Cecioni, David J. Vocadlo. Department of Chemistry, Simon Fraser University, Burnaby, BC, Canada

Purpose: The rise of antibiotic resistant bacteria is a growing societal concern. Mutations in the bacterial genome give rise to strains which can degrade antibiotics, circumvent their binding, or expel them via efflux pumps. One common antibiotic strategy is to inhibit pathways that are essential for survival and growth of bacteria. However, this approach imparts an immense pressure on the bacteria to develop antibiotic resistance via natural selection. A complementary strategy to target bacteria would be to inhibit factors that contribute to the virulence of the pathogen without being essential for their survival. This approach is interesting as it should impart significantly less evolutionary pressure and thereby delay the onset of resistance. The enzyme endo-hexosaminidase $\mathrm{D}$, an established virulence factor of S. pneumoniae, is found on the cell wall of this bacterium and it acts to degrade $\operatorname{Man}(\alpha 1-$ 4)GlcNAc $(\alpha 1-4)$ GlcNAc glycans attached to host antibodies, which undermines immune detection of bacteria by the host. Inhibitors of endohexosaminidase D should block enzyme activity and therefore compromise virulence of $S$. pneumoniae.

Method: NAG-thiazoline is a non-selective inhibitor of hexosaminidase enzymes with modest inhibitory potency. Based on knowledge of the natural substrate and the X-ray structure of NAG-thiazoline bound to endo-hexosaminidase $\mathrm{D}$, an accessible binding pocket near the 4-OH position of the inhibitor appears as though it could be exploited in the design of more selective and potent inhibitors. Toward this goal NAG-thiazoline was synthesized and selectively protected at the 3 and 6 positions followed by propargylation at the 4 position. Using this intermediate, multiple aromatic azides were conjugated to the propargyl moiety for testing as inhibitors.

Results: The chemical strategy we designed allows for the rapid synthesis of a panel of NAG-thiazolinebased inhibitors. These probes will be used to screen for potent selective inhibition of endohexosaminidase $\mathrm{D}$ over other hexosaminidase enzymes.

Conclusion: A synthetic methodology has been developed for the synthesis of modified NAGthiazoline analogues. These will be used to test for the inhibition of endo-hexosaminidase $\mathrm{D}$ and eventual testing in virulence models. 


\section{Pharmacokinetics \& Pharmacodynamics}

\section{The Influence of Inflammation on the Ontogeny of L-Carnitine Homeostasis Mechanisms in the Rat Neonate}

Akhilreddy Thoutreddy and Jane Alcorn.

Faculty of Pharmacy and Nutrition, University of Saskatchewan, Saskatoon, Saskatchewan, Canada.

Purpose: L-Carnitine homeostasis mechanisms undergo maturation in early neonatal stages. Limited data is available on whether exposure to disease can alter normal maturation of these mechanisms during the neonatal period. The aim of this study was to evaluate the effects of an inflammatory stimulus on maturation of different L-carnitine homeostasis mechanisms at different stages of postnatal development.

Method: We studied expression of Octn2, Tmlh, Bbh, Cpt1 and Cpt2, activity of Cpt2 and Bbh, high energy phosphate levels, and serum and heart free Lcarnitine levels in two groups of Sprague-Dawley rat pups ( $\mathrm{n}=4$ dams each group with 3-4 pups pooled per dam) administered saline $(0.1 \mathrm{~mL}$, IP) or bacterial lipopolysaccharide (LPS) $(0.1 \mathrm{mg} / \mathrm{kg}, 0.1$ $\mathrm{mL}$, IP) at postnatal day (PD) 3,7 or 14 with euthanasia (isoflurane) at $3 \mathrm{~h}$ or $16 \mathrm{~h}$ postintraperitoneal injection. At sacrifice tissues (kidney, heart, liver and intestine) were immediately collected and frozen in liquid nitrogen with storage at $-80^{\circ} \mathrm{C}$ until analysis. Serum samples were prepared from blood collected and stored at $-20^{\circ} \mathrm{C}$ for further analysis.

Results: In control pups, free L-carnitine levels in serum and heart, mRNA expression of heart, kidney and intestinal Octn2, mRNA expression of liver Bbh and Tmlh, liver Bbh activity, and heart creatine levels demonstrated significant increases with postnatal development. LPS caused significant decreases in mRNA expression of liver Tmlh as well as Octn2 in kidney, heart and intestine at all postnatal ages and at each time point collection. LPS also caused significant decreases in liver Octn2 at PD7 and PD14 at $16 \mathrm{~h}$ post-LPS administration. LPS administration significantly decreased Bbh mRNA expression in liver at each postnatal day, but Bbh activity was decreased only at postnatal day 3 and 7 . In general for heart Cptlb and Cpt2 LPS did not change mRNA expression or activity of these enzymes. Creatine phosphate levels were deceased significantly by 16 hours post-LPS administration at all postnatal ages; however, LPS generally did not influence heart ATP, ADP, and creatine phosphate levels.

Conclusions: Results obtained from our study suggests acute inflammation alters the expression and activity of several key L-carnitine homeostasis mechanisms during postnatal maturation. Enzymes involved in L-carnitine biosynthesis (Bbh, Tmlh), as well as enzymes and transporters required for Lcarnitine disposition (Cpt1b, Cpt2 and Octn2) showed significant deviation from control with induction of acute inflammation during postnatal development.

\section{Quantifying Dabigatran Etexilate Pharmacokinetics and Pharmacodynamics in Hemodialysis Patients}

Matthew J Morrison $^{1}$, Kerry B Goralski ${ }^{1,2}$, Steven D Soroka $^{3}$, David R Anderson ${ }^{4}$, Paula Mossop ${ }^{3}$ and JoAnne Wilson ${ }^{1,3}$.

College of Pharmacy, Faculty of Health Professions ${ }^{1}$ and Department of Pharmacology, Faculty of Medicine $^{2}$, Dalhousie University; Division of Nephrology ${ }^{3}$, Division of Hematology ${ }^{4}$, Department of Medicine, Capital District Health Authority (CDHA)

Purpose: Dabigatran etexilate represents a possible improved alternative to warfarin for anticoagulation in hemodialysis patients with atrial fibrillation (AF). However, there is a lack of pharmacokinetic and pharmacodynamic data to guide dabigatran dosing in hemodialysis patients. The aim was to determine dabigatran plasma concentration and anticoagulant effects of dabigatran in hemodialysis patients.

Methods: We conducted a single center, open-label, non-randomized study in which a single oral dose of dabigatran etexilate $(110 \mathrm{mg})$ was administered to 10 adult patients (age 25-69) of the CDHA Renal Program immediately prior to starting hemodialysis. Plasma and dialysate samples were collected intermittently over a 48-hour period, starting after the drug was administered. High Performance Liquid Chromatography Mass Spectrometry (HPLCMS) was used to measure free and total dabigatran concentrations. The dabigatran anticoagulant effects were quantified by the Hemoclot thrombin inhibitors assay. For each sample, the thrombin time (TT) ratio was calculated by comparing the sample clotting 
time to the clotting time of control pooled plasma.

Results: The median time $\left(\mathrm{t}_{\max }\right)$ to reach maximum plasma concentration $\left(\mathrm{C}_{\max }\right)$ was $2 \mathrm{~h}$ (range 1-3 h). The mean $\mathrm{C}_{\max }$ was $95.0 \pm 34 \mathrm{ng} \mathrm{mL}{ }^{-1}$. The mean elimination half-life on hemodialysis $\left(\mathrm{t}_{1 / 2 \mathrm{ON}}\right)$ was 2.6 $\pm 1.1 \mathrm{~h}$ and the elimination half-life off hemodialysis $\left(t_{1 / 2 \text { OFF }}\right)$ was $30 \pm 8 \mathrm{~h}$. Similar to previous reports in humans with normal renal function, there was a strong correlation between plasma dabigatran concentrations and pharmacological effect (TT ratio). The $\mathrm{r}^{2}$ values for linear regression of TT with free and total dabigatran were 0.758 and 0.740 , respectively. The maximal TT was 2.1 and coincided with dabigatran $\mathrm{t}_{\max }$. The hemodialysis extraction ratios were $0.63 \pm 0.07$ for free dabigatran and $0.58 \pm 0.08$ for total dabigatran.

Conclusions: A $110 \mathrm{mg}$ oral dabigatran dose prior to hemodialysis was well tolerated by the study subjects, was rapidly absorbed and achieved therapeutic concentrations. Hemodialysis effectively removed dabigatran from the plasma and is a possible mechanism for dabigatran detoxification.

Acknowledgement: Funding was provided by the Faculty of Health Professions and the Division of Nephrology, Capital Health. Matthew Morrison is an awardee of the National Summer Student Research Program Awards to Present Research Findings sponsored by GlaxoSmithKline Inc.

\section{Hyperbranched Polyglycerol Conjugation Significantly Improves Vascular Residence and Reduces the Toxicity of Small Molecular Weight Iron Chelator}

Jasmine L. Hamilton ${ }^{1}$; Mohammad Imran Ul-haq ${ }^{1}$; Benjamin F. Lai ${ }^{1}$; Louise Creagh ${ }^{2}$; and Jayachandran N. Kizhakkedathu, ${ }^{1,3}$.

${ }^{1}$ Centre for Blood Research, Department of Pathology and Laboratory Medicine; ${ }^{2}$ Department of Chemical and Biological Engineering; and ${ }^{3}$ Department of Chemistry, The University of British Columbia, Vancouver BC, Canada

Purpose: There is no optimal treatment currently available to iron overloaded patients. Iron chelation therapy (ICT) using desferrioxamine B (DFO) is the oldest treatment form for transfusion dependent iron overload patients. However, due to its short circulation half-life $(\mathrm{t} 1 / 2)$ (20 min in humans), it is administered by subcutaneous infusion over 8-12 hr a day, 5-7 days per week. This tedious regimen, as well as side effects associated with DFO has led to suboptimal adherence to ICT. Using highly biocompatible, dendritic polymer-hyperbranched polyglycerol (HPG)-we have generated DFO conjugates (HPG-DFO) which have significantly prolonged the $t_{1 / 2}$, reduced toxicity and improved the iron excretion efficiency of DFO.

Methods: The influence of HPG MW and DFO density on DFO iron binding of HPG-DFO was determined using Isothermal Titration Calorimetry (ITC) and UV-visible spectroscopy. The safety of HPG-DFO was evaluated by in human blood and endothelial cells. Tolerance was studied by injecting up to $1000 \mathrm{mg} / \mathrm{kg}$ of HPG-DFO in mice and monitoring body weight, lactate dehydrogenase levels and organs morphology at 14 days. Tritium labeled HPG-DFO was used to determine the circulation $t_{1 / 2}$ in mice. Iron excretion efficacy was tested in iron overloaded mice by treating the animals with $150 \mathrm{mg} / \mathrm{kg}$ DFO or DFO equivalent. The iron content of organs, urine and feces was analyzed to determine the amount of iron excreted.

Results: ITC and UV analysis demonstrated that the conjugation of DFO to HPGs did not alter the iron chelating properties of DFO. HPG-DFOs did not activate platelets, coagulation or the complement system. Mice tolerance studies showed that the HPG-DFO conjugates were non toxic; the maximum tolerated dose was not reached even at $1000 \mathrm{mg} / \mathrm{kg}$. The $t_{1 / 2}$ of HPG-DFO in normal mice was $16 \mathrm{~h}$ for the $50 \mathrm{kDa}$ conjugate and $44 \mathrm{~h}$ for the $500 \mathrm{kDa}$ conjugate. The iron excretion efficiency as measured by urinary iron of the $50 \mathrm{kDa}$ HPG-DFO in iron overloaded showed significant improvement compared to placebo $(\mathrm{p}=0.0002)$ and DFO treated mice $(\mathrm{p}=0.0011)$.

Conclusions: HPG-DFO shows a significant increase in $t \frac{1}{2}$ which may result in the maintenance of much higher plasma concentrations and more effective iron removal. This approach has the potential to significantly decrease the number and duration of injections required to offload significant amounts of organ and total body iron in transfusion dependent patients. 


\section{Pharmaceutical \& Analytical Chemistry}

\section{Gastric Anti-ulcer, Anti-secretory and Cytoprotective Properties of Celery "Apium graveolens L." in Rats}

Tawfeq AlHowiriny ${ }^{a *}$ Abdulmalik Alsheikh†, Mohammed Al-Yahya*, Kamal ElTahir* and Syed Rafatullah ${ }^{\mathrm{a} *}$.

*Departments of Pharmacognosy and Pharmacology, College of Pharmacy, King Saud University; †Department of Pathology, King Khalid University Hospital, King Saud University, Riyadh; ${ }^{a}$ Medicinal, Aromatic and Poisonous Plants Research Center (MAPPRC), College of Pharmacy, King Saud University, Riyadh, Saudi Arabia

Purpose: Celery seed is generally regarded as safe for human consumption as a spice, natural seasoning and plant extract/essential oil. The present study was carried out to assess the possible anti-gastric ulcer, cytoprotective and antisecretory properties of ethanolic extract of Apium graveolens in rats in order to substantiate the traditional Unani, Arab and Ayurvedic medicine practitioners' claim of its use in stomach disorders.

Methods: 500 grams of the shade dried aerial parts of celery was coarse powdered and macerated in 3 liters of $96 \%$ ethanol for 72 hours using percolation method. Wistar albino rats were used. The stomach was removed, opened along the greater curvature, washed with saline and the inner surface was examined with a $6.4 \times$ binocular magnifier. Celery extract was administered orally (250 and $500 \mathrm{mg} / \mathrm{kg}$ body weight) 30 minutes before indomethacin. The rats were killed 6 hours after indomethacin administration. Gastric antisecretory activity was evaluated in rats. The animals were deprived of food for $36 \mathrm{~h}$ with access to water ad libitum. Under light ether anaesthesia, a small midline abdominal incision was made and the pylorus ligated. The wound was closed using sterile suture. The plant extract or normal saline was administered intraperitoneally immediately after pylorus ligation. Six hours after pylorus ligation the animals were sacrificed by cervical displacement. The stomachs were removed from both groups (treated and control), the gastric contents collected and centrifuged. The volume of the supernatant was measured and titratable acidity of liquid gastric content was recorded and calculated.

Results: Celery extract produced a dose-dependent significant protection against the ulcerogenic effect induced by indomethacin. In the ethanol and strong alkali-induced ulcer protocol, it was observed that the treatment with ethanolic extract of celery ( 250 and $500 \mathrm{mg} / \mathrm{kg}$ ) significantly reduced the lesion index. A highly significant reduction of ulceration in rats' stomach and intraluminal bleeding was recorded after celery extract pretreatment at the dose of $500 \mathrm{mg} / \mathrm{kg}$ orally. In the gastric secretion determination model, using ligated pylorus for $6 \mathrm{~h}$, the treatment with celery extract $(250$ and $500 \mathrm{mg} / \mathrm{kg}$ i.p.), reduced the volume of basal gastric secretion, titratable acidity and ulceration significantly in comparison with control group.

Conclusion: The results show that ethanol extract of Celery displays gastroprotective activity, as demonstrated by its significant inhibition of the formation of ulcers induced by different experimental models, and its ability to decrease basal gastric acid secretion. This gastric antiulcer capacity of celery extract could be related to its antioxidant properties, resulting in reduction of the lipid peroxidation and elevation of the NP-SH contents, besides, improving mucus coat of the stomach. Therefore, we suggest that due to its antioxidative effects, it may be useful in the prevention of gastric disorders.

\section{A Simple and Sensitive Method for Simultaneous Determination of Vitamins $D_{3}$ and $K_{1}$ in Rat Plasma: Application for an in- vivo Pharmacokinetic Study}

Pavel Gershkovich $^{1}$, Fady Ibrahim ${ }^{1}$, Olena Sivak ${ }^{1}$, Jerarld W. Darlington ${ }^{2}$, Kishor M. Wasan ${ }^{1}$.

${ }^{1}$ Faculty of Pharmaceutical Sciences, University of British Columbia, Vancouver, Canada; ${ }^{2}$ AMCOL International Inc. Arlington Heights, IL

Purpose: To develop and to validate a simple but sensitive method for determination of vitamins $D_{3}$ and $\mathrm{K}_{1}$ in rat plasma.

Methods: The sample treatment included protein precipitation by cold $\left(4^{\circ} \mathrm{C}\right)$ acetonitrile; evaporation; reconstitution with methanol; and filtration. The chromatography conditions included Xterra RP18 $3.5 \mu \mathrm{m} 4.6 \times 100 \mathrm{~mm}$ column at ambient temperature and mobile phase consisting of methanol/water $(93 / 7, \mathrm{v} / \mathrm{v})$ at $0.5 \mathrm{ml} / \mathrm{min}$ flow rate. Vitamin $\mathrm{D}_{3}$ was detected at $265 \mathrm{~nm}(10.3 \mathrm{~min})$, vitamin $\mathrm{K}_{1}$ at $244 \mathrm{~nm}$ 
(23min) and probucol (internal standard) at $265 \mathrm{~nm}$ (6.5min). Rats equipped with jugular vein catheter were administered intravenously by $0.1 \mathrm{mg} / \mathrm{kg}$ of vitamin D3 $(\mathrm{n}=3)$ in propylene glycol: ethanol $(9: 1$, $\mathrm{v} / \mathrm{v})$ or $0.1 \mathrm{mg} / \mathrm{kg}$ of vitamin $\mathrm{K} 1(\mathrm{n}=3)$ in PEG-400: ethanol $(8: 2, \mathrm{v} / \mathrm{v})$. The blood samples were withdrawn pre-administration, $5,15,30 \mathrm{~min}, 1 \mathrm{~h}, 3 \mathrm{~h}$, $6 \mathrm{~h}, 10 \mathrm{~h}, 24 \mathrm{~h}, 36 \mathrm{~h}$ and $48 \mathrm{~h}$ following the administration. The pharmacokinetic analysis was performed by a non-compartmental approach.

Results: The calibration curves in rat plasma were linear up to $5000 \mathrm{ng} / \mathrm{ml}$ for both vitamins. The limit of quantification was $20 \mathrm{ng} / \mathrm{ml}$ for vitamin $\mathrm{D}_{3}$ and $40 \mathrm{ng} / \mathrm{ml}$ for $\mathrm{K}_{1}$. Inter and intra-day precision and accuracy of low, medium and high concentrations of vitamins were below 15\% (Table).

The pharmacokinetic parameters of vitamin D3 following intravenous administration were: $\mathrm{AUC}_{0-\infty}$ $=11323 \pm 1081 \mathrm{~h}^{*} \mathrm{ng} / \mathrm{ml} ; \mathrm{V}_{\mathrm{d}}=218 \pm 80 \mathrm{ml} / \mathrm{kg} ; \mathrm{CL}=$ $8.9 \pm 0.8 \mathrm{ml} / \mathrm{h} / \mathrm{kg} ; \quad \mathrm{t}_{1 / 2}=16.8 \pm 5 \mathrm{~h}$. The pharmacokinetic parameters of vitamin K1 following intravenous administration were: $\mathrm{AUC}_{0-\infty}$ $=2495 \pm 297 \mathrm{~h} * \mathrm{ng} / \mathrm{ml} ; \mathrm{V}_{\mathrm{d}}=60 \pm 24 \mathrm{ml} / \mathrm{kg} ; \mathrm{CL}=$ $40.5 \pm 5.1 \mathrm{ml} / \mathrm{h} / \mathrm{kg} ; \mathrm{t}_{1 / 2}=1.1 \pm 0.5 \mathrm{~h}$.

Conclusion: The developed HPLC-UV assay is simple and sensitive method for determination of vitamin $\mathrm{D}_{3}$ and $\mathrm{K}_{1}$ in rat plasma. To the best of our knowledge, this is the most sensitive HPLC-UV method reported for these compounds in literature. A higher dose of vitamin $\mathrm{K}_{1}$ should be used in future studies for accurate estimation of pharmacokinetic parameters. The data show the suitability of the assay for pharmacokinetic studies in rats. The method would be especially useful in monitoring malabsorption of lipid-soluble vitamins as an adverse effect of new pharmaceuticals or nutraceuticals.

\section{Structure-activity Relationships of Inhibitors of Human O-GlcNAc Hydrolase}

Nevena Cekic, Julia Heinonen, and David J Vocadlo*.

Department of Chemistry and Molecular Biology and Biochemistry, Simon Fraser University, Burnaby, British Columbia

Purpose: $\quad \mathrm{O}$-linked $\mathrm{N}$-acetylglucosamine $(\mathrm{O}$ GlcNAc) is an abundant post-translational modification of intracellular proteins that is found on serine and threonine residues. The two enzymes which are known to regulate this modification are the anabolic $O$-GlcNAc transferase (OGT) and catabolic $O$-GlcNAc hydrolase (OGA). Recently, it was shown that the inhibition of OGA was a useful tool for manipulating the levels of $O$-GlcNAc in cells and animals. Furthermore, OGA-inhibition was also demonstrated to have potential utility as a disease modifying approach for Alzheimer's disease. The mechanism of OGA involves the neighbouringgroup participation of the 2-acetamido group of the substrate which displaces the glycosidically-linked leaving group, resulting in the formation of an oxazoline intermediate (1). The aim of this work was to (i) synthesize a panel of amino-thiazolinecontaining OGA inhibitors, which mimic the oxazoline intermediate, containing varying $\mathrm{R}$-groups on the exocyclic amine (2), (ii) to determine the $K_{\mathrm{i}}$ values for each compound, and (iii) to establish the relationship of these between the $K_{\mathrm{i}}$ values and the pKa of each analogue.
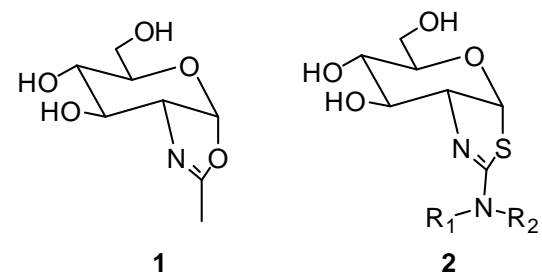

Methods: We synthesized inhibitors using, as a common intermediate, per-O-acetylated $\beta$-Dglucosamine hydrochloride. Treatment of this glucosamine salt with thiophosgene produced an advanced isothiocyanate intermediate which was reacted with various amines to afford a series of thiourea-containing compounds. Under acidic conditions, these were cyclized to give the corresponding thiazoline analogues. Subsequent deprotection using $\mathrm{K}_{2} \mathrm{CO}_{3}$ in methanol afforded the desired inhibitors. The $K_{\mathrm{i}}$ values against recombinant human OGA were established by Dixon plot analysis using fluorescent 4-methylumbelliferylGlcNAc as a substrate. pKa values were determined by titration experiments and correlated with inhibitor potency.

Results: We clarified the structure-activity relationships for this series of OGA inhibitors, established the importance of their $\mathrm{pKa}$ values for enzyme inhibition, and identified several nanomolar inhibitors.

Conclusion: These findings should prove useful in the generation of improved OGA inhibitors with potential utility as a disease-modifying approach for the treatment of Alzheimer's disease. 


\section{Drug Delivery \& Pharmaceutical Technology}

\section{Synthesis and in vitro Characterization of Hyaluronic Acid $\alpha$-tocopherol Succinate Based Self- assembling Micelles for Targeted Delivery of Rifampicin to Macrophages}

Yuan Gao a, Muhammad Khan Sarfraza, SophieDorothee Clas ${ }^{\mathrm{b}}$, Wilson $\mathrm{Roa}^{\mathrm{c}}$, Raimar Löbenberg ${ }^{\mathrm{a}, *}$. ${ }^{a}$ Faculty of Pharmacy and Pharmaceutical Sciences, University of Alberta, Edmonton, Alberta, Canada; ${ }^{b}$ Merck, Basic Pharmaceutical Sciences, West Point, PA, USA; 'Department of Radiation Oncology, Cross Cancer Institute, University of Alberta, Edmonton, Alberta, Canada

Purpose: The aim of this study was to develop a self-assembled nano-sized rifampicin (RIF) micelle system for target delivery to CD 44-ligand receptors of macrophages.

Methods: Chemical conjugation of hydrophobic $\alpha$ tocopherol succinate (TS) to hydrophilic hyaluronic acid (HA) leads to an amphiphilic conjugate with self-assembly characteristics. The new HA-TS conjugate was characterized by FTIR, ${ }^{1} \mathrm{H}-\mathrm{NMR}$ and elemental analysis. Rifampicin loaded micelles (RIF-HA-TS) were prepared using the conjugate. The drug loading, in vitro release as well as RIFHA-TS uptake by alveolar macrophages (MH-S) was investigated. In addition, the cytotoxicity of the micelle system was evaluated by MTT assay.

Results: HA-TS conjugates can form selfaggregating micelles in an aqueous medium via hydrophobic interactions between the TS subunits. The micelle size was in the range of $200-300 \mathrm{~nm}$ with a polydispersity index less than 0.5 depending on the degree of substitution (DS) of the hydrophobic moiety. IR and ${ }^{1} \mathrm{H}-\mathrm{NMR}$ spectra confirmed that TS was successfully grafted to the HA chain. The critical micelle concentration increased from 0.005 to $0.013 \mathrm{mg} / \mathrm{mL}$ as the DS of TS decreased from 10 to 7 . DSC and XRD studies confirmed that the drug-loaded micelles were not physical mixtures. The micelles efficiently encapsulated RIF with drug loadings of 70.7-79.1\%. The micelles were stable for 2 weeks without aggregation at $37^{\circ} \mathrm{C}$. The in vitro release curves showed a sustained released of RIF from the micelles. Cellular uptake studies demonstrated that the RIF-HA-TS micelles were more efficiently taken up (nearly 3 fold) by the MH-S cells than the free RIF solution. The cytotoxicity of the RIF-HA-TS was comparable to that of free RIF.

Conclusions: The HA-TS micelles showed good colloidal stability and biocompatibility. The RIFHA-TS micelles showed high drug loading and sustained drug release. The HA-TS micelles improved the cellular uptake of RIF presumably via a HA interaction with a membrane receptor. Thus HA-TS micelles are a potential nano-carrier for targeted drug delivery to macrophages.

\section{The Behaviour of Rifampicin Loaded Hyaluronic Acid a-tocopherol Succinate Micelles in Alveolar Macrophages}

Yuan Gao a, Muhammad Khan Sarfraz, SophieDorothee Clas ${ }^{\mathrm{b}}$, Wilson Roa $^{\mathrm{c}}$, Raimar Löbenberg ${ }^{\mathrm{a}, *}$

${ }^{a}$ Faculty of Pharmacy and Pharmaceutical Sciences, University of Alberta, Edmonton, Alberta, Canada; ${ }^{\mathrm{b}}$ Merck, Basic Pharmaceutical Sciences, West Point, PA, USA; ${ }^{\mathrm{C}}$ Department of Radiation Oncology, Cross Cancer Institute, University of Alberta, Edmonton, Alberta, Canada.

Purpose: To study the effect of rifampicin loaded hyaluronic acid-tocopherol succinate (RIF-HA-TS) micelles targeted delivery system for the treatment of tuberculosis, and investigate the uptake mechanism as well as cytokine secreting activities of RIF-HA-TS on murine alveolar macrophage (MH-S).

Methods: The MH-S cells were exposed to RIFHA-TS micelles and then the RIF taken up by the cells were determined by HPLC. A cell uptake study was performed for different factors, which included concentration, time course, and molecular size of the polymer and temperature dependency. Competitive uptake inhibitors such as Anti-CD44 mAb IMF7, HA and Cytochalasin B were used to study the uptake mechanism of RIF-HA-TS micelles by cells. Confocal microscopy and FACS analysis were used to demonstrate CD44 expression on the MH-S cells. Raybio cytokine antibody array was used to assess the changes of cytokine secreting profiles in MH-S cells triggered by the uptake of the RIF-HA-TS micelles or free RIF.

Results: The results of the studies indicate that (i) the uptake of RIF-HA-TS micelles is dose and energy dependent (ii) RIF-HA-TS micelles had a significant uptake, with the highest uptake at $12 \mathrm{~h}$ (iii) RIF-HA-TS micelles were taken up into cells 
via phygocytosis as well as CD44 receptor-mediate endocytosis (iv) The RIF-HA-TS micelles were primarily localized in cytoplasm (v) there was a significant increase uptake of RIF-HA-TS micelles in the E. coli LPS activated MH-S cells than in the cells without LPS treatment (vi) RIF-HA-TS micelles induced higher concentration of Th1 cytokines than free RIF.

Conclusions: The results of the current studies demonstrate the feasibility of targeting macrophages and the suitability of using these synthetically HATS micelles for tuberculosis.

\section{Design and Evaluation of M1 Acetylcholine Receptor Selective Allosteric Potentiator BQCA Loaded PLGA Nanoparticles to treat Alzheimer's Disease}

Rizwan Basha Khatwal $^{1}$, Anil Dubala ${ }^{1}$, Jayasankar Kosaraju $^{2}$, Chinni Santhi Vardhan ${ }^{2}$, Manjunatha Narayanappa ${ }^{3}$, Afzal Azam ${ }^{4}$, MN Satish Kumar ${ }^{2}$, Malay K Samanta ${ }^{1}$.

${ }^{1}$ Department of Pharmaceutical Biotechnology, ${ }^{2}$ Department of Pharmacology, ${ }^{3}$ Department of Pharmaceutics, ${ }^{4}$ Department of Pharmaceutical Chemistry, JSS College of Pharmacy, JSS College of Pharmacy, Ootacamund, India

Purpose: Benzyl quinolone carboxylic acid (BQCA) is a novel highly selective allosteric Potentiator of M1 Muscarinic acetylcholine receptor over other subtypes (M2-M5) in a way that effectively enhancing the cognitive effect by reducing $A \beta 42$ peptides without producing unwanted cholinergic side effects and also increases activity of medial prefrontal cortical neurons with restores impairments in reversal learning. Central nervous system drug efficacy depends upon the ability of a drug to cross the blood-brain barrier and reach therapeutic concentrations in brain following systemic administration. The clinical failures of most of the potentially effective therapeutics to treat the central nervous system disorders are often not due to a lack of drug potency but rather shortcomings in the method by which the drug is delivered. Drugs deliver through nano-drug delivery could enhance neuroprotection by rapid accumulation of drugs in the brain and a slow metabolism of the compound. Hence, considering the importance of treating Alzheimer's disease (AD), we made an attempt to target the allosteric Potentiator BQCA into the brain using polysorbate- 80 coated poly lactide-co- glycolide (PLGA) nanoparticles (NPs).

Method: BQCA containing NPs were prepared by modified double emulsion solvent diffusion technique and evaluated brain targeting efficacy of BQCA after intravenous injection in rats as BQCA was administered alone, bound to NPs and bound to polysorbate- 80 coated NPs and also evaluated influence of developed NPs of BQCA on learning and memory capacities, Morris Water Maze Test was performed in streptozotocin-induced rat model.

Results: The developed BQCA loaded NPs exhibited a particle size of less than $100 \mathrm{~nm}$, $88.37 \pm 0.82 \%$ drug entrapment efficiency and a zeta potential of $-21.4 \pm 1.22 \mathrm{mV}$ (Figure 1). In vitro drug release was found in sustained release manner and follows first-order Fickian diffusion kinetics. In the brain a significant increase in BQCA concentration was observed in the case of polysorbate- 80 coated PLGA NPs compared to the uncoated NPs and the free drug. Administration of BQCA solution in streptozotocin-induced animals did not result in any noticeable improvement in learning and memory capacities, whereas administration of polysorbate- 80 coated PLGA NPs of BQCA in streptozotocininduced animals significantly $(\mathrm{P}<0.05)$ decreased escape latency. These results indicated that, compared to BQCA solution polysorbate- 80 coated PLGA NPs of BQCA resulted in faster memory regain in streptozotocin-induced animals.

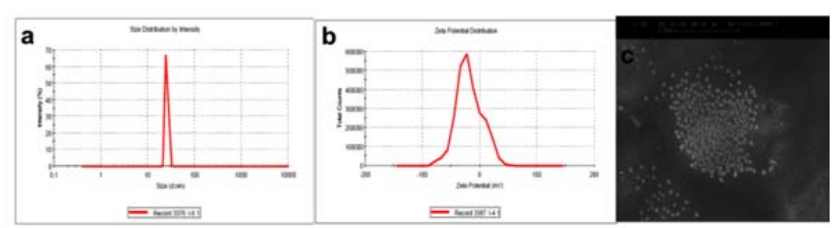

Figure 1: a) Particle size distribution b) Zeta potential distribution c) SEM analysis of BQCA loaded NPs

Conclusion: In conclusion, this study indicates that polysorbate-80 coated PLGA NPs could be a feasible carrier for novel Allosteric Potentiator BQCA to deliver rapid and higher extent of transport into the brain. Also, preventing the cognitive deficits caused by streptozotocin-induced in rats. Together, these results indicate the potential of developed polysorbate- 80 coated NPs to treat Alzheimer's disease. 


\section{Cytotoxic Effect of Novel Dehydro- epiandrosterone Derivatives on Different Cancer Cell Lines}

Eugene Bratoeff, Department of Pharmacy, Faculty of Chemistry, University of Mexico City, Mexico; Marisa Cabeza, Department of Biological Systems, Metropolitan University-Xochimilco, Mexico; Mariana Garrido, Francisco Cortes; and Jose Gutierez, Department of Pharmacy, University of Mexico City, Mexico

Purpose: The aim of this study was to determine the cytotoxic effect on human cancer lines of a series of novel dehydroepiandrosterone derivatives containing a triazole ring at $\mathrm{C}-17$, a formyl group at $\mathrm{C}-16$ and an ester moiety at C-3 with beta configuration. The panel cancer cells used in this study were the following: PC-3- prostate cancer, MCF-7-breast cancer, SKLU-1-lung cancer

Methods: Dehydroepiandrosterone was used as the starting material. The first step in this synthesis was the esterification of the C-3 hydroxyl group with the correspondding acid. In the subsequent step, the ester was formylated at C-16, using the Vilsmayer reaction. A 17-chloro, C-16 formyl derivative was obtained. In the next step, the $\mathrm{C}-17$ chloro derivative was reacted with triazole and cesium carbonate, thus obtaining the final compounds, the corresponding esters at C-3 with the triazole group in C-17.

Results: The results from this study indicated that the steroidal derivatives having at $\mathrm{C}-3$ the following ester moiety: cyclopropanoate, cyclobutanoate, cyclopentanoate, cycloheptanoate, pmethoxybenzoate, p-methylbenzoate, benzoate, $\mathrm{p}$ trifluoromethyl benzoate, $\mathrm{p}$-cyanopbenzoate and $\mathrm{p}$ nitrobenzoate showed a much higher cytotoxic activity as compared to those having the same ester moiety at $\mathrm{C}-3$ however with a pyrazole ring at $\mathrm{C}-17$. The difference in this activity could be attributed to the ability of the triazole ring (three nitrogen atoms) to form stronger hydrogen bonds with the active site of the cell as compared to the pyrazole group having two nitrogen atoms. On the other hand a comparison of the above aromatic esters with the steroids having a cycloalkyl ester moiety with both series contaning a triazole ring at $\mathrm{C}-17$ showed a much higher cytotoxic activity for the compounds having an aromatic ring. Apparently the electronegative phenyl ring increased the polarity of the molecule, thus increasing the dipole-dipole association of the steroidal molecule with the reaction site of the cell.

Conclusion: Several new esters of dehydro- epiandrosterone were synthesized having a high cytotoxic activity against prostate breast and lung cancer cell lines.

\section{Preparation and in vitro Characterization of Mixed Micelles System to Improve Solubility of Poorly Soluble Drug Nicergoline}

Girish Kore, Rima Kotadia, Atul Kolate, Ambikanandan Misra.

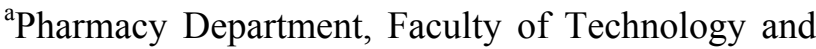
Engineering, The Maharaja Sayajirao University of Baroda, Gujarat, India

Purpose: The present investigation was aimed to develop a polymeric micelle delivery system to improve the solubility of poorly soluble neuroprotective drug Nicergoline and assessment of its in-vitro properties.

Methods: Mixed micelles of Nicergoline were prepared by thin film hydration technique using Pluronic F127 and d-alpha tocopheryl polyethylene glycol 1000 succinate (TPGS). The critical micellar concentration (CMC), particle size and polydispersity index of Nicergoline loaded micelles were determined by using Dynamic light scattering (DLS). The micelles were also evaluated for drug loading content, entrapment efficiency, in-vitro drug release, dilution stability, Differential scanning Calorimetry (DSC) and Fourier transform infrared spectroscopy (FTIR) studies. In-vitro cytotoxicity study as well as cell uptake study for developed micelles were performed using SY SH5Y cell line. Neuroprotective efficacy of drug loaded micelle were compared with free drug in hydrogen peroxide induced cell death model in SY SH5Y cell line.

Results: Mixed micelles of Pluronic F127/TPGS were successfully prepared. DLS analysis showed $37 \mathrm{~nm}$ an average hydrodynamic diameter, CMC of Nicergoline loaded micelle was found to be $5 \times 10^{-5} \mathrm{M}$. The solubility of drug was increased form $0.002 \mathrm{mg} / \mathrm{ml}$ to $4 \mathrm{mg} / \mathrm{ml}$ in water. The entrapment efficiency of Nicergoline was $98.1 \pm 0.45 \%$ and drug loading was about $10.00 \pm 0.51 \%$. In DSC and FTIR studies characteristic peaks of Nicergoline drug were absent in case of drug loaded micelle formulation which confirms that Nicergoline is completely encapsulated inside the micelle. The in-vitro release showed initial burst release followed by slow and gradual release for 5 days. Results from cellular uptake studies indicated that mixed micelles had 
significant cellular uptake in SY SH5Y cells. The cell toxicity showed concentration dependent increase in cell death for mixed micelle. The neuroprotective efficacy of Nicergoline loaded mixed micelle was significant as compared to free drug.

Conclusion: Mixed micelles of Pluronic F-127 and TPGS provide a more efficient solubilisation of the poorly soluble drug Nicergoline. Micellar system is able to retain the incorporated Nicergoline and show significant cell uptake in neuroblastoma cell lines. This mixed micellar system can serve as potential nanocarrier to improve the solubility and biological activity of Nicergoline.

\section{Targeted Gemini Surfactant-Based Nucleic Acid Delivery for Melanoma Gene Therapy}

Waleed Mohammed-Saeid ${ }^{1}$, Jackson Chitanda ${ }^{1}$, Kamaljit Kaur ${ }^{2}$, Rania Soudya ${ }^{2}$, Ronald Verrall ${ }^{3}$, Ildiko Badea ${ }^{1}$.

${ }^{1}$ Drug Design and Discovery Research Group, College of Pharmacy and Nutrition, University of Saskatchewan, Saskatoon, Saskatchewan, Canada; ${ }^{2}$ Faculty of Pharmacy and Pharmaceutical Sciences, University of Alberta, Edmonton, Alberta, Canada; ${ }^{3}$ Department of Chemistry, University of Saskatchewan, Saskatoon, Saskatchewan, Canada

Purpose: Cationic gemini surfactants have been extensively studied as non-viral vectors for gene therapy and satisfactory levels of gene expression were achieved. In this work, we developed and evaluated novel peptide-targeted gemini surfactantbased lipoplexes. These lipoplexes will be used for melanoma gene therapy.

Methods: Two cancer targeting peptides (cyclic RGD, p18-4 [WxEAAYQrFL]) were either chemically coupled to a gemini surfactant backbone or physically co-administered. Several formulations and transfection methods were developed in order to achieve cancer cell targeting transfection activity. In vitro transfection efficiencies and cell toxicity of lipoplexes constructed from plasmid DNA (P), gemini surfactant $(\mathrm{G})$, helper lipid DOPE (L) and the ligand peptide were evaluated in A375 cell line (human amelanotic melanoma cell line) using ELISA and MTT assays. Structural properties of peptide modified lipoplexes were examined by using circular dichroism, dynamic light scattering, zeta potential, and small-angle X-ray scattering (SAXS).

Results: As expected, the incorporation of the ligand peptide in the lipoplex systems, either by chemical attachment or physical co-administration, improved the gene expression significantly in melanoma cells in comparison to non-modified gemini surfactant lipoplexes. Physical co-administration of p18-4 peptide with the lipoplexes showed 6-fold increase in transfection activity compared to the non-targeted $(\mathrm{P} / \mathrm{G} / \mathrm{L})$ system. Similarly to the previous generation of amino acid/peptide-modified gemini lipoplexes, the new conjugates showed low cytotoxicity. Particle size and zeta potential were altered when the targeting peptide(s) were incorporated in the formulations. However, particle sizes were maintained below $200 \mathrm{~nm}$ with positive zeta potential for all lipoplexes. SAXS results showed ordered structures and the presence of diverse multiple phases in different formulations.

Conclusion: The modification of gemini surfactant lipoplexes with cyclic RGD and p18-4 enhanced the uptake and gene expression activity of the transfection system by melanoma cells in comparison to non-targeted lipoplexes. The alterations in the physiochemical properties of modified lipoplexes indicate that the presence of the peptide in the lipoplex system induces changes in the lipid phase structures.

\section{Cell Toxicity Correlation with Physicochemical Characteristics of Curcumin Analog Inclusion in Novel Cyclodextrin- gemini Delivery Agent}

Masoomeh Poorghorban ${ }^{1}$, Deborah Michel 1, Jackson Chitanda ${ }^{2}$, Umashankar Das ${ }^{1}$, Jonathan Dimmock $^{1}$, Ronald Verrall ${ }^{2}$, Pawel Grochulski ${ }^{1,3}$, Ildiko Badea ${ }^{1}$.

${ }^{1}$ College of Pharmacy and Nutrition, University of Saskatchewan; ${ }^{2}$ Department of Chemistry, University of Saskatchewan; ${ }^{3}$ Canadian Light Source, Saskatoon

Purpose: Many highly efficient anticancer agents such as curcumin analogs suffer from poor solubility $(\log P$ values of 4.5$)$ leading to low bioavailability. We engineered a novel solubilizing/delivery agent by grafting a cyclodextrin ring onto self-assembling cationic gemini surfactant to improve the uptake and efficiency of these molecules.

Methods: The efficiency of the nanoparticulate formulations of curcumin analog NC 2067 encapsulated in three different types of cyclodextringemini molecules has been investigated in A375 
human melanoma cell line using MTT assay. The cell death pathway was determined using flow cytometry. Physicochemical properties, such as size and zeta potential of the nano particles were measured using Zetasizer. Synchrotron-based small angle X-ray scattering was utilized to determine the structural organization of the lipid-based nanoparticles.

Results: The $\mathrm{IC}_{50}$ value for the three different inclusions at 1:2 drug/carrier molar ratio was similar $(2.5 \mathrm{uM})$ and was significantly lower than the $\mathrm{IC}_{50}$ of a model antimelanoma drug melphalan(39uM). Furthermore, the curcumin/cyclodextrin-gemini inclusions showed that cell death occurred through apoptosis after 24 hours, similarly to the drug in DMSO. The cyclodextrin-gemini molecules alone did not reveal apoptosis. DNA cell cycle analysis revealed that the inclusion of the NC 2067 in cyclodextrin-gemini did not affect cellular arrest in S-phase.

Conclusion: Correlation of the physicochemical properties and drug delivery efficiency of the curcumin analog/cyclodextrin-gemini inclusion complexes will lead to development of the competent formulations to treat melanoma topically.

\section{Novel Biosimilar Gemini Surfactant Lipid- Based Nanoparticles as Effective and Safe Non-Viral Gene Delivery Agents.}

Mays Al-Dulaymi ${ }^{1}$, Waleed Mohammed-Saeid ${ }^{1}$, Jackson Chitanda ${ }^{1}$, Anas El-Aneed ${ }^{1}$, Ronald Verrall $^{2}$, Ildiko Badea ${ }^{1}$.

1. College of Pharmacy and Nutrition, University of Saskatchewan, Saskatoon, SK, Canada; 2. Department of Chemistry, University of Saskatchewan, Saskatoon, SK, Canada

Purpose: Cationic gemini surfactants hold a promising future in the development of non-viral gene delivery. In order to capitalize on the potential of these agents, there is a need to design gemini surfactants with higher transfection efficiency and lower toxicity. Recently, we have developed a series of novel peptide-modified gemini surfactant-based gene delivery nanoparticles. The aim of this study was to investigate the changes in the activity and toxicity as a function of carbon tail length and to compare with the conventional parent gemini surfactants.

Methods: Three novel third-generation peptidesubstituted gemini surfactants, biolipids, were used to engineer DNA nanoparticles at phosphate to nitrogen charge ratios of 1:1, 1:2.5, 1:5, 1:10, 1:15 and 1:20 in the presence of a helper lipid, DOPE. The in vitro gene expression and cell toxicity of gemini nanoparticles were evaluated in Cos-7 cells. Characterization of the delivery systems was accomplished by using dynamic light scattering (DLS), zeta $(\zeta)$ potential analysis and small angle $X-$ ray scattering (SAXS) measurements.

Results: The highest activity of biosimilar lipids was observed with the 16 carbon tail compound compared to the 12 and 18:1 carbon tail compounds and the most efficient phosphate to nitrogen charge ratios were 1:2.5-1:5. All lipids exhibited significantly lower toxicity compared to commercially available transfection agents. The DNA/gemini lipid/ helper lipid (P/G/L) nanoparticles showed a wide range of particle size, $50-800 \mathrm{~nm}$. The zeta potential value also varied depending on the charge ratios. SAXS results indicated structural diversity in the morphology of the $\mathrm{P} / \mathrm{G} / \mathrm{L}$ nanoparticles.

Conclusion: The new generation biosimilar gemini surfactants show high gene transfer efficiency and low toxicity in a structure and ratio-dependent manner with $16-7 \mathrm{~N}(\mathrm{GK})-16$ being the best agent at a 1:2.5 charge ratio. This might be attributed to a balanced electrostatic interaction that protects the genetic material from enzymatic degradation and facilitates intracellular release. Among the tested compounds, the low critical micelle concentration (CMC) of the 16-7N(GK)-16 compound might have contributed to its higher efficiency. In addition, this biolipid was most efficient at a charge ratio which was lower than the optimal charge ratio of the previous generations of gemini lipids, (1:10). This means less material is needed, thus less toxicity is triggered. Particle size of the nanoparticles with the highest transfection efficiency was less than $100 \mathrm{~nm}$ wich was optimal for efficient cellular uptake. The positive surface charge facilitated the interaction with the negatively charged cell surface, leading to internalization of the nanoparticles. 


\section{Cross-linked Hyaluronic Acid-lipoic Acid Micelles for Enhanced Solubility, Stability and Targeted Delivery of Curcumin to Breast Cancer Cells}

Yuan Gao, ${ }^{\text {a }}$ Muhammad Khan Sarfraz, ${ }^{\text {a }}$ Wilson Roa, ${ }^{\mathrm{b}}$ and Raimar Löbenberg ${ }^{\mathrm{a}, *}$.

${ }^{a}$ Faculty of Pharmacy and Pharmaceutical Sciences, University of Alberta, Edmonton, Alberta; ${ }^{b}$ Department of Radiation Oncology, Cross Cancer Institute, University of Alberta, Edmonton, Alberta, Canada

Purpose The aim of this study was to develop a new nano-sized system for the delivery of curcumin (CUM) to breast cancer cells.

Methods New amphiphilic conjugates were synthesized by chemical conjugation of hydrophobic lipoic acid (LA) to the hydrophilic hyaluronic acid (HA). Their chemical structure was investigated by ${ }^{1} \mathrm{H}-\mathrm{NMR}$, IR and elemental analysis. CUM loaded micelles were characterized by DSC and XRD. The inhibitory effect of CUM loaded micelles was evaluated on human breast cancer cells MDA-MB231 in comparisons with controls. The intracellular distribution was investigated by confocal laser scanning microscope (CLSM). In addition, the uptake mechanism of CUM loaded micelles was determined using uptake inhibitors.

Results The new conjugates can self assemble into micelles (HA-LA) in aqueous solution. The micelles can be cross-linked (Cro) by dithiothreitol to form Cro-HA-LA, with a particle size of $120-180 \mathrm{~nm}$. Compared with that in HA-LA, CUM in Cro-HALA has a smaller particle size, higher colloidal stability, higher drug loading as well as a lower release rate. Cro-HA-LA also significantly enhanced the aqueous solubility and stability of CUM. CUM in Cro-HA-LA micelles have the higher potency in inhibiting the growth of MDA-MB-231 cells for 96 $\mathrm{h}$ than the free CUM, while blank micelles are biocompatible with no toxicity observed at the concentrations up to $400 \mu \mathrm{g} / \mathrm{ml}$. CLSM studies showed that CUM in Cro-HA-LA localized in both cytoplasm and nucleus. Finally, CUM in Cro-HALA micelles were taken up by MDA-MB-231 cells via a combination of $\mathrm{HA}$ receptor mediated endocytosis and with energy dependent pathway.

Conclusions These results reveal the promising potential of Cro-HA-LA micelles as an effective nano-vehicle for targeted cancer treatment.

\section{Prospects of Drug Delivery using Dendritic Polymer Functionalized Red Blood Cells}

Rafi Chapanian, Iren Constantinescu, Donald E. Brooks and Jayachandran N. Kizhakkedathu.

Centre for Blood Research, Department of Pathology and Laboratory Medicine, and Department of Chemistry, University of British Columbia, Vancouver, British Columbia, Canada

Purpose: Therapeutic molecules are conjugated to red blood cells (RBCs) to enhance their circulation half-life and bioavailability. The life span of human red blood cells in vasculature is 120 days and is excellent system for drug conjugation and systemic delivery. In this abstract we present our results on functional modification of RBCs via surface grafting of hyperbranched polyglycerol (HPG) and their potential in systemic drug delivery using a model drug. The impact of polymer graft concentration and molecular weight on the circulation and the immunogenicity of HPG-grafted RBCs are investigated in mice.

Method: HPG polymers were prepared by the anionic ring opening multi branching polymerization of glycidol. An optimum number of hydroxyls on the surface of HPG were acid functionalized and activated with N-hydroxyl succinimide and grafted to surface proteins of RBCs. To investigate the circulation of HPG grafted RBCs in mice, cells were functionalized with PKH26 lipid marker, and the circulation was followed using the flow cytometry. The immnogenecity of HPG grafted RBCs was investigated by studying the circulation profiles of multiple injections in mice. Methods were developed to conjugate a therapeutic molecule to the cell surface using azide-alkyne 'click chemistry'. An optimum number of hydroxyls on the surface of HPG were azide functionalized that was attached to alkyne functionalized therapeutic using the click chemistry.

Results: Compared to polymer size, the polymer graft density had more significant impact on the circulation of HPG grafted RBCs. RBCs grafted with 0.25 and $0.5 \mathrm{mM}$ of HPG had circulation profiles that are similar to the control; modified RBCs stayed in circulation for approximately 50 days. RBCs grafted with higher concentrations of HPG (0.75 $\mathrm{mM}$ and higher) had shorter circulation. HPG-grafted RBCs were non-immunogenic as evident from the circulation profiles of repeated administrations in mice. Using lysozyme as a model therapeutic, azide-alkyne conjugation proved to be 
successful in conjugating a model drug to HPG molecules.

Conclusions: The normal circulation, nonimmunogenic nature, and the potential to modulate the circulation time of modified cells without toxicity make the HPG based cell surface modification approach attractive for drug delivery and other cell based therapies.

\section{In vitro Susceptibility Testing Candida spp and Aspergillus spp to New Formulation of Itraconazole for Pulmonary Administration}

Valery Aoun ${ }^{1}$, Patrice LePape ${ }^{2}$, Patrice Hildgen ${ }^{1}$ and Grégoire Leclair'.

${ }^{1}$ Faculté de pharmacie, Université de Montréal, Montréal, Canada; ${ }^{2}$ Département de Parasitologie et Mycologie Médicale, Université de Nantes, Nantes, France

Purpose: In order to improve antifungal activity against Candida and Aspergillus strains and reduce the therapeutic efficient dose of itraconazole (ITZ) for pulmonary diseases, we develop and evaluate a novel formulation encapsulating the drug inside a poly(lactic acid) grafted with poly(ethylene glycol) polymer (PEG-grafted-PLA) nanoparticles (NPs). NPs were characterized for their physicochemical properties. Antifungal activity was tested against Candida spp and Aspergillus fumigatus, two fungi pathogens targets of conazole-drugs. The interactions of NPs with the pathogens were investigated by fluorescence microscopy.

Method: Methoxy-PEG 2000 Da and Diol-PEG $2000 \mathrm{Da}$ were grafted over PLA backbones with 5\% grafting density to create PEG5\%-g-PLA. NPs/ITZ were prepared using an $\mathrm{O} / \mathrm{W}$ solvent evaporation method; the drug and the polymer were dissolved in $\mathrm{CHCl}_{3}$ prior to being subjected to emulsification into an external aqueous phase. NPs size and zeta potential were characterized by dynamic light scattering (DLS) using a Malvern Zetasizer NS. ITZ encapsulation efficiency was determined by HPLC. Antifungal activity was obtained by the determination of MIC50 (minimum inhibitory concentration at $50 \%$ ) and was done on C. albicans and A. fumigatus cultures. Cells of C. albicans and A. fumigatus were suspended in RPMI 1640 and treated with ITZ, blank NPs and NPs/ITZ. MIC50 was evaluated after 48 hours by spectrofluorometry $(\lambda=590 \mathrm{~nm})$. CLSI specifications were used to differentiate susceptible (MIC $<0.5 \mathrm{mg} / \mathrm{l}$ ) and non- susceptible (MIC $>1 \mathrm{mg} / \mathrm{l}$ ) strains. Yeast quality controls were also performed to confirm the method. Blank-NPs with the fluorescent molecule rhodamine $(\mathrm{RH})$ grafted on the polymer were prepared as a tool to investigate NPs interaction with C. albicans and A. fumigatus strains. Fluorescence and DIC images were monitored on an Olympus IX81 fluorescence microscope. Fluorescence and DIC images were collected simultaneously with the same focus settings and merged with MetaMorph Advanced $\mathbb{R}$ Software (Olympus).

Results: Physicochemical characteristics analysis of NPs/ITZ show mean size values around $150 \mathrm{~nm}$ (found by DLS). Results obtained by AFM confirmed particle size found by DLS and also revealed that NPs were spherical with a smooth surface. The drug loading efficiency was found to be $23 \%(\mathrm{w} / \mathrm{w})$. In vitro antifungal activity results of ITZ against $C$. albicans and $A$. fumigatus strains are reported in Table 1. In vitro antifungal activity results of ITZ against $C$. albicans strains showed that MIC50 of NPs/ITZ was lower than MIC50 of free ITZ against Candida spp. As observed in Figure 1 , fluorescence can be noticed in C. albicans cells. This indicates the internalization of RH-Blank NPs inside the cell. In vitro antifungal activity of ITZ was tested against $A$. fumigatus strains over a period of $48 \mathrm{~h}$ and is reported in Table 1 . Results obtained were quite different for $A$. fumigatus from $C$. albicans. Free ITZ was superior to NPs/ITZ against A. fumigatus species (approximately 2-fold increase in MIC50). It can be hypothesized that NPs/ITZ have unfavorable affinity with $A$. fumigatus surface.

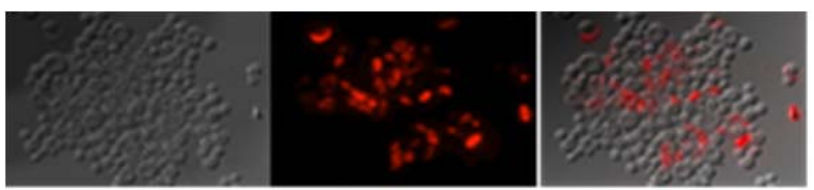

Figure 1. Fluorescent pictrues of RH-Blank NPs in water suspension at $1 \mathrm{mg} / \mathrm{ml}$. 10ul pipetted onto C.albicans grown for 24 hours and photographed after 3 hours at 100X magnification. From up to down, photos shown as differential interference contrast (DIC), fluorescence and DIC and fluorescence overlay.

However at this point, the interaction and the mechanism behind the enhanced antifungal activity of NPs/ITZ on Candida and A. fumigatus species remains unknown.

Conclusion: It has been demonstrated that NPs/ITZ promotes an efficient antifungal activity on $A$. Fumigatus. It has also been demonstrated that, the application of polymeric NPs in the field of mycology has the potential to improve therapeutic 
results. Further studies on interactions between the formulation and fungal cell walls are needed for a better understanding of the NPs contribution to the antifungal efficacy.

\section{Enhanced Avian Influenza Specific Immune Responses Using Dendritic Cell Targeted DNA Loaded Chitosan Nanoparticles via Intranasal Immunizaton}

Dharmendra Raghuwanshi ${ }^{1,2}$, Dipankar Das ${ }^{1}$, Vivek Mishra $^{1}$, Kamaljit Kaur ${ }^{1}$ and Mavanur R. Suresh ${ }^{1}$.

${ }^{1}$ Faculty of Pharmacy and Pharmaceutical Sciences, University of Alberta, Edmonton, Canada. ${ }^{2}$ Department of Biological Sciences, University of Alberta, Edmonton, Canada.

Purpose: The plasmid DNA vaccines against infectious diseases have been shown to induce antigen-specific immune responses but the application of DNA vaccines is hampered due to their poor immunogenicity. We hypothesize that weak immunogenicity of DNA vaccines could be overcome by targeting these vaccines to the dendritic cells (DCs). Therefore, a unique approach to target nanoencapsulated DNA vaccine to DCs using the DEC-205/CD205 receptor (DEC) via the intranasal route was explored.

Methods: Plasmid DNA encoding for H5N1 hemagglutinin (pHA) protein was selected as a vaccine antigen and biotinylated chitosan was chosen as a DNA carrier. The pHA loaded biotinylated chitosan nanoparticles (NPs) were formulated using complex coacervation process and characterized. To achieve DC targeted delivery of DNA vaccines the biotinylated NPs were decorated with a recombinant bifunctional fusion protein (bfFp). The bfFp is a recombinant fusion protein consisting of a truncated core-streptavidin arm fused with anti-DEC-205 single chain antibody ( $\mathrm{scFv}$ ). In this system, the core-streptavidin arm can bind with biotinylated NPs, while anti-DEC-205 $\mathrm{scFv}$ can target DEC-205 receptor on DCs. To study immune responses, the mice were immunized intranasally and intramuscularly with soluble DNA and with non-targeted and targeted nanoparticulate vaccines formulations. Following immunization, hemagglutinin (HA)-specific systemic, mucosal and cellular immune responses were analyzed.

Results: The average size of pHA DNA loaded biotinylated chitosan NPs was found to be $225 \pm$ $15.5 \mathrm{~nm}$, while the zeta potential of these formulations was $12.5 \pm 2.6 \mathrm{mV}$. The results of immune response studies indicate that bfFp decorated NP formulations induced higher levels of HA-specific IgG titers compared to naked DNA and non-targeted NPs. Further, the magnitude of IgG titers was significantly enhanced when a DC maturation stimulus (anti-CD40 mAb) was included with DC targeted formulations. Analysis of mucosal immune responses suggested that only intranasal delivery of bfFp targeted formulations administered with anti-CD40 mAb resulted in significantly higher IgA responses in nasal and vaginal fluids. The bfFp targeted vaccine formulations along with anti-CD40 $\mathrm{mAb}$ also showed augmented cellular immune responses as indicated with higher ex vivo levels of IFN- $\gamma$ and IL- 4 cytokines.

Conclusions: The current data indicates that dendritic cell targeted delivery of delivery of chitosan nanoparticle encapsulated DNA antigens via the mucosal route could serve as a potential new avenue for the development of a mucosal vaccine against avian influenza.

\section{Development of Thermo-Reversible Gels Based on Tri Block Copolymers of Poly(ethylene glycol) and Functionalized Poly(E-caprolactone) for Drug Delivery}

Nazila Safaei Nikouei ${ }^{1}$, Mohammad Reza Vakili ${ }^{1}$, Ali Akbari ${ }^{3}$ and Afsaneh Lavasanifar ${ }^{1}{ }^{2 *}$.

${ }^{1}$ Faculty of Pharmacy and Pharmaceutical Sciences; ${ }^{2}$ Department of Chemical and Material Engineering; ${ }^{3}$ Department of Agricultural, Food and Nutritional Science, University of Alberta, Edmonton, Alberta, Canada

Purpose: The aim of this study was to assess the potential of tri block copolymers based on poly(ethylene glycol) and $\alpha$-carbon functionalized poly( $\varepsilon$-caprolactone) in formation of thermo responsive gels and investigate their thermo/pH responsive release for stimulus responsive delivery of model macromolecules.

Methods: Tri block copolymers composed of poly(ethylene glycol) (PEG) in the middle and poly $(\alpha$-benzyl- $\varepsilon$-caprolactone) on sides were synthesized through ring opening polymerization of $\alpha$-benzyl carboxylate- $\varepsilon$-caprolactone by dihydroxylated PEG in the absence of any catalyst. The debenzylation of synthesized copolymer, i.e., poly $(\alpha$-benzyl carboxylate- $\varepsilon$-caprolactone)- $b$-PEG$b$-poly $(\alpha$-benzyl-carboxylate- $\varepsilon$-caprolactone) 
(PBCL- $b$-PEG- $b$-PBCL), in the presence of hydrogen gas at different catalyst (activated charcoal) levels and reaction times led to a controlled level of reduction of the PBCL producing $\operatorname{poly}(\alpha$-carboxyl-co-benzyl caboxylate- $\varepsilon$ caprolactone) PCBCL in the lateral blocks. The solgel transition behavior of prepared block copolymers in aqueous media was assessed by inverse flow method, differential scanning calorimetry, and ${ }^{1} \mathrm{H}$ NMR at different temperatures in the $8-60^{\circ} \mathrm{C}$ range and at different polymeric concentrations. The loading and release of Tetramethyl RhodamineDextrose (TMR-D) with two different molecular weights, in response to changes in the $\mathrm{pH}(5,7.4$, and 9), and temperature $\left(25,37\right.$, and $\left.50{ }^{\circ} \mathrm{C}\right)$ of release media was assessed.

Results: The presence of carboxylic group on PCBCL chain introduced thermo sensitivity to the polymeric aqueous solution. In general PCBCLPEG-PCBCL block copolymers have shown sol-gel transition behavior in $8-38^{\circ} \mathrm{C}$ temperature range. The percentage of debenzylation affected the transition temperature and the critical gelation concentration of block copolymers. The $54 \%$ debenzylated polymer showed a sol-gel transition at $31^{\circ} \mathrm{C}$ at $7 \%(\mathrm{~W} / \mathrm{W})$ concentration. Decreasing the debenzylation from $54 \%$ reduced the sol-gel transition temperature. Loading of TMR-D in this gel did not affect the transition temperature of polymer solution to gel. The in vitro release of TMR-D was sustained by thermo-responsive gel at $37^{\circ} \mathrm{C}$. Moreover, the amount of TMR-D released from hydrogel was significantly influenced by $\mathrm{pH}$, or temperature of release media. Increasing temperature of release media to $50^{\circ} \mathrm{C}$, or decreasing the $\mathrm{pH}$ to 5 causes significant increase in the amount of TMR-D released.

Conclusion: The results points to a potential of tri block copolymers of PCBCL- $b$-PEG- $b$-PCBCL in the formation of thermo-responsive gels, for sustained delivery of small drugs or macromolecules, with a capacity for temperature and/or $\mathrm{pH}$ controlled drug release property.

\section{In Vivo Assessment of Optimized Small Long Circulating Lipid Nanoparticles for Delivery of Bioactive Agents to bone}

Genc Basha, Chen Wan, Yan Liu and Pieter R. Cullis.

NanoMedicines Research Group, Department of Biochemistry and Molecular Biology, University of British Columbia, Vancouver, Canada

Purpose: A major challenge in the treatment of metabolic skeletal disorders associated with impaired bone formation is the delivery of bioactive agents (i.e. siRNA, EP4 inhibitors and RAR antagonists) in poorly perfused bone tissue. Lipid nanoparticles (LNPs) are currently the most effective in vivo delivery systems for gene knockdown employing small interfering RNA (siRNA). Silencing of bone-formation-inhibitory genes in osteogenic-lineage or terminally differentiated osteocytes could prove beneficial for skeletal diseases. Our objective is to develop LNP systems with optimized ability to penetrate and accumulate in bone tissue for gene silencing in mesenchymal stem cells (MSCs) and osteocytes.

Method: Using novel microfluidic formulation techniques, we generated long-circulating LNPs of $30 \mathrm{~nm}$ loaded with siRNA.

Results: We identified and characterized bone residing MSCs, and demonstrated significant accumulation of $30 \mathrm{~nm}$ LNPs in almost $90 \%$ of MSCs as assessed by flow cytometry. In addition, we observed that delivery of LNPs containing antiGFP siRNA significantly reduced the eGFP target protein in these cells, after a single IV injection at 5 or $10 \mathrm{mg} / \mathrm{kg}$ doses with no toxicity. Finally, using confocal microscopy, we demonstrated the presence of the LNP systems in osteocytes in vivo.

Conclusions: These results suggest that newly designed small long-circulating LNPs can be highly efficient systems for delivery of bioactive agents to bone. This approach could be exploited to promote bone formation, enhance bone micro-architecture and ultimately increase bone mass. 


\section{Targeted LNP-siRNA Systems for Silencing the Androgen Receptor}

$\underline{\text { Justin B. Lee }}^{1, \dagger}$, Kaixin Zhang ${ }^{2, \dagger}$, Yuen Yi C. Tam ${ }^{1}$, Ying K. Tam ${ }^{1}$, Nathan M. Belliveau ${ }^{1}$, Paulo J. C. Lin $^{1}$, Sam Chen ${ }^{1}$, Yan Liu ${ }^{1}$, Paul S. Rennie ${ }^{2, \S}$ and Pieter R. Cullis ${ }^{1, \S}$.

${ }^{1}$ Department of Biochemistry and Molecular Biology at the University of British Columbia, Vancouver, British Columbia; ${ }^{2}$ Vancouver Prostate Centre, Vancouver, British Columbia, Canada; ${ }^{\dagger}$ Co-First authors; ${ }^{\S}$ The Cullis and Rennie labs contributed equally

Purpose: The androgen receptor (AR) plays a critical role in the progression of prostate cancer. Silencing this protein has previously been performed using short-hairpin RNA (shRNA) and smallinterfering RNA (siRNA) resulting in significant decreases in serum prostate specific antigen (PSA) and tumor growth inhibition. We are currently focused on investigating the ability of targeted lipid nanoparticle (LNP) formulations of siRNA to silence AR (LNP AR-siRNA) in human prostate tumor cells in vitro and in LNCaP xenograft tumors following intravenous (i.v.) injection.

Methods: Optimization of LNP AR-siRNA was performed by stabilizing the AR-siRNA sequence through introduction of a phosphorothioate backbone and methylations of nucleotides at the 2'O position and also employing an optimized cationic lipid DMAP-BLP. In addition, specific targeting to prostate-specific membrane antigen (PSMA) on LNCaP cells was made possible via chemical conjugation of a small molecule DUPA to the PEGlipid formulated into LNP AR-siRNA (DUPA-LNP AR-siRNA). For in vitro experiments, DUPA-LNP AR-siRNA and non-targeted LNP AR-siRNA were administered to LNCaP cells at 1,5 and $10 \mathrm{mg} / \mathrm{ml}$ for $48 \mathrm{~h}$ to assess cellular uptake and AR knockdown. For in vivo experiments, DUPA-LNP AR-siRNA and non-targeted LNP AR-siRNA were i.v. administered at $5 \mathrm{mg}$ siRNA/ $\mathrm{kg}$ body weight into mice bearing LNCaP xenograft tumors on Days 1, 2 and 3, followed by a second set of i.v. injections on Days 7, 9, and 11. Serum PSA levels, AR expression, cellular proliferation and apoptosis were all examined to assess the effect of targeted DUPALNP AR-siRNA in vivo.

Results: As expected, with the incorporation of the DUPA-targeting moiety, a 5-fold increase in cellular uptake was observed in $\mathrm{LNCaP}$ cells in vitro, as well as a dramatic improvement in AR knockdown. The
PEG-lipid employed in formulating the LNP was also optimized to produce longer circulation lifetimes that result in improved accumulation at the distal tumor site. It is shown that as a result of these improvements the doses of siRNA employed in LNP-siRNA systems could be reduced by a factor to two as compared to previous systems. In addition, improved regressions in serum PSA, cellular proliferation, and AR levels were also observed.

Conclusion: These results support the potential clinical utility of LNP-siRNA systems to silence the $\mathrm{AR}$ for treatment of advanced prostate cancer.

\section{Production of Limit Size Lipid Nanoparticle Systems with a Potential Utility as Drug Delivery Systems}

Igor Jigaltsev $^{1}$, Nathan Belliveau ${ }^{1,2}$, Ismail Hafez ${ }^{1}$, Alex K. K. Leung ${ }^{1}$, Jens Huft ${ }^{3}$, Carl Hansen ${ }^{3}$ and Pieter R. Cullis ${ }^{1}$.

${ }^{1}$ Department of Biochemistry and Molecular Biology, Faculty of Medicine, University of British Columbia, BC, Canada; ${ }^{2}$ Precision NanoSystems, Vancouver, BC; ${ }^{3}$ Department of Physics and Astronomy, University of British Columbia, BC.

Purpose: Size matters in drug delivery. Particles in the size range 10-50 $\mathrm{nm}$ are expected to be the most potent in accessing extravascular target tissues and the synthesis of such systems is of intense interest for biomedical applications. In principal, the rational engineering of the smallest possible "limit size" nanoparticle systems consistent with the proportions and physical properties of the components should be possible. To realize this potential requires that the kinetics of component mixing and particle assembly be precisely controlled so that limit size particles are achieved. Here we demonstrate the rational engineering of limit size lipid nanoparticle (LNP) systems consisting of 1-palmitoyl-2-oleoyl phosphatidylcholine (POPC), cholesterol (Chol) and the triglyceride triolein (TO) and having either polar and non-polar cores.

Method: Limit size LNP consisting of POPC, Chol and TO were synthesized by mixing a stream of ethanol containing dissolved lipid with an aqueous stream, employing a staggered herringbone micromixer. Millisecond mixing of aqueous and ethanol streams at high flow rate ratios was used to rapidly increase the polarity of the medium, driving bottom-up synthesis of limit size LNP systems by spontaneous assembly. 
Results: For POPC/TO systems the limit size structures consisted of a hydrophobic core of TO surrounded by a monolayer of POPC where the diameter could be rationally engineered over the range $20 \mathrm{~nm}$ to $80 \mathrm{~nm}$ by varying the $\mathrm{POPC} / \mathrm{TO}$ ratio. In the case of POPC and $\mathrm{POPC} / \mathrm{Chol}$ (55/45; $\mathrm{mol} / \mathrm{mol}$ ) the limit size systems achieved were bilayer vesicles of approximately $20 \mathrm{~nm}$ and $40 \mathrm{~nm}$ diameter, respectively. We further show that doxorubicin, a representative weak base drug, can be efficiently loaded and retained in limit size POPC LNP, establishing potential utility as drug delivery systems.

Conclusion: To our knowledge this is the first report of stable triglyceride emulsions in the $20-50 \mathrm{~nm}$ size range, and the first time vesicular systems in the 20$50 \mathrm{~nm}$ size range have been generated by a scalable manufacturing method. These results establish microfluidic mixing as a powerful and general approach to access novel LNP systems, with both polar or non-polar core structures, in the sub-100 nm size range.

\section{Lipid Nanoparticle Delivery of siRNA to Silence Neuronal Gene Expression in the Brain}

Ravi L. Rungta ${ }^{1 *}$, Hyun B. Choi ${ }^{1 *}$, Paulo J.C. Lin ${ }^{2 *}$, Rebecca Ko ${ }^{1}$, Jay Nair ${ }^{3}$, Muthiah Manoharan ${ }^{3}$, Pieter R. Cullis ${ }^{2}$ and Brian A. MacVicar ${ }^{1}$.

${ }^{1}$ Brain Research Centre, Department of Psychiatry, University of British Columbia; ${ }^{2}$ Department of Biochemistry and Molecular Biology, University of British Columbia; ${ }^{3}$ Alnylam Pharmaceuticals, Cambridge, MA.

*These authors contributed equally to this work.

Purpose: Manipulation of gene expression in the brain is fundamental to understanding the function of proteins involved in neuronal processes. Current strategies for manipulating neuronal gene expression in vivo are costly, time consuming and often inefficient. Here we show a method for delivery of siRNA in lipid nanoparticles (LNPs) that provides a highly effective method for silencing neuronal gene expression in the brain.

Method: Lipid nanoparticles systems carrying siRNA were formulated by using a novel formulation method using a microfluidics micromixer. LNP-siRNA were then firstly treated in cultured rat primary neurons to monitor LNP-siRNA uptake (by microscopy) and gene silencing (western blotting) followed by intracranial (cortex) administration of LNP-siRNA systems to monitor the in vivo distribution and gene silencing in the brain of Sprague-Dawley rats (postnatal day 26-30). Whole-cell patch clamp recordings using neurons of the somatosensory cortex were used for functional analysis of NMDA receptor after silencing of the GRIN1 gene.

Results: We show that neurons accumulated these LNPs in an apolipoprotein E dependent fashion, resulting in very efficient uptake both in cell culture and in vivo, with little apparent toxicity. When the LNPs contain siRNA, selective knockdown of the target gene is achieved as robust PTEN knockdown was observed at doses of $1.67 \mu \mathrm{g}$ siPTEN $/ \mathrm{mL}$ in primary cell cultures. We also showed that a single intracranial administration to cortex of rats with 500 $\mathrm{nL}$ at $5 \mathrm{mg} / \mathrm{mL}$ siRNA of LNP-siPTEN showed sustained PTEN silencing for over 15 days with a robust silencing within $1 \mathrm{~mm}$ from injection tract. Also, electrophysiology studies were performed showcasing the in vivo delivery of LNPsiRNA against GRIN1 (encoding GluN1 subunit of the NMDA receptor) which resulted in significant functional disruption of NMDAR currents.

Conclusion: LNP delivery of siRNA rapidly manipulated expression of proteins involved in neuronal processes in vivo, possibly enabling development of gene therapies for neurological disorders.

Poster will also be presented at 7th Annual Meeting of the Canadian Association for Neuroscience May 21-24, 2013 Toronto. 


\section{Microfluidic Synthesis of Highly Potent Limit-Size Lipid Nanoparticles for In Vivo Delivery of siRNA}

Nathan M. Belliveau, Department of Bioengineering, California Institute of Technology, Pasadena, California, USA; Jens Huft, and Carl L. Hansen, Department of Physics and Astronomy, Vancouver, BC, Canada; Paulo J. C. Lin, Sam Chen, Justin B. Lee, and Pieter R. Cullis, Department of Biochemistry and Molecular Biology, University of British Columbia, Vancouver, BC; Timothy J. Leaver, Andre W. Wild, and Robert J. Taylor, Precision NanoSystems, Vancouver, BC; Ying K. Tam' Alcana Technologies, Vancouver, BC, Canada

Purpose: Lipid nanoparticles (LNP) are the leading systems for in vivo delivery of siRNA for therapeutic applications. Formulation of LNP siRNA systems requires rapid mixing of solutions containing cationic lipid with solutions containing siRNA. Current formulation procedures employ macroscopic mixing processes to produce systems $70 \mathrm{~nm}$ diameter or larger that have variable siRNA encapsulation efficiency, homogeneity and reproducibility. The aim of this work was to determine whether microfluidics would provide a more robust formulation platform for the assembly of potent LNP siRNA systems.

Method: Standard soft lithography techniques were used to fabricate microfluidic mixing devices containing staggered herringbone structures (SHM), capable of mixing two input fluids. Input 1 contained the lipid species dissolved in ethanol (DLinKC2-DMA, DSPC, Cholesterol, and PEG-cDMA), while input 2 contained siRNA dissolved in acetate buffer, $\mathrm{pH} 4$. Upon mixing at low $\mathrm{pH}$, the charged DLinKC2-DMA complexes with the negatively charged siRNA and formation of lipid nanoparticles. The size characteristics of LNP siRNA systems were determined by dynamic light scattering and cryo-transmission electron microscopy (cryo-TEM). Finally, the potency of the LNP siRNA were determined using a mouse model targeting Factor VII in hepatocytes.

Results: Here we show that microfluidic mixing techniques, which permit millisecond mixing at the nanoliter scale, can reproducibly generate LNP siRNA systems $20 \mathrm{~nm}$ and larger with essentially complete encapsulation of siRNA over a wide range of conditions. LNP siRNA were homogeneous in size and exhibited electron-dense morphology when visualized by cryo-TEM. Optimized LNP siRNA systems produced by microfluidic mixing achieved $50 \%$ target gene silencing in hepatocytes at a dose level of $10 \mu \mathrm{g} / \mathrm{kg}$ siRNA in mice, comparable to current gold standards.

Conclusion: Microfluidic mixing is shown to enable routine production of LNP siRNA in the size range of 20-60 $\mathrm{nm}$ and also offers advantages of ease of design, narrow size distributions, high siRNA encapsulation efficiency and potent silencing in mice. We anticipate that microfluidic mixing, a precisely controlled and readily scalable technique, will become the preferred method for formulation of LNP siRNA delivery systems.

\section{Development of Lipid Nanoparticles for Targeted Drug Delivery to Bone}

Mina Ordobadi ${ }^{1}$, Yuen Yi C. Tam ${ }^{1}$, Gang Chen $^{2}$, Nag S. Kumar ${ }^{2}$, Robert N. Young ${ }^{2}$ and Pieter R. Cullis ${ }^{1}$.

${ }^{1}$ Department of Biochemistry and Molecular Biology, University of British Columbia, Vancouver, British Columbia, Canada; ${ }^{2}$ Department of Chemistry, Simon Fraser University, Burnaby, British Columbia, Canada

Purpose: Many drugs for treatment of bone diseases such as osteoporosis lack efficiency and specificity. Lipid nanoparticles (LNP) are drug carriers that can effectively target and deliver drugs to cells and tissues. It has been shown previously that bisphosphonate has high affinity for bones. This study aims to develop drug-loaded LNP systems capable of targeting bones with high specificity by using bisphosphonate as a targeting ligand. These LNP can be loaded with prostaglandin receptor agonists, which are known to enhance bone regeneration through prostaglandin receptor induction.

Method: Bisphosphonate-lipid was synthesized and incorporated into LNP. The binding efficiency of bisphosphonate-conjugated LNP to bone was tested in vitro by incubation with bone powder and analyzing the recovery of particles following the incubation. Binding specificity of bisphosphonateconjugated LNP was determined by comparison to a negative control (LNP without targeting ligand). Different amounts of bisphosphonate were tested to achieve optimal binding to bone powder. Prostaglandin receptor agonists were then encapsulated in LNP using different $\mathrm{pH}$-gradient loading methods and the encapsulation efficiency 
was confirmed by HPLC analysis.

Results: As expected, bisphosphonate functioned as an efficient targeting ligand for LNP in bone powder binding. We observed that a trace amount of bisphosphonate (as little as $0.0625 \mathrm{~mol} \%$ ) was sufficient to enhance binding of LNP to bone in vitro, while ligand-free nanoparticles were unable to bind the bone powder. LNP were successfully loaded with prostaglandin receptor agonists with greater than $70 \%$ encapsulation efficiency. The stability of drugs within the nanoparticles was confirmed by HPLC analysis.

Conclusion: We showed that LNP containing bisphosphonate as a targeting ligand bind efficiently to bone and that prostaglandin receptor agonists can be loaded into LNP by $\mathrm{pH}$-gradient method. We anticipate that these targeted LNP systems loaded with prostaglandin receptor agonists can potentially treat bone diseases such as osteoporosis.

\section{Engineered Breast Tumor Targeting Peptide Ligand Modified Liposomal Doxorubicin and the Effect of Peptide Density on Anticancer Activity}

Mostafa Shahin ${ }^{\mathrm{a}}$, Rania Soudy ${ }^{\mathrm{a}}$, Hamidreza M. Aliabadi $^{\mathrm{b}}$, Norman Kneteman ${ }^{\mathrm{c}}$, Kamaljit Kaur ${ }^{\mathrm{a}}$, Afsaneh Lavasanifar ${ }^{\mathrm{a}, \mathrm{b}}$.

${ }^{a}$ Faculty of Pharmacy and Pharmaceutical Sciences, University of Alberta, Edmonton, Alberta, Canada; ${ }^{b}$ Department of Chemical and Material Engineering, University of Alberta, Edmonton, Alberta; ${ }^{c}$ Department of Surgery, Faculty of Medicine and Dentistry, University of Alberta, Edmonton, Alberta.

Purpose: This study aimed to develop actively targeted liposomal formulations of doxorubicin (DOX) using an engineered breast tumor targeting peptide ligand, p18-4 (WxEAAYQrFL).

Methods: Stealth liposomes bearing different molar ratios of p18-4 peptide (1.5 and 0.3 peptide/total lipid mol \%), namely HD and LD liposomes, were successfully prepared. The effect of p18-4 peptide modification and density on breast cancer cell uptake, selective cytotoxicity as well as inhibition of tumor growth and the tissue disposition of encapsulated DOX in breast tumor xenograft models in mice were assessed.

Results: A 2.4 and 5 folds decrease in the $\mathrm{IC}_{50}$ of HD liposomes in MDA-MB-435 and MCF-7 breast tumor cells, respectively. Although LD liposomes showed less (1.6 and 2.2 folds) decrease in the $\mathrm{IC}_{50}$ of DOX in the same breast cancer cell lines, they were more selective in their cytotoxic effect and uptake towards breast cancer over normal breast epithelial cells, MCF10A. Evaluation of the anticancer activity in NOD-SCID mice bearing MDA-MB-435 xenografts after receiving six i.v. injections of $2.5 \mathrm{mg} / \mathrm{kg} /$ week DOX equivalent showed a superior anticancer activity for LD liposomal DOX compared to HD and unmodified liposomal formulations. Mice treated with LD liposomal DOX illustrated 4.8 folds reduction in the mean relative tumor volume compared to nontargeted DOX liposomes. This was despite similar tumor accumulation of DOX as part of LD liposomes compared to that for unmodified liposomes $24 \mathrm{~h}$ following the last injection. In contrast, HD liposomes showed decreased DOX accumulation in the tumor and preferential uptake by liver and spleen. Treatment with unmodified and LD liposomes did not have any adverse impact on the activity level and mean body weight of live animals during the study period.

Conclusion: Surface modification of liposomal DOX with engineered p18-4 peptide at an optimum density can improve the antitumor efficacy and selectivity of liposomal DOX.

\section{A Novel Tropically Stable Oral Amphotericin B Formulation (Ico-010) Exhibits Efficacy against Visceral Leishmaniasis in a Murine Model}

Wasan $\quad \mathrm{EK}^{1}$, Gershkovich $\mathrm{P}^{2}$, Zhao $\mathrm{J}^{2}$, Zhu $\mathrm{X}^{3}$, Werbovetz $\mathrm{K}^{3}$, Tidwell $\quad \mathrm{RR}^{4}$, Clement $\mathrm{JG}^{5}$, Thornton $\mathrm{SJ}^{2}$, Wasan $\mathrm{KM}^{2}$.

${ }^{1}$ School of Health Sciences, British Columbia Institute of Technology, Burnaby, BC; ${ }^{2}$ Faculty of Pharmaceutical Sciences, University of British Columbia, Vancouver, BC; ${ }^{3}$ Division of Medicinal Chemistry and Pharmacognosy, College of Pharmacy, The Ohio State University, Columbus, $\mathrm{OH} ;{ }^{4}$ Department of Pathology and Lab Medicine, Consortium for Parasitic Drug Development, University of North Carolina, Chapel Hill, NC; ${ }^{5} \mathrm{iCo}$ Therapeutics Inc., Vancouver, BC, Canada

Purpose: To develop an oral formulation of amphotericin B (AmB) that is stable at the temperatures of WHO Climatic Zones 3 and 4 (30$43^{\circ} \mathrm{C}$ ) and to evaluate its efficacy in a murine model of visceral leishmaniasis (VL).

Methods: The stability testing of four novel oral 
lipid AmB formulations composed of mono- and diglycerides and pegylated esters (iCo-010 to iCo-013) was performed over $60 \mathrm{~d}$ and analyzed by HPLCUV. In addition, the four formulations were incubated $4 \mathrm{~h}$ in fasted-state simulated intestinal fluid. AmB concentration was measured spectrophotometrically and emulsion droplet diameter was assessed by dynamic light scattering. Antileishmanial activity of iCo-010 was evaluated at increasing oral doses $(2.5$ to $10 \mathrm{mg} / \mathrm{kg}$ ) in a murine model of VL.

Results: AmB stability in the lipid formulation (iCo-010) was $>75 \%$ over 60 days. After $4 \mathrm{~h}$ in fasted-state simulated intestinal fluid, $\mathrm{AmB}$ concentration was $>95 \%$. iCo-010 demonstrated significant efficacy when orally administered to VLinfected mice bid for five days (inhibition of $99 \%$, $98 \%$, and $83 \%$ at 10,5 and $2.5 \mathrm{mg} / \mathrm{kg}$ compared to the vehicle control). In addition, the qd dose of 20 $\mathrm{mg} / \mathrm{kg}$ provided $96 \%$ inhibition compared to the vehicle control.

Conclusions: The oral AmB formulation $\mathrm{iCo}-010$ is stable at the temperatures of WHO Climatic Zones 3 and 4 (30-43 $\left.{ }^{\circ} \mathrm{C}\right)$. iCo-010 showed excellent antileishmanial activity at both $10 \mathrm{mg} / \mathrm{kg}$ po bid for 5 days ( $<99 \%$ reduction in parasitic infection) and $20 \mathrm{mg} / \mathrm{kg}$ po qd for 5 days (95\% inhibition when compared to control).

\section{Biodistribution of Solid Lipid Nanoparticles (SLN) Incorporated into Insitu Forming System}

Golnar Dorraj and Hamid Reza Moghimi. Department of Pharmaceutics, School of Pharmacy, Shahid Beheshti University of Medical Sciences, Tehran, Iran

Purpose: Among novel drug delivery approaches, nanoparticulated systems are the most popular and vastly used, although their invivo application faces different challenges such as rapid clearance by reticulo endothelial system. In an attempt to solve this problem, this investigation aimed to prepare an in-situ forming SLN-containing poloxamer gel for controlled drug delivery.
Method: Solid lipid nanoparticles (SLN) were prepared by diluting a warm oil-in-water $(\mathrm{o} / \mathrm{w})$ microemulsion containing stearic acid, surfactants, and cosurfactants in cold water. Lipophilic fluorescence probe was loaded in SLNs. After purification, the mean particle size and zeta potential of the particles were determined and encapsulation efficacy was measured by HPLC assay of extracted probe. In the next step, particles were dispersed in a thermosensitive polymer aqueous s solution at $4{ }^{\circ} \mathrm{C}$ in optimized concentration. Sol-gel transition temperature checked over 4 to $37^{\circ} \mathrm{C}$. Rheological behavior of the system was investigated. Thermal behavior of the system was determined by DSC. Invitro release of the probe from nanoparticles and then after gel incorporation of the SLN was performed using a membrane-less dissolution method at $37^{\circ} \mathrm{C}$. Probe loaded SLN and Insitu forming system contain them were injected intraperitoneal into mice. Then whole body and organ distribution of tow systems were evaluated by small animal imaging Kodak F-pro.

Results: SLN size was found to be $270 \pm 6 \mathrm{~nm}$ and zeta potential of the SLN dispersion was obtained to be $-55 \pm 0.8$. DSC analysis confirmed proper inclusion of SLN into gel. Rheological studies showed that presence of SLN decreases gelling time and temperature sweep revealed interaction between polymer and SLN. Invitro release studies which was investigated simultaneously with the erosion profiles of polymeric gel indicated slow release of probe . Loading into insitu forming system showed nonsignificant effect on release behavior of probe from nanoparticles. In body imaging investigation, SLNs loaded into polymeric system showed longer invivo release from injection site and slower liver uptake in comparison to aqueous dispersion of nanoparticles and probe solution.

Conclusion: Present results show that the prepared system has a proper thermoresponsive properties in the presence of SLN and has a potential for application in controlled drug delivery of nanoparticles in vivo. 


\section{CC-CRS Posters - Session 2}

\section{Wednesday to Thursday, June 12-13}

\section{Oxygen Delivery for Tissue Engineering}

\author{
Huaifa Zhang $^{1}$, Faleh Tamimi Marino ${ }^{1}$, Jake \\ Barralet $^{1,2}$. \\ ${ }^{1}$ Faculty of Dentistry, McGill University, Montreal, \\ QC, Canada; ${ }^{2}$ Division of Orthopaedics, Department \\ of Surgery, Faculty of Medicine, McGill University, \\ Montreal, QC, Canada
}

Purpose: Hypoxia and anoxia, which are common difficulties encountered in tissue engineering and wound healing, inhibit cell growth and induce cell death. [1, 2] Peroxide materials decompose to produce molecular $\mathrm{O}_{2}$ in situ, however they generate cytotoxic $\mathrm{H}_{2} \mathrm{O}_{2}$ and do not release $\mathrm{O}_{2}$ in a sustained manner. [3] This reaction occurs with the formation of alkaline by-products. [4] To control the release of oxygen, encapsulation of peroxide within a hydrogel such as sodium alginate, known for its biocompatibility and biodegradability, is an attractive option for cell and tissue culture. [5] Here, we developed an alginate hydrogel sandwich composite containing $\mathrm{CaO}_{2}$. Polycaprolactone (PCL, hydrophobic and biodegradable) was used to further reduce $\mathrm{CaO}_{2}$ decomposition rate. [6] Citric acid [7] was employed to neutralize the $\mathrm{Ca}(\mathrm{OH})_{2}$ by-product and retain $\mathrm{Ca}^{2+}$ ions. Adipose tissue explants were used to evaluate oxygen delivery capacity of the composite through hypoxic culture in vitro.

Method: Construction of alginate hydrogel sandwich composites: 1) preparation of sodium alginate hydrogel by $\mathrm{Ca}^{2+}$ crosslinking; [5] 2) deposition of $\mathrm{CaO}_{2}$ between two layers of hydrogel; and 3) sealing of the former materials through crosslinking. $\mathrm{CaO}_{2}$-PCL composites were prepared by mixing $\mathrm{CaO}_{2}$ with PCL in chloroform and drying. $\mathrm{O}_{2}$ release was measured using a contactless optical oxygen sensor in a sealed reactor containing deionized $\mathrm{H}_{2} \mathrm{O}$. pH changes of the $\mathrm{H}_{2} \mathrm{O}$ were recorded by a $\mathrm{pH}$ probe and data recorder. Adipose tissues were cultured in vitro with the $\mathrm{O}_{2}$ release composite in a sealed container. To create extreme hypoxia, $\mathrm{O}_{2}$ absorber was put into the container and $\mathrm{N}_{2}$ flushing was performed beforehand. After culture, adipose tissues were stained by live/dead assay and examined under confocal microscope. Cell viability was determined through counting the stained cells in tissues.

Results: Experimental results showed that the hydrogel sandwiched composites released oxygen. We were able to control the $\mathrm{O}_{2}$ release rate by varying sodium alginate concentrations, hydrogel volumes and $\mathrm{CaO}_{2}$ amounts. Preliminary results on $\mathrm{pH}$ changes suggested PCL as being a promising candidate to further reduce $\mathrm{O}_{2}$ release. The addition of citric acid successfully neutralized $\mathrm{Ca}(\mathrm{OH})_{2}$. The $\mathrm{O}_{2}$ release material appeared to enhance cell viability in adipose tissues.

Conclusion: In conclusion, an $\mathrm{O}_{2}$ delivery material with controlled release rate was developed. It enhanced adipose tissue viability under extreme hypoxia. Further work will focus on the interaction of hypoxic and anoxic cells with our material.

\section{Reference:}

[1] A. Carreau, et al, Journal of Cellular and Molecular Medicine, 15 (2011) 1239-1253.

[2] A. Di Carlo, et al, Journal of Biological Chemistry, 279 (2004) 16332-16338.

[3] S. Oh, et al, Biomaterials, 30 (2009) 757-762.

[4] L. Chevalier, Journal of Environment and Waste Management, 2 (2008) 245-256.

[5] J. Rowley, et al, Biomaterials, 20 (1999) 45-53.

[6] K. Lee, et al, Polymer, 44 (2003) 1287-1294.

[7] K. Islam, World's Poultry Science Journal, 68(2012) 104-118.

\section{The Effect of Polymer Architecture on Drug Release Kinetics of Injectable, Degradable Hydrogels}

Emilia Bakaic, Niels M.B. Smeets, and Todd Hoare. Department of Chemical Engineering, McMaster University, Hamilton, Ontario, Canada

Purpose: Improved control over the spatial and temporal delivery of drugs can reduce unwanted side effects and improve the efficacy of medical treatment. Minimally-invasive drug delivery devices designed for sustained release offer a favourable solution for many therapeutic applications. 
However, advances in controlled drug delivery (particularly with hydrogels) are limited by a lack of fundamental understanding of the effect of the gel morphology on the release kinetics. To address this challenge, we have designed morphologically distinct but chemically analogous injectable and degradable hydrogels materials consisting of linear, hyperbranched, and microgel precursors, allowing us to directly investigate the effect of hydrogel architecture on the controlled release kinetics and thus tune drug release for specific applications.

Methods: The composite hydrogels are prepared by co-extruding a synthetic hydrazide-functionalized poly(oligoethylene glycol methacrylate) (POEGMA) polymer (linear, hyperbranched or microgel architecture) with a natural aldehyde-functionalized dextran (DEX) polymer. Gelation is achieved by the fast reaction between the hydrazide and aldehyde groups, which condense to form hydrolytically degradable hydrazone bonds. Low molecular weight hydrophilic (sodium fluorescein) and hydrophobic (fluorescein, dexamethasone) drugs as well as high molecular weight model drugs (fluorescein-labeled dextrans) were incorporated into the hydrogels to investigate the effect of the POEGMA polymer architecture on the release kinetics.

Results: The three composite hydrogel systems were compared based on their mechanical strength, optical transmittance, cytotoxicity, and drug release profiles for both hydrophilic and hydrophobic drugs. Mechanical strength was governed by POEGMA polymer morphology and the availability of hydrazide groups to form hydrazone bonds, with increasing storage modulus observed with microgel $<$ hyperbranched $<$ linear. At $37^{\circ} \mathrm{C}$, increasing optical transmittance was observed with microgel $<$ hyperbranched $<$ linear, whereas the optical transmittance decreased for all hydrogels at $22^{\circ} \mathrm{C}$. Polymer architecture was found to influence drug release profiles of both hydrophilic and hydrophobic small molecule model drugs, while sustained drug release for 3 weeks (after initial burst) was observed from all composite materials. Particular differences in release were observed for the small hydrophobic model drug used (fluorescein), in which release rate scaled with morphology as linear $<$ hyperbranched $<$ microgel. MTT assays showed minimal cytotoxicity in vitro to $3 \mathrm{~T} 3$ mouse fibroblast cells when exposed to all composite formulations and all of their precursor materials. All systems were shown to be fully degradable.

Conclusion: The design of composite hydrogel systems based on varying polymer architecture offers an effective tool for sustained controlled drug delivery. The injectable, degradable POEGMA-DEX composite hydrogel allows for tunable drug release kinetics governed by simple morphological variations (independent of chemistry).

\section{Acetylcholine Esterase Inhibitors Favor Bone Mass}

Hazem Eimar ${ }^{a, k}, \quad$ Faleh Tamimi ${ }^{\mathrm{a},}$, Sharifa Alebrahim $^{\mathrm{a}}$, Monzur Murshed ${ }^{\mathrm{a}, \mathrm{b}}$.

${ }^{a}$ Faculty of Dentistry, McGill University, Montreal, Quebec, Canada; ${ }^{b}$ Faculty of Medicine, McGill University, Montreal, Quebec, Canada.

"Both authors contributed equally to this work.

Purpose: The cholinergic parasympathetic nervous system (PSNS), specifically the muscarinic activity, is known to regulate bone mass. However, this physiological mechanism has never been explored as potential treatments for bone disease. This, in vivo, study was designed to assess the effects of acetylcholinesterase inhibitors (AChEIs), a group of drugs that stimulate cholinergic parasympathetic receptors, on bone mass accrual.

Methods: To accomplish this objective, we injected 2 groups of mice (5 weeks-old) either with donepezil (an AChEI that stimulates cholinergic receptors) or saline (controls), respectively. All mice were treated for 4 weeks before being sacrificed. Tibia and vertebra were dissected and fixed for further analyses. Bone mass accrual was assessed by microcomputed tomography scans and by histomorphometric analyses. Bone crystallinity, degree of mineralization and bone mineral density (BMD) were measured by X-ray diffraction and DEXA. Bone mechanical properties were evaluated by three-point bending test and by Vickers microindenter. The data obtained was analyzed with Student t-test, and the statistical significance was set at $\mathrm{p}<0.05$.

Results: Our results illustrated that stimulation of cholinergic receptors by donepezil might regulate body metabolites and bone. Indeed, our data showed that donepezil treated mice had a distinct increase in body mass index, weight and fat tissue compared to those treated with saline $(\mathrm{p}<0.05)$. Moreover, tibia and vertebra collected from donepezil treated mice had a marked increase in their mass accrual, degree of crystallinity, BMD and mechanical properties compared to those obtained from mice treated with saline $(\mathrm{p}<0.05)$. 
Conclusion: Within the limitation of this animal study, our data represents the first experimental evidence that pharmacological stimulation of the cholinergic parasympathetic arm of the autonomous nervous system by donepezil is able to increase bone mass accrual and becomes a potential treatment for osteoporosis.

92. The Effect of Core Structure on the Physicochemical and Biological Stability of Polymeric Micelles based on Poly(ethylene Oxide) and Functionalized Poly(epsiloncaprolactone): an in-vitro Study

Shyam Garg, Mohammad Reza Vakili, Afsaneh Lavasanifar.

Faculty of Pharmacy and Pharmaceutical Sciences, University of Alberta, Edmonton, Canada

Purpose: The biodegradability and biocompatibility of a block copolymer micellar system is of major concern when used as nano-drug delivery devices. Our research group has reported on the development of a novel family of block copolymers based on poly(ethylene oxide) and poly(caprolactone) (PEO$b$-PCL) having different side groups on PCL. The aim of this study was to investigate the effect of side-group on PCL and functionalized PCL degree of polymerization on the physicochemical and biological stability of self-assembled structures in an in-vitro setting.

Methods: Polymeric micelles of PEO- $b$-PCL with 20, 42, 62, and 79 degree of polymerization (DP) for PCL block, PEO- $b$-PCL bearing benzyl carboxylate (PEO- $b$-PBCL) with 19, 31, and 58 DP for PBCL block, and PEO-b-PCL bearing carboxyl (PEO- $b$ PCCL) with 19, 30, and 46 DP for PCCL block were prepared in aqueous solution. The micelles were assessed for aggregation and degradation by incubation in PBS solution followed by characterization by DLS and ${ }^{1} \mathrm{H}$ NMR at regular time intervals. The biocompatibility was assessed by serum protein adsorption on micelles using gel permeation chromatography to separate free from adsorbed protein followed by protein assay. The effect of micellar structure on the maturation of bone-marrow derived dendritic cells (BMDCs) was also assessed as an in-vitro test of immunogenicity. After $24 \mathrm{~h}$ incubation, the cells were examined for DC surface maturation markers (CD40, CD86) using FACS and release of cytokines (IL-12) using ELISA.
Results: Both PEO- $b$-PCL and PEO- $b$-PBCL maintained their micellar integrity over the entire 100 days of incubation with less than $10 \%$ of the core being degraded. The rate of degradation was inversely proportional to the DP of the core. In contrast, PEO- $b$-PCCL micelles dissociated in solution during the incubation period, with 57.1, 73.2 , and $86.6 \%$ of the core being degraded within 60 days for $\mathrm{PEO}_{114}-b-\mathrm{PCCL}_{19}, \mathrm{PEO}_{114}-b-\mathrm{PCCL}_{30}$, and $\mathrm{PEO}_{114}-b-\mathrm{PCCL}_{46}$, respectively. The rapid degradation for PEO- $b$-PCCL micelles can be attributed to the pendent $-\mathrm{COOH}$ groups which can autocatalyze the hydrolysis reaction. Protein adsorption studies in serum showed minimal and insignificant protein adsorption for all block copolymer micelles. Protein adsorption increased significantly as the DP and the hydrophobicity of the core increased. The polymeric micelles under study did not show upregulation of CD40 and CD86, and secretion of IL-12 above what was observed for the untreated DCs.

Conclusion: This study elucidates the effect of changes to the core forming block on the stability, degradation, and biocompatibility of PEO- $b$-PCL based micelles in an in-vitro setting.

\section{Carboxymethyl Starch and Lecithin Complex used as Matrix for Targeted Drug Delivery}

Maria Mihaela Friciu ${ }^{1}$, Canh Tien Le ${ }^{1}$, Pompilia Ispas-Szabo ${ }^{1}$, Max Arella ${ }^{1,2}$ and Mircea Alexandru Mateescu ${ }^{1}$.

${ }^{1}$ Department of Chemistry and Centre Pharmaqam, Université du Québec à Montréal, Montréal, Québec, Canada; ${ }^{2}$ Matripharm, Québec, Canada

Purpose: The use of Melasamine for treatmentof inflammatory bowel disease requires repeated administrations to maintain the patient life quality. This drug acts locally in the colon and for successful treatment, a delivery device is necessary in order to limit the undesired systemic absorption decreasing effectiveness andcausing side effects. Various delayed release systems are currently commercialized. Most of them are basedon $\mathrm{pH}-$ dependent concept having as weakness certain sensitivity to gastrointestinal $\mathrm{pH}$ variation. This report proposes a novel excipientbased on the complexation between carboxymethyl-starch (CMS) and Lecithin (Lec) used as monolithic tablet for colon delivery. Largelydifferent to those existing in the market, the present excipient is $\mathrm{pH}$-independent, 
inexpensive, exhibits a high drug loading capacity andsimple to manufacture.

Methods: The excipient complex was prepared by simply mixing of CMA and Lec in hydro-alcoholic medium and spray-dried to obtain the corresponding powders. Dissolution assays for Mesalamine (400 $\mathrm{mg}, 75 \%$ ) monolithic tablets formulated with $25 \%$ of CMA/Lec complex were carried out in $900 \mathrm{~mL}$ simulated gastric fluid (SGF, pH 1.2 during $2 \mathrm{~h}$ ) and then followed in $900 \mathrm{~mL}$ simulated intestinal fluid (SIF, $\mathrm{pH}$ 7.2), according to the USP (apparatus II) method. At predetermined intervals, samples of 1 $\mathrm{mL}$ were withdrawn from dissolution media, and properly diluted before reading at $303 \mathrm{~nm}$ for SGF and at $330 \mathrm{~nm}$ for SIF media.

Results: Dissolution data showed that the release of Mesalamine formulated with CMA/Lec complex started after $4 \mathrm{~h}$ ( $2 \mathrm{~h}$ SGF followed $2 \mathrm{~h} \mathrm{SIF}$ ) and was totally completedafter $10 \mathrm{~h}$ in SIF. No significant differences were observed for Mesalamine kinetic profiles in media with various $\mathrm{pH}$ (6-5-7.5) values. FTIR, X-Ray and SEM structural analysis showed stabilization between CMA and Lec by polar and hydrophobic interactions supporting the hypothesis of complexation.

Conclusion: CMS and Lec were successfully combined to generate a novel complex with interesting characteristics as excipientfor $\mathrm{pH}$ independent delivery system of Mesalamine. This complex can also be used to formulate other drugs affording a medication with improved safety, efficacy and patient compliance.

\section{Synthesis, Characterization and Biodistribution Studies of ${ }^{125}$ I-Radioiodinated di-PEGylated Bone Targeting Salmon Calcitonin Analogue in Normal Rats}

Yang Yang, Krishna H. Bhandari, Arash Panahifar, Michael R. Doschak ${ }^{*}$.

Faculty of Pharmacy \& Pharmaceutical Sciences, University of Alberta, Edmonton, Alberta, Canada

Purpose: FDA approved salmon calcitonin ( $\mathrm{sCT}$ ) has been widely used in treatment of metabolic bone diseases (Paget's disease, osteoporosis, and hypercalcemia); however, sCT has a short biological half-life (16.9-57.3 min). Moreover, calcitonin receptors does not only exist on osteoclast cells (i.e. bone resorbing cells), but also other organs such as kidney, brain, lung etc., resulting in a reduced delivery of sCT to desired site of action. Hence, the aim of this study was to develop a bisphosphonate (BP) mediated and PEGylated salmon calcitonin conjugate which possesses longer half-life and higher bone affinity compared to $\mathrm{SCT}$.

Methods: In this research, commercial sCT was PEGylated with bi-functional NHS-PEG-MAL followed by conjugation with Thiol-BP. The resultant sCT-PEG-BP analogues were purified by HPLC to isolate major product di-sCT-2(PEG-BP). Possible PEGylation sites were determined by trypsin digestion and stability of di-PEGylated sCT2(PEG-BP) in desired buffer was studied by MALDI-TOF over time. In vitro bone mineral affinity was evaluated towards hydroxyapatite (HA). Also, after ${ }^{125}$ I radio-iodination, its in vitro bone mineral affinity was assessed using HA binding test. Stability of ${ }^{125} \mathrm{I}$-sCT-2(PEG-BP) was determined in $20 \mathrm{mM}$ acetate buffer $(\mathrm{pH} \quad 5.0)$ at $-30^{\circ} \mathrm{C}$. Biodistribution of the bone-targeting $\mathrm{sCT}$ in various tissues in normal rats was also evaluated.

Results: ${ }^{125} \mathrm{I}-\mathrm{sCT}-2$ (PEG-BP) exhibited significantly increased bone mineral affinity over ${ }^{125} \mathrm{I}$-sCT and the compound remained stable for at least 30 days in an appropriate buffer. In vivo studies revealed that diPEGylated SCT analogue possesses significantly increased bone retention, as well as prolonged plasma circulation, compared to the control ${ }^{125} \mathrm{I}-\mathrm{sCT}$. Conclusion: In comparison to $\mathrm{sCT}$, synthetic and HPLC-isolated bisphosphonate mediated bone targeting di-PEGylated sCT analogue demonstrated significantly improved in vitro/vivo bone mineral binding affinity, and plasma circulation, which suggested sCT-2(PEG-BP) as a potential candidate for further evaluation on its efficacy in treatment of resorptive bone diseases such as osteoporosis.

\section{External, Targeted Control of Drug Release using Thermosensitive Magnetic Nanocomposite Hydrogels}

Scott B. Campbell, Danielle Maitland, and Todd Hoare.

Department of Chemical Engineering, McMaster University, Hamilton, Ontario, Canada

Purpose: Devices that can offer precise, userdefined, pulsatile release via non-invasive means would be highly beneficial in cases where the disease progression is uncertain (e.g. chemotherapy or chronic pain management) or pulsatile, on-off or high-low release of a drug is clinically required (e.g. insulin delivery). However, the development of 
devices with such capabilities has proven difficult to achieve. To address this challenge, we have entrapped microgels and magnetite nanoparticles inside an in situ-injectable, degradable hydrogel that can be externally and non-invasively triggered to deliver high/low doses of a drug locally inside the body.

Methods: The composites are prepared by mixing hydrazide-functionalized PNIPAM and aldehydefunctionalized dextran along with the microgel (0-12 $\mathrm{wt} \%$ ), superparamagnetic iron oxide nanoparticles (SPIONs, $5 \mathrm{wt} \%$ ), and the drug of interest. The hydrazide and aldehyde groups condense to form hydrolytically degradable hydrazone cross-linking bonds, forming a bulk hydrogel with the other components entrapped within it. The polymer precursor chain lengths are $38 \mathrm{kDa}$ or less, allowing for renal clearance after degradation. The thermosensitive microgels were designed to have a volume phase transition temperature (VPTT) just above physiological temperatures, meaning that the volume of these microgels dramatically decreases (by 55\%) when their surrounding temperature exceeds $\sim 40^{\circ} \mathrm{C}$. After injection, these microgels can be heated above their VPTT the heat produced by the SPIONs via an external oscillating magnetic field (OMF) to create pores that encourage drug release from the composite materials.
Results: The nanocomposite hydrogels were characterized for their rheological properties, swelling characteristics, controlled drug delivery capacity, and their cytotoxicity. The hydrogel composites have enhanced mechanical strength over controls without SPIONs or microgels, where the mechanical properties are primarily dependent on the microgel content. A $8 \mathrm{wt} \%$ microgel content composite was shown to significantly enhance the release of bupivacaine (a local anaesthetic) upon heating above $37^{\circ} \mathrm{C}$ via OMF application, increasing the rate of release by over $200 \%$ even after multiple days. The effects of microgel content and the mechanism of enhanced release are also observed. Notably, the composites and all of their constituent materials were shown to exhibit minimal cytotoxicity using an MTT assay with 3T3 mouse fibroblast cells.

Conclusion: The combination of thermosensitive polymers with magnetite nanoparticles is a powerful tool in the fabrication of composites for drug delivery. The injectable and externally-triggerable drug delivery nanocomposites reported herein offer significant advantages over current drug delivery techniques in terms of facilitating triggered changes in drug dosing using a non-invasive, patient-friendly technology. 


\section{Index}

\section{A}

Abbott, Frank S., 87

Acosta, Crystal May R., 115

Aebersold, Ruedi, 5, 50

Afshinmanesh, Elham, 105

Aghazadeh-Habashi, Ali, 83, 84, 85, 90

Ahmadie, Roien, 102

Akbari, Ali, 131

Akinwumi, Bolanle, 82

Alameh, Mohamad-Gabriel, 110

Alcorn, Jane, 83, 93, 120

Al-Dulaymi, Mays, 128

Alebrahim, Sharifa, 139

Alghonaim, Mohammed, 97

AlHowiriny, Tawfeq, 122

Aliabadi, Hamidreza M., 136

Aljuffali, Ibrahim, 97

Almukainzi, M., 96

Al-Omrani, Abdullah, 97

Alshamsan, Aws, 97

Alsheikh, Abdulmalik, 122

Al-Yahya, Mohammed, 122

Amsden, Brian, 3, 4, 40

Anantasit, Nattachai, 88

Anderson, David R, 120

Anderson, Hope, 81, 82

Aoun, Valery, 130

Arella, Max, 140

Asghar, Waheed, 83, 84, 85, 90

Au, Hilda, 114

Aubin, Jane, 6, 60

Azam, Afzal, 125

\section{B}

Baart, Nathan, 102

Bachtold, Kali, 93

Badea, Ildiko, 127, 128

Badran, Mohamed, 97

Bahmani, Mehrnoosh, 99

Bakaic, Emilia, 138

Bandiera, Stelvio M., 116

Baoukina, Svetlana, 105

Barbosa, Bruna, 104

Barralet, Jake, 106, 138

Bartlett, Karen, 91

Basha, Genc, 132

Belliveau, Nathan M., 105, 133, 135

Bénard , Francois, 7, 74

Bhandari, Krishna H., 141

Bhardwaj, Atul, 89

Binkhathlan, Ziyad, 97
Boison, Joe, 93

Bolger, Michael B., 64, 65

Bou-Chacra, Nadia, 6, 63, 104

Boyd, John, 86, 88

Bratoeff, Eugene, 126

Brooks, Donald E., 80, 103, 129

Buschmann, Michael D., 4, 48, 108, 110

C

Cai, Ping, 103

Cai, Zhongli, 95

Campbell, Scott B., 107, 141

Carleton, Bruce C., 43

Carter, Cedric J., 80

Cecioni, Samy, 119

Cekic, Nevena, 123

Cerruti, Marta, 106

Chang, Thomas K.H., 87, 92, 116

Chapanian, Rafi, 129

Chattopadhyay, Niladri, 95

Chen, Gang, 135

Chen, Sam, 133, 135

Chen, Yufei, 101, 102

Cheung, Richard, 2, 22

Chitanda, Jackson, 127, 128

Choi, Hyun B., 134

Clas, Sophie-Dorothee, 124

Clement, JG, 136

Constantinescu, Iren, 129

Conte, Juliana Denise, 104

Cortes, Claudia, 115

Creagh, Louise, 121

Creagh, Louise A ., 80

Cullis, Pieter R., 75, 105, 132, 133, 134, 135

D

Daneshtalab, Noriko, 113

Darlington, Jerarld W., 122

Das, Dipankar, 131

Das, Umashankar, 127

Dash, Alicia, 101

Davies, Neal M., 82, 92, 101

Davit, Barbara M., 6, 68

Dawes, Martin, 7, 76

Di, Yun-yun, 83

Dimmock, Jonathan, 127

Dorraj, Golnar, 137

Doschak, Michael R., 106, 141

Dubala, Anil, 125

Dubois, Anick, 118 


\section{$\mathbf{E}$}

Eichler, Hans-Georg, 6, 59

Eimar, Hazem, 139

El-Aneed, Anas, 128

ElTahir, Kamal, 122

Ernsting, M. J., 98

Es Sabar, Karimah, 2, 23

\section{$\mathbf{F}$}

Farra, Robert, 3, 38

Fleisig, Helen B., 114

Francis, Mira, 94

Friciu, Maria Mihaela, 140

Friedman, Jan, 7, 78

\section{G}

Gallicano, Keith, 6, 67

Gao, Yuan, 124, 129

Garg, Shyam, 140

Gelmon, Karen A, 71

Gershkovich, Pavel, 91, 100, 122

Gilibili, Ravindranath Reddy, 116

Goralski, Kerry B., 120

Gorski, Sharon, 117

Goya, Rodrigo, 117

Grochulski, Pawel, 127

Gu, Jijin, 101

Gu, Kaien, 101

Gurny, Robert, 4, 40

\section{H}

Habte, Ruth M., 80

Hafez, Ismail M., 105, 133

Hamelin, Bettina, 6, 61

Hamilton, Jasmine L., 121

Hansen, Carl L., 105, 133, 135

Haynes, Charles A., 80

He, Juan, 6, 68

Heinonen, Julia, 123

Hildgen, Patrice, 130

Ho, Emmanuel A, 102

Ho, Emmanuel A, 102

Ho, Emmanuel A., 4, 47

Hoare, Todd, 107, 138, 141

Holmes, Ingrid, 94

Holwell, N., 98

Hope, Michael J., 105

Huang, Zhangjian, 89

Huft, Jens, 133, 135

Hukezalie, Kyle R., 114

Huntsman, David G., 34

\section{I}

Ibrahim, Fady, 91, 122

Ispas-Szabo, Pompilia, 140
Jamali, Fakhreddin, 83, 84, 85, 90, 94

Jan, Eric, 114

Jang, Christopher, 114

Jigaltsev, Igor, 133

Jowett, Christopher J., 3, 31

\section{$\mathbf{K}$}

Kalam, Mohd. Abul, 97

Kalathottukaren, Manu Thomas, 80

Kaur, Jatinder, 89

Kaur, Kamaljit, 127, 131, 136

Kearney, Paul, 2, 26

Khatwal, Rizwan Basha, 125

Kim, Jenny Hanbi, 112

Kim, Richard B., 44

Kizhakkedathu, Jayachandran N., 80, 100, 103, 121, 129

Knaus, Edward E., 89

Kneteman, Norman, 136

Ko, Rebecca, 134

Kolate, Atul, 126

Kore, Girish, 126

Korn, Darlene, 118, 119

Kosaraju, Jayasankar, 125

Koss, Kyle, 109

Kotadia, Rima, 126

Kovacic, Suzana, 116

Krämer, Johannes, 5, 54

Krol, Ed, 83

Kumar, MN Satish, 125

Kumar, Nag S., 135

Kumar, Rav, 2, 21

L

Lai, Benjamin F., 80, 100, 121

Lanchote, Vera Lucia, 94

Lau, Aik Jiang, 92

Lavasanifar, Afsaneh, 95, 131, 136, 140

Lavertu, Marc, 108

Le, Canh Tien, 140

Leaver, Timothy J., 135

Lebovitz, Chandra, 117

Leclair, Grégoire, 108, 130

Leclaire, Marie-Eve, 108

Lee, David K., 6, 59

Lee, Frederick, 2, 25

Lee, Justin B., 133, 135

Lefebvre, Marc, 94

Legault, Eric, 94

LePape, Patrice, 130

Lesko, Lawrence J., 4, 42

Leung, Alex K.K., 105, 133

Li, S.D., 98

Li, Shyh-Dar, 5, 57

Lin, Paulo J.C., 133, 134, 135

Liu, Peter, 5, 53

Liu, Yan, 132, 133 
Löbenberg, Raimar, 1, 5, 63, 96, 104, 124, 129

Lu, Yan, 81

Lynd, Larry, 87

\section{M}

MacVicar, Brian A., 134

Mahmoudi, Morteza, 106

Maitland, Danielle, 141

Makowsky, Mark, 118

Manoharan, Muthiah, 134

Mansi, James A., 28

Marcotte, Isabelle, 108

Marcoux, Tanya, 115

Marra, Carlo, 7, 8, 77

Marra, Marco, 117

Martinez, Stephanie E., 92

Mateescu, Mircea Alexandru, 140

Matus, Johanna, 93

McNeill, John H., 41

Merzouki, Abderrazzak, 110

Meulien, Pierre, 6, 62

Michel, Deborah, 127

Miller, Donald W., 80

Miller, Ronnie, 2, 20

Mishra, Vivek, 131

Misra, Ambikanandan, 126

Moghimi, Hamid Reza, 137

Mohammed-Saeid, Waleed, 127, 128

Mole, Jon, 6, 64

Morin, Ryan, 117

Morrison, Matthew J, 120

Mossop, Paula, 120

Murakami, M., 98

Murshed, Monzur, 139

\section{$\mathbf{N}$}

Nair, Jay, 134

Namaka, Michael P., 115

Narayanappa, Manjunatha, 125

Nguyen, Thanh-Giau, 82

Nislow, Corey, 7, 70

Noghani, Mahsa Alizadeh, 103

\section{$\mathbf{0}$}

Ordobadi, Mina, 135

\section{$\mathbf{P}$}

Panahifar, Arash, 106, 141

Patterson, Scott D., 29

Pearce, Nelson, 113

Pimstone, Simon, 2, 21, 22

Poorghorban, Masoomeh, 127

Popovich, Brad, 2, 6, 24

Prasad, Preethy, 103

Pun, Suzie, 4, 48, 49

\section{$\mathbf{R}$}

Rafatullah, Syed, 122

Raghuwanshi, Dharmendra, 131

Ratner, Buddy D., 32

Rauth, Andrew M., 103

Reilly, Raymond M., 95

Remsberg, Connie M., 92

Rennie, Paul S., 133

Rizzardo, Shirin, 87

Roa, Wilson, 124, 129

Robertson, Gordon, 117

Roden, Dan, 2, 19

Rodrigues, Brian, 112

Ross, Colin, 4, 45

Roy, A., 98

Rungta, Ravi L., 134

Russell, James A., 7, 76, 77, 86, 88

S

Sachs-Barrable, Kristina, 97

Safaei Nikouei, Nazila, 131

Sagartz, John E., 5, 55

Salomon, Daniel R., 5, 51, 52

Samanta, Malay K, 125

Sanaee, Forugh, 94

Santhi Vardhan, Chinni, 125

Sarfraz, Muhammad Khan, 96, 124, 129

Sayre, Casey, 101

Schilsky, Richard L., 73

Seo, Isaac K., 119

Shah, Sohrab, 3, 35

Shahin, Mostafa, 136

Sharma, Devinder, 92

Sharma, Sai Kiran, 89

Shenoi, Rajesh A., 80, 100

Sherman, Matthew A., 92

Sicard, Eric, 94

Siu, Lillian L., 72

Sivak, Olena, 91, 122

Smeets, Niels M.B., 138

Soleymani, Hoda, 95

Sorensen, Poul H.B., 36

Soroka, Steven D., 120

Soudy, Rania, 127, 136

Soudya, Rania, 127, 136

Steidl, Christian, 4, 35, 36

Strandman, Satu, 106

Sun, Zhizhi, 80

Surendradoss, Jayakumar, 87

Suresh, Mavanur R., 131

\section{$\mathbf{T}$}

Tam, Ying K., 133, 135

Tam, Yuen Yi C., 133, 135

Tamimi, Faleh, 138, 139

Taylor, R. James, 2, 26, 27

Taylor, Robert J., 135

Tebbutt, Scott J., 52, 53 
Tehrani, Ali, 3, 28, 29

Terry, Patrick F., 58

Thain, Katherine, 86

Thoutreddy, Akhilreddy, 120

Thudi, Nageshwar Rao, 6, 66

Thumati, Naresh R, 114

Tidwell, RR, 136

Tieleman, D. Peter, 105

Tirunellai, Krishnan, 5, 56

Tomai, Mark, 3, 38, 39

\section{U}

Ul-haq, Mohammad Imran, 121

Ul-haq, Muhammad Imran, 100

Undzys, E., 98

Unsworth, Larry D., 1, 4, 48, 109

\section{V}

Vakili, Mohammad Reza, 95, 131, 140

Valente Neves, Daniel, 94

Veilleux, Daniel, 108

Verrall, Ronald, 127, 128

Vezenkov, Lubomir L., 116

Vocadlo, David J., 119, 123

Vogl, A. Wayne, 116

\section{W}

Walley, Keith, 86, 88

Wan, Andrea, 112, 113

Wan, Chen, 132

Wang, Yingjin, 86

Wasan, EK, 136

Wasan, Ellen K., 91

Wasan, Kishor M., 136

Wasan, Kishor M., 91, 97, 100, 112, 122

Weiner, Russell, 3, 30
Weinshilboum, Richard, 4, 44, 45

Wettig, Shawn, 99

Wild, Andre W., 135

Wilson, Jo-Anne, 120

Wilson-McManus, Janet, 5, 51

Wong, Judy M., 114

Woodbury, Murray, 93

Wu, Xiao Yu, 103

Wuest, Frank, 89

\section{$\mathbf{X}$}

Xu, Jinke, 106

\section{Y}

Yang, Kaiyu, 95

Yang, Sidi, 101

Yang, Yang, 141

Yeung, Pollen K.F., 115

Yoganathan, T. Nathan, 29

Yong, Alex, 2, 25

Young, Robert N., 82, 116, 135

Yu, Lawrence X., 55, 56

\section{$\mathbf{Z}$}

Zaraa, Sarra, 108

ZengM, Xi-Lei, 114

Zhang, Dahai, 112

Zhang, Huaifa, 138

Zhang, Kaixin, 133

Zhao, Rafael C., 114

Zhao, J, 136

Zhao, Jinying, 100

Zhigaltsev, Igor V., 105

Zhu, Julian X.X., 106

Zhu, $X, 136$

Zhuang, Kai, 6, 65 